University of Nebraska - Lincoln

DigitalCommons@University of Nebraska - Lincoln

$5-2020$

\title{
Evaluation of the Dynamic Behavior of Steel Staircases with Concrete Filled Pan Treads
}

Tyler Sondag

University of Nebraska - Lincoln, tsondag101@gmail.com

Follow this and additional works at: https://digitalcommons.unl.edu/archengdiss

Part of the Architectural Engineering Commons, and the Construction Engineering and Management Commons

Sondag, Tyler, "Evaluation of the Dynamic Behavior of Steel Staircases with Concrete Filled Pan Treads" (2020). Architectural Engineering -- Dissertations and Student Research. 57.

https://digitalcommons.unl.edu/archengdiss/57

This Article is brought to you for free and open access by the Architectural Engineering and Construction, Durham School of at DigitalCommons@University of Nebraska - Lincoln. It has been accepted for inclusion in Architectural Engineering -- Dissertations and Student Research by an authorized administrator of DigitalCommons@University of Nebraska - Lincoln. 


\title{
Evaluation of the Dynamic Behavior of Steel Staircases with
} Concrete Filled Pan Treads

by

Tyler Sondag

\begin{abstract}
A THESIS
Presented to the Faculty of The Graduate College at the University of Nebraska

In Partial Fulfillment of Requirements For the Degree of Master of Science
\end{abstract}

Major: Architectural Engineering

Under the Supervision of Professor Ece Erdogmus and Professor Jay Puckett

Lincoln, Nebraska

May 2020 
Evaluation of the Dynamic Behavior of Steel Staircases with Concrete Filled Pan Treads Tyler Sondag, M.S.

University of Nebraska, 2020

Advisors: Ece Erdogmus and Jay Puckett

Vibration serviceability of staircases has been a growing challenge for structural engineers due to changing materials and structural forms. In order to prevent or correct serviceability problems due to structural vibrations, structural engineers should be able to predict the dynamic performance of a staircase structure. However, there are few technical guides available for designing steel staircases, and the ones that do exist are often limited in their applications. Currently, there is a lack of research on staircases that are less prone to vibrations, such as staircases with concrete filled pans that are composed of face and wall stringers. Therefore, the goal of this thesis is to improve the understanding and accuracy of the overall vibration response (natural frequencies and mode shapes) predictions of concrete filled pan tread stairs. In order to determine the vibration response, experimental data was collected on two types of staircases and used to create and update finite element models. Using the experimentally updated finite element models, various parameters such as railing mass and boundary conditions were altered, demonstrating the staircases' response to changes in these parameters. This study also demonstrated different methods for modeling the unknown boundary condition stiffness contributions in the staircase structure. In addition, this thesis evaluated the potential limitations of the AISC design guide equation that quickly calculates a prediction of the first mode frequency of a staircase. This thesis also suggested an empirical factor to be 
applied to the AISC equation that would allow the equation to be used for staircases with a boundary condition created by a wall stringer. Finally, this thesis work has created suggestions for designers on how to model these types of staircases. 


\section{AUTHOR'S ACKNOWLEDGEMENTS}

I express my gratitude and thanks to the following persons who made it possible for me to complete my master's thesis:

Ece Erdogmus, Ph.D., P.E., my advisor and thesis committee chair, for giving me the time, assistance, and opportunity to pursue this research project, providing guidance, instruction, and assistance across the scope of this research.

Jay Puckett, Ph.D., P.E., my co-advisor and thesis committee chair, for providing me with the assistance to pursue this research, as well as for the time, advice, and support needed to complete this project.

Christine Wittich, Ph.D., my thesis committee member, for kindly providing the time to evaluate my work.

Todd Feldman, P.E., for generously providing time and advice, as well as providing an industry perspective on how to make this research more useful to practicing engineers.

Tunc Deniz Uludag, for helping to answer the questions I had involving SAP 2000.

Special thanks to the UNL Durham School of Architectural Engineering and Construction for providing funding for this research. 


\section{Table of Contents}

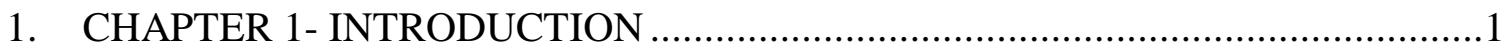

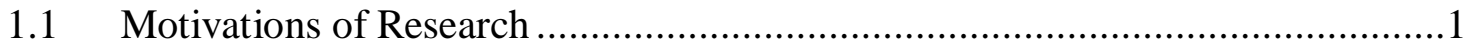

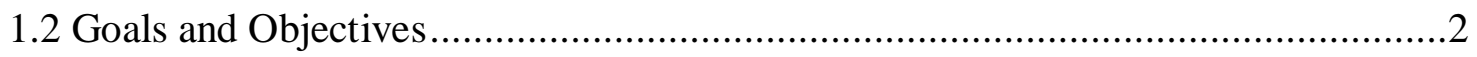

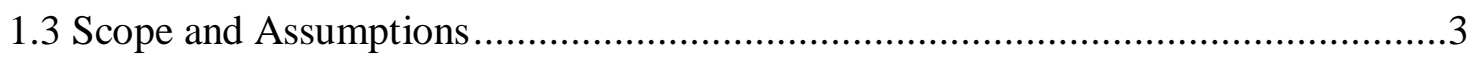

2. CHAPTER 2- LITERATURE REVIEW ........................................................5

2.1 Fundamentals of Structural Vibration .......................................................

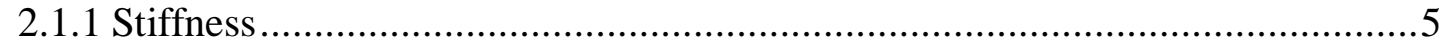

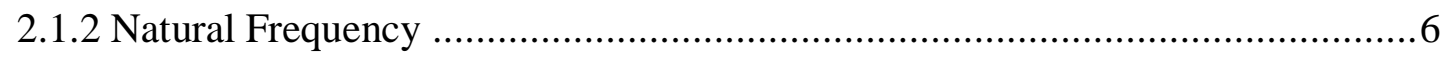

2.1.3 Fundamental Mode ................................................................................. 7

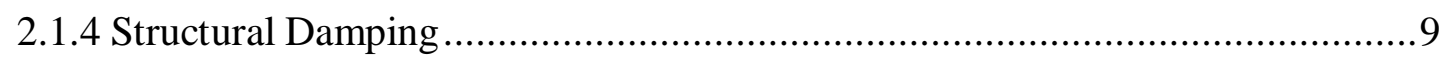

2.1.5 Degrees of Freedom of a System (DOF) ............................................ 9

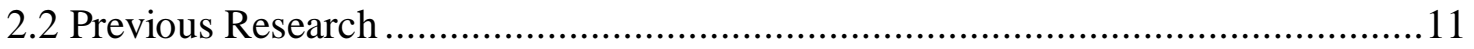

2.2.1 Effects of Human Loading on Staircases .............................................. 11

2.2.2 Experimental Assessment of Vibration Serviceability of Stair Systems .......... 12

2.2.3 Slender Steel Monumental Stair Vibration Serviceability ............................ 13

2.2.4 Prediction of the Vibration Response of High-Frequency Steel Staircases ...... 17

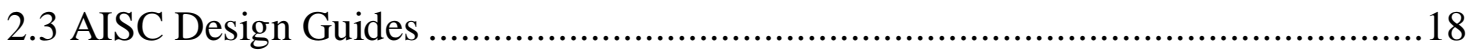

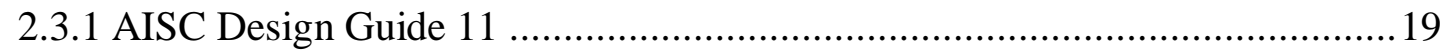

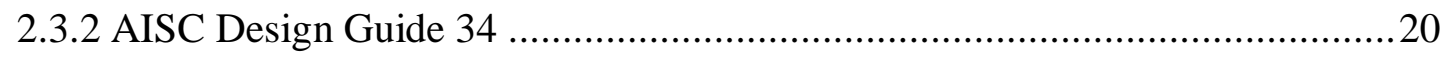

2.4 Finite Element Modeling Procedures ...........................................................21

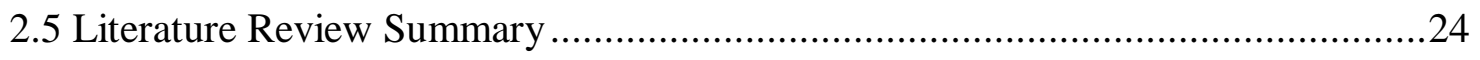

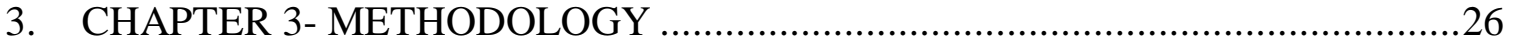

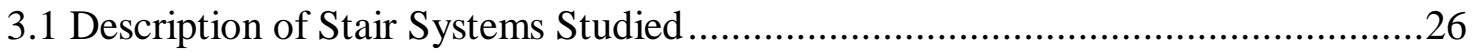

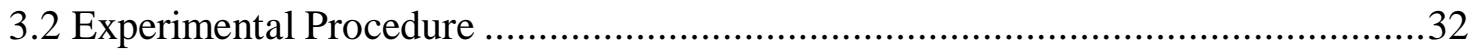

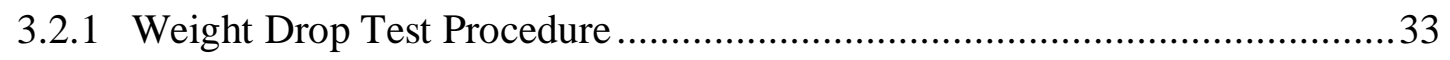

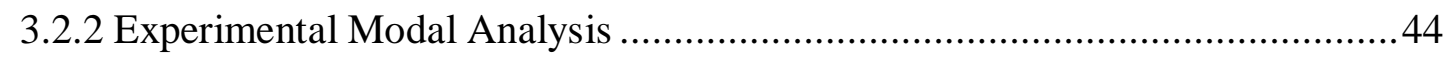

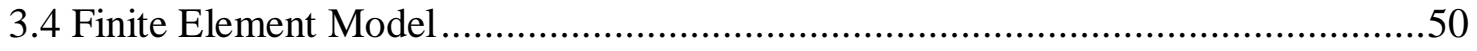

3.4.1 Model Geometries and Material Properties ..............................................50

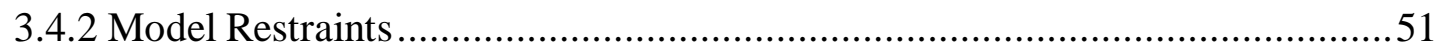




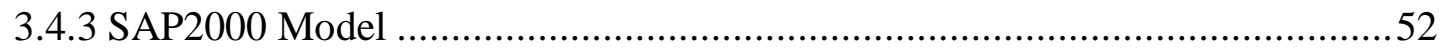

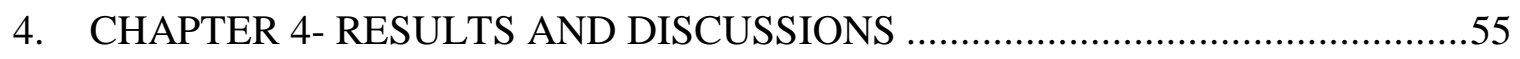

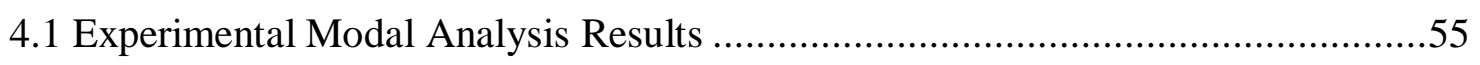

4.2 Finite Element Analysis Results .............................................................63

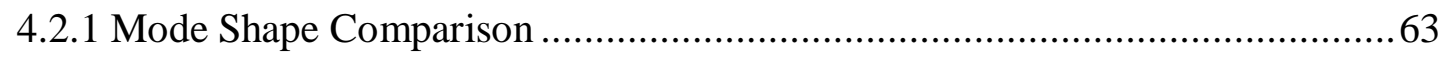

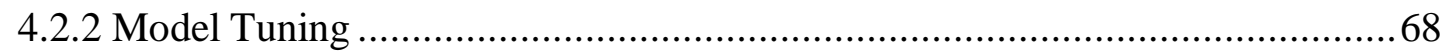

4.2.3 Influence of the Magnitude of Railing Mass on Modal Frequency ..................77

4.2.4 Influence of Railing Stiffness on First Mode Frequency ................................ 84

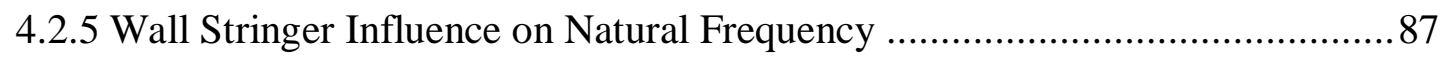

4.2.6 Alternative Modeling Techniques ................................................... 98

4.2.7 Effect of Translational Stiffness on First and Second Mode Frequency ......... 107

4.2.8 AISC Design Guide 11 First Mode Frequency Equation Application ........... 118

4.3 Model Design Recommendations ............................................................ 125

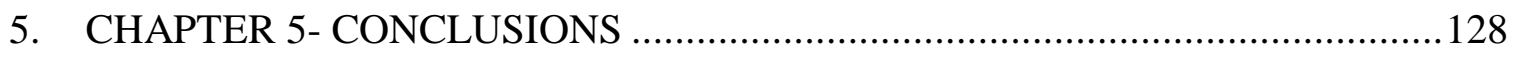

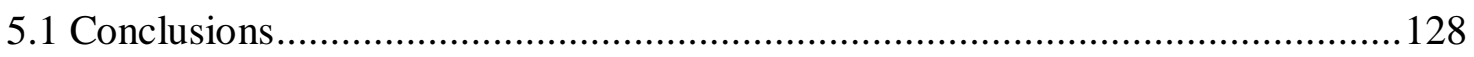

5.2 Recommendations for Future Work ............................................................. 132 


\section{List of Figures}

Figure 2.1: Mode Shapes of a Simply Supported Beam........................................

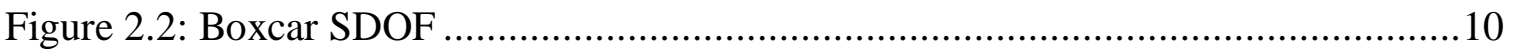

Figure 2.3: Simply Supported Beam FBD .......................................................... 15

Figure 2.4: Stair Case Structure Used in Study......................................................21

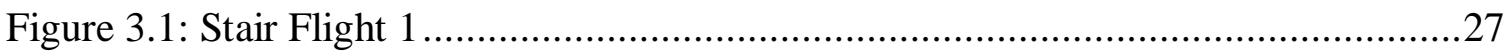

Figure 3.2 : Schematic Drawing of Flight 1 ..........................................................2

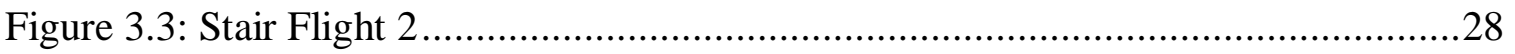

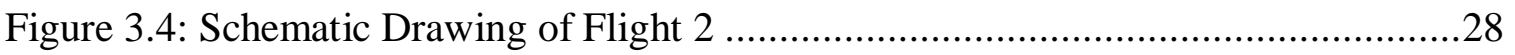

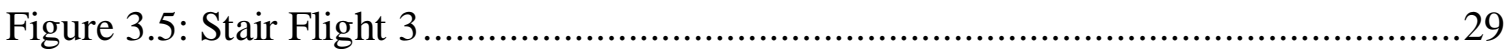

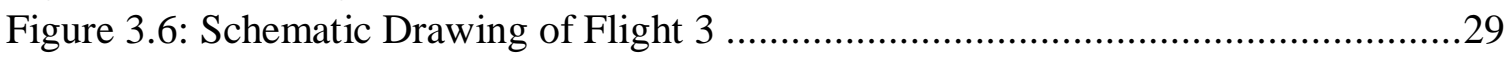

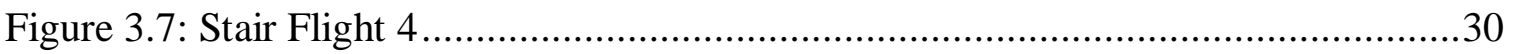

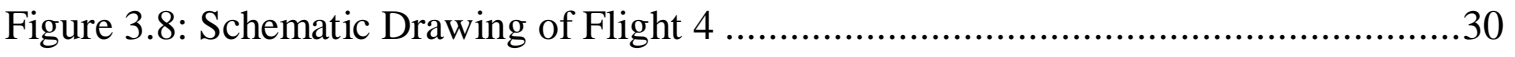

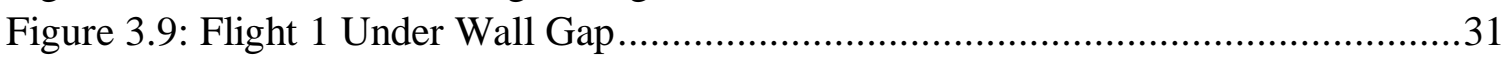

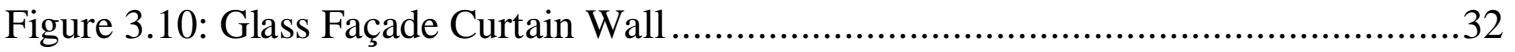

Figure 3.11: Accelerometer Placement and Impact Points ..........................................34

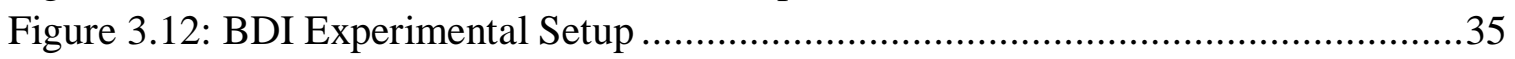

Figure 3.13 : Zoomed in Accelerometer Installation..................................................35

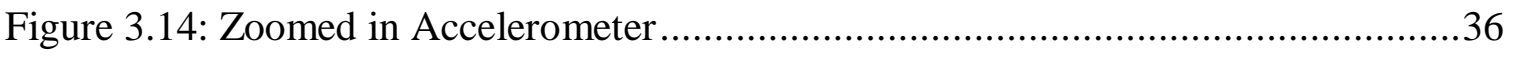

Figure 3.15: Acceleration vs. Time ......................................................................4 41

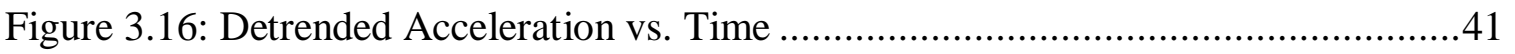

Figure 3.17: Frequency vs. Amplitude .....................................................................42

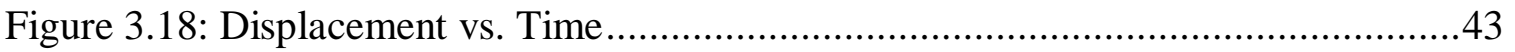

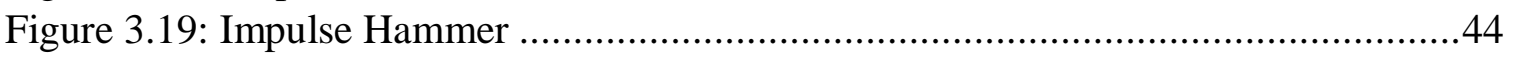

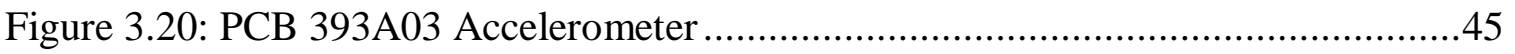

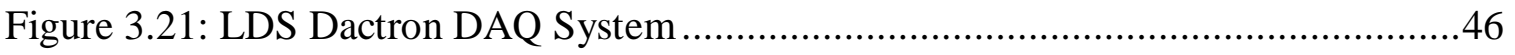

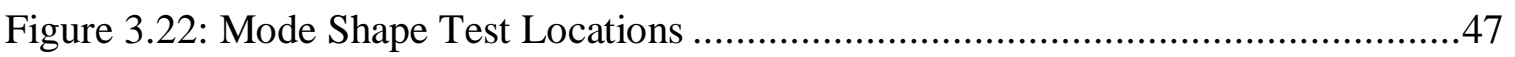

Figure 3.23: CATSModal/Star6 Stair Model .......................................................48

Figure 3.24: Schematic of Stair Flight (Based on DLR Group PKI As-Built Drawings) .50

Figure 3.25 : Stringer Connections..........................................................................52

Figure 3.26: Pinned Base Model Structure ......................................................53

Figure 3.27: Zoom in of Pinned Restraints ..................................................................54

Figure 4.1: Type 2 Experimental Mode1 (Left) ..........................................................64

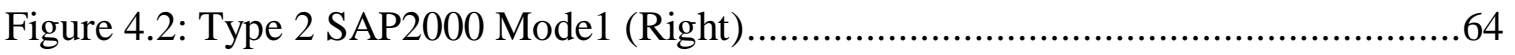

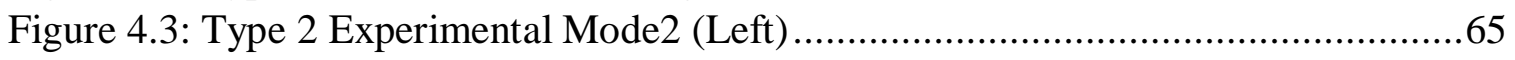

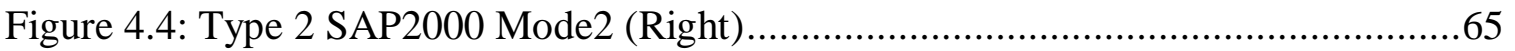

Figure 4.5: Type 2 Experimental Mode 3 (Left) .........................................................65

Figure 4.6: Type 2 SAP2000 Mode3 (Right)......................................................65

Figure 4.7: Type 2 Experimental Mode 4 (Left) .....................................................66

Figure 4.8: Type 2 SAP2000 Mode4 (Right)........................................................66 


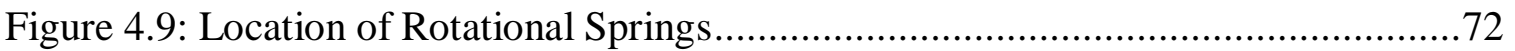

Figure 4.10: Location of Rotational Springs...................................................... 73

Figure 4.11: Two Stringer Rotational Spring Restraints vs. Frequency.........................75

Figure 4.12: One Stringer Rotational Spring Restraint vs. Frequency ..........................76

Figure 4.13: First Mode Frequency vs. Additional Two Rail Mass ...............................79

Figure 4.14: Second Mode Frequency vs. Additional Two Rail Mass...........................79

Figure 4.15: First Mode Frequency vs. Additional One Rail Mass ................................81

Figure 4.16: Second Mode Frequency vs. Additional Two Rail Mass...........................81

Figure 4.17: Two Stringer Mass Distribution Line of Best Fit .................................. 83

Figure 4.18: One Stringer Mass Distribution Line of Best Fit .................................... 83

Figure 4.19: Stair Flight Modeled with Railings..................................................... 85

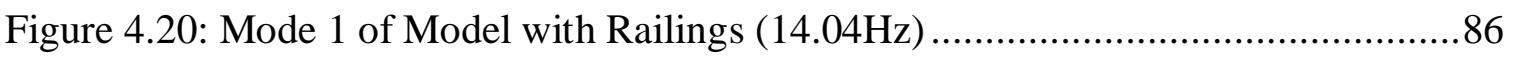

Figure 4.21: Mode 2 of Model with Railings $(14.04 \mathrm{~Hz})$............................................86

Figure 4.22: Modeled Type 1 Stair Schematic with Links and Springs ........................90

Figure 4.23: Model with Edge Links ........................................................... 91

Figure 4.24: Close up of Edge Links .....................................................................91

Figure 4.25: Type 1 Experimental Mode 1 (Left) ..................................................94

Figure 4.26: Type 1 SAP2000 Mode 1438 kN/m Links (Right)...............................94

Figure 4.27: Type 1 Experimental Mode 2 (Left) ..................................................95

Figure 4.28: Type 1 SAP2000 Mode 2438 kN/m Links (Right)...............................95

Figure 4.29: Type 1 Mode 110000 kN/rad Links........................................................97

Figure 4.30: Type 1 Mode 210000 kN/rad Links...................................................97

Figure 4.31: Plane Directions .................................................................................99

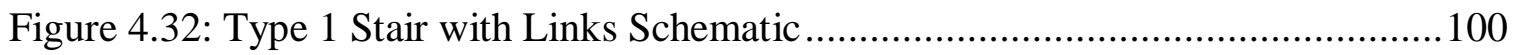

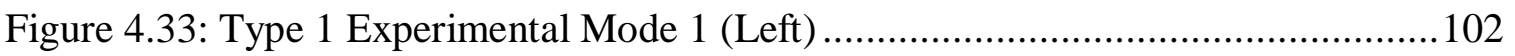

Figure 4.34: Type 1 SAP2000 Mode 1 Modeled only with Links (Right) ..................... 102

Figure 4.35: Type 1 Experimental Mode 2 (Left) ................................................... 103

Figure 4.36: Type 1 SAP2000 Mode 2 Modeled only with Links (Right) ...................... 103

Figure 4.37: Type 2 Experimental Mode 1 (Left) ..................................................... 106

Figure 4.38: Type 2 SAP2000 Mode 1 Modeled with only Links (Right).................... 106

Figure 4.39: Type 2 Experimental Mode 2 (Left) ...................................................... 106

Figure 4.40: Type 2 SAP2000 Mode 2 Modeled with only Links (Right) .................... 106

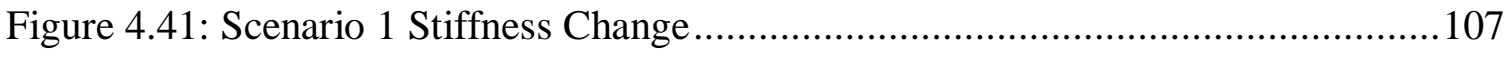

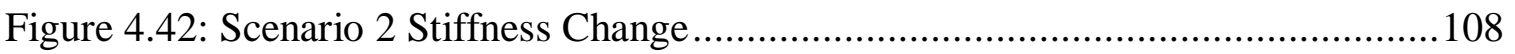

Figure 4.43: Mode 1 Frequency vs. In-Plane Stiffness .......................................... 109

Figure 4.44: Mode 2 Frequency vs. In-Plane Stiffness ........................................ 110

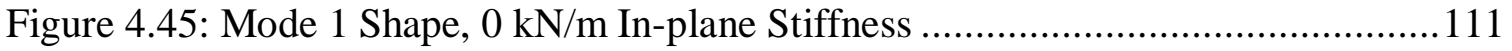

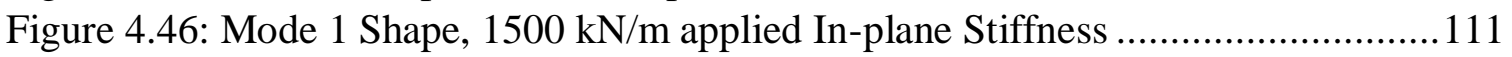

Figure 4.47: Mode 2 Shape, 0 kN/m applied In-Plane Stiffness................................112

Figure 4.48: Mode 2 Shape, 1500kN/m applied In-Plane Stiffness ........................... 113

Figure 4.49: Mode 1 Frequency vs. Out-of-Plane Stiffness ..................................... 114 
Figure 4.50: Mode 2 Frequency vs. Out-of-Plane Stiffness ....................................... 114

Figure 4.51: Mode 1 Shape, 0 kN/m applied Out-of-plane Stiffness .......................... 115

Figure 4.52: Mode 1 Shape, 1000kN/m applied Out-of-plane Stiffness ........................116

Figure 4.53: Mode 2 Shape, 0 kN/m applied Out-of-Plane Stiffness........................... 117

Figure 4.54: Mode 2 Shape, 1000 kN/m applied Out-of-Plane Stiffness ...................... 117

Figure 4.55: Model with Length-to-Width Ratio of Approximately Three.................... 122

Figure 4.56: Model with Length-to-Width Ratio of Approximately Four .....................122 


\section{List of Tables}

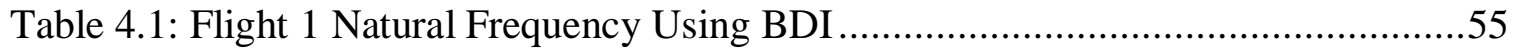

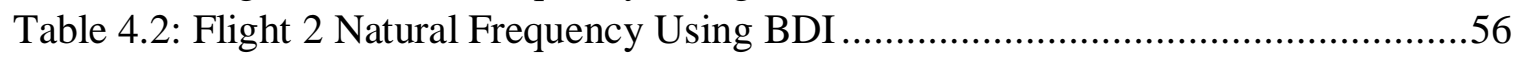

Table 4.3: Flight 3 Natural Frequency Using BDI ....................................................56

Table 4.4: Flight 4 Natural Frequency Using BDI .....................................................56

Table 4.5: Summary of Natural Frequencies Using BDI .......................................57

Table 4.6: Damping Ratio .........................................................................................5

Table 4.7: Stair Flight Mode Frequencies using Instrumented Hammer........................59

Table 4.8: Modal Participation Factor of SAP2000 Base Model....................................59

Table 4.9: BDI to CATSModal/Star6 Frequency Comparison ...................................60

Table 4.10: Summary of Natural Frequencies .........................................................61

Table 4.11: Difference in First and Second Modes for Similar Flights ........................62

Table 4.12: Type 1 and Type 2 Staircase Frequency Comparison................................63

Table 4.13: Mode 1 Comparison of Base Model to Experimental Results .....................66

Table 4.14: Mode 2 Comparison of Base Model to Experimental Results .....................67

Table 4.15 Mode 1 Comparison of Tuned Model to Type 2 Experimental Results .........70

Table 4.16: Mode 2 Comparison of Tuned Model to Type 2 Experimental Results ........71

Table 4.17: Change Frequency for Four Rotational Restraints.....................................74

Table 4.18: Change in Frequency for Two Rotational Restraints .................................74

Table 4.19: Type 1 Single Stringer Mass with 5000 kN-m/rad Springs First Mode

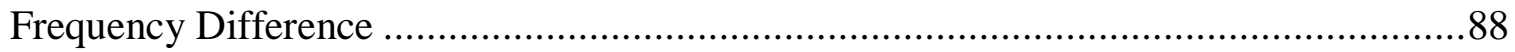

Table 4.20: Type 1 Single Stringer Mass with 5000 kN-m/rad Springs Second Mode

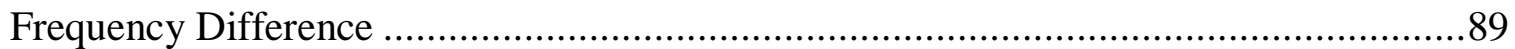

Table 4.21: Type 1 No Translation Link Applied Mode 1 Frequency ...........................92

Table 4.22: Type 1438 kN/m Translation Link Applied Mode 1 Frequency .................92

Table 4.23: Type 1 No Translation Link Applied Mode 2 Frequency ...........................93

Table 4.24: Type 1438 kN/m Translation Link Applied Mode 2 Frequency .................93

Table 4.25: 5000 kN-m/rad and 10000 kN/m Link Mode 1 Comparison ......................96

Table 4.26: $5000 \mathrm{kN}-\mathrm{m} / \mathrm{rad}$ and $10000 \mathrm{kN} / \mathrm{m}$ Link Mode 2 Comparison .......................96

Table 4.27: Type 1 Mode 1 Frequency with 438kN/m Links in U1, U2, and U3 Direction

101

Table 4.28: Type 1 Mode 2 Frequency with 438kN/m Links in U1, U2, and U3 Direction

101

Table 4.29: Type 2 Mode 1 Frequency with 438kN/m Links in In-Plane Direction ...... 105

Table 4.30: Type 2 Mode 2 Frequency with 438kN/m Links in In-Plane Direction ...... 105

Table 4.31: Comparison of Experimentally Determined Natural Frequency to Predicted

Natural Frequency for Type 2 Staircase ......................................................... 120

Table 4.32: Modeled Aspect Ratio vs. Equation Predicted Mode 1 Frequency .............. 123

Table 4.33: Comparison of the Empirically Adjusted Fundamental Natural Frequency

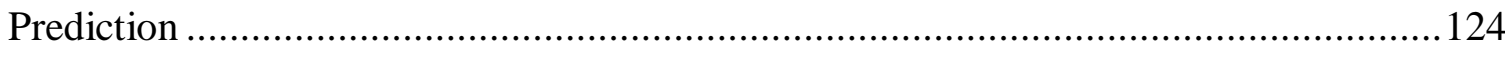




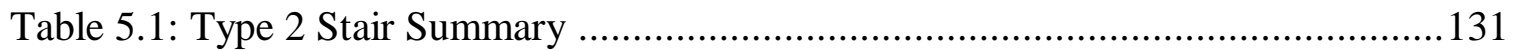

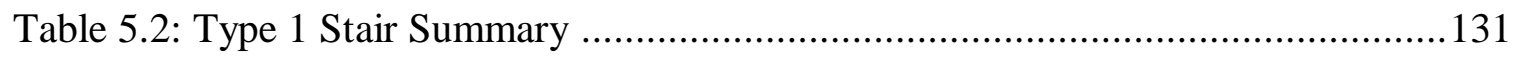




\section{CHAPTER 1- INTRODUCTION}

The goal of this thesis is to improve the accuracy of the predicted vibration response of staircases, specifically steel staircases with concrete filled pan treads, and to provide a better understanding of the effect of the design parameters on the vibration response (natural frequency and mode shape). This thesis utilized two different studies to accomplish this goal. The first study was an experimental study of four different flights of stairs used to understand the dynamic response of a concrete pan filled staircase system. The second study utilized the experimental results from the first study to perform a numerical analysis using a finite element model in SAP2000, which represented the stair flight structure. A parametric study was conducted on the model by altering the railing mass and restraint stiffness, to better understand the vibration response that these parameters have on the stair flight. In addition, AISC recommended design computations were also utilized.

\subsection{Motivations of Research}

According to Santos et al. (2019), in the past, staircases were designed to be very robust, so their mass, stiffness, and strength were high enough to avoid poor structural behavior. However, as material strengths and durability increased, staircases are being designed lighter and more slender. This change in design has led to an increase in vibration serviceability issues in staircases.

However, there is a lack of technical guides and research available that encompasses information about multiple different factors that influence a stair structure's natural 
frequency, such as the influence of railings and boundary conditions. According to Kim et al. (2016), the current design guides for staircases are not yet fully developed compared to building floor design guides due to the lack of sufficient and relevant research. Even though some investigations have been conducted in the past, the issue is that engineering assumptions about the dynamic behavior of staircases are often extended beyond the limitations of their initial research. Therefore, the procedures and parameters used for the numerical modeling of staircases must be validated through experimental analysis to ensure these assumptions are correct.

Due to the lack of research and understanding of the vibration characteristics of staircases, engineers often have the problem of either being overly conservative in staircase design, resulting in increased weight and/or cost, or under designing slender staircases. Under designing staircases can then result in natural frequencies low enough to allow resonant responses, and therefore potential serviceability issues (Davis and Avci 2015).

Thus, the contribution of this study will be to provide suggestions for a more refined finite element modeling procedure, as well as to provide a better understanding of the effect of the various parameters on the staircase vibration response to aid designers.

\subsection{Goals and Objectives}

The goal of this thesis is to provide analytical/design, numerical, and experimental modal comparisons for a typical steel frame staircase. The effects of the boundary conditions are explored with four nearly identical flights with various 
nonstructural components at the sides. The comparisons help to inform practical design methods.

The following objectives will achieve this goal:

1) To perform experimental investigations on the dynamic behavior of two types of staircases

2) Develop experimentally validated SAP2000 models for both types of staircases tested

3) To perform parametric studies on the experimentally validated SAP2000 models, to determine the influence of the following on the natural frequencies and mode shapes:

a. Simulation of stringer end restraints with rotational springs

b. The staircase flights' railing stiffness and mass

c. Boundary condition differences between wall and face stringers

4) To determine the validity of using translational links as an alternative technique for modeling unknown boundary condition stiffness

5) To conduct AISC recommended design computations

\subsection{Scope and Assumptions}

The scope of this research was limited to analyzing the effects of straight steel staircases with concrete filled tread pans. The scope was also limited to the experimental analysis of four different flights of stairs. These four flights were grouped into two categories. The first category is Type 1, and are composed of one wall stringer, one face 
stringer, and one railing. Flights 1 and 3 tested in this research fall into this category. The second category is Type 2, composed of two face stringers and two railings. Flights 2 and 4 tested in this research fall into this category. Where a wall stringer is defined as a stringer that sits flush against an adjacent wall on one side and is connected to the treads and risers on the other side, and a face stringer is a stringer exposed to the air on one side and attached to the risers and treads on the other. In addition, the scope was limited to analyzing vertical accelerations. This research considered only vertical accelerations because as occupants use staircases, typically, the foot strike impacts vertically onto the structure, creating the most excitation in this direction. Finally, the scope of the response data included natural frequency, damping, and mode shape.

Some of the assumptions made are as follows:

- During the experimental analysis, the weight of the equipment and persons testing the staircase was ignored

- The FEM model was constructed using engineering judgment, as defined by Pavic et al. (2007), meaning that it will utilize only information that is typically available to engineers during design, such as construction and architectural drawings, as well as specifications. 


\section{CHAPTER 2- LITERATURE REVIEW}

This chapter discusses relevant literature on the following topics:

1. Fundamental terminology for dynamic characteristics of structures

2. Relevant research that conducted on staircases in the past

3. Current methods used to determine the defined dynamic characteristics

4. Modeling/analysis techniques for finite element modeling (FEM)

The chapter concludes with an overview of the critical findings of past research and how they apply to the goals and methodology of this thesis.

\subsection{Fundamentals of Structural Vibration}

To fully discover the properties of interest for this study, it was critical to review the fundamentals of structural vibration characteristics. The properties of interest for this study included stiffness, natural frequency, fundamental mode shape, and damping.

\subsubsection{Stiffness}

Stiffness refers to the extent to which a structural element can resist deformation under an applied force. Stiffness is represented by the resistance of a system against movement/deflection per unit force applied (i.e., Force/Displacement). For a staircase under impact loading, stiffness can refer to the resistance to vibration. Therefore the stiffer the structural element, the less vibration energy it is likely to transfer.

The stiffness of a member in bending is influenced by the elastic modulus, moment of inertia, and span length. Stiffness is proportional to the elastic modulus and moment of inertia but is inversely proportional to the length, which means that the larger 
the moment of inertia, the higher the stiffness, which results in less bending. In addition, a shorter member length will bend less under the same applied load as a longer member. When stiffness is increased, the deflection that occurs under an applied load is reduced. The flexural stiffness relationship of a beam can be seen in Equation (2.1).

$$
\mathrm{k}=\frac{E I}{L}
$$

Where $E(P a)$ is the elastic modulus, $I\left(\mathrm{~m}^{4}\right)$ is the moment of inertia, and $L(m)$ is the length of the member.

Stiffness is an important characteristic for the understanding of the dynamic response of staircases because the stiffer the staircase elements, the less likely they are to displace or transfer vibration, which raises the natural frequency. A stiffer structure, given that it has the same mass, will have a higher natural frequency and a shorter natural period.

\subsubsection{Natural Frequency}

Frequency is the number of waves that pass a fixed point in a unit of time and is measured in units of $\mathrm{Hz}(1 / \mathrm{sec})$. In structures, the time required for an undamped system to complete one cycle of free vibration is the natural period of vibration, which is directly related to the natural circular frequency of vibration (Chopra 2012). The natural frequency is the frequency at which a system tends to oscillate without a driving force. If a force is applied at the dominant natural frequency, the displacement grows without bound, i.e. resonates. The natural frequency can be found by initiating a disturbance to the system and moving the system out of static equilibrium with a displacement and 
velocity. Analyzing the response of the structure, after this change to the system is applied, allows for the natural frequency and damping in the system to be found.

The natural frequency of a structure is influenced by two different factors. The first factor is stiffness, denoted as " $\mathrm{k}$ ". The second factor is the mass, denoted as " $\mathrm{m}$ ". The relationship between the two is defined by the radial frequency (or circular frequency) equation in Equation (2.2), (Chopra 2012).

$$
\omega_{\mathrm{n}}=\sqrt{\frac{\mathrm{k}}{\mathrm{m}}}
$$

The relationship of the natural circular frequency $\left(\omega_{n}\right)$ to the natural frequency is given in Equation (2.3), (Chopra 2012).

$$
f_{n}=\frac{\omega_{n}}{2 \pi}
$$

\subsubsection{Fundamental Mode}

A mode shape is the displaced form of a structure when a particular frequency of excitation is applied. The fundamental mode shape of a single-span structure, such as a beam, can be visualized as flexure where all the deflection has the same sign. However, the higher the mode, the more complex the deflection shape becomes, making it more difficult it becomes to visualize. The first three mode shapes of a simplified simply supported beam can be found in Figure 2.1. 


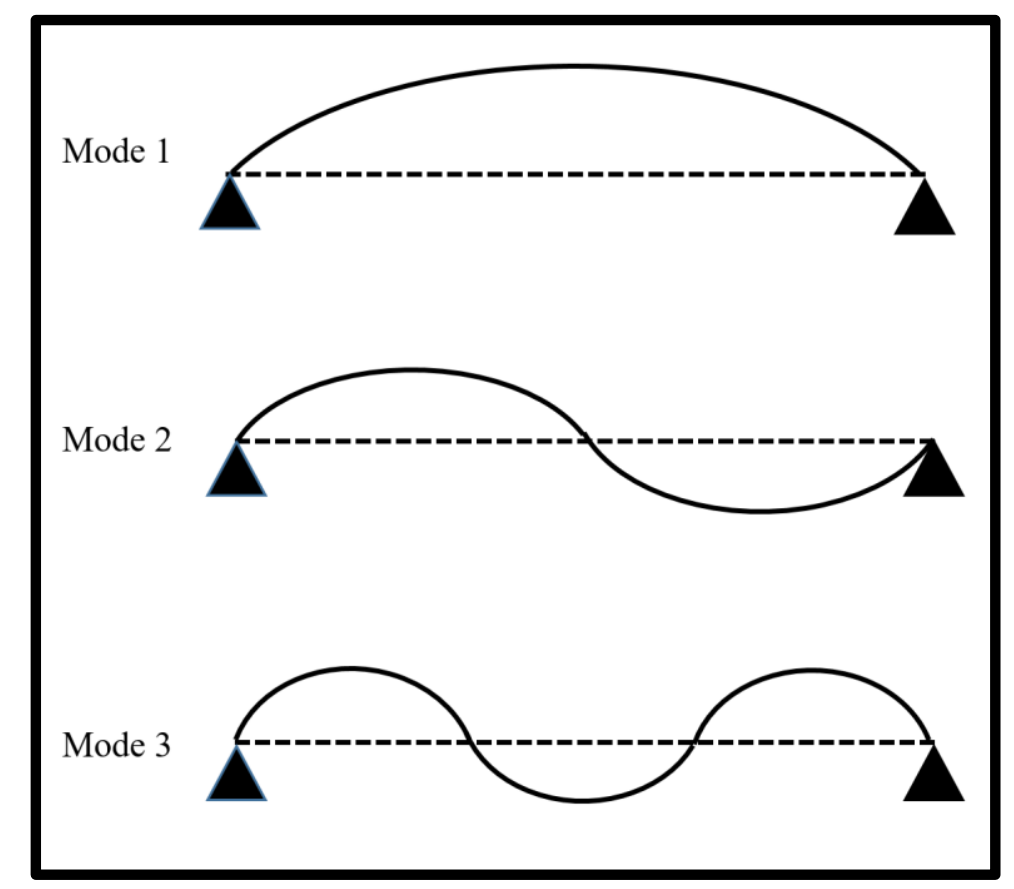

Figure 2.1: Mode Shapes of a Simply Supported Beam

In order to determine the mode shape associated with different frequencies, an experimental modal analysis process must be used.

Another property associated with mode shapes is that they are orthogonal. The orthogonality of mode shapes means that the work done by the nth-mode inertia forces is going through the rth-mode displacements is zero (Chopra 2012). In addition, the modal orthogonality implies that the work done by equivalent static forces associated with displacements in the nth mode is going through the rth-mode displacements is zero (Chopra 2012). This means that the modular arrangements of the structure are autonomous with the normal mode shape.

Mode shapes are important characteristics when comparing a finite element model of a structure to the experimental response. The mode shape can be used as one of the 
indicators that demonstrate the accuracy of the numerical model if the model's mode shapes match the experimentally obtained mode shapes.

\subsubsection{Structural Damping}

Damping is "the process by which vibration steadily diminishes in amplitude" (Chopra 2012), and represents "the efficiency with which a structure dissipates the energy input" (Jeary 1997). In structures, damping is caused by a variety of different conditions, such as rubbing friction, usually at connections, material damping caused by the contact among different structural elements, and thermal effects. Damping is the loss of mechanical energy in a vibrating system, generally expressed as a percent of critical viscous damping. "Viscous" damping means that the reduction of energy is related to a retarding force that is proportional to velocity. Damping of a structure can be determined from an analysis of the decay of vibrations following an impact (Jeary 1997). Percent of critical damping in steel stairs has typically been found to be between $1-7 \%$ by both Bishop et al. (1995) and Kim et al. (2008).

Damping is only present under dynamic loading and has been shown that as amplitude increases damping does as well (Jeary 1997). Different types of damping include viscous damping, hysteretic damping (due to nonlinear/inelastic behavior), Rayleigh damping, and coulomb damping. This thesis considers only viscous damping.

\subsubsection{Degrees of Freedom of a System (DOF)}

A structure that has only one degree of freedom is known as a single-degree-offreedom system (SDOF) system (Chopra 2012). An SDOF consists of a single mass that is concentrated at one location on the system. SDOF systems are used as a simplification 
of structural models to aid in the understanding of a structures' dynamic behavior. An example of a simplified SDOF boxcar model is found in Figure 2.2.

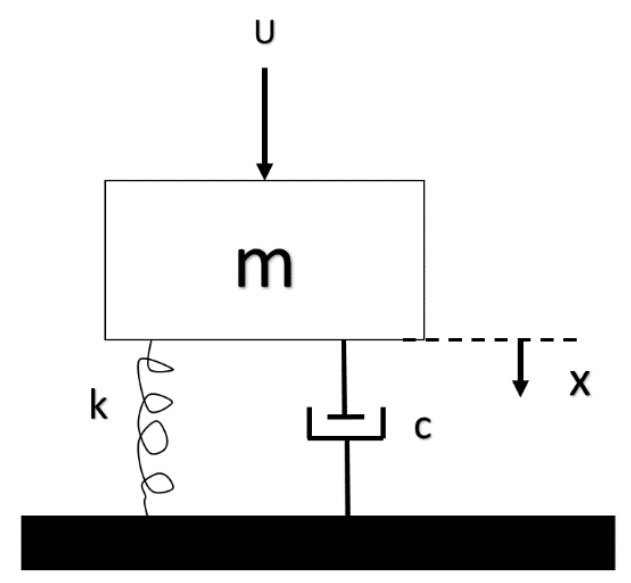

Figure 2.2: Boxcar SDOF

The basic equation of motion for any SDOF system is provided by (Chopra 2012) in Equation (2.4).

$$
\mathrm{mü}-\mathrm{c} \dot{\mathrm{u}}-\mathrm{ku}=\mathrm{P}(\mathrm{t})
$$

Where, $m=$ mass, $c=$ damping, $k=$ stiffness, $\ddot{u}=$ acceleration, $\dot{u}=$ velocity, and $u=$ displacement.

If more than one mass is used to represent the structure, it is a multi-degree-offreedom system (MDOF). An MDOF is a system that contains multiple degrees of freedom represented by multiple masses that are connected by frame elements (Chopra 2012). However, for this research, the stair structure will be considered as an MDOF system and will be discussed further in Chapter 3 . 


\subsection{Previous Research}

This section presents past research that has been conducted on staircases to better understand the currently available research involving staircase design and behavior.

\subsubsection{Effects of Human Loading on Staircases}

Kerr and Bishop (2001) conducted research investigating the influence of human loads on staircases. Their research resulted in suggestions as to what conditions should warrant concern by staircase designers. Kerr and Bishop (2001) cited that the motivation for conducting their investigation was due to a lack of satisfactory guidance for staircase designers, who would often "rely on experience from footbridge and floor design" to design staircases (Kerr and Bishop 2001). However, they state that this should not be done because "footfall rates (walking paces) and harmonic amplitudes can be vastly different" for staircases compared to floor or bridge slabs (Kerr and Bishop 2001). In their work, Kerr and Bishop (2001) analyzed the differences between staircase and floor footfall forces. In addition, they collected data from staircase occupants to set a standard for appropriate occupant vibration tolerability levels, since none existed at the time. They utilized force plate testing to conduct and quantify the impact loading produced by subjects walking along a horizontal platform, as well as ascending and descending a staircase. Fourier analysis techniques were utilized to determine the harmonic amplitudes and frequencies in order to compare the two loading conditions. Kerr and Bishop determined that not predicting a staircase's natural frequency accurately "could lead to serious vibration problems" (Kerr and Bishop 2001). 
As a result of their work, Kerr and Bishop came up with a suggested minimum natural frequency tolerance level for staircases. They determined that if a staircase has a frequency of less than $10 \mathrm{~Hz}$, it may lead to unacceptable levels of vibration for stair occupants. This research highlights the importance of understanding the natural frequency for the purpose of serviceability.

\subsubsection{Experimental Assessment of Vibration Serviceability of Stair Systems}

Kim et al. (2008) performed research investigating the serviceability performance of both steel and reinforced concrete stairs. They were motivated by the importance of serviceability as a design consideration and the increasing industry trend toward building steel staircase systems, which are typically lighter than concrete staircases. In their study, they measured the dynamic properties of a variety of staircases and compared them to the serviceability criteria provided by AISC (1997) and Bishop et al. (1995). Their study included reinforced concrete stairs, steel stairs with laminated tread boards, and steel stairs with reinforced concrete stair treads. They considered stair flights individually, where each flight connected a floor to a landing at mid-story height. A heel-drop test and accelerometers were utilized to determine the natural frequency and damping of each staircase. They also utilized a human walker moving at various speeds up and down the stairs to discover the peak acceleration of the stair structures. They concluded that the dynamic response of a steel stair system is much higher than that of a reinforced concrete staircase. Meaning that reinforced concrete staircases are more prone to achieve serviceability standards than that of similar steel staircases. 


\subsubsection{Slender Steel Monumental Stair Vibration Serviceability}

In 2009, Davis and Murray conducted an experimental and analytical study of slender monumental staircases. The goal of their study was to further the understanding of stair vibration issues and to provide additional guidance to staircase designers. Their primary motivation resulted from the increase in the use of stairs that act as monumental architectural features. They stated that the architectural requirements of these types of staircases usually lead to structures that are slender and have long clear spans, which create potential serviceability issues (Davis and Murray 2009). The design standards for these stairs are more stringent because slender stairs often have heavier treads and guardrails, as well as slender stringers, which can result in low natural frequencies, making them more susceptible to vibration issues under walking excitation.

Davis and Murray (2009) also described the methodologies used to experimentally and analytically determine the vibration characteristics of a staircase. Their research observed both modal and walking tests to estimate the fundamental natural frequency and damping of the structure. In addition, finite element modeling was used to predict the data collected by the experiments. In their research, Davis and Murray (2009) considered lateral vibration as insignificant because they predicted the fundamental lateral vibration mode to be high enough not to cause serviceability issues, as is the case for many staircases. In order to predict the stair's natural frequency and mode shapes, standard eigenvalue analyses were used.

After they conducted their research, they proposed a design footstep force evaluation procedure, predicting the harmonic that matches the fundamental frequency 
and applying adjustment factors for the number of occupants. A summary of the procedure includes the following steps:

1. Build an accurate finite-element model

2. Use steady-state analysis to predict the acceleration response at the location of interest

3. Determine which harmonic of the walking force matches the natural frequency

4. Multiply the peak accelerance magnitude by the harmonic design force from the provided table to predict the steady-state acceleration due to a single walker.

Understanding the natural frequency of the stairs is important in determining which harmonics created by walkers could potentially lead to serviceability issues in the staircase.

In order to avoid the creation of a finite element model, Davis and Avci (2015) conducted a study to identify a simplified vertical acceleration prediction method that could be done by hand for slender staircases. In their research, an experimental modal analysis was utilized to discover the damping, mode shape, and natural frequency of two slender monumental steel staircases. They also investigated the peak accelerations due to occupant walkers to find the peak acceleration at the $2^{\text {nd }}, 3^{\text {rd }}$, and $4^{\text {th }}$ harmonic. 
Davis and Avci (2015) verified that linear stairs have natural vibration modes resembling those of parallel beams. As a result, the assumption was made that a linear staircase, with only end connections, can be treated as a simply supported beam.

Therefore, the equation for the natural frequency of a simply supported beam can be used to estimate the first mode frequency of a steel staircase. An image of this idealized free body diagram can be found in Figure 2.3.

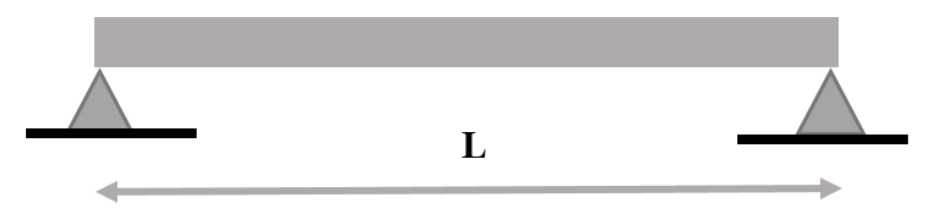

Figure 2.3: Simply Supported Beam FBD

The equation used to represent a simply supported beam with uniform mass is presented in Equation (2.5), and was also presented as a method by (Murray et al. 1997).

$$
f_{n}=\frac{\pi}{2} *\left[\frac{g * E_{s} * I_{t}}{W_{s} * L_{s}^{3}}\right]^{0.5}
$$

Where; $E_{s} * I_{t}(N-m)=$ stringer vertical flexural stiffness, $L_{s}(m)=$ stringer length between supports, $W_{s}(N)=$ weight of the stair, $f_{n}(\mathrm{~Hz})=$ fundamental natural frequency, $g\left(\mathrm{~m} / \mathrm{s}^{\wedge} 2\right)=$ acceleration of gravity.

Davis and Avci (2015) used Equation (2.5) to predict the natural frequency of two staircases. For Stair 1, the equation predicted $5.1 \mathrm{~Hz}$, but their measured natural frequency was $7.3 \mathrm{~Hz}$, meaning that it had a predicted-to-measured ratio of 0.70 or a 
difference of $35.5 \%$. For Stair 2, the equation predicted a natural frequency of $8.0 \mathrm{~Hz}$, but the equation predicted $6.74 \mathrm{~Hz}$, meaning that it had a predicted-to-measured ratio of 0.84 or a difference of $17.1 \%$. They determined that since the results were conservative and relatively close to the actual value that this method is accurate enough to use for design. It is important to note that the known uses for using Equation (2.5) are limited to slender stairs having frequencies below $10 \mathrm{~Hz}$, as well as limited to linear stairs.

In 2016, Jurgensen investigated the vibration serviceability of monumental stairs. Her motivation was to address how to model monumental stairs in SAP2000 to reliably predict their natural frequencies. In order to do this, the measured field data were compared to the results predicted using a computer model. Jurgensen (2016) conducted experimental modal testing using an electrodynamic shaker on two staircases. From this data, the mode shapes and natural frequency were determined. After the field data was acquired, a computer model was constructed using SAP2000. The stair model was created using a combination of frame and shell elements. One important thing to note was that the guardrail was modeled as a distributed load since it was not considered as part of the structural system. After the computer model was created, it was updated so that the first mode frequencies and mode shapes matched the experimentally determined mode shapes. Jurgensen (2016) concluded that that the frame connections and releases differed between the stair structures tested and that proper modeling is critical to achieving accurate predictions. 


\subsubsection{Prediction of the Vibration Response of High-Frequency Steel Staircases}

In 2016, Kim et al. researched how to better create an impulse model for the prediction of vibration responses in high-frequency steel staircases, staircases with frequencies larger than $10 \mathrm{~Hz}$. Their research was driven by the lack of technical guides appropriate for designing high-frequency steel staircases with low damping. Kim et al. (2016) noted that compared to building floors, a basic framework for the design of staircases has not yet been fully developed, and few experimental studies have been carried out. In addition, in the past, reinforced concrete stairs have been widely used in multi-story residential and office buildings. However, there is an increasing amount of designers opting for steel staircases. Compared to reinforced concrete staircases, steel staircases are lighter in weight and often have lower damping, making them more sensitive to vibration responses (Kim et al. 2016). As a result, their goal was to propose a new effective footfall impulse formula to predict the vibrational response of highfrequency steel staircases, due to the increase in their use and the lack of available design guidelines.

Kim et al. (2016) utilized seven full-scale steel staircases that were fabricated for the test. The experimental models were constructed using steel stringers with the treads and risers attached to the top of stringers.

While conducting their research, impact hammers were used to excite the structure, and accelerometers attached at the bottom mid-span along the length of the stringers were used to capture the vibration data. The center of the staircase, for both length and width, was used as the measurement location since it was determined to be 
where the highest acceleration was likely to occur. Kim et al. (2016) were able to determine the natural frequency and damping ratios by evaluating the time and frequency domain data collected from the tapping on the staircase. The natural frequencies determined ranged between 16.0 and $32.0 \mathrm{~Hz}$. The damping was determined to range between $2.1 \%$ and $4.6 \%$ of critical.

The following are assumptions utilized and confirmed by Kim et al. (2016) during their study. The first assumption is that the fundamental mode is the only mode to consider when the fundamental frequency is relatively high. This is because the fundamental frequency of the steel staircase tested is several times higher than the pace of the walking excitation, so higher mode frequencies are of little concern for stair design. Kim et al. (2016) also verified experimentally that the effect of the concrete filling on damping ratios was minor, and could be excluded. They also determined that if the damping of the staircase is in the range of $2-4 \%$ of critical, it is justifiable to neglect the effect of damping.

\subsection{AISC Design Guides}

Two of the primary documents that engineers use in the design of staircases are AISC Design Guide 11, by Murray et al. (2016), and AISC Design Guide 34, by Friedman (2018). AISC Design Guide 11 primarily describes the procedure to design floors. However, in the most recent 2016 edition, there are a few sections involving slender steel staircases. AISC Design Guide 34 involves the design of staircase structures but refers to Design Guide 11 for vibration calculations. 


\subsubsection{AISC Design Guide 11}

AISC Design Guide 11 created by Murray et al. (2016) was developed to inform designers on how to design and predict the vibrations of steel-framed structural systems due to human activity. One of the topics AISC Design Guide 11 (Murray et al. 2016) covers is the vibration tolerance levels of staircases. AISC Design Guide 11 (Murray et al. 2016) states that when the natural frequency of stairs exceeds 9 to $10 \mathrm{~Hz}$, the resonance becomes less important for human-induced vibration. In order to aid designers in predicting whether or not a staircase meets this serviceability condition, the first mode natural frequency of a linear staircase was determined to be predicted by equation (2.6).

$$
f_{n}=\frac{\pi}{2} *\left[\frac{g * E_{s} * I_{t}}{W_{s} * L_{s}^{3}}\right]^{0.5}
$$

Where; $E_{s} * I_{t}(N-m)=$ stringer vertical flexural stiffness, $L_{s}(m)=$ stringer length between supports, $W_{s}(N)=$ weight of the stair, $f_{n}(\mathrm{~Hz})=$ fundamental natural frequency, $g\left(\frac{m}{s^{2}}\right)=$ acceleration of gravity.

AISC Design Guide 11 (Murray et al. 2016) also includes Fourier series parameters that summarize several common dynamic loads applied by individual walkers and runners, which can be used to better understand which serviceability conditions are applicable to the stair structure being designed. AISC Design Guide 11 (Murray et al. 2016) includes a table summarizing these parameters. This table was created using a combination of the works of Kerr and Bishop (2001), Davis and Murray (2009), and Davis and Avci (2015). 
AISC Design Guide 11 (Murray et al. 2016) also outlines the evaluation criteria for human comfort levels and discusses some of the existing tolerance levels that have been established for persons occupying a structure. It was determined that as the frequency applied to the staircase changes, the peak acceleration serviceability amount also changes. It was determined that if the frequency falls outside the range of 4 to $8 \mathrm{~Hz}$, people tend to accept higher accelerations.

AISC Design Guide 11 (Murray et al. 2016) also discusses the importance of understanding the fundamental natural frequency. This is because if the fundamental frequency is low enough, the harmonic forces created by a walker could cause resonance in the structure. Therefore the rule of thumb threshold for a structure described as a lowfrequency system is $5 \mathrm{~Hz}$, according to AISC Design Guide 11 (Murray et al. 2016). It also notes that high-frequency responses are almost always relatively small but can still cause problems when the tolerance limit is stringent. The threshold of $5 \mathrm{~Hz}$ differs from other literature, such as Kerr and Bishop (2001), which states, “any staircases having a natural frequency of less than $10 \mathrm{~Hz}$ may be dynamically responsive to the pedestrians using it and produce unacceptable levels of vibration". The $10 \mathrm{~Hz}$ threshold is also utilized in other literature. Therefore, the research for this thesis will consider $10 \mathrm{~Hz}$ as the threshold frequency for occupant tolerability.

\subsubsection{AISC Design Guide 34}

AISC Design Guide 34 (Friedman 2018) provides engineers with terminology related to staircase design and construction, and it is broken into the following sections: General Staircase Information, Code Requirements, Stairway Design, Lateral Bracing, 
Diaphragm Design, and Stairway Connections. This design guide defines terms that are important to this research, such as staircase classification. Using the design guide, the staircases used in this study are defined as straight concrete pan filled tread staircases, as seen in Figure 2.4.

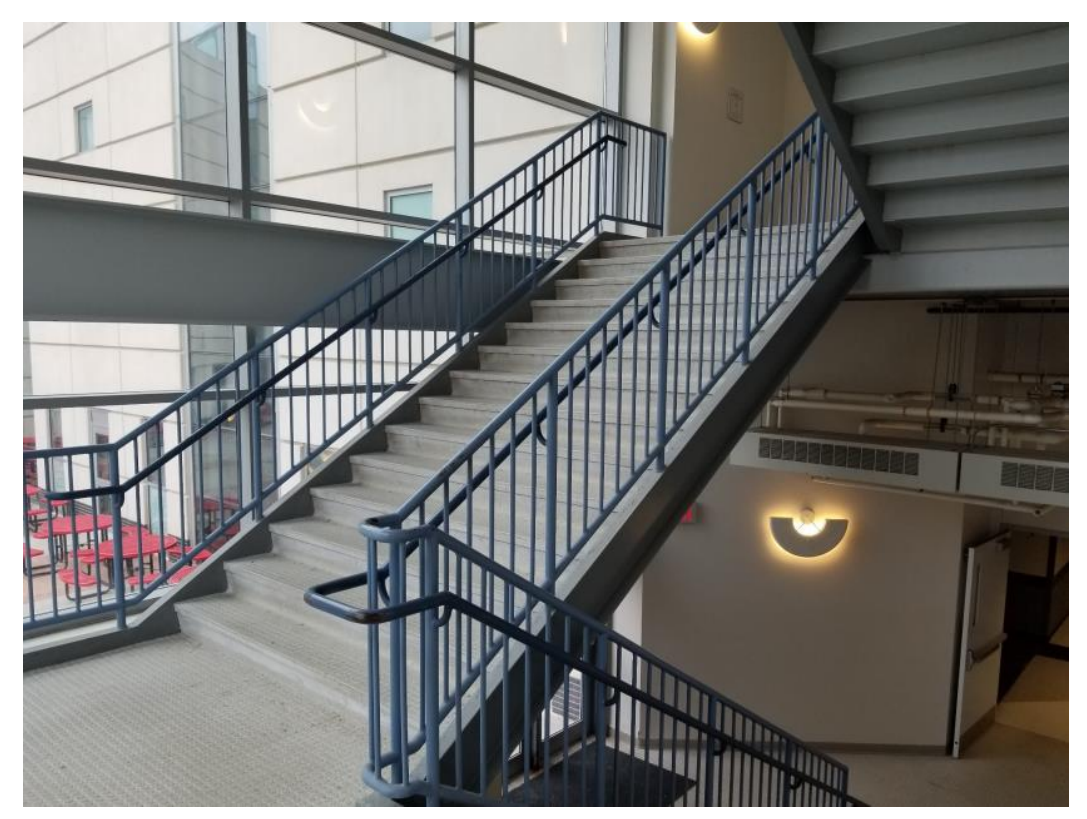

Figure 2.4: Stair Case Structure Used in Study

In addition, the design guide describes how staircases are composed of stringers, treads, and risers. The staircase utilized in this research have concrete filled pan treads that are constructed using light-gauge steel to form a pan that is filled with concrete. The tread is then supported by welded carrier angles that are welded to both the stringers and the pans.

\subsection{Finite Element Modeling Procedures}

In order to compare the experimentally obtained data to the numerical data, a Finite Element Model (FEM) needs to be created. Moragaspitiya (2012) states that the 
main advantage of using FEM in structural analysis is the ability to generate numerical modes to simulate the action effects, stresses, and strains under variable conditions of stiffness and loads.

Since one of the purposes of this thesis is to investigate the modeling parameters needed to accurately depict the mode shape, damping, and natural frequency characteristics of a steel staircase with concrete treads, it is important to make sure that the model properly represents the structure. Comparing the FEM to collected experimental data is important because it can provide insight into the accuracy of a model developed using existing modeling techniques and practices. This comparison allows for a better understanding of how to update the model to improve its correlation with experimental data.

The latest version of AISC Design Guide 11 (Murray et al. 2016), provides designers with information regarding the use of a finite element analysis procedure, a section that did not exist in the previous version of the guideline. The design guide discusses how finite element analysis is often needed when the structural system or dynamic loads fall outside the limitations of manual calculation methods.

Chapter 7 of the AISC Design Guide 11 discusses some commonly used methodologies used to create finite element models. However, a limitation to this section is that the evaluation method, originally proposed by Davis and Murray (2009) and Davis and Avci (2015), was created for slender monumental stairs. This does not include pantype or short, stiff stairs, both of which characterize the structure being analyzed in this research. 
One technique traditionally used to create a FEM is to model the entire stair as if it is a beam, by excluding the additional surrounding structures and representing them with appropriate boundary conditions. The supporting structure is typically excluded because if the supporting structure has a larger mass, it can lead to an amplification of minor errors in the modeling, which in turn results in increased errors in the results (Murray et al. 2016).

One way in which a well-developed FEM model can be created, as suggested by Pavic et al. (2007), is first to create a model using "best engineering judgment", i.e., only the information available from the design, which includes construction and architectural drawings and specifications.

However, finite element models can be limited in the accuracy they provide. Pavic et al. (2007) found that even a detailed FEM of a floor system, which was developed based on the authors' best engineering judgment, had an error predicting natural frequencies by $10-15 \%$ in some of the first four modes of vibration. Therefore, it can be assumed that there will also be a certain level of inaccuracy in the models' predictions of the staircase natural frequencies created in this thesis as well.

There are a variety of reasons why FEM results can vary from experimentally determined results. The primary reason is improperly identifying boundary conditions. The boundary condition that is a major unknown in staircases is the degree of rotational restraint of the stringer end connections (Davis and Salmon 2019). It is difficult to predict the end restraint boundary conditions because there are numerous factors 
affecting these restraints. Therefore, model updating is often applied in order to represent realistic boundary conditions.

Another reason for variation in a FEM from experimental data includes over and underestimations of the stiffness of the main structural components. To accurately model a structure, it may be required to update a model by changing the model's parameters to better match the experimentally determined properties. Such updating can help increase the shortcomings of a finite element model that is based on best engineering judgment (Pavic et al. 2007).

The goal of updating the model is to reduce the initial differences between the FEM and the experimental results. After tuning, the model should resemble the real structure relatively closely (Pavic et al. 2007). There are two stages to tuning a model. The first is model refinement. During this stage, the preliminary model created is adjusted by adding additional features such as elements and springs, to model the boundary conditions, as well as improving and detailing the geometry. The second stage is parameter adjustment. In this stage, uncertain modeling parameters in the already refined model are varied by trial and error within reasonable limits to improve how close the model matches the real structure (Pavic et al. 2007). The research in this thesis utilized both model refinement and parameter adjustment stages.

\subsection{Literature Review Summary}

The following is a summary of some of the major concepts that were taken from the following literature and how they will be applied to this research. 
Kim et al. (2016) presented a straightforward and effective procedure for testing the serviceability of staircases. This research is important because Kim et al.'s study analyzed staircases similar to the ones used in this thesis: staircases with shorter span stringers where one side has a wall stringer abutting a wall. This research differs from other research, which is focused on monumental staircases having two face stringers.

Davis and Murray (2009) also had some key findings that were applicable to this thesis. The first is that when a staircase has a natural frequency of less than $10 \mathrm{~Hz}$, it has a higher chance of being responsive to pedestrians, and may produce "unacceptable levels of vibration" (Davis and Murray, 2009), similar to the findings in other literature. Although this thesis is focused on understanding and predicting the natural frequency and mode shape of a stair structure, Davis and Murray's research was important for the understanding of how to create an experimental program to be able to capture the natural frequency of a staircase.

In addition, the natural frequency for slender stairs can be estimated using Equation (2.6), which can be found in AISC Design Guide 11 (Murray et al. 2016) and Davis and Avci (2015). Although this equation had been applied previously to predict the natural frequency of slender staircases, those with less than $10 \mathrm{~Hz}$, the extent to which this equation can be used has not fully been tested.

Finally, Pavic et al. (2007) and AISC Design Guide 34 (Friedman 2018) provided insight on how to update a FEM, so that the model more accurately depicts the boundary conditions of experimentally determined structures. It is suggested that this can be done by applying springs and links in the model. 


\section{CHAPTER 3- METHODOLOGY}

This chapter describes an overview of the structures analyzed, the data collection procedure, and the finite element modeling performed in this study.

\subsection{Description of Stair Systems Studied}

All of the staircase flights tested are located in the southwest corner stairwell of the Peter Kiewit Institute (PKI), located on the Scott Campus of the University of Nebraska-Lincoln, in Omaha. Four staircase flights were utilized in this study, and all of them are composed of 13 treads measuring $30.48 \mathrm{~cm} \mathrm{x} 220.98 \mathrm{~cm}$ (12 in. x 87 in.) and 14 risers with height $17.78 \mathrm{~cm}$ (7 in.) set at a $2.54 \mathrm{~cm}(1 \mathrm{in}$.) offset from the base to the top of the riser. The risers are constructed using 12 gauge steel, and the tread is constructed using a concrete filled 12 gauge steel pan. The staircase stringers are $4.3 \mathrm{~m}$ (14.1 ft.) long C12 x 20.7 channel shapes. The treads are connected to the stringers via welded steel angles. The treads are also covered with a thin rubber matting. Images of Flights 1-4 and schematic drawings of these staircases can be found in Figure 3.1-Figure 3.8. These stairs were chosen for this research because the geometries of all the stair flights are the same, but have varying boundary conditions. The use of these stairs allows for the differences in frequency and mode shape behavior to be attributed to the difference in boundary conditions, and not a difference in geometry. 


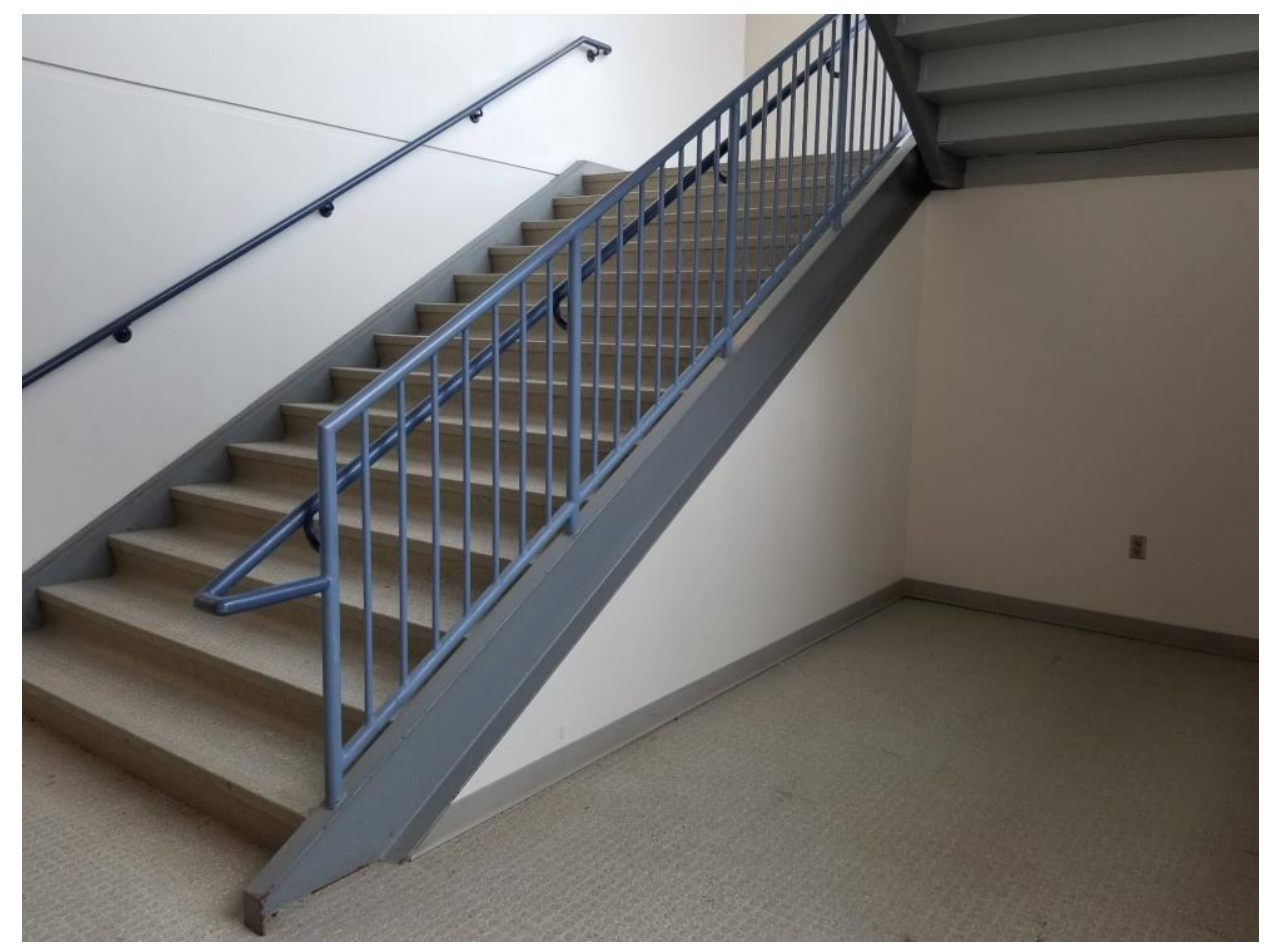

Figure 3.1: Stair Flight 1

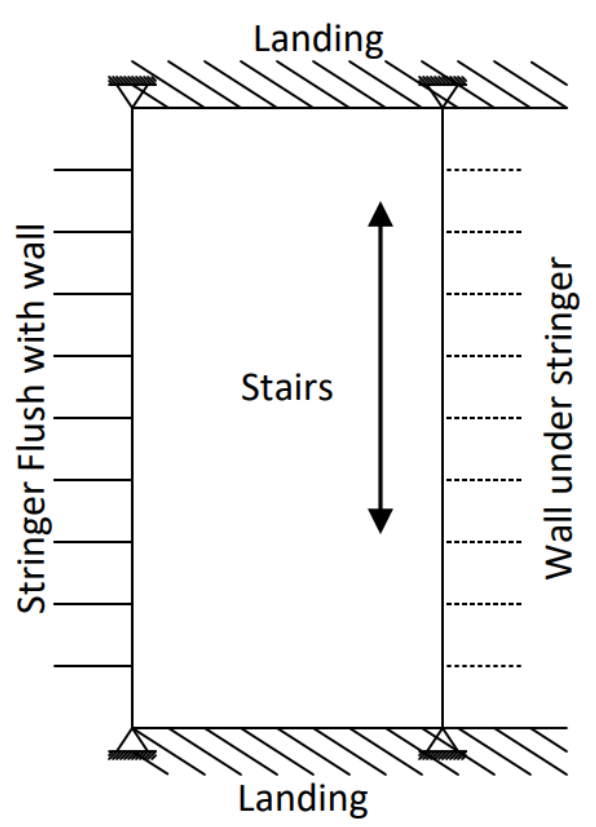

Figure 3.2 : Schematic Drawing of Flight 1 


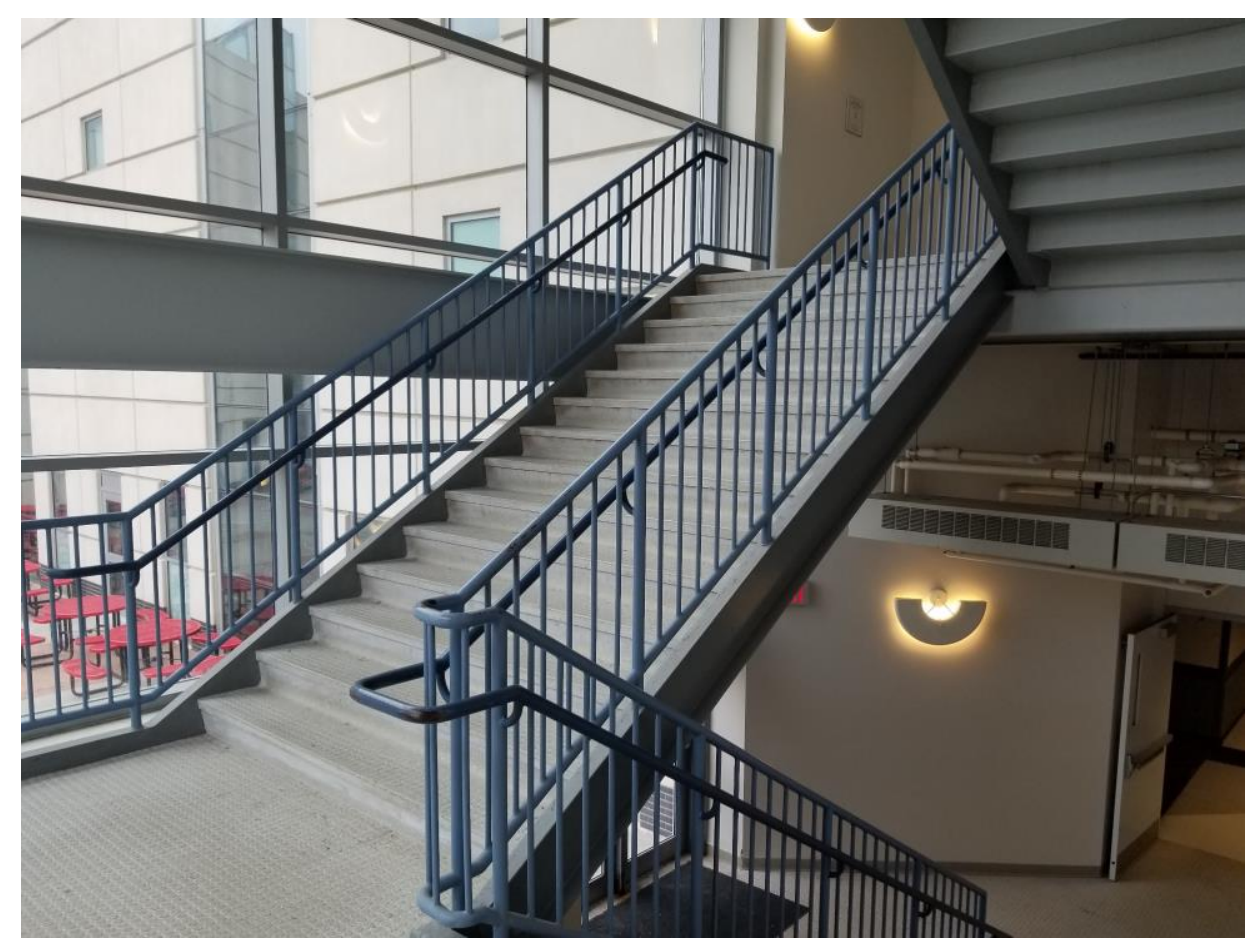

Figure 3.3: Stair Flight 2

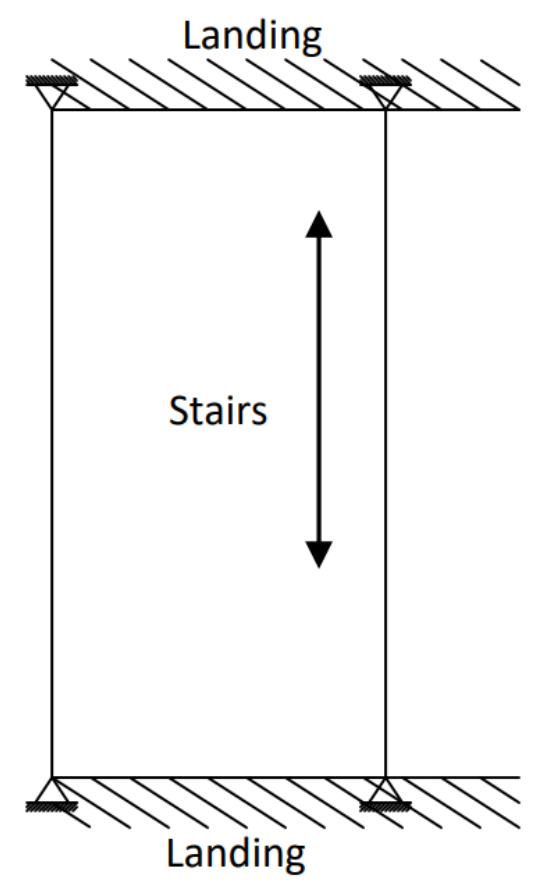

Figure 3.4: Schematic Drawing of Flight 2 


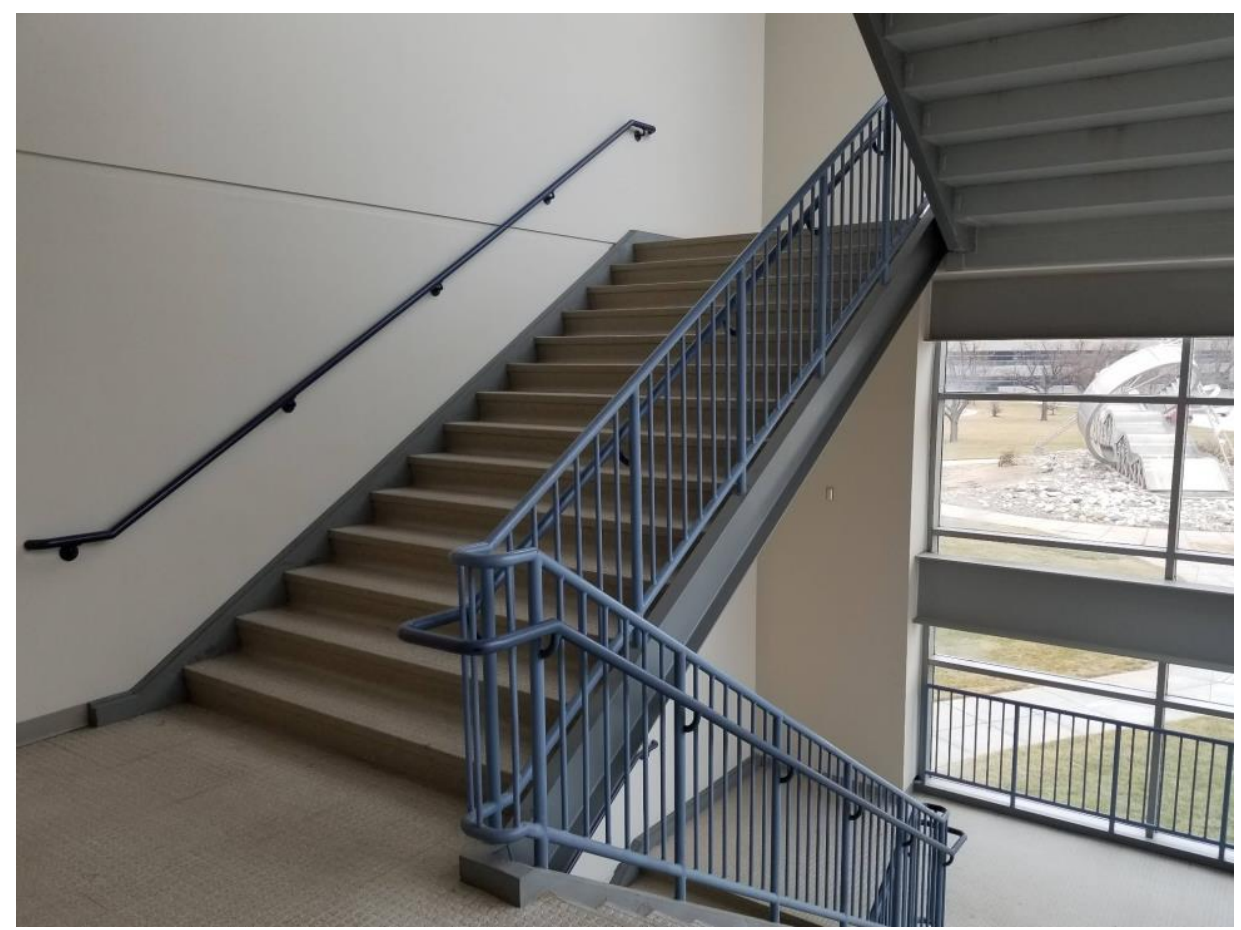

Figure 3.5: Stair Flight 3

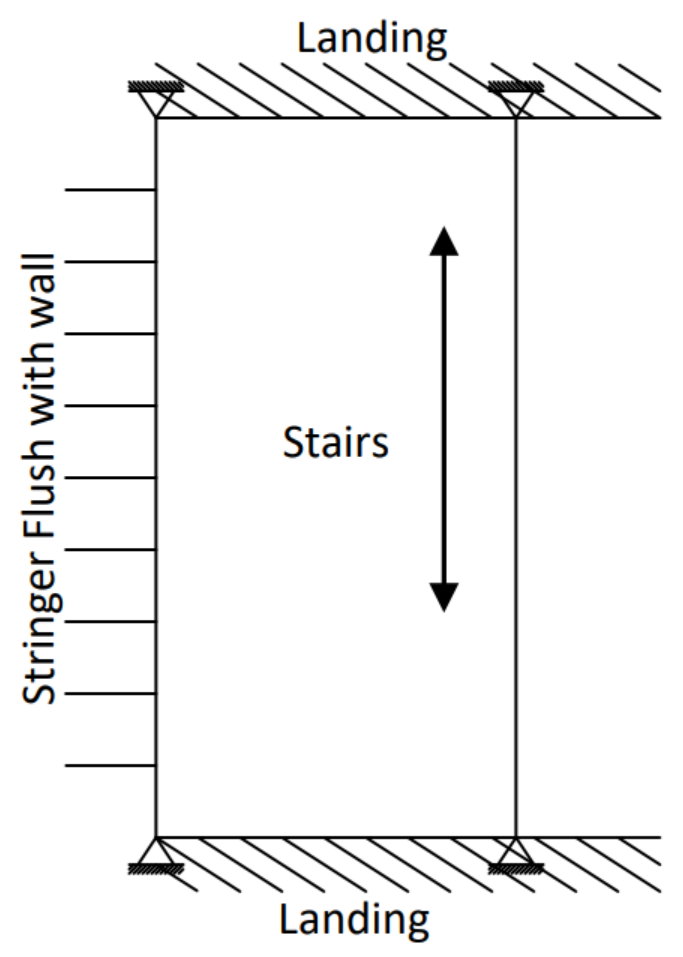

Figure 3.6: Schematic Drawing of Flight 3 


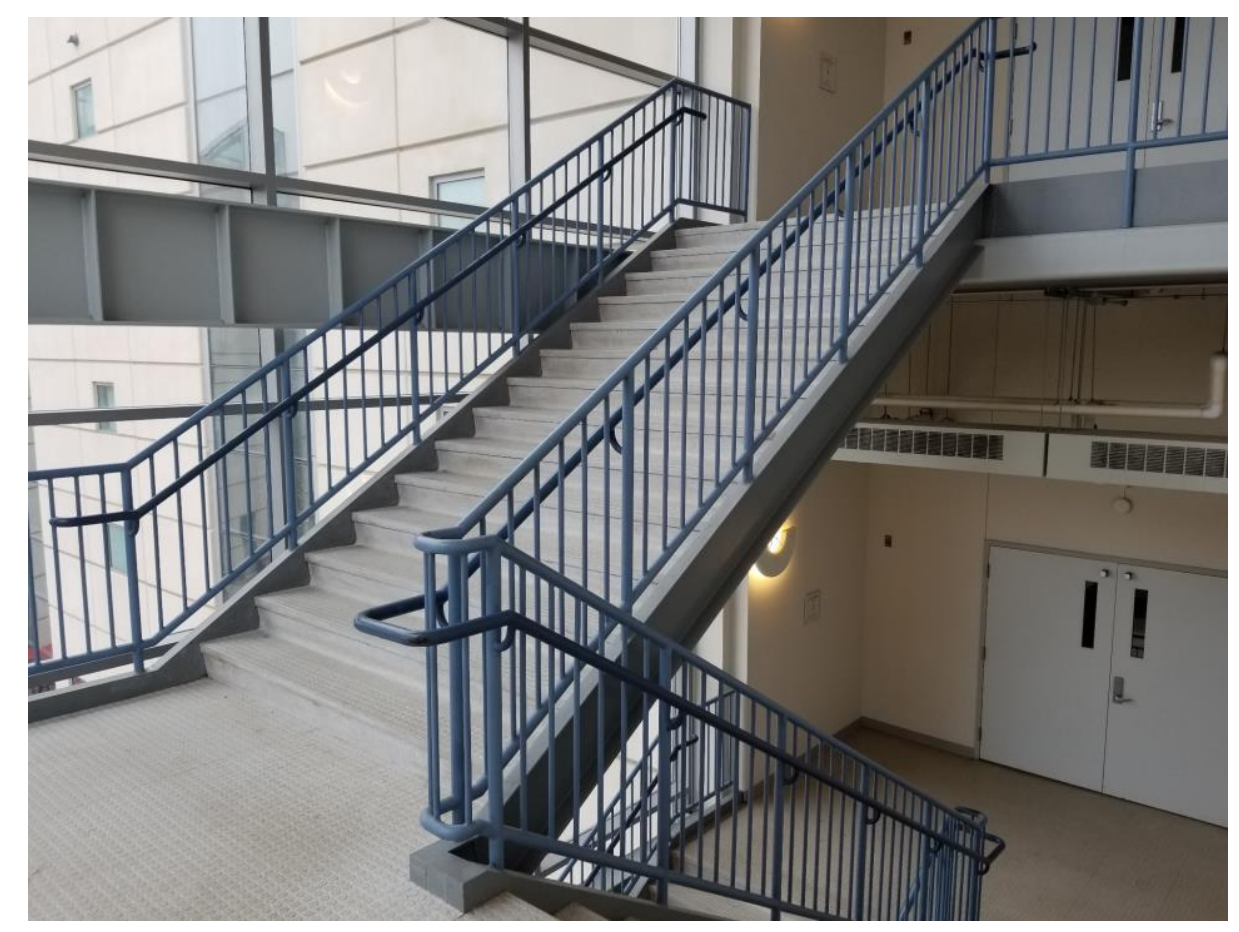

Figure 3.7: Stair Flight 4

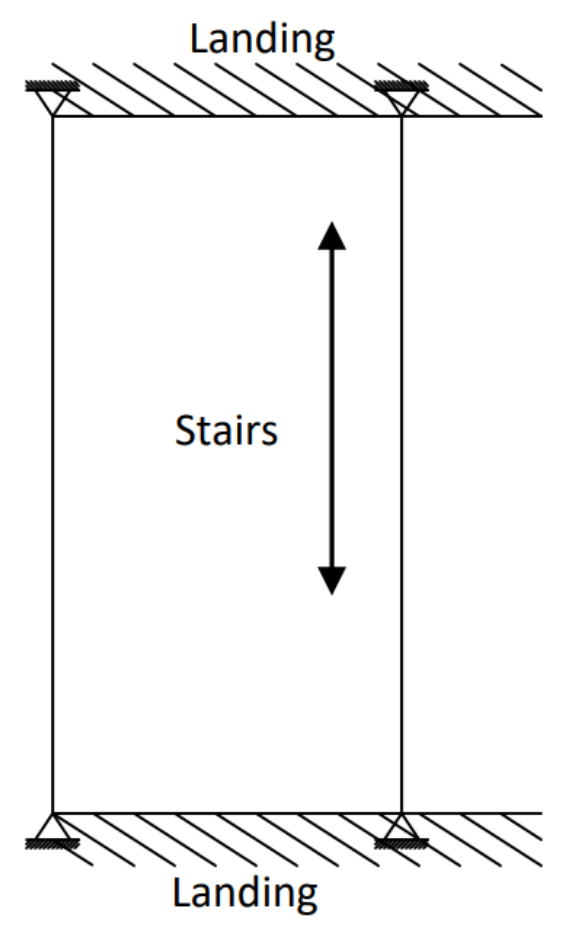

Figure 3.8: Schematic Drawing of Flight 4 
Flight 1 is composed of a wall stringer (i.e., a stringer flanking the wall), and a face stringer, (i.e., a stringer open to the air). This flight is considered to be Type 1, as described in Chapter 2. There is also a metal stud wall built underneath the face stringer. However, there is a small gap between this wall and the stringer, as seen in Figure 3.9.

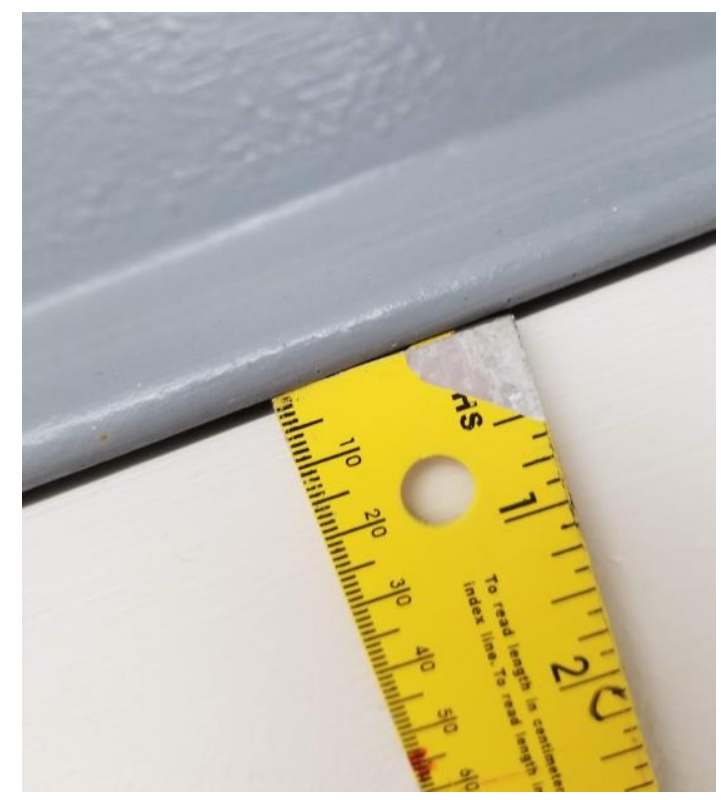

Figure 3.9: Flight 1 Under Wall Gap

After the experimental tests were completed, it was determined that this wall had little to no effect on the natural frequency of the stair flight, as compared to the results of Flight 3, the other Type 1 stair. Therefore, it was determined that this wall has a negligible effect on the dynamic behavior of this stair flight. Flight 2 is characterized as having two face stringers and two railings. Flight 2 is a Type 2 stair, as described in Chapter 2. Flight 3, is characterized as having one face stringer, one wall stringer, and one railing, the same as Flight 1 . However, Flight 3 does not have a stud wall below the face stringer. Flight 3 is a Type 1 staircase, as described in Chapter 2. Flight 4 is the same as Flight 2 and is considered to be a Type 2 stair. The stairwell where the flights are 
located consists of CMU walls on the south-facing wall, and a glass façade curtain wall on the north and west facing wall, as seen in Figure 3.10.

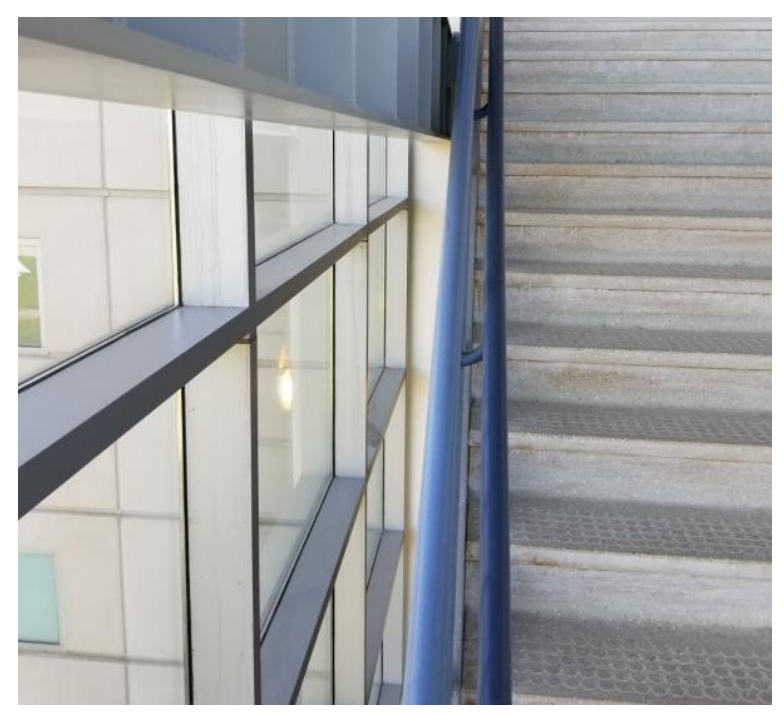

Figure 3.10: Glass Façade Curtain Wall

\subsection{Experimental Procedure}

The first set of experimental data was obtained using a methodology similar to that laid out by Kim et al. (2016). In their research, Kim et al. used heel-drops to excite vibrations in the stair systems and then determined the fundamental natural frequency and damping value from that data. This thesis uses a similar approach but uses a roving impulse test, where an accelerometer is fixed and the point of impact moves. After the impulse data was collected, it was possible to utilize post-processing techniques to find the natural frequency and damping of the staircase flights. The fundamental natural frequency was later used to compare the stair flights with one another and to compare the experimental data to analytical results. Two experimental tests will be used in order to validate the experimental data. 


\subsubsection{Weight Drop Test Procedure}

The first test procedure consisted of a weight drop to create a forced impulse to determine the natural frequency and damping of the different flights. In this impulse test, an accelerometer is fixed at a location, and the point of impact is varied. To execute the dynamic test, a 10-pound medicine ball was dropped from a height of $1 \mathrm{~m}(3.28 \mathrm{ft}$.) to create the impulse force. This procedure was used as a substitute for the heel-drop test because it created a stronger impact leading to a clear signal response. The medicine ball was deflated in order to eliminate any second impact that may occur due to bouncing. The striking point of the impulse was at the center of the tread board, a point that was identified in Kim et al. (2008) as a target location that would create a defined excitation response in the structure. Three strikes were applied vertically to the treads with enough time for the impulse to die out before the next strike began. The strikes were applied to the center of steps $2,6,8$, and 12 . After the data was processed for each strike location for each flight, the first mode frequency and the damping ratios found at each location were averaged to determine the global first mode frequency and damping ratio of each stair flight.

The vertical accelerations were measured using BDI A1521 accelerometers connected to the structure at the midpoint of the tread on the seventh step, halfway up the run of the stairs. The location of the accelerometer and the impact points on the staircase can be seen in Figure 3.11 denoted by $\mathrm{O}$ and $\mathrm{X}$, respectively. 


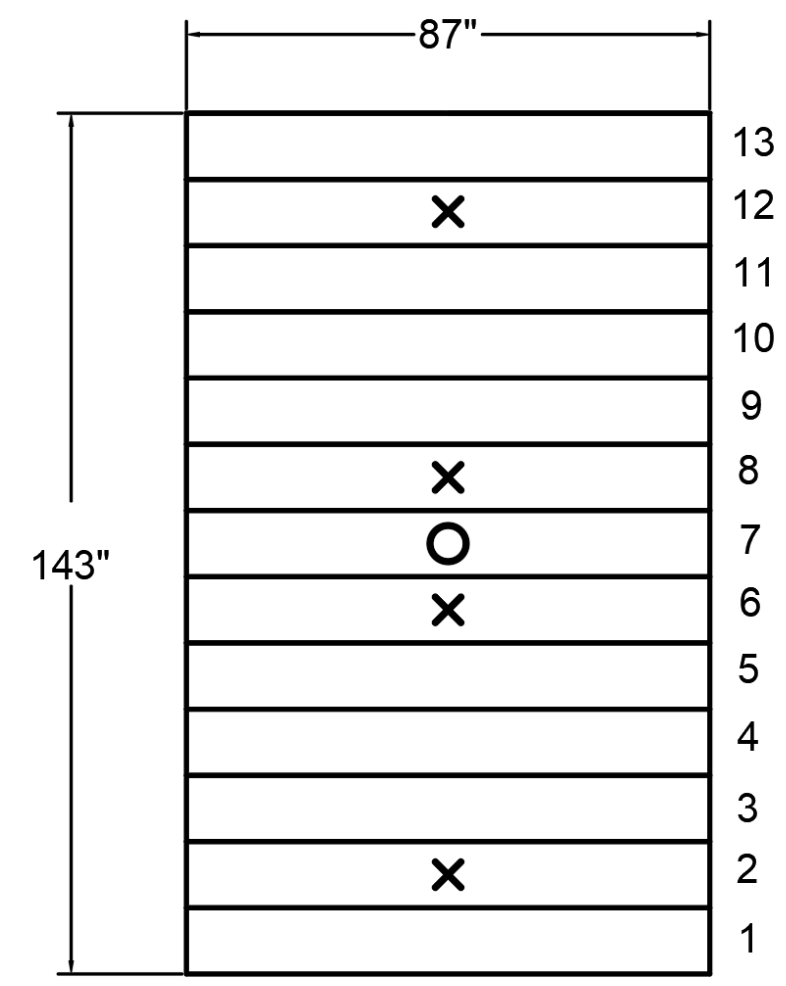

Figure 3.11: Accelerometer Placement and Impact Points

The accelerometer for each flight was placed at these locations because it is the location where the vibrations were expected to be the highest for the first mode. The accelerometers were installed using the BDI's suggested tab and glue method, where the accelerometer tabs were glued to the structure to assure there is no slippage of the accelerometer during the test. The accelerometer input was recorded using the BDI STS LIVE software.

Figure 3.12 shows the installation of the accelerometer on Flight 2. This setup was consistent among all the stair flights. A zoomed-in picture of the accelerometer is found in Figure 3.13 and Figure 3.14. 


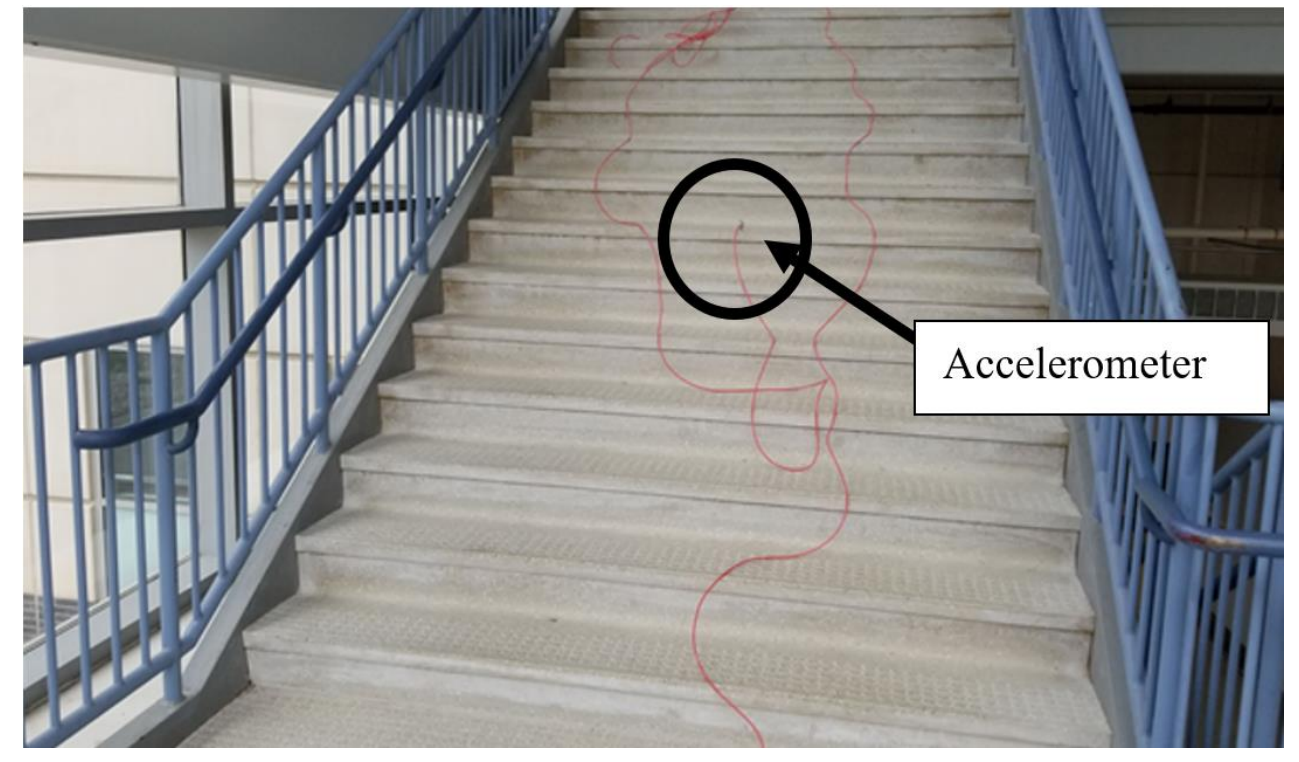

Figure 3.12: BDI Experimental Setup

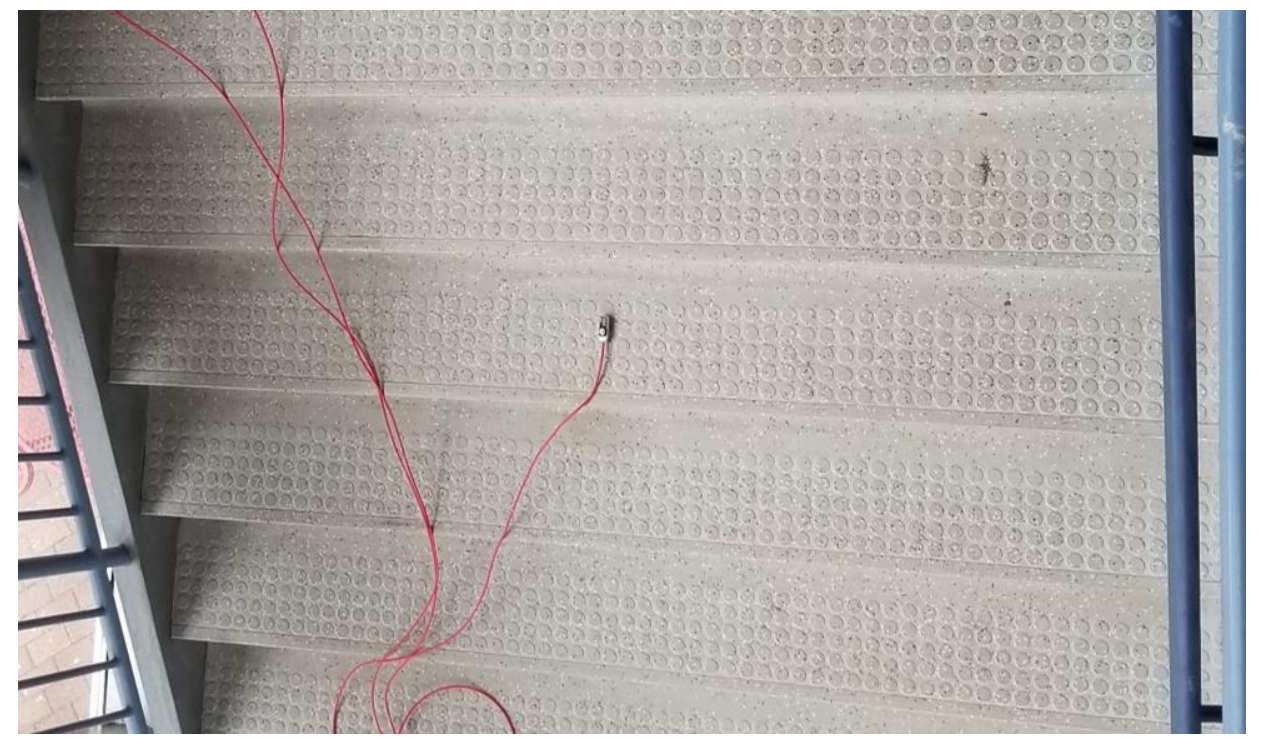

Figure 3.13 : Zoomed in Accelerometer Installation 


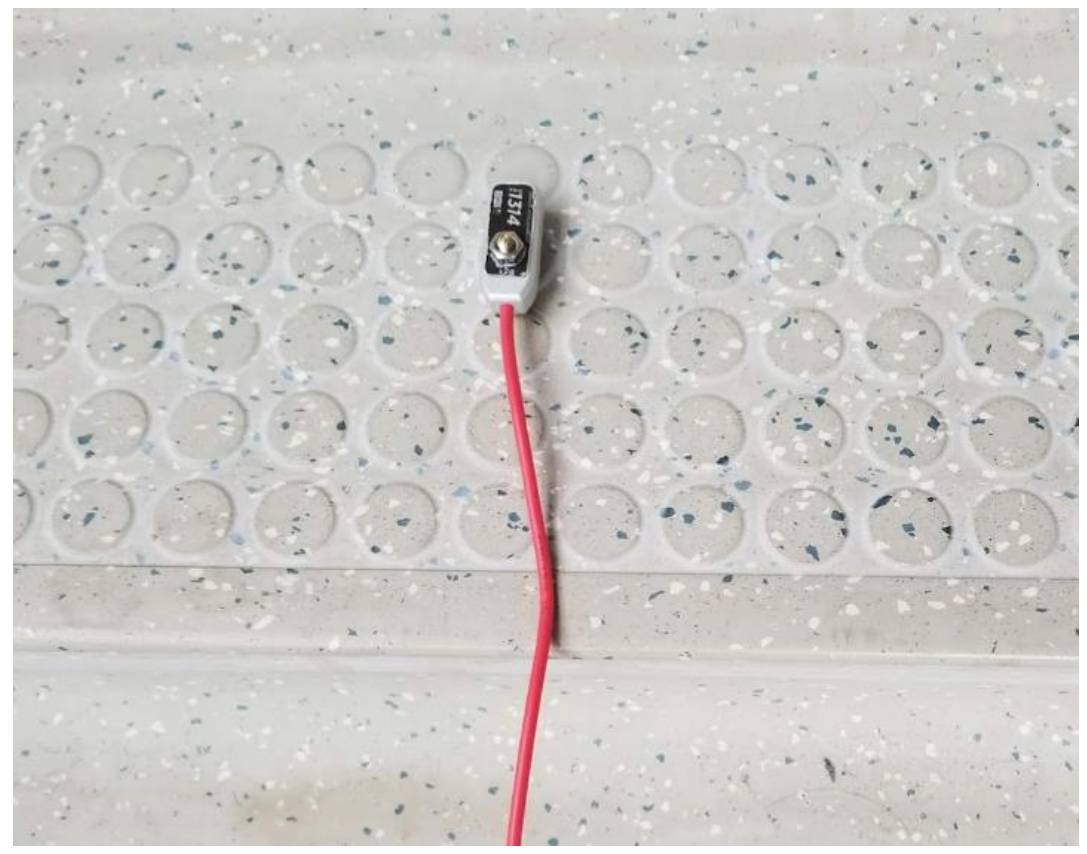

Figure 3.14: Zoomed in Accelerometer

The accelerometer data was collected at a rate of 200 samples per second. This collection frequency was chosen after conducting a preliminary test and finding out that the fundamental natural frequency for all the flights was around $20 \mathrm{~Hz}$. According to Shannon's sampling theorem, if the function $\mathrm{x}(\mathrm{t})$ contains no frequencies higher than $\mathrm{B}$ hertz, then a sufficient sample rate is anything larger than 2B samples per second. This is summarized in Equation (3.1).

$$
\mathrm{B}<f_{s} / 2
$$

Where $B$ is the maximum frequency of importance and $f_{s}$ is the sampling frequency.

Since the preliminary testing showed that the first mode frequency for all the types of staircases would fall between 16 and $20 \mathrm{~Hz}$, using a max capture frequency of $100 \mathrm{~Hz}$ was more than enough to capture the first mode frequency for the structures tested. Therefore, a sampling rate of 200 samples per second provides more than enough 
range for this data collection. The extra range for the data was captured just in case there was a point tested that was an anomaly with a much higher first mode frequency. If the sampling range was set too narrow, if there was outlier data, it would not have been captured. Shannon's sampling theorem is also similar to the Nyquist frequency, which states that all meaningful frequency components exist below the Nyquist frequency, which is defined the same as the Shannon sampling theorem, the recorded frequency divided by two.

After the accelerometer data was collected, the data was converted from the time domain to the frequency domain. This conversion was done using the Fast Fourier Transform (FFT) process in MATLAB. The FFT procedure is a Discrete Fourier Transform (DFT) method. The FFT procedure was chosen because it is a computationally efficient algorithm that can represent an acceleration with varying frequencies and amplitudes by representing them as a sum of sine waves. The frequency-domain allows for a clearer interpretation of dominant frequencies, compared to analyzing a timedomain graph on its own.

In addition, data filtering was used to eliminate the noise that was created when plotting the frequency graphs. Filtering was used to extract the most important information from the signal. For this data analysis, the Butterworth Filter was used to reduce the number of unwanted frequencies. The Butterworth filter is a low pass filter which only keeps frequencies lower than a set cutoff value and eliminates any frequencies higher than the set cutoff value. This filter is beneficial because it has 
minimal effect on altering the desired target frequencies. The Butterworth filter is designed to have a frequency response from $0 \mathrm{~Hz}$ to the cut-off frequency.

The generalized equation representing the "nth" Order Butterworth filter is seen in Equation (3.2).

$$
H_{(j \omega)}=\frac{1}{\sqrt{1+\varepsilon^{2}\left(\frac{\omega}{\omega_{p}}\right)^{2 n}}}
$$

Where $n$ is the filter order, $\omega$ is equal to $2 \pi f$, and $\varepsilon$ is the maximum passband gain.

The Butterworth Filter was carried out using the MATLAB "butter(n, Wn)" function. The inputs are " $n$ ", the nth-order of the filter, and Wn, the normalized cutoff frequency. The limitation of the nth-order is determined by the Nyquist criterion. Since the sample rate is 200 samples per second only signal frequencies under $100 \mathrm{~Hz}$ can be represented accurately. Therefore, if the cutoff frequency is to be set at $30 \mathrm{~Hz}$, the largest harmonic that can be determined is the third harmonic $(90 \mathrm{~Hz})$. The fourth harmonic $(120$ $\mathrm{Hz}$ ) cannot be found because it is larger than $100 \mathrm{~Hz}$. The cutoff frequency is normalized by the Nyquist criterion and is computed using Equation (3.3).

$$
\mathrm{Wn}=\frac{f_{c}}{\frac{f_{S}}{2}}
$$

In addition to being filtered, the acceleration input data was also de-trended using the "detrend" function in MATLAB. The detrend function was used to remove sensor drift by subtracting the mean of all the data from each data point. This function eliminated the slight drift that was occurring in the acceleration data, and also removed the DC-offset in the data. 
The MATLAB code used to perform the FFT procedure can be found in the Appendix. An explanation of the code is as follows.

1) The function clears all previous data.

2) The code reads and imports the acceleration data into MATLAB. The acceleration data is brought in as a single array from a .txt file.

3) The user defines the capture frequency, and then "dt" defines the time between each data point. Time is defined by creating an array the same length as the acceleration input. The time array starts at zero and is spaced as defined by the sampling rate, where each point is created at a time difference of "dt".

4) The code then plots the raw acceleration data as a figure.

5) The function detrends the acceleration input, moving the average to zero. A time array is then defined for this function.

6) Fc, the cutoff frequency, is defined by the user; for this analysis, the cutoff frequency considered is $30 \mathrm{~Hz}$. Wn is defined as the normalized cutoff frequency. " $\mathrm{n}$ " is the order of the filter, and for the parameters used in this research is defined as 3. The second-order filter was also used in addition to the third-order filter. The difference between using the second-order versus third-order filter resulted in negligible differences in the average first mode frequencies. It was found that there was less than $1 \%$ difference in the determined first mode frequency for Flights 1 and 3, and no changes for Flight 2 and 4 between the second-order and third-order filter. The butter filter, low-frequency filter, is then applied to the input data, and the adjusted acceleration versus time graph is plotted. 
7) A Fast Fourier Transform is used to convert the detrended acceleration data from the time domain to the frequency domain.

8) The absolute value is taken for the array, in order to convert non-real values from the Fourier Transform into real values. The $\mathrm{x}$-axis of the data is created by making an array the same length as the acceleration data, where each point is a sequential whole number.

9) The x-axis array is then converted to the frequency domain by multiplying it by the sampling frequency divided by the length of the array.

10) The amplitude versus frequency graph is then plotted in a figure.

An example of an Acceleration versus Time, Detrended Acceleration versus Time, and an Amplitude versus Frequency graph from one of the data points can be found below in Figure 3.15, Figure 3.16, and Figure 3.17. Each location tested was designated a code number, the key for the code number is as follows. $\mathrm{C} 1=\mathrm{Case} 1, \mathrm{R} 1=$ Flight 1, S2= Second Step, B= middle of step. The rest of the detrended acceleration versus time graphs can be found in the Appendix. 


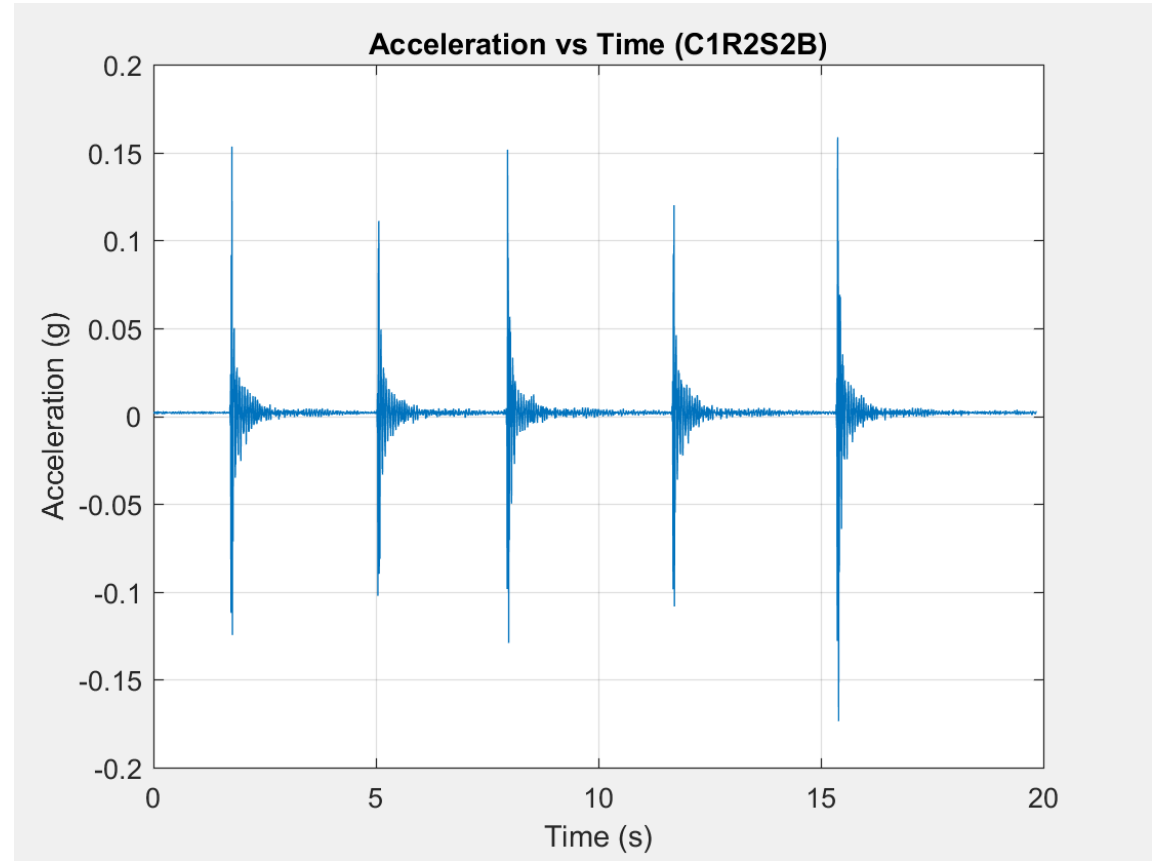

Figure 3.15: Acceleration vs. Time

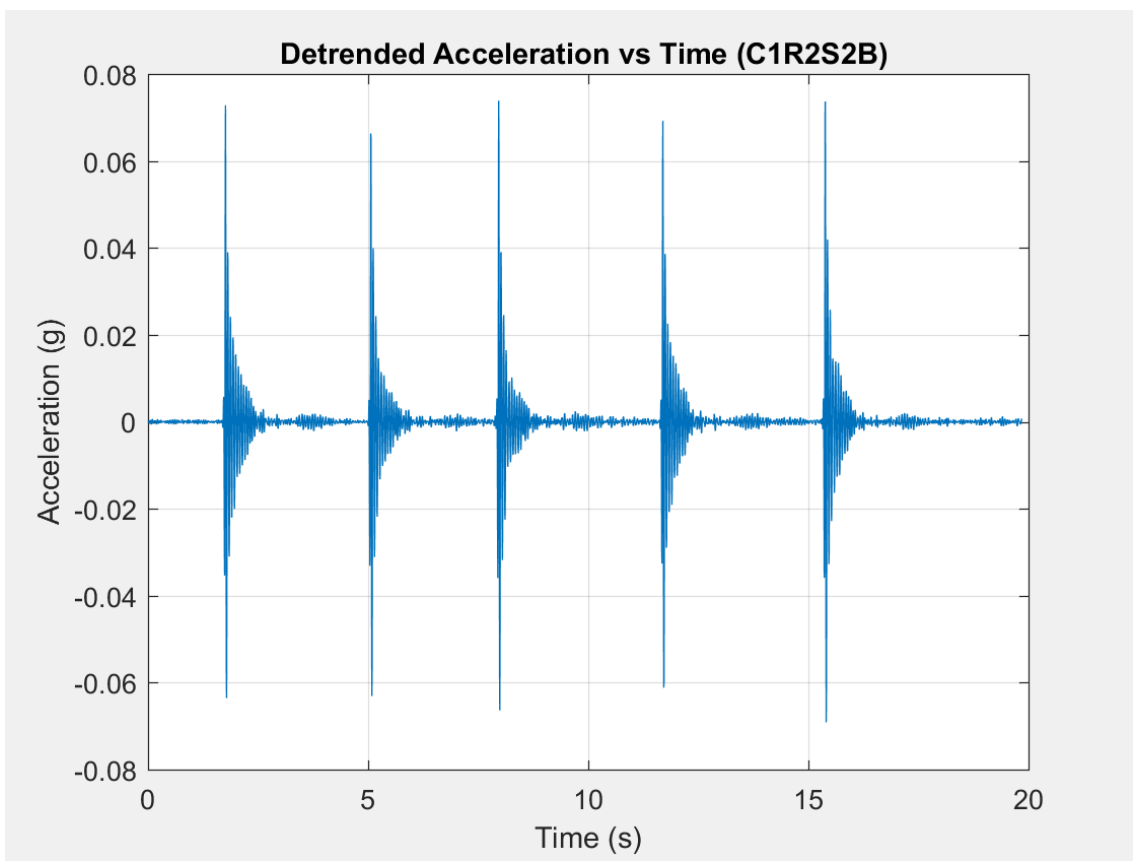

Figure 3.16: Detrended Acceleration vs. Time 


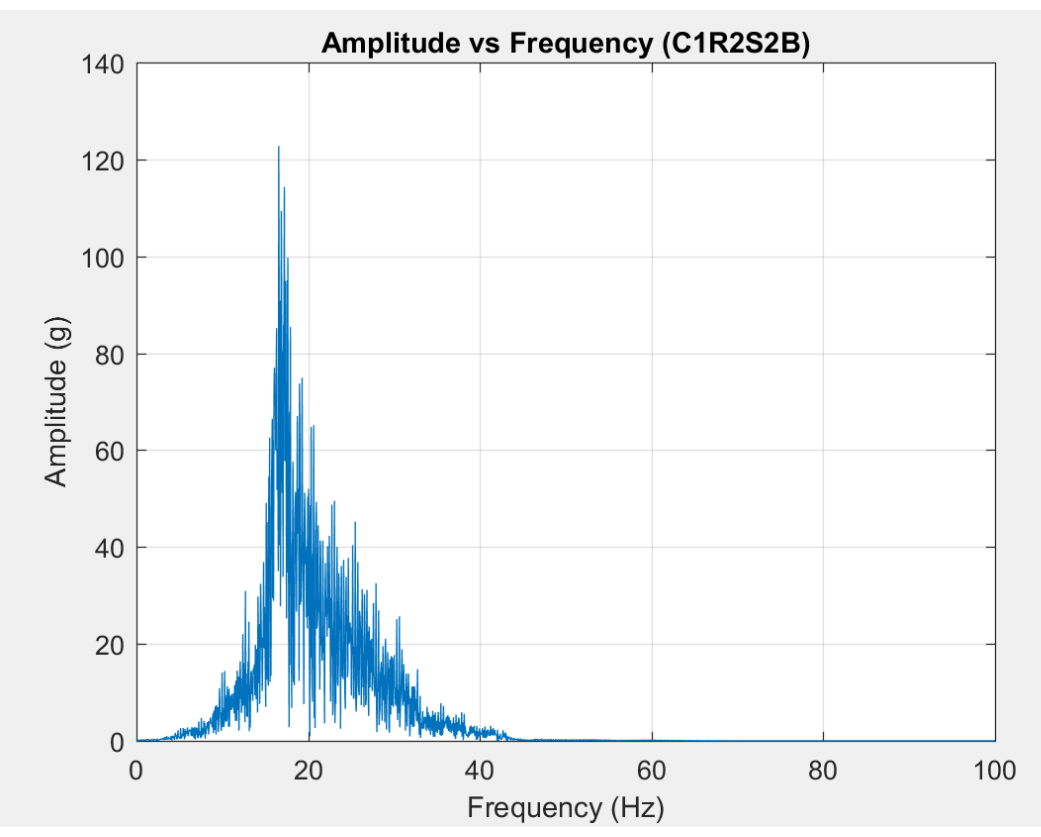

Figure 3.17: Frequency vs. Amplitude

The damping of each stair flight was found using the same BDI acceleration data used to find the fundamental natural frequency. The critical damping ratio was found using the logarithmic decrement method. This method was utilized to estimate the damping ratio using successive peaks to determine the rate of energy dissipation in the system, i.e., the damping. In order to apply this method, the Displacement versus Time graph was plotted by integrating the Acceleration versus Time graph twice. The integration was performed in MATLAB using the cumtrapz function. In order to clean the data and remove the sensor drift, a moving average of the velocity and displacement was subtracted from the velocity and displacement graph data, respectively.

An example of the Displacement versus Time graph from impact location C1R2S2B can be found in Figure 3.18. 


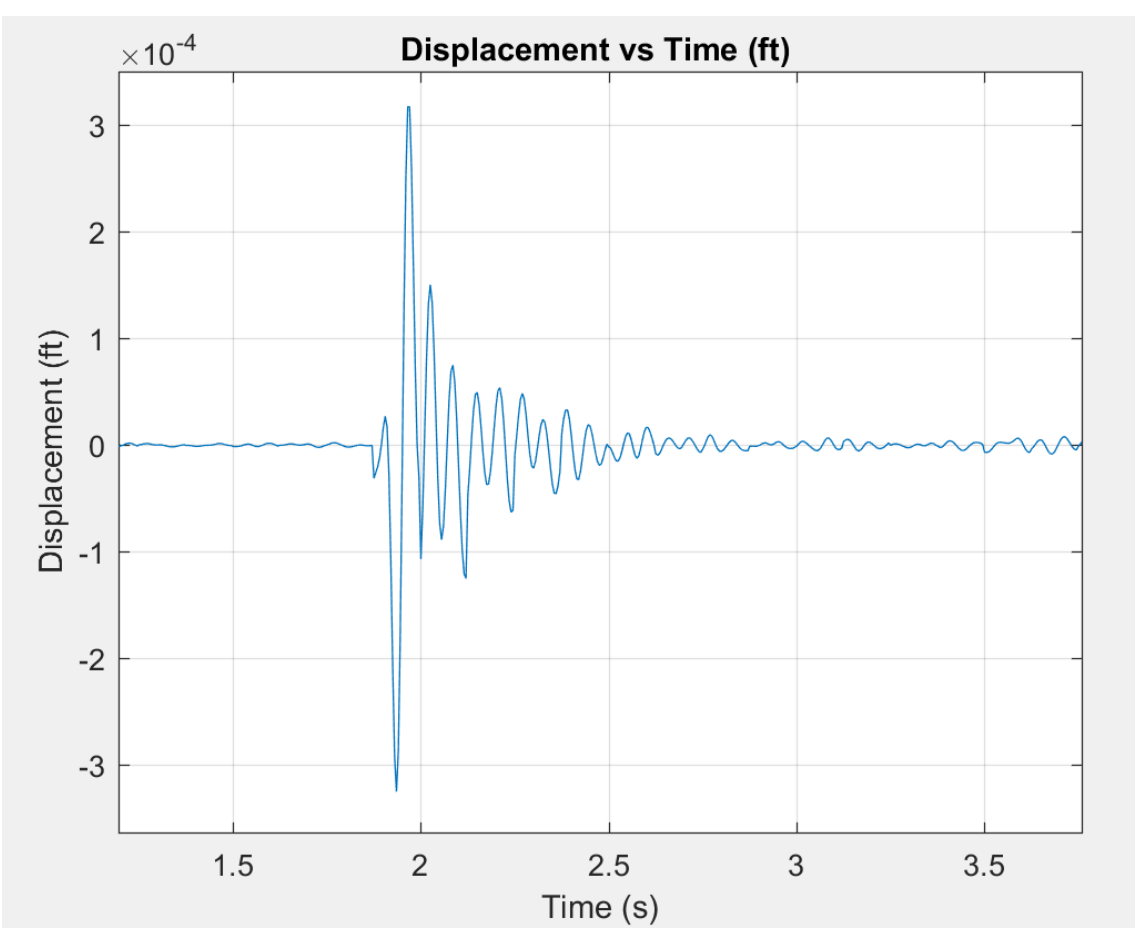

Figure 3.18: Displacement vs. Time

After determining the Displacement versus Time graph, the successive peaks could be used to determine the damping ratio using logarithmic decrement. The first step of this method was to find the logarithmic decrement using Equation (3.4)

$$
\delta=\frac{1}{n} * \ln \left(\frac{X_{i}}{X_{i+1}}\right)
$$

The next step was to find the damping ratio using Equation (3.5).

$$
\zeta=\frac{\delta}{\sqrt{(2 \pi)^{2}+\delta^{2}}}
$$

The procedure was completed using four points for each flight, the same ones used for the natural frequency. The points tested were the midpoint of the second, sixth, eighth, and twelfth steps. The damping ratio was estimated for each of the three impulses taken at each testing location using the process above. An average was determined for 
each test location, and these averages were averaged to find the global damping for each flight. The complete results of the procedure can be found in the Appendix and are summarized in the results section, Chapter 4.

\subsubsection{Experimental Modal Analysis}

A modal analysis was conducted in order to formulate a mathematical model that represents the mode shapes of the first two modes for each of the flights. The purpose of finding mode shapes is to be able to verify that the restraint conditions in the finite element model are representative of the actual structure. The mode shape is determined from the frequency response functions (FRF), found using an impact hammer test. The FRF function relates the input applied to a structural system to the output of the structure. The FRF is a transfer function, meaning that it is the ratio of the acceleration response to the force input.

For this thesis, a PCB 086D20 Short-sledge Impulse Hammer was utilized, as pictured in Figure 3.19.

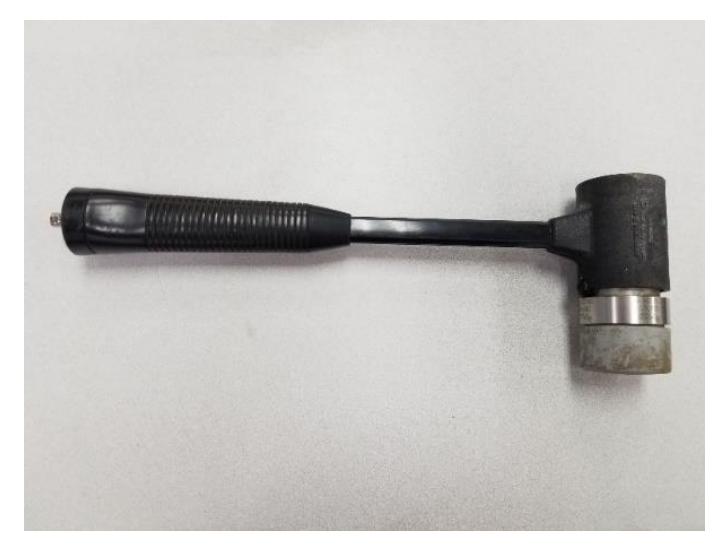

Figure 3.19: Impulse Hammer

An impact hammer test requires both a known input and output. The input is created and measured using an instrumented hammer, and the output is measured using 
an accelerometer to record the acceleration response of the structure. An impact from the hammer causes a single impulse that can excite a broad range of modes and frequencies. Similar to the previous test, the point of impact created by the hammer changed, while the accelerometer location remained fixed.

In order to record the acceleration response for each point tested, a single direction PCB 393A03 Seismic ceramic shear ICP accelerometer was utilized, as pictured in Figure 3.20. In this case, the accelerometer captured the acceleration in the direction perpendicular to the tread surface.

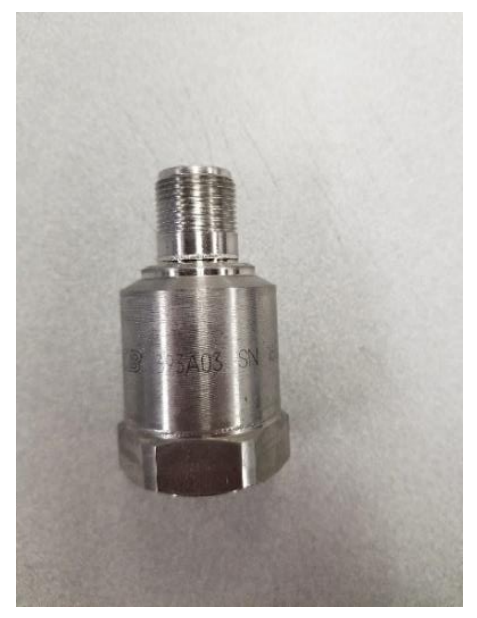

Figure 3.20: PCB 393A03 Accelerometer

Both the acceleration and force input data were simultaneously captured using a Data Acquisition (DAQ) system. The DAQ system used for this research was an LDS DACTRON Photon II, as pictured in Figure 3.21. 


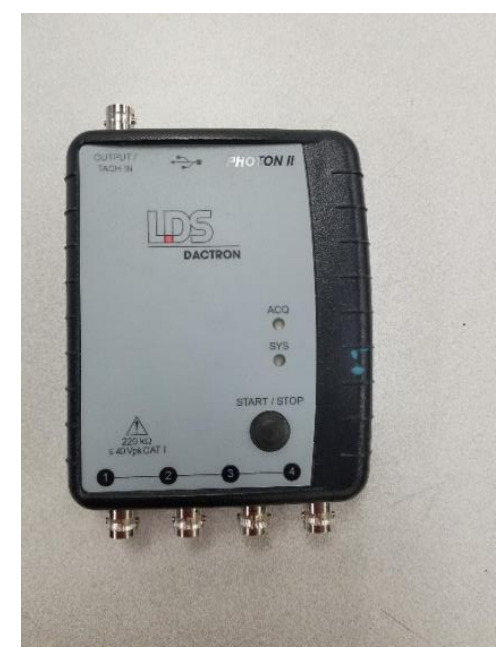

Figure 3.21: LDS Dactron DAQ System

The DAQ system works by taking the electrical inputs from the instrumented hammer and the accelerometer and converting them into acceleration and force values. The DAQ system connects to a computer and operates using an accompanying RT Pro Photon software. This software automatically captures both the input force and response; then outputs an FRF graph in a universal file format (UFF). These file types are then directly compatible with the CATSModal/STAR6 software, where the UFF file can be converted into a visualization of the mode shape of the structure being tested.

The DAQ system and software were used to conduct a roving hammer test in order to find the mode shape and frequencies of the first two modes for each flight of stairs. The points of impact for the hammer were located at the same location for each flight. The testing points for each step tested were located at the ends, quarter, half, and three-quarter points of the tread. The test locations were located roughly every $55.25 \mathrm{~cm}$ (21.75in) along the length of the tread. In addition, only every other step was tested. Testing every other step allowed for the overall behavior of the mode shape to be 
captured while saving time. The location of each test point was assigned a number, as denoted in Figure 3.22.

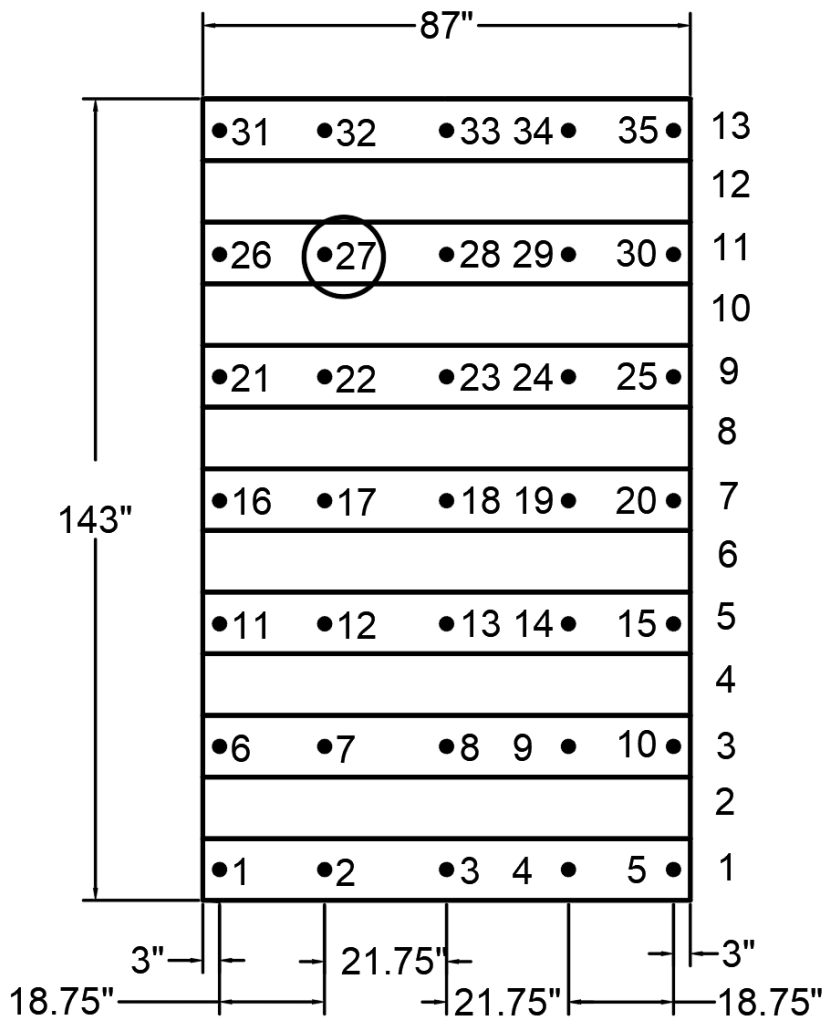

Figure 3.22: Mode Shape Test Locations

The accelerometer was placed at test point number 27 for every flight of stairs. The accelerometer was placed at that location in order to avoid placing it on a node of one of the higher mode shapes. The preliminary predicted mode shapes, based on past research, was a response similar to a simply supported structure, where the first mode shape is in flexure with no nodes, the second mode shape has a torsional effect, and the third mode exhibits having a single node in the center of the staircase.

After the system was set up, three hammer strikes were applied to each of the 35 designated points, with enough time for the impulse to die out between each strike. The 
FRF data from the three strikes at each location was then averaged by the software. The hammer and accelerometer were connected to the LDS Dactron DAQ system. The DAQ used the RT Pro Photon software to create the FRF data associated with each point. The collection of the data began via a trigger mechanism in the software, which started the data collection when the input was created by the hammer. This procedure was repeated for each stair flight tested.

After the FRF data was collected, the next step was to identify the natural frequency for the first mode and create a visual representation of the mode shape using CATSModal/Star6 software. The mode shape modeling process began by creating a template based on the geometry of the staircase. The stair flights were represented as a sloped plane with horizontal lines representing the location of the steps. Although this model is a simplified version of the actual structure, it was appropriate to use because the model was able to demonstrate the vertical displacements and overall global behavior of the structure. The points of impact were identified as points on the modeled system. The point model can be found in Figure 3.23.

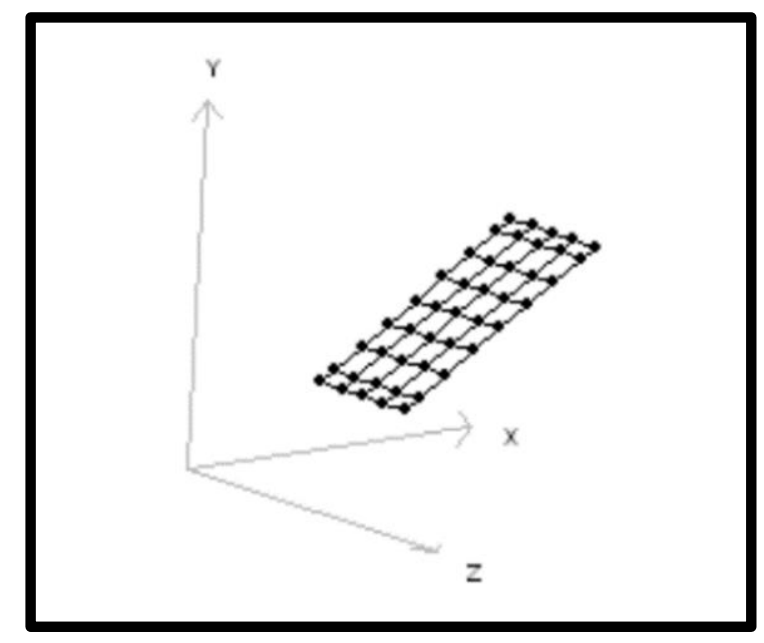

Figure 3.23: CATSModal/Star6 Stair Model 
During the modeling stage, the geometry points were aligned with the measurement points. This step associates the model points with the physical location defined during the data acquisition stage. The next step was to import the acquired data, captured at each location point with the Photon II equipment, into the model. As the data was imported, the y-axis was defined as being the direction perpendicular to the stair tread.

After the data was imported, a curve fit was applied to the data in order to identify the modal peaks of the system. The next step of the process was to identify the frequency of the first four modes from the modal peaks graph. After this, mode shapes could then be viewed. The first four modes were identified to compare the initial FEM to the experimental data in order to validate the accuracy of the modal behavior. However, after the initial FEM comparison, only the first two modes were of interest to the rest of this study. This is because, according to Kim et al. (2016), when the first mode frequency is relatively high, the first mode will be the only one of interest. This is because only the first mode frequency has the possibility of being excited by human walking excitation. Although, according to Kim et al. (2016), the higher modes are considered to be insignificant, the second mode was utilized throughout the rest of this thesis as a check to make sure that the mode shape behavior was still being preserved during the modeling process. It was found consistently during the modeling process in this research if the second mode shape behavior was preserved, the higher mode shape behaviors were also preserved. 


\subsection{Finite Element Model}

This section outlines the procedure taken to set up the finite element model of the staircases. The finite element model was created in SAP2000. Note: The model created in this section does not include any model updating/tuning. These changes will be presented in Chapter 4: Results and Discussions.

\subsubsection{Model Geometries and Material Properties}

The model geometry was created using measurements of the stair flights, as well as the building's architectural and structural drawings created by Dana Larson Roubal and Associates Architects and Engineers (DLR Group). A schematic of the stair flight based on the drawings can be seen Figure 3.24.

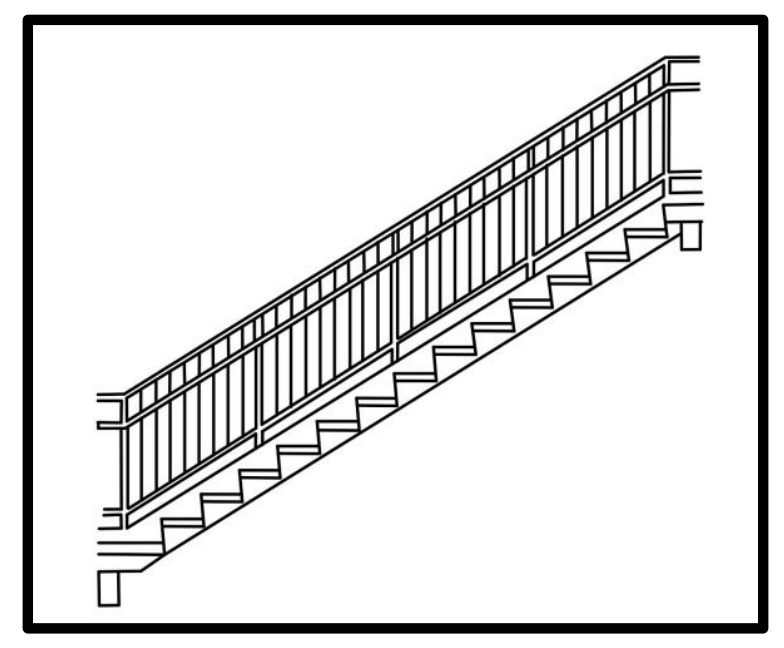

Figure 3.24: Schematic of Stair Flight (Based on DLR Group PKI As-Built Drawings)

The staircase is composed of two primary materials, steel and concrete. The stringers are A36 steel C12x20.7 channel shapes. The tread pans and risers are composed of bent A36, 12 gauge steel. The treads were filled with a 2 in. layer of unreinforced concrete. The concrete was assumed to be $27.57 \mathrm{MPa}$ (4000 psi) strength, normal weight concrete, $7182 \mathrm{pa}(150 \mathrm{psf})$. Since documentation could not be found as to what type of 
concrete was used for the tread fill, assuming a normal weight concrete results in a more slightly more conservative estimate of the natural frequency because it has a higher mass than a lightweight concrete. The railing's guard post and handrail were composed of $3.18 \mathrm{~cm}$ (1.25 in.) A53 Gd. B pipes. The rail guard infill was composed of spaced $1.91 \mathrm{~cm}$ ( $3 / 4$ in.) A36 bars. In the model, the steel channel stringers were modeled as frame elements, and the pans and risers were modeled as thin shell elements.

\subsubsection{Model Restraints}

Properly identifying boundary conditions is critical to modeling the structure accurately. According to Davis and Salmon (2019), one of the major unknown modeling factors in staircase design is the degree of rotational restraint at the stringer ends. This is because the end restraint of a stair can be assumed to behave somewhere between a fixed and a pinned connection. In this thesis, one of the major elements influencing the rotational restraint is the connection of the stair flights to the deck. For the flights tested, the stairs are integral to the landing deck, which is supported by an HSS tube near the stringer ends. Therefore the rotational stiffness at the end of the flights will most likely be influenced by the bending of the deck and the torsional stiffness of the HSS supports. The rotational stiffness due to these factors was modeled by applying pinned end restraints on the stringers and then adding rotational springs to these pinned restraints. Increasing spring stiffness makes the restraint behave more like a fixed connection. On the other hand, having a spring stiffness of zero results in no change to the pinned restraint. Therefore, rotational joint springs were applied to the ends of the stringers so that the restraint stiffness could be altered to match the natural frequency of the model to the 
experimentally determined natural frequency. This procedure is discussed further in Chapter 4.

\subsubsection{SAP2000 Model}

The first step to modeling the staircase in SAP2000 was to model the two C12x20.7 stringers, located on the edges of the stair flights, as beam elements. These stringers were modeled at an angle of approximately 30 degrees the same as the staircase, and spacing of $221 \mathrm{~cm}$ (87in.) separating the two stringers. The treads were then added connecting the two stringers, which were modeled using composite thin shell areas. The shell was defined as having a base of 12 gauge A36 steel and a two-inch layer of 27.57 MPa (4000 psi) concrete on top. The risers were modeled using thin shell areas, defined as 12 gauge steel. The thin shell areas were then meshed into areas no greater than $10.16 \mathrm{~cm} \times 10.16 \mathrm{~cm}$ (4in. $\mathrm{x}$ 4in.). Joints were added along the stringer so that the stringer was connected to the end midpoints for every tread and riser. This was to represent the connections between the stringer and risers, as seen in Figure 3.25.

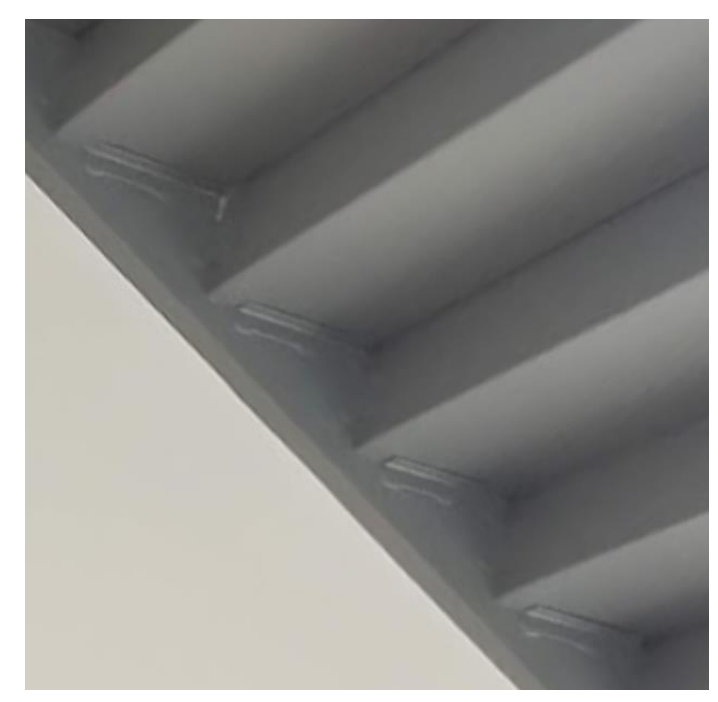

Figure 3.25 : Stringer Connections 
The next step was to add restraints to the system. As mentioned before, pinned restraints were used on the ends of both stringers. In addition, pin restraints were used along the edge of the terminal risers at both ends of the stair flights. A modal analysis was then run on the model to make sure that the first two mode shapes were representative of the experimentally determined mode shape. The model with restraints is pictured in Figure 3.26, and a zoomed-in image of the pinned restraints can be found in Figure 3.27.

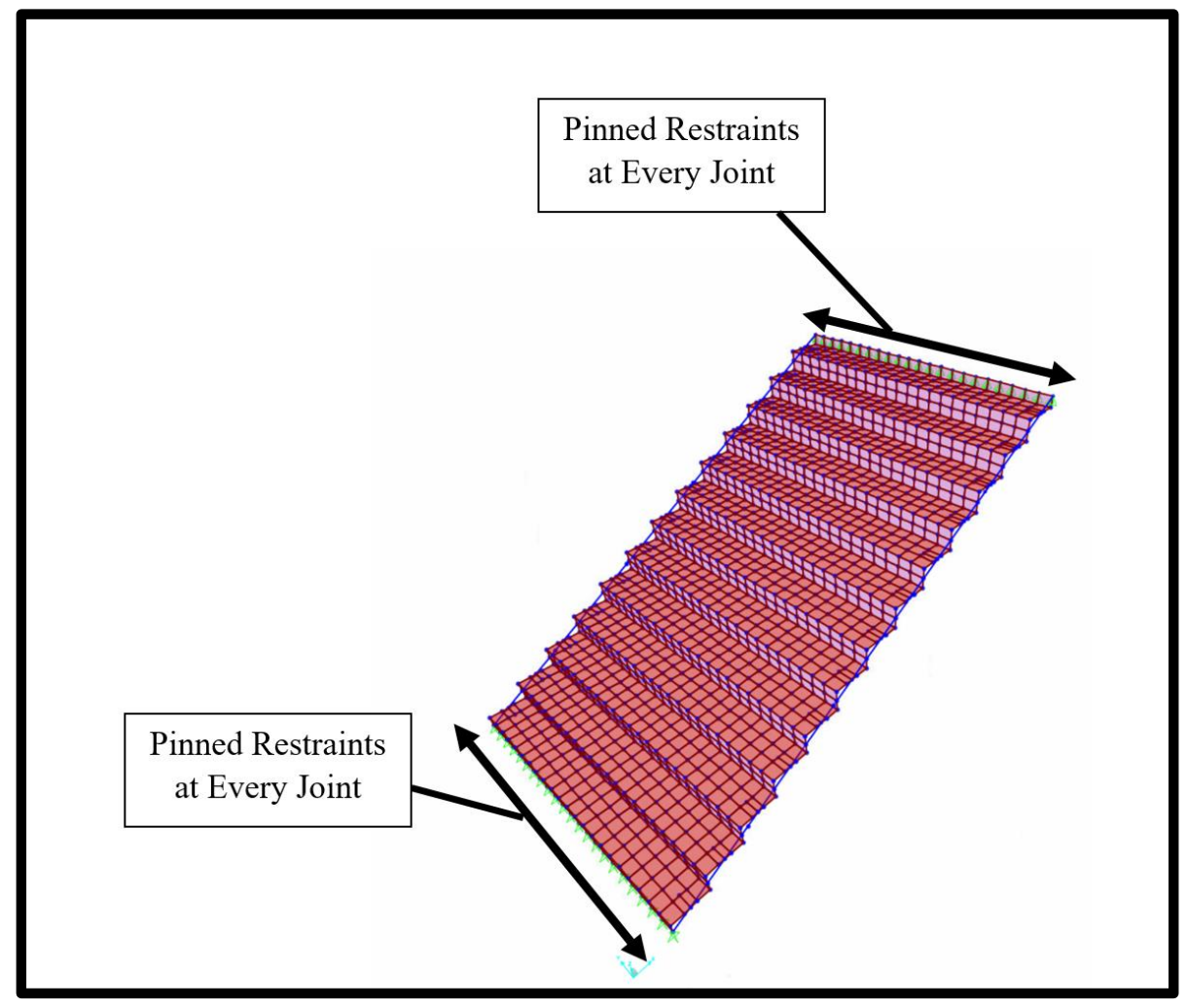

Figure 3.26: Pinned Base Model Structure 


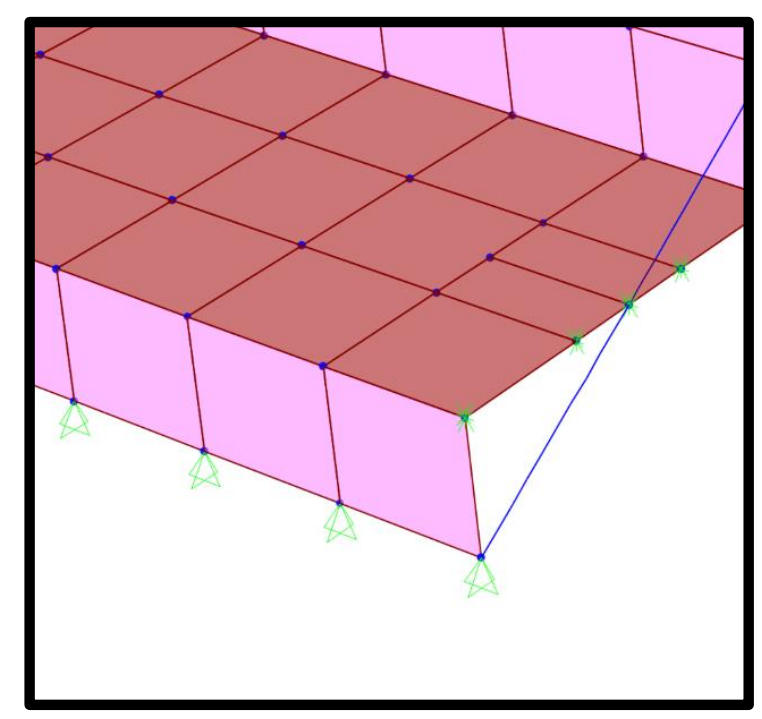

Figure 3.27: Zoom in of Pinned Restraints

After the model geometry was setup, additional masses due to the rubber stair tread matting were calculated and added to the model. The mass per area of the rubber stair tread was assumed to be $1.5 \frac{\mathrm{lbs}}{\mathrm{ft}^{2}}\left(7.32 \frac{\mathrm{kg}}{\mathrm{m}^{2}}\right)$, determined from materials specs of similar matting. The mass of the rubber matting was applied to both the treads and risers, where it is found on the actual staircase. In addition, the mass due to the railing was applied to the model. The total mass of the railing was calculated by taking the mass of each piece of the railing and summing them together. The mass was then distributed along the length of the stringer. The calculation for the mass of the railing can be found in the Appendix. The distributed mass was determined to be $27 \frac{\mathrm{kg}}{\mathrm{m}}$. The mass was then distributed along both stringers. The model created using the above assumptions exhibited a first mode natural frequency of $12.90 \mathrm{~Hz}$.

Mode shape comparisons and additional modifications made to further understand the behavior of the stair flights are presented in the next section, Chapter 4 . 


\section{CHAPTER 4- RESULTS AND DISCUSSIONS}

The results section is broken into two parts. The first provides a summary and discussion of the experimentally determined first and second mode natural frequency. The second section utilizes the experimentally verified SAP2000 model to perform a parametric study to determine the influence of railing stiffness, mass, and boundary conditions on the natural frequency and mode shape of the structure.

\subsection{Experimental Modal Analysis Results}

The first step in making sure that the experimentally determined first mode frequency was identified correctly, was to compare the first mode frequencies found using the BDI equipment and MATLAB software with the frequencies found using the instrumented hammer system and CATSModal/Star6 software.

A summary of the first mode natural frequencies found using the weight drop test for the four flights can be seen in Table 4.1-Table 4.4. Each location tested was designated a code number, the key for the code number is as follows: $\mathrm{C} 1=\mathrm{Case} 1, \mathrm{R} 1=$ Flight 1, S2= Second Step, B= middle of the step.

Table 4.1: Flight 1 Natural Frequency Using BDI

\begin{tabular}{|c|c|c|c|}
\hline ID & Flight & Step Number & Dominant Natural Frequency (Hz) \\
\hline C1R1S2B & 1 & 2 & 24.79 \\
\hline C1R1S6B & 1 & 6 & 19.92 \\
\hline C1R1S8B & 1 & 8 & 20.31 \\
\hline C1R1S12B & 1 & 12 & 20.52 \\
\hline Average & 1 & N/A & 21.39 \\
\hline
\end{tabular}


Table 4.2: Flight 2 Natural Frequency Using BDI

\begin{tabular}{|c|c|c|c|}
\hline ID & Flight & Step Number & Dominant Natural Frequency (Hz) \\
\hline C1R2S2B & 2 & 2 & 16.57 \\
\hline C1R2S6B & 2 & 6 & 16.71 \\
\hline C1R2S8B & 2 & 8 & 16.10 \\
\hline C1R2S12B & 2 & 12 & 16.77 \\
\hline Average & 2 & N/A & 16.54 \\
\hline
\end{tabular}

Table 4.3: Flight 3 Natural Frequency Using BDI

\begin{tabular}{|c|c|c|c|}
\hline ID & Flight & Step Number & Dominant Natural Frequency (Hz) \\
\hline C1R3S2B & 3 & 2 & 21.82 \\
\hline C1R3S6B & 3 & 6 & 20.99 \\
\hline C1R3S8B & 3 & 8 & 21.85 \\
\hline C1R3S12B & 3 & 12 & 22.18 \\
\hline Average & 3 & N/A & 21.71 \\
\hline
\end{tabular}

Table 4.4: Flight 4 Natural Frequency Using BDI

\begin{tabular}{|c|c|c|c|}
\hline ID & Flight & Step Number & Dominant Natural Frequency (Hz) \\
\hline C1R3S2B & 4 & 2 & 16.35 \\
\hline C1R3S6B & 4 & 6 & 16.46 \\
\hline C1R3S8B & 4 & 8 & 16.29 \\
\hline C1R3S12B & 4 & 12 & 16.67 \\
\hline Average & 4 & N/A & 16.44 \\
\hline
\end{tabular}

A summary of averaged natural frequencies for each flight was determined and are summarized in Table 4.5 . 
Table 4.5: Summary of Natural Frequencies Using BDI

\begin{tabular}{|c|c|}
\hline Flight & $\begin{array}{c}\text { Dominant Natural } \\
\text { Frequency }(\mathrm{Hz})\end{array}$ \\
\hline 1 & 21.39 \\
\hline 2 & 16.54 \\
\hline 3 & 21.71 \\
\hline 4 & 16.44 \\
\hline
\end{tabular}

The first mode frequencies found in Table 4.5 verifies the assumption made at the beginning, that Flight 1 and Flight 3 can be classified as the same stair type, Type1. The assumption that the wall below Flight 1 will not have a significant effect on the frequency due to the gap between the wall and the stringer was verified since the difference between the Flight 1 and Flight 3 frequencies was only $1.5 \%$.

The averaged results of the calculated damping found using logarithmic decrement are summarized below in Table 4.6. The complete tables used to calculate the logarithmic decrement are found in the Appendix.

Table 4.6: Damping Ratio

\begin{tabular}{|c|c|}
\hline Flight & $\begin{array}{c}\text { Damping Ratio } \\
(\%)\end{array}$ \\
\hline 1 & $3.3 \%$ \\
\hline 2 & $5.3 \%$ \\
\hline 3 & $4.9 \%$ \\
\hline 4 & $4.8 \%$ \\
\hline
\end{tabular}


The damping ratios determined in this thesis fall in the $1-7 \%$ range that was determined for steel staircases in the literature by Bishop et al. (1995) and Kim et al. (2008). However, the damping ratio results demonstrated that Flight 1 had a lower damping ratio at $3.3 \%$, compared to the average damping ratio of the other three flights at around 5\%. One possible explanation for why Flight 1 had a measured damping ratio that was less than the other flights, is because this flight is in contact with the floor on one end and is integral with the landing on the other end. The other flights have integral connections with the landings on both ends. Although it was observed that this difference has little effect on the natural frequency, the integral interface between the flight and the landing may be causing additional frictional energy dissipating effects that are not occurring at the interface between the flight and the floor. Another possible reason why the damping may be slightly different for Flight 1 is that although the wall underneath does not appear to have any significant influence on the frequency of the structure, it may be possible that there is a slight contact with the stair, out of sight from what can be visibly determined, that may be having an effect on the damping value.

The last set of experimental data is summarized in Table 4.7 and is a summary of the first four mode frequencies for each flight identified with the hammer test, using the Photon DAQ system and the CATSModal/STAR6 software. The experimental data obtained demonstrated that all of the staircase flights tested in this research met the required frequency serviceability standards of being greater than $10 \mathrm{~Hz}$. 
Table 4.7: Stair Flight Mode Frequencies using Instrumented Hammer

\begin{tabular}{|c|c|c|c|c|}
\hline Stair Flight & $\begin{array}{c}\text { Mode 1 } \\
\text { Frequency (Hz) }\end{array}$ & $\begin{array}{c}\text { Mode 2 } \\
\text { Frequency (Hz) }\end{array}$ & $\begin{array}{c}\text { Mode 3 } \\
\text { Frequency (Hz) }\end{array}$ & $\begin{array}{c}\text { Mode 4 } \\
\text { Frequency (Hz) }\end{array}$ \\
\hline 1 & 20.11 & 30.39 & 39.92 & 49.44 \\
\hline 2 & 16.48 & 31.86 & 39.87 & 55.66 \\
\hline 3 & 21.61 & 33.33 & 42.11 & 53.83 \\
\hline 4 & 16.11 & 30.40 & 42.11 & 59.69 \\
\hline
\end{tabular}

From this table, it is evident that the higher the mode number, the larger the variation in modal frequency between the different flights. This increased variation could be due to the fact that the modal participation factor for the first mode is much higher than that of the other modes. Therefore, the higher the mode, the more difficult it becomes to determine the natural frequency of the modes. The modal participation factor in the direction perpendicular to the stair treads for the Type 2 staircase is found in Table 4.8 .

Table 4.8: Modal Participation Factor of SAP2000 Base Model

\begin{tabular}{|c|c|c|}
\hline Mode Number & Period (Sec) & Sum UZ (Unitless) \\
\hline 1 & 0.077504 & 0.5972 \\
\hline 2 & 0.040781 & 0.5972 \\
\hline 3 & 0.027162 & 0.5972 \\
\hline 4 & 0.01985 & 0.6465 \\
\hline 5 & 0.016842 & 0.6465 \\
\hline 6 & 0.014763 & 0.6583 \\
\hline$\ldots$ & $\ldots$ & $\ldots$ \\
\hline 38 & 0.005466 & 0.929 \\
\hline
\end{tabular}


It was determined that even though the experimentally determined frequencies varied slightly amongst the flights, the experimentally determined mode shapes of each of the stair flights remained similar to each other. The first four mode shapes for every flight can be found in the Appendix. The first mode is characterized as having a flexure with no nodes. The second mode is characterized as having a torsional motion. The third mode is characterized as having one node located in the center of the stair flight. The fourth mode is characterized as having two nodes located at the third points. These mode shapes verified the predicted modal behavior of these stair structures.

After the averages of the first mode frequencies were determined by the two experimental tests, a comparison between the results was made. The comparison of the first mode frequencies can be found in Table 4.9 .

Table 4.9: BDI to CATSModal/Star6 Frequency Comparison

\begin{tabular}{|c|c|c|c|}
\hline \multirow{2}{*}{ Stair Flight } & $\begin{array}{c}\text { BDI Mode 1 } \\
\text { Frequency }(\mathrm{Hz})\end{array}$ & $\begin{array}{c}\text { CATSModal/Star6 } \\
\text { Mode 1 Frequency } \\
(\mathrm{Hz})\end{array}$ & Difference (\%) \\
\hline 1 & 21.39 & 20.11 & $6.17 \%$ \\
\hline 2 & 16.54 & 16.48 & $0.36 \%$ \\
\hline 3 & 21.71 & 21.61 & $0.46 \%$ \\
\hline 4 & 16.44 & 16.11 & $2.03 \%$ \\
\hline
\end{tabular}

Since the maximum observed difference between these two testing methods was only $1.28 \mathrm{~Hz}(6.17 \%)$, the CATSModal/STAR6 first mode frequency was determined to be correctly identified. Therefore moving forward in this thesis, the experimentally determined data will refer to the first and second mode natural frequencies found using 
the CATSModal/STAR6 software since the mode shapes can also be visualized using that data. It is also important to note that since both sets of first mode frequencies for all of the flights tested are above $10 \mathrm{~Hz}$, the frequency serviceability criteria are satisfied for these stair flights.

A summary of the first and second mode natural frequencies for each flight identified with the hammer test and using the Photon DAQ system and the CATSModal/STAR6 software is summarized below in Table 4.10.

Table 4.10: Summary of Natural Frequencies

\begin{tabular}{|c|c|c|}
\hline Flight & $\begin{array}{c}\text { Mode 1 Natural } \\
\text { Frequency }(\mathrm{Hz})\end{array}$ & $\begin{array}{c}\text { Mode 2 Natural } \\
\text { Frequency }(\mathrm{Hz})\end{array}$ \\
\hline 1 & 20.11 & 30.39 \\
\hline 2 & 16.48 & 31.86 \\
\hline 3 & 21.61 & 33.33 \\
\hline 4 & 16.11 & 30.40 \\
\hline
\end{tabular}

A few observations can be made from the frequency values presented in Table 4.10. The first observation is that the first and second mode frequencies for the two types of staircases, Type 1 and Type 2, with similar construction and geometry, are fairly similar in first and second mode frequency values, within a $10 \%$ difference for the Type 1 stairs and within a 5\% difference for the Type 2 stairs, for both the first and second mode frequency. This validates that Flights 1 and 3 grouped together as Type 1 and Flights 2 and 4 grouped together as Type 2 is a valid assumption. A summary of the differences in the first and second mode frequencies for the Type 1 and Type 2 staircases are summarized in Table 4.11. 
Table 4.11: Difference in First and Second Modes for Similar Flights

\begin{tabular}{|c|c|c|c|c|c|}
\hline Type & Flights & $\begin{array}{c}\text { Mode1 } \\
\text { Frequency (Hz) }\end{array}$ & $\begin{array}{c}\text { Difference } \\
\text { Between Type } \\
\text { 1 Flights and } \\
\text { Type 2 Flights } \\
(\%)\end{array}$ & $\begin{array}{c}\text { Mode2 } \\
\text { Frequency (Hz) }\end{array}$ & $\begin{array}{c}\text { Difference } \\
\text { Between Type } \\
\text { 1 Flights and } \\
\text { Type 2 Flights } \\
(\%)\end{array}$ \\
\hline \multirow{2}{*}{1} & 1 & 20.11 & \multirow{2}{*}{$7.19 \%$} & 30.39 & \multirow{2}{*}{$9.23 \%$} \\
\cline { 2 - 3 } 2 & 3 & 21.61 & \multirow{2}{*}{$2.27 \%$} & 33.33 & \multirow{2}{*}{$4.69 \%$} \\
\cline { 2 - 3 } & 4 & 16.48 & & 30.40 & \\
\hline
\end{tabular}

The first mode natural frequency for the Type 1 stairs differs by $1.50 \mathrm{~Hz}(7.19 \%)$. The first mode natural frequency for the Type 2 stairs differs by $0.37 \mathrm{~Hz}(2.27 \%)$. The percent difference between the Type 1 flights' first mode frequencies may seem large in comparison to the Type 2 flights' first mode frequencies. However, the percent difference between the Type 1 flights' first mode frequency, as determined in the first experimental test using the BDI equipment and the weight drop, was a difference between $21.39 \mathrm{~Hz}$ and $21.71 \mathrm{~Hz}$, or a difference of $0.32 \mathrm{~Hz}(1.48 \%)$. Therefore, the first BDI experimental test added additional verification to the closeness of the behavior of the two Type 1 flights.

Another observation of importance was made from comparing the average first and second mode frequencies of the two types of stairs, as seen in Table 4.12. 
Table 4.12: Type 1 and Type 2 Staircase Frequency Comparison

\begin{tabular}{|c|c|c|c|c|}
\hline & Type 1 & Type 2 & Difference (Hz) & Difference (\%) \\
\hline $\begin{array}{c}\text { Avg. Mode 1 Frequency } \\
(\mathrm{Hz})\end{array}$ & $20.86 \mathrm{~Hz}$ & $16.30 \mathrm{~Hz}$ & $4.56 \mathrm{~Hz}$ & $24.25 \%$ \\
\hline $\begin{array}{c}\text { Avg. Mode 2 Frequency } \\
(\mathrm{Hz})\end{array}$ & $31.86 \mathrm{~Hz}$ & $31.13 \mathrm{~Hz}$ & $0.73 \mathrm{~Hz}$ & $2.32 \%$ \\
\hline
\end{tabular}

The experimental data demonstrated that there is a $24.25 \%$ difference in the average first mode frequency between the Type 1 and Type 2 staircases. The data also demonstrated that there is a much smaller difference, $2.32 \%$, between the average second mode frequencies of the Type 1 and Type 2 staircases. The fairly large difference in the first mode frequency demonstrates that the wall stringer increases the overall stiffness of the system. This conclusion can be made because the only major difference between the two types of stairs, other than the influence of having one versus two railings, is the boundary condition change created by the wall stringer. Therefore it is recommended that future modeling should take into consideration the boundary condition effect of having a wall stringer during an analysis of an existing staircase. This will be further discussed later in this chapter.

\subsection{Finite Element Analysis Results}

This section involves findings using a modification of the model developed and discussed in Chapter 3.

\subsubsection{Mode Shape Comparison}

In order to make sure that the model developed in Chapter 3 was created properly, it is important to compare the mode shapes found experimentally to those found in the 
model. This step was completed using the base model created in Chapter 3 before the model was updated with springs and/or links. The model mode shapes were compared with the experimentally determined mode shapes found using the CATSModal/STAR6 software. The SAP2000 model was compared to the Type 2 staircase because the base model considers two face stringer boundary conditions. The mode shapes from both experimental and analytical data can be found in Figure 4.1 through Figure 4.8.

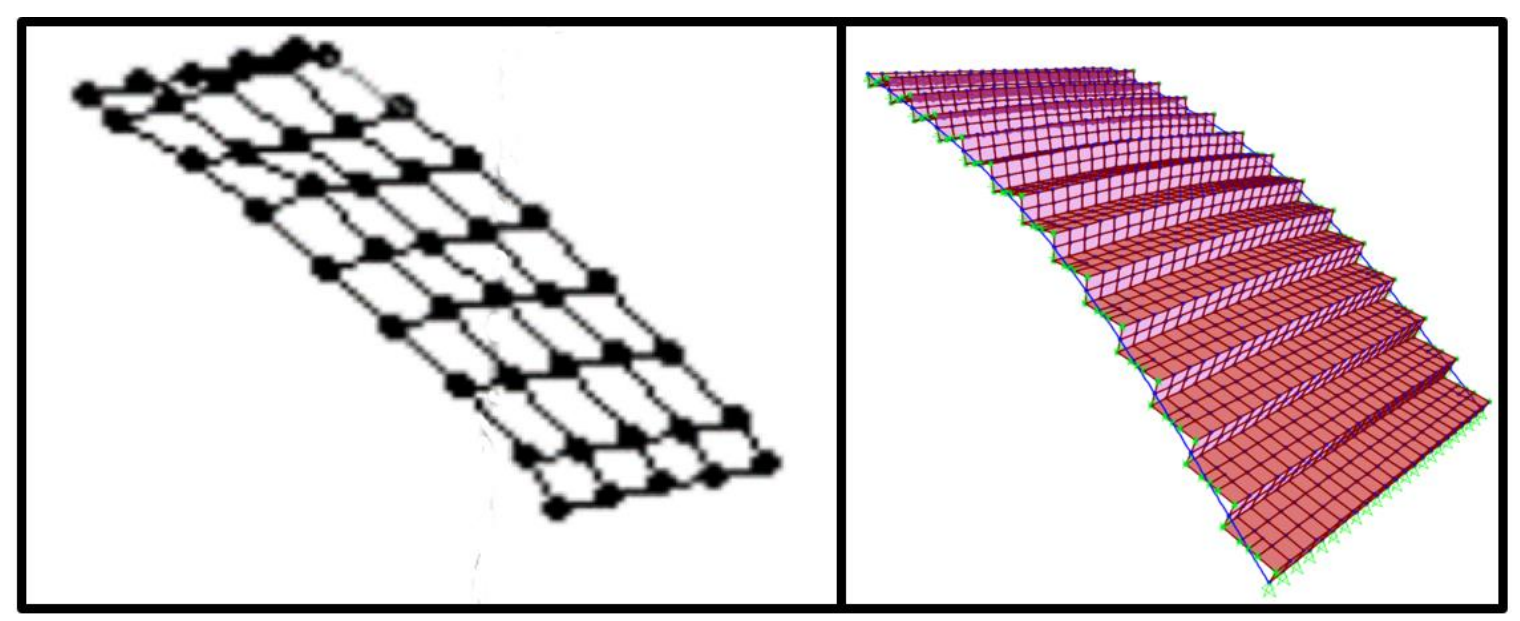

Figure 4.1: Type 2 Experimental Mode1 (Left)

Figure 4.2: Type 2 SAP2000 Mode1 (Right) 


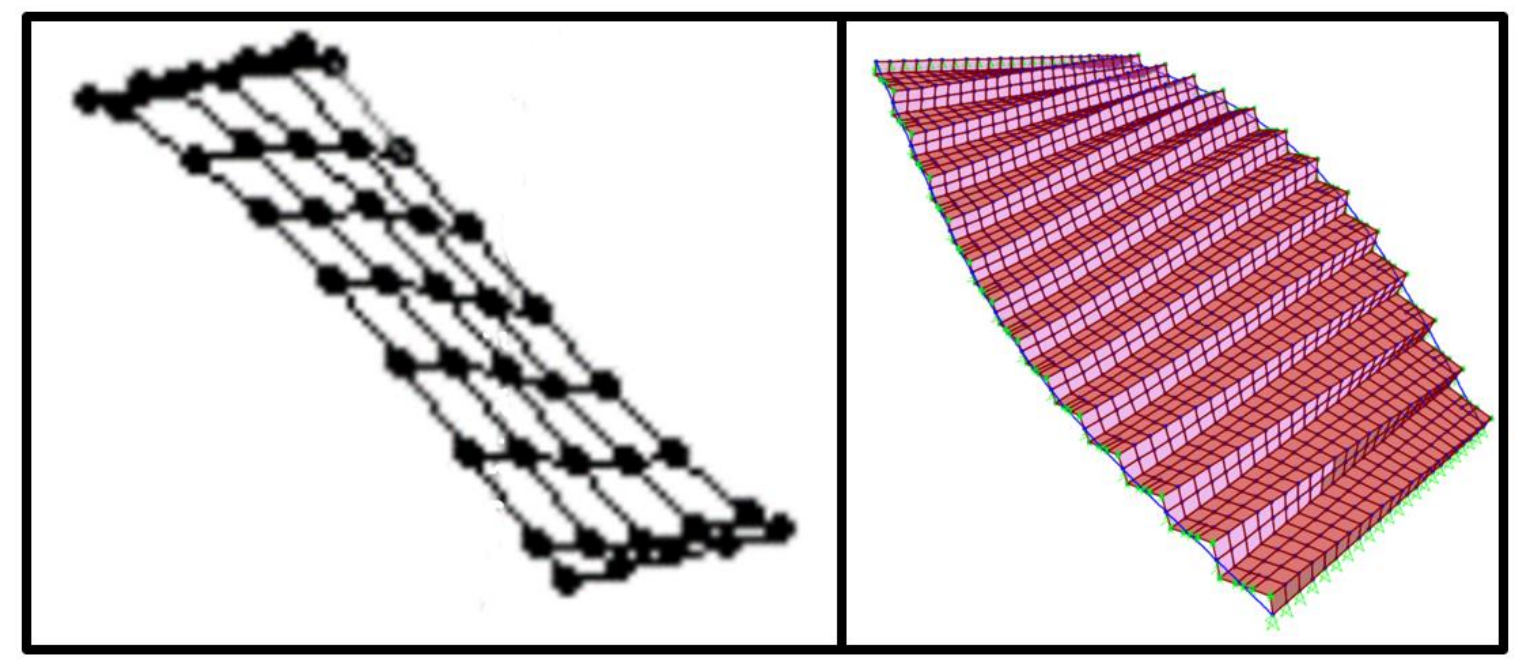

Figure 4.3: Type 2 Experimental Mode2 (Left)

Figure 4.4: Type 2 SAP2000 Mode2 (Right)

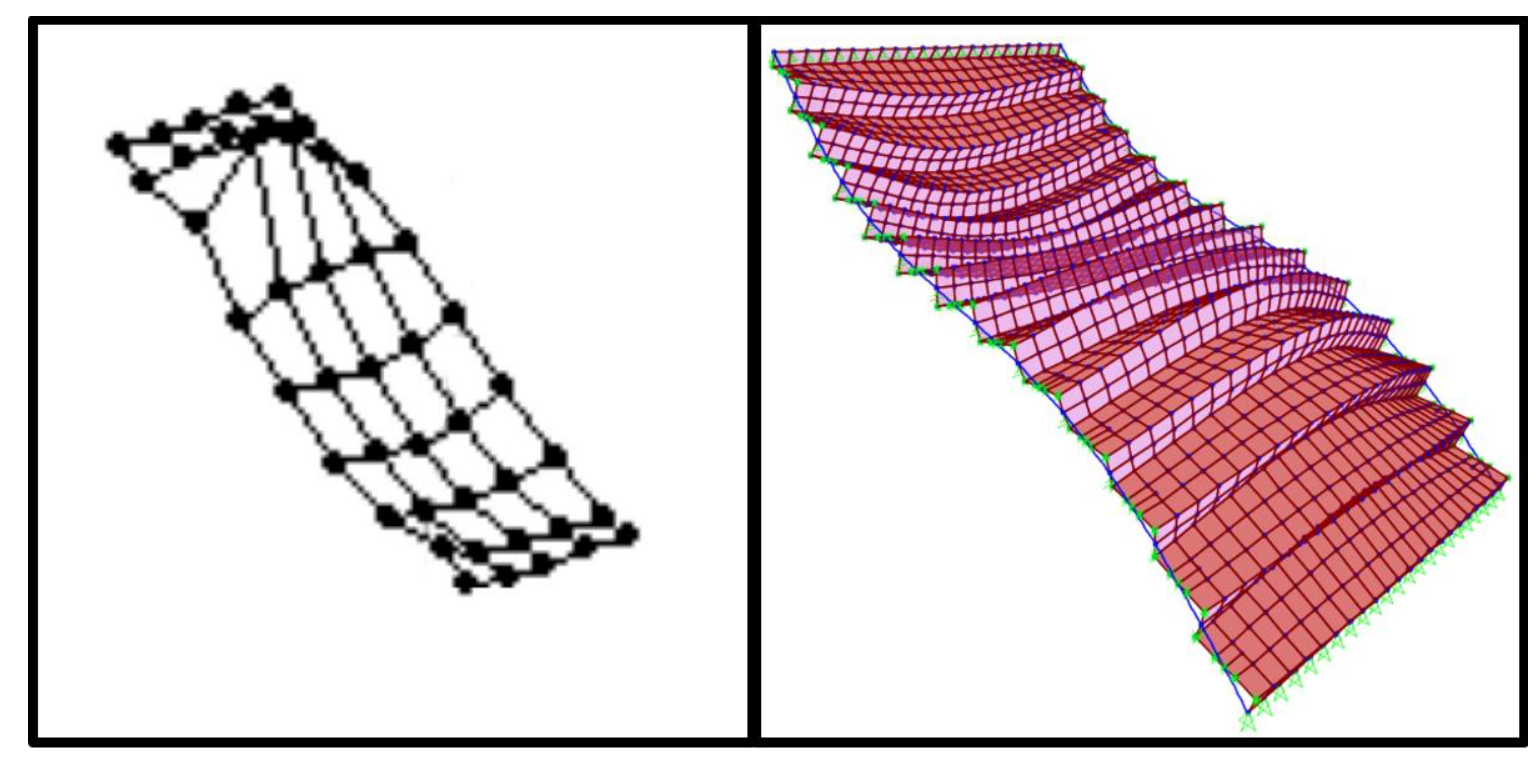

Figure 4.5: Type 2 Experimental Mode 3 (Left)

Figure 4.6: Type 2 SAP2000 Mode3 (Right) 


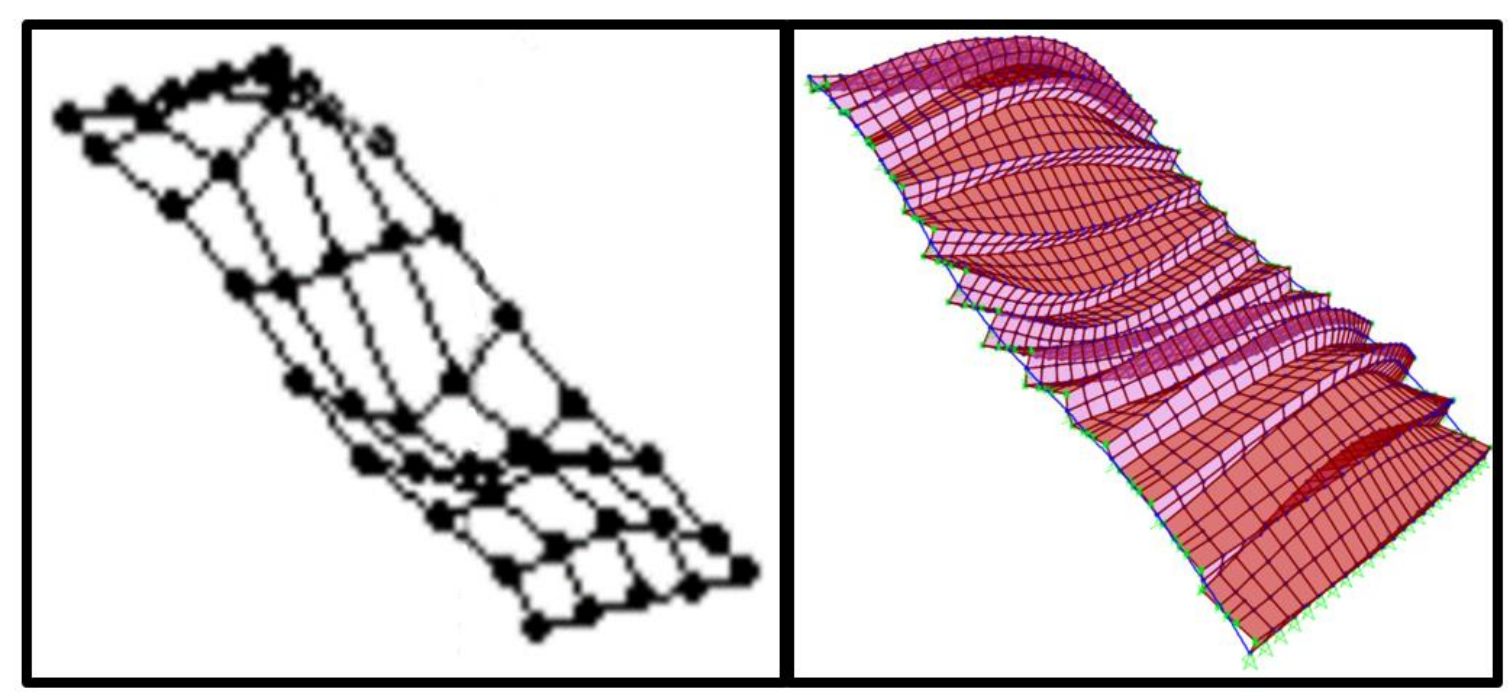

Figure 4.7: Type 2 Experimental Mode 4 (Left)

Figure 4.8: Type 2 SAP2000 Mode4 (Right)

It is evident from the comparison of the mode shapes that the base model captured the same mode shapes as determined by the experimental analysis.

The next step after the mode shape behavior was captured was to determine, before model tuning/adjustment, how close the base model's first and second mode frequency were to the experimentally determined Type 2 staircase frequencies. The comparison of the first and second mode frequencies can be found in Table 4.13 and Table 4.14.

Table 4.13: Mode 1 Comparison of Base Model to Experimental Results

\begin{tabular}{|c|c|c|c|}
\hline Stair Flight Type 2 & $\begin{array}{c}\text { Experimentally } \\
\text { Determined Mode 1 } \\
\text { Frequency }(\mathrm{Hz})\end{array}$ & $\begin{array}{c}\text { SAP2000 Base } \\
\text { Model Mode 1 } \\
\text { Frequency (Hz) }\end{array}$ & $\begin{array}{c}\text { Difference in } \\
\text { Frequency (\%) }\end{array}$ \\
\hline Flight 2 & 16.48 & 12.90 & $24.37 \%$ \\
\hline Flight 4 & 16.11 & 12.90 & $22.13 \%$ \\
\hline Average & 16.30 & 12.90 & $23.29 \%$ \\
\hline
\end{tabular}


Table 4.14: Mode 2 Comparison of Base Model to Experimental Results

\begin{tabular}{|c|c|c|c|}
\hline Stair Flight Type 2 & $\begin{array}{c}\text { Experimentally } \\
\text { Determined Mode 2 } \\
\text { Frequency }(\mathrm{Hz})\end{array}$ & $\begin{array}{c}\text { SAP2000 Base } \\
\text { Model Mode 2 } \\
\text { Frequency }(\mathrm{Hz})\end{array}$ & $\begin{array}{c}\text { Difference in } \\
\text { Frequency (\%) }\end{array}$ \\
\hline Flight 2 & 31.86 & 24.52 & $26.04 \%$ \\
\hline Flight 4 & 30.40 & 24.52 & $21.41 \%$ \\
\hline Average & 31.13 & 24.52 & $23.76 \%$ \\
\hline
\end{tabular}

The comparison of the first and second mode frequency of both the model and experimentally determined frequency demonstrated, on average, that there is a greater than $22 \%$ difference between the respective mode frequency values. The acceptable level of accuracy for the differences between the modeled and experimental frequencies used in this thesis was defined by Davis and Avci (2015). In their research, utilizing first mode frequency predictive equations, the predicted first mode frequencies of the two staircases tested differed by $35.5 \%$ and $17.1 \%$, respectively. Even though the variations between the predicted and measured first mode frequencies may seem high, Davis and Avci (2015) determined that the predictions were "accurate enough for design usage". Therefore, although the difference between the base model and the experimental frequencies in this thesis was $23 \%$ for the first mode, the estimate is conservative and can still be useful for design. The variation between the experimental and predicted frequencies is due to a conservative assumption of the boundary conditions, which assumed pinned restraints. The base model was created using pinned restraints because past research has determined that the rotational end restraint actually behaves somewhere between a pin and fixed 
connection (Davis and Salmon 2019). This means that the model needs to be adjusted in order to account for differences in rotational restraints and boundary conditions in order to more accurately determine the modal frequencies of the staircase. Therefore, assuming a pin-pin connection would provide for the conservative estimate of the stairs' modal natural frequencies. However, this assumes that the mode shapes are unaffected by this assumption.

If the conservative pinned restraint condition were used to predict the first mode frequency, and the predicted frequency was higher than $10 \mathrm{~Hz}$, it can be assumed that further tuning of the model would only increase the first mode frequency. Therefore for this scenario, no additional iterations of the model would be necessary to make sure the stair is achieving serviceability standards. However, if designers were to assume this conservative boundary condition and the resulting frequency either falls below the $10 \mathrm{~Hz}$ or is close to it, a more refined model would be necessary to check if the stair would need to be redesigned to meet the serviceability conditions.

\subsubsection{Model Tuning}

The base model was tuned using experimental data so that the first mode frequency of the model better matches the experimentally determined first mode frequency. After the model was tuned, the goal was to compare the accuracy of the model's second mode frequency to the experimentally determined second mode frequency.

In order to tune the model's first mode frequency, rotational springs were applied to the pin restraints at the ends of the stringers. It was anticipated that the restraint at the 
end of the stair flight acts somewhere in-between a pin and a fixed restraint. Therefore, the ends of the stringers can be modeled as pins, and rotational springs can be applied to tune the stiffness of the restraint to fall in-between a pin and a fixed restraint. This method was utilized by Davis and Salmon (2019). The first mode frequency was tuned by varying the rotational stiffness applied to the stringer ends between $4000 \mathrm{kN}-\mathrm{m} / \mathrm{rad}$ and $5500 \mathrm{kN}-\mathrm{m} / \mathrm{rad}$. It was determined that applying a $5000 \mathrm{kN}-\mathrm{m} / \mathrm{rad}$ rotational spring on the ends of both stringers allowed for the first and second mode frequencies to be the closest to their respective experimentally determined values while limiting the variance in the first mode frequency. Applying the rotational restraints to this model resulted in a first mode frequency that was closer to the experimental frequency compared to the second mode frequency. Therefore, the first mode frequency would have to be over predicted compared to the experimentally determined average frequency in order to get the second mode frequency to match the experimentally determined value. However, the overestimation of the model's first mode frequency was limited to $1 \%$ greater than the largest experimentally determined value and within $5 \%$ of the average experimental frequency. Tuning the model's first mode frequency to be slightly larger than the average allowed for the model's second mode frequency to be driven closer to the experimentally determined value. The reason for trying the get the modeled first and second mode frequency values close to the average experimental frequencies was because it was later found that preserving the balance between the accuracy of the first and second mode frequency resulted in the best comparison between the modeled and experimentally determined mode shapes. Therefore, even though a lower value for the rotational spring 
would allow for a closer match between the first mode frequency and experimentally determined average, a lower value for the rotational spring would push the second mode frequency farther away from the experimentally determined value. On the other hand, although a higher value for the rotational spring would allow for a better balance of the differences in the first and second mode frequency, it would non-conservatively push the first mode frequency farther away from the experimental average.

After the springs were applied, the model's mode shapes were once again checked with experimental mode shapes. From this comparison, it was determined that the application of the rotational springs resulted in mode shapes that matched those determined experimentally. After the pin restraint springs were adjusted, the new modeled first mode frequency differences ranged between $0.85-3.12 \%$, and an average of $1.94 \%$, compared to the experimentally determined first mode frequencies of the Type 2 stairs. Table 4.15 contains a comparison of the experimentally determined first mode frequency to the new adjusted SAP2000 model frequency.

Table 4.15 Mode 1 Comparison of Tuned Model to Type 2 Experimental Results

\begin{tabular}{|c|c|c|c|}
\hline Stair Flight & $\begin{array}{c}\text { Experimentally } \\
\text { Determined Mode 1 } \\
\text { Frequency (Hz) }\end{array}$ & $\begin{array}{c}\text { Adjusted SAP2000 } \\
\text { Model Mode 1 } \\
\text { Frequency (Hz) }\end{array}$ & $\begin{array}{c}\text { Difference in } \\
\text { Frequency (\%) }\end{array}$ \\
\hline Flight 2 & 16.48 & 16.62 & $0.85 \%$ \\
\hline Flight 4 & 16.11 & 16.62 & $3.12 \%$ \\
\hline Average & 16.30 & 16.62 & $1.94 \%$ \\
\hline
\end{tabular}

After the pin restraint springs were adjusted to match the fundamental frequency, the model's second mode frequency was compared to the experimentally determined 
second mode frequency. The average difference was $6.81 \%$ and was found using the average of the experimentally determined second mode frequencies, $31.13 \mathrm{~Hz}$, compared to the model's second mode frequency, which was $29.08 \mathrm{~Hz}$. A summary of these Type 2 stair comparisons can be found in Table 4.16.

Table 4.16: Mode 2 Comparison of Tuned Model to Type 2 Experimental Results

\begin{tabular}{|c|c|c|c|}
\hline Stair Flight & $\begin{array}{c}\text { Experimentally } \\
\text { Determined Mode 2 } \\
\text { Frequency }(\mathrm{Hz})\end{array}$ & $\begin{array}{c}\text { Adjusted SAP2000 } \\
\text { Model Mode 2 } \\
\text { Frequency }(\mathrm{Hz})\end{array}$ & $\begin{array}{c}\text { Difference in } \\
\text { Frequency (\%) }\end{array}$ \\
\hline Flight 2 & 31.86 & 29.08 & $9.12 \%$ \\
\hline Flight 4 & 30.40 & 29.08 & $4.44 \%$ \\
\hline Average & 31.13 & 29.08 & $6.81 \%$ \\
\hline
\end{tabular}

In order to understand where the $5000 \mathrm{kN}-\mathrm{m} / \mathrm{rad}$ spring stiffness falls on the spectrum between a pinned and fixed restraint, the rotational stiffness of the end restraints was increased starting at $0 \mathrm{kN}-\mathrm{m} / \mathrm{rad}$ until an equivalent fixed restraint condition was reached. This procedure was done for two scenarios. The first scenario altered all four end rotational springs. Visualization of where the rotational springs were applied can be found in Figure 4.9, where the stars represent the location of the rotational springs. 


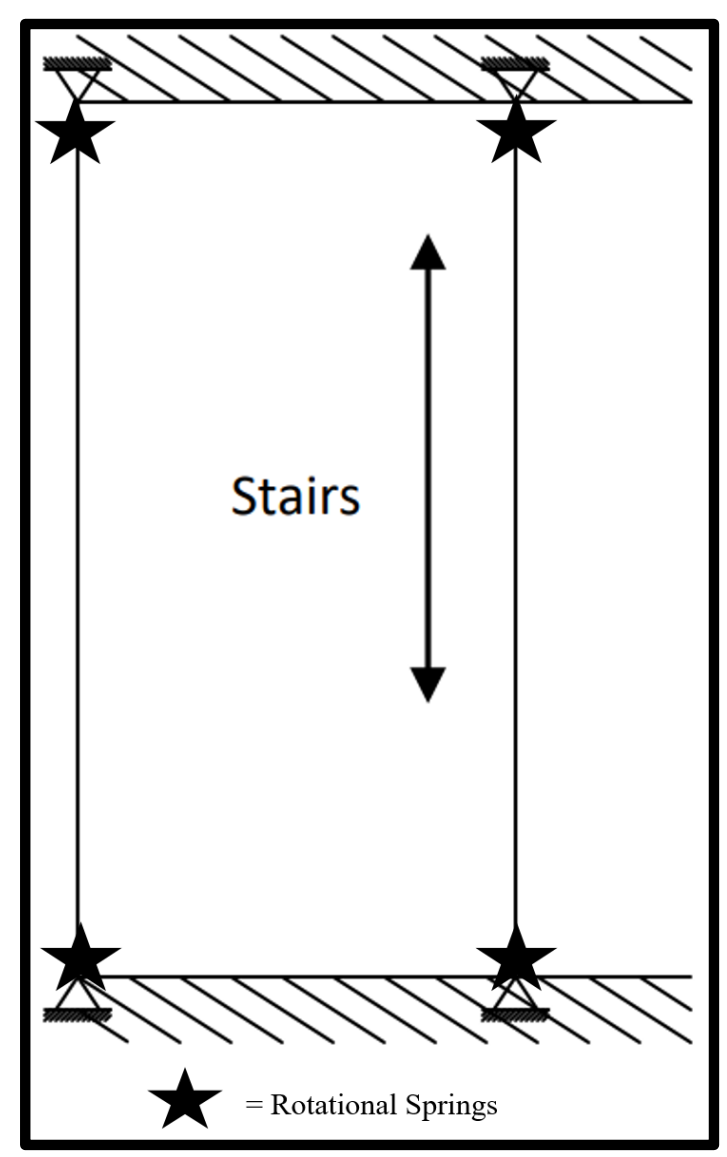

Figure 4.9: Location of Rotational Springs

The second scenario only changed two joint springs on one stringer, while keeping the other stringer's end restraints pinned. Visualization of where the rotational springs were applied can be found in Figure 4.10, where the stars represent the location of the rotational springs. 


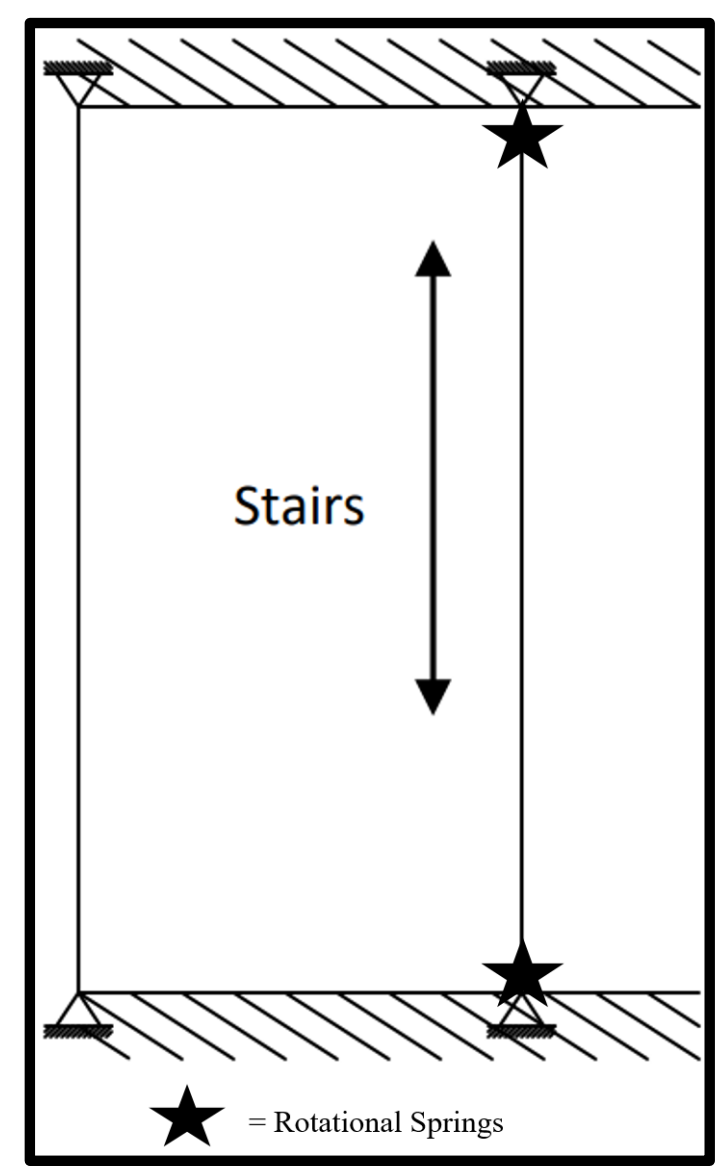

Figure 4.10: Location of Rotational Springs

The stringer rotational springs were applied at every 1 and 5 value on a

logarithmic scale, meaning that the spring stiffness tested was $1,5,10,50$, etc. The stiffness was increased until the change in frequency slope on the graph flattened out, and an equivalent fixed restraint behavior was reached. A table summarizing the change in the first and second mode frequency due to the change in rotational spring restraints for the two scenarios can be found in Table 4.17 and Table 4.18, respectively. 
Table 4.17: Change Frequency for Four Rotational Restraints

\begin{tabular}{|c|c|c|c|c|c|}
\hline Mode & $\begin{array}{c}\text { Pin- Pin } \\
\text { Natural } \\
\text { Frequency } \\
(\mathrm{Hz})\end{array}$ & $\begin{array}{c}\text { Base Model- } \\
5000 \mathrm{k}-\mathrm{m} / \text { rad pins } \\
\text { Mode1 Frequency } \\
(\mathrm{Hz})\end{array}$ & $\begin{array}{c}\text { Experimental } \\
\text { Frequency } \\
(\mathrm{Hz})\end{array}$ & $\begin{array}{c}\text { Fix-Fix } \\
\text { Natural } \\
\text { Frequency } \\
(\mathrm{Hz})\end{array}$ & $\begin{array}{c}\text { Percent } \\
\text { Change (\%) }\end{array}$ \\
\hline 1 & 12.90 & 16.62 & 16.30 & 25.82 & $66.77 \%$ \\
\hline 2 & 24.52 & 29.07 & 31.13 & 43.30 & $53.88 \%$ \\
\hline
\end{tabular}

Table 4.18: Change in Frequency for Two Rotational Restraints

\begin{tabular}{|c|c|c|c|c|c|}
\hline \multirow{3}{*}{ Mode } & $\begin{array}{c}\text { Pin- Pin } \\
\text { Natural } \\
\text { Frequency } \\
(\mathrm{Hz})\end{array}$ & $\begin{array}{c}\text { Base Model- } \\
\text { 5000k-m/rad pins } \\
\text { Mode1 Frequency } \\
(\mathrm{Hz})\end{array}$ & $\begin{array}{c}\text { Experimental } \\
\text { Frequency } \\
(\mathrm{Hz})\end{array}$ & $\begin{array}{c}\text { Fix-Fix } \\
\text { Natural } \\
\text { Frequency } \\
(\mathrm{Hz})\end{array}$ & $\begin{array}{c}\text { Percent } \\
\text { Change } \\
(\%)\end{array}$ \\
\hline 1 & 12.90 & 14.47 & 16.30 & 16.33 & $23.47 \%$ \\
\hline 2 & 24.52 & 27.08 & 31.13 & 36.49 & $39.23 \%$ \\
\hline
\end{tabular}

Plotted graphs of the frequency versus rotational restraint for the two scenarios can be found in Figure 4.11 and Figure 4.12. 


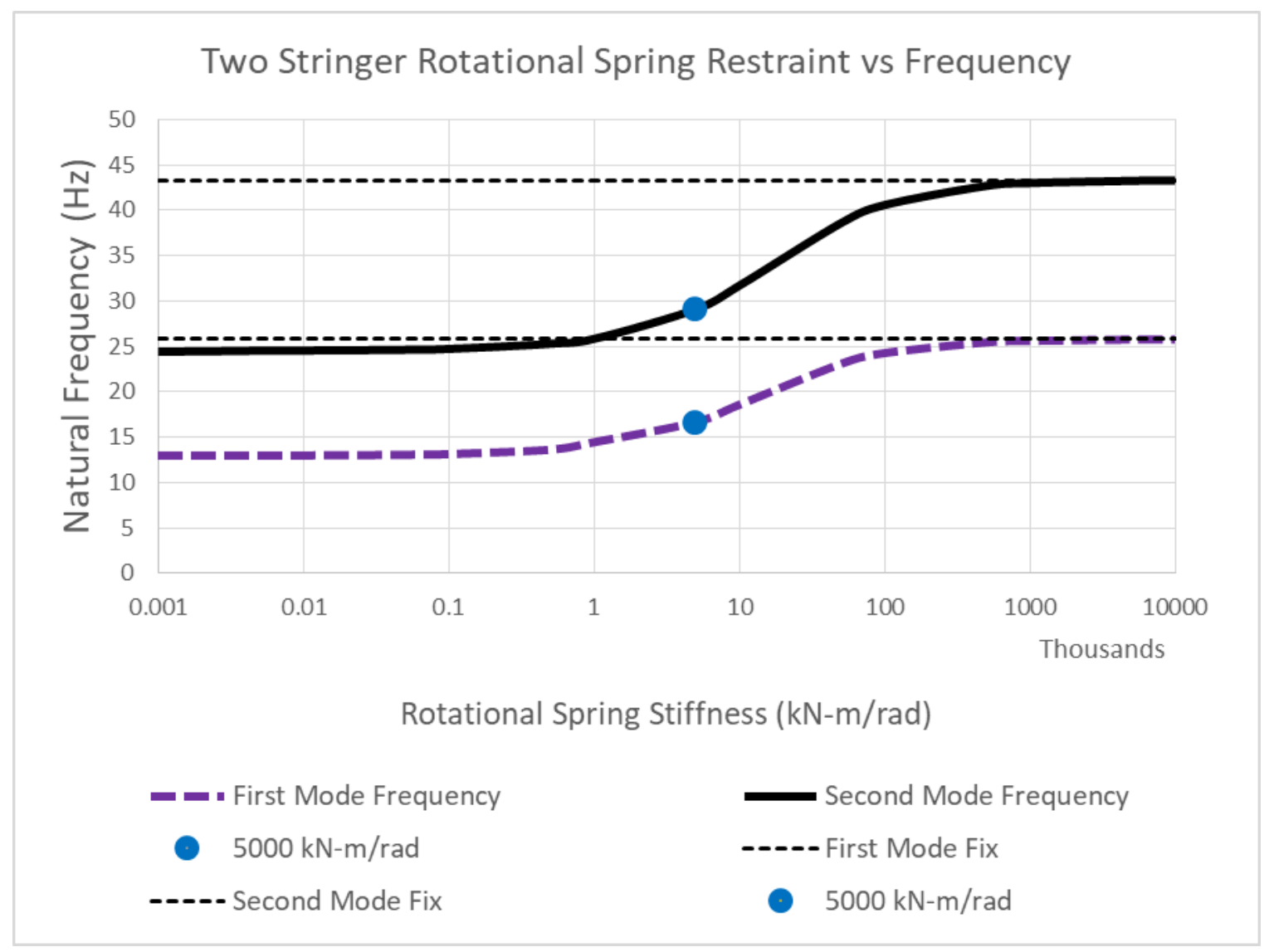

Figure 4.11: Two Stringer Rotational Spring Restraints vs. Frequency 


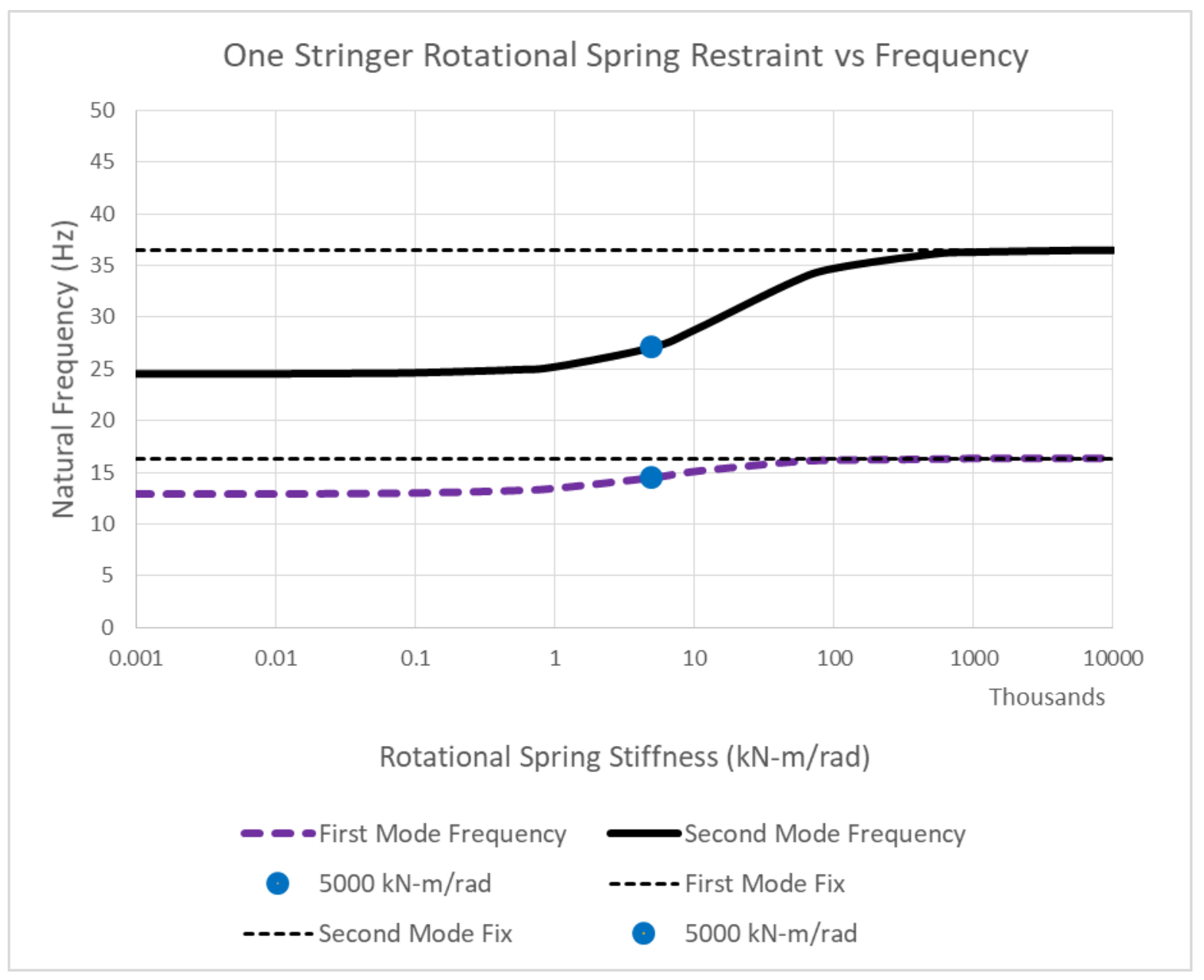

Figure 4.12: One Stringer Rotational Spring Restraint vs. Frequency

Looking at the restraint stiffness versus frequency graphs for scenario 1 , as the rotational spring stiffness is increased, the restraint started out as behaving as a pin-pin restraint and increased until it leveled off at an equivalent fix-fix behaving restraint. From this graph, it was noted that the magnitude of the first mode frequency was more affected than the second mode frequency when all stringer end restraints were changed. The change of the restraints from a pin-pin to a fix-fix connection for scenario one resulted in a $66.8 \%$ change in the first mode, while the second mode exhibited a $53.9 \%$ change. However, when the end springs were only changed at the ends of one stringer, scenario 2, 
the first mode was more affected by the change in rotational stiffness than the second mode. The change from a pinned restraint to a fixed restraint, on one stringer, resulted in a $23.4 \%$ change in the first mode, but a $39.2 \%$ change in the second mode. From both scenarios, it was also observed that the $5000 \mathrm{kN}-\mathrm{m} / \mathrm{rad}$ spring stiffness behaves more like a spring restraint than a fixed restraint based on where the stiffness falls on the graph.

\subsubsection{Influence of the Magnitude of Railing Mass on Modal Frequency}

The next step was to determine the effect of the railing mass on the first and second mode frequency of the structure. This section was completed by taking the Type 2 stair model with the $5000 \mathrm{kN}-\mathrm{m} / \mathrm{rad}$ adjusted pin restraint springs and eliminating the mass due to the railings. Once the railings were eliminated, it was possible to determine the effect that the railing mass has on the staircase's natural frequency and mode shape. Eliminating the mass of the railing decreased the total system from $1951 \mathrm{~kg}$ to $1719 \mathrm{~kg}$. The $232 \mathrm{~kg}$ reduction in mass resulted in a $1.38 \%$ increase in the first mode frequency, changing from $16.62 \mathrm{~Hz}$ to $16.85 \mathrm{~Hz}$. The reduction in mass resulted in a $3.44 \%$ increase in the second mode, an increase from $29.07 \mathrm{~Hz}$ to $30.07 \mathrm{~Hz}$. Although the frequency changed slightly more for the second mode frequency, the respective mode shapes remained unchanged.

In order to more completely understand how the frequency is influenced by the magnitude of the mass of the railings, increasing masses were applied along both stringers, and the corresponding changes in frequencies were recorded. It is to be noted that the increase of the applied mass along the stringer did not account for any changes in the torsional mass contribution created by the railing height. This is acceptable because 
the purpose of this test was to understand the influence of solely the effect of uneven mass distribution on the staircases' frequencies.

The mass applied to the two stringers started at $0 \%$ and increased in increments of $5 \%$ of the total mass of the structure, which excluded the mass of the railings, until $100 \%$ was applied, doubling the mass of the structure. For example, the mass of the stair flight without railings was $1719 \mathrm{~kg}$, so an application of $10 \%$ of the total mass would add 171.9 $\mathrm{kg}$ to the system, or $85.95 \mathrm{~kg}$ to each stringer. The percent railing mass to frequency was then plotted for the first two modes to better understand the influence of mass on the behavior of the stair structure. In addition, the idealized curve derived from $\omega_{n}=\sqrt{\frac{k}{m}}$ was plotted to determine if the parametric curve departs from this behavior. The idealized curve was plotted using scalars applied to the initial frequency, which assumed a mass "m" of one. For example, when the applied mass was $100 \%$ that of the structure, the total mass was doubled, so a scalar of $\sqrt{\frac{1}{2}}$ was applied to the initial frequency. The idealized equation frequency values assumed that the mass was evenly distributed and were compared to the modeled behavior, where the mass was unevenly distributed. The results were plotted in Figure 4.13 and Figure 4.14. 


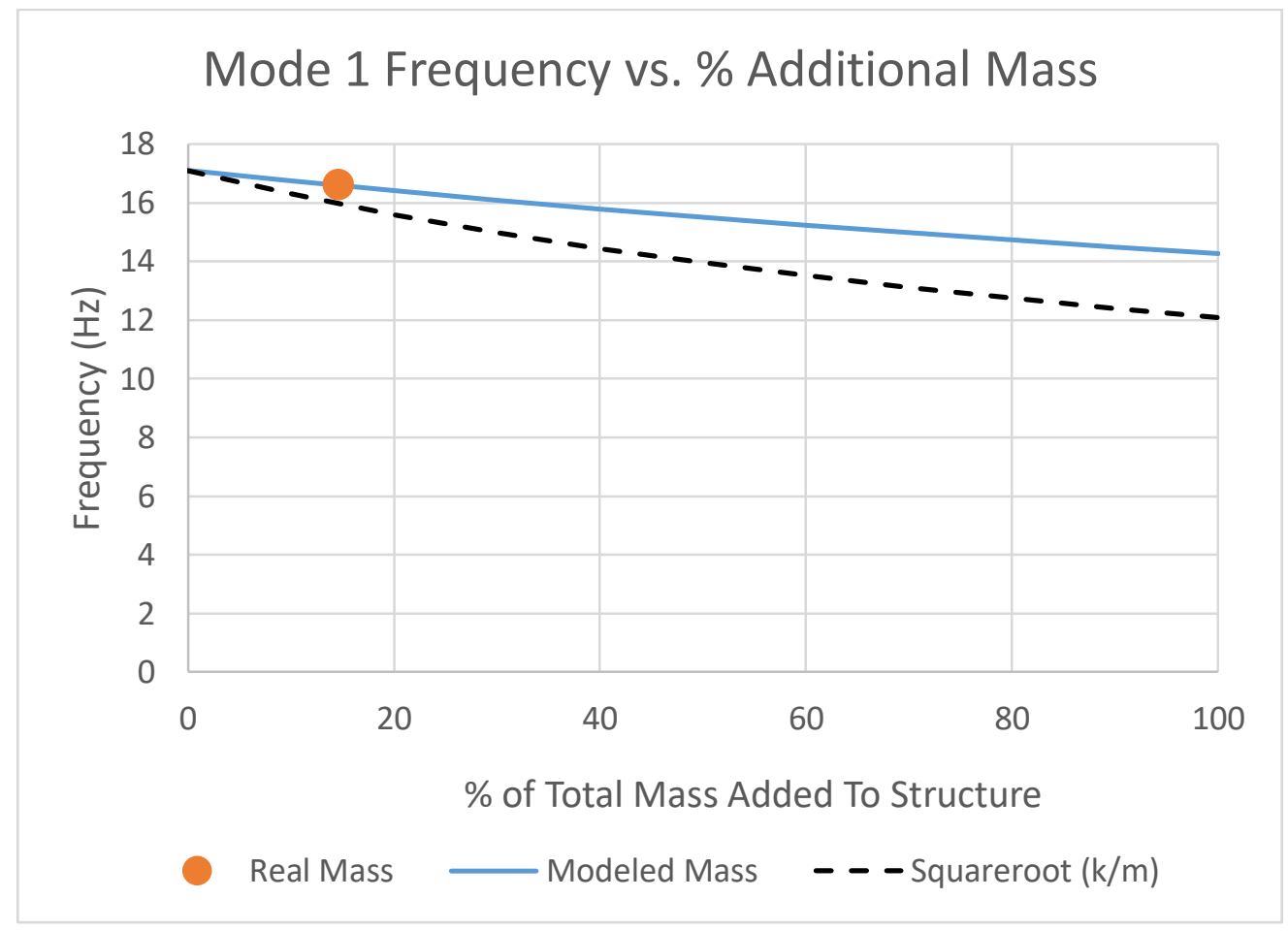

Figure 4.13: First Mode Frequency vs. Additional Two Rail Mass

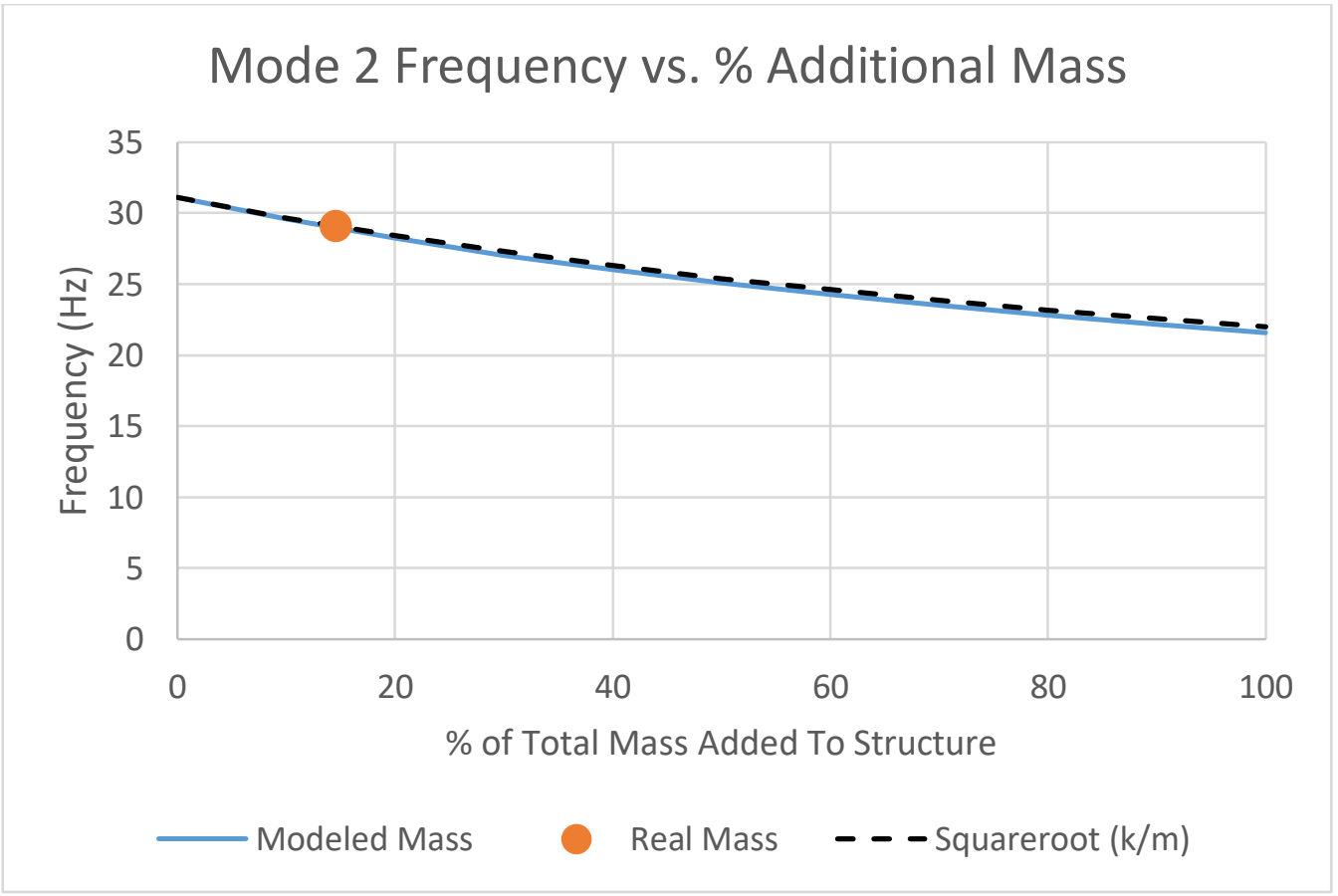

Figure 4.14: Second Mode Frequency vs. Additional Two Rail Mass 
The first mode frequency graph in Figure 4.13, demonstrates that the frequency of the structure deviates from the equation for the circular frequency in Equation (2.2). The deviation of the two slopes in the graph is attributed to the effects of having large masses on the edge of the stair flight, creating an uneven mass distribution on the system. However, the graph of the second mode frequency versus \% additional mass in Figure 4.14, demonstrates that the second mode frequency closely follows the equation of circular frequency. Therefore, it was observed that the mass distribution does not have much effect on the torsional second mode, but has a noticeable effect on the first mode frequency.

The next step was to repeat the same procedure, except this time, all the mass applied to the railing was distributed on one stringer instead of distributed on two. As before, measurements were taken for every $5 \%$ of the total mass applied. The percent mass to frequency was then plotted for the first and second mode, in Figure 4.15 and Figure 4.16, respectively. 


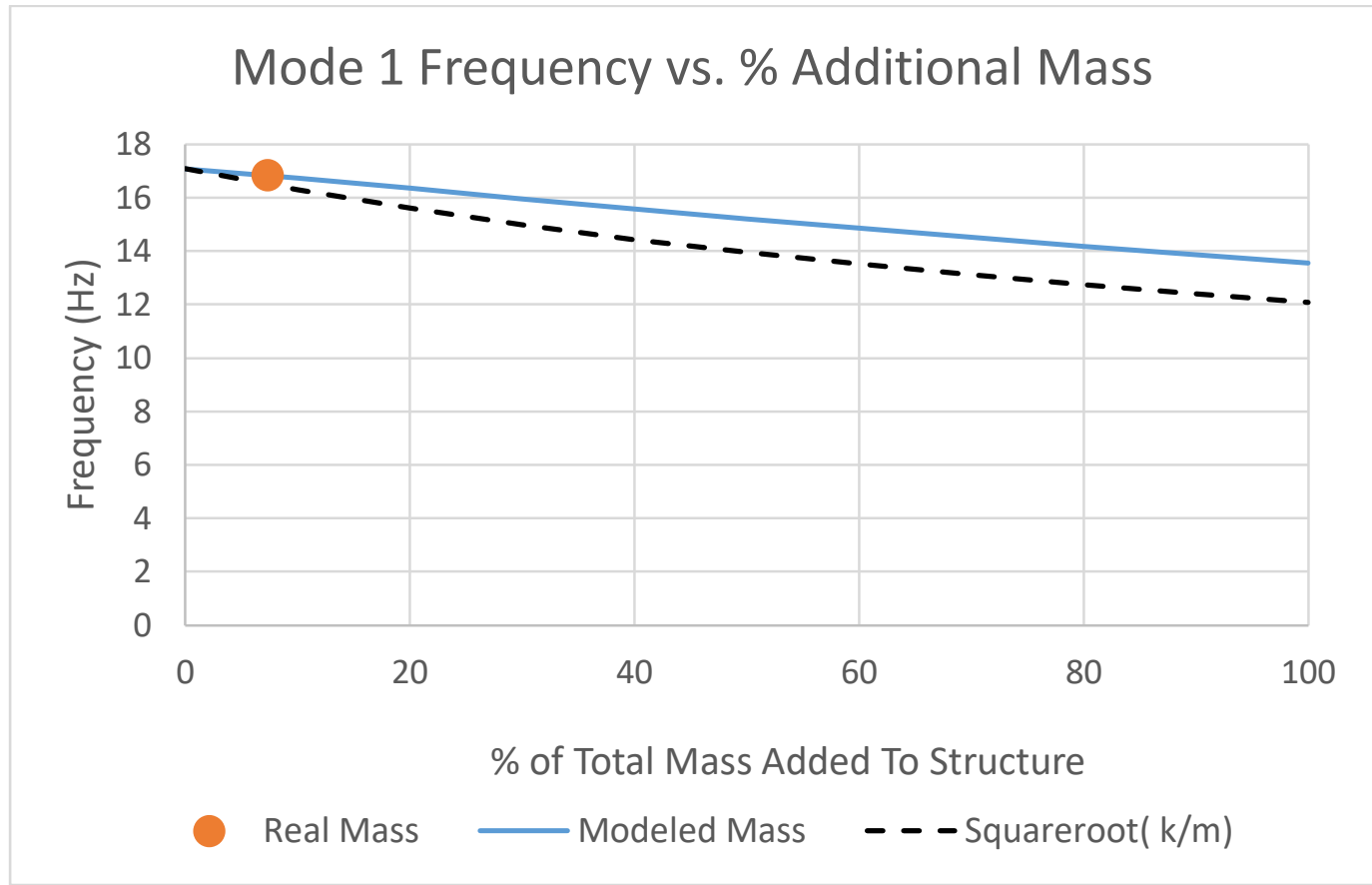

Figure 4.15: First Mode Frequency vs. Additional One Rail Mass

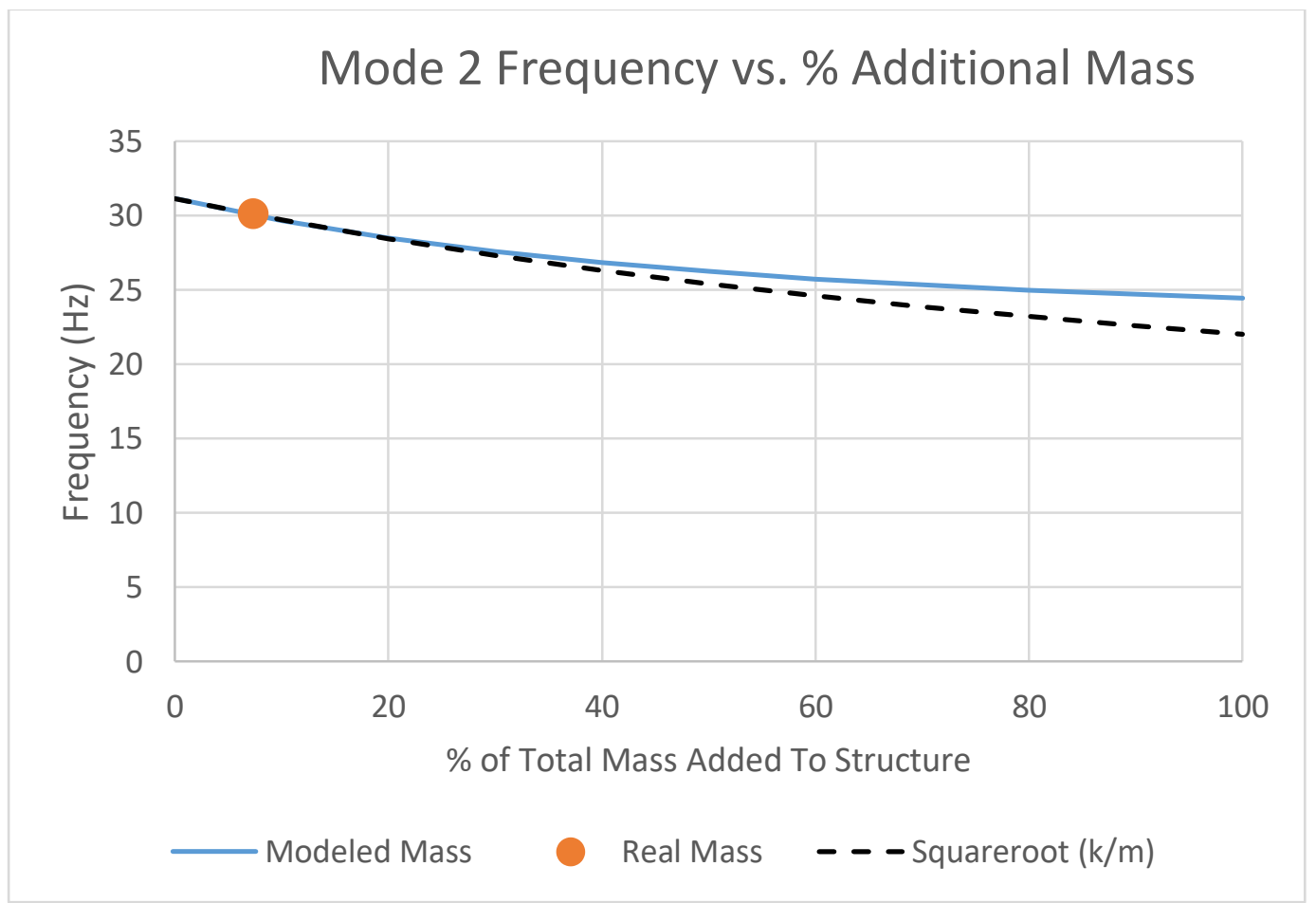

Figure 4.16: Second Mode Frequency vs. Additional Two Rail Mass 
The graph of the first mode, in Figure 4.15, demonstrates that the change in first mode frequency deviates from the equation of circular frequency in Equation (2.2). The deviation of the model's frequency slope from the frequency slope found using the circular frequency equation, once again, is assumed to be attributed to the uneven mass distribution created by the large concentrated mass on the edge of the stair flight. Similar to when the mass is distributed on two railings, the second mode graph in Figure 4.16 demonstrates a close following of the circular frequency equation for the first $20 \%$ additional mass applied. However, after more than $20 \%$ additional mass is applied, the second mode frequency begins to depart from this idealized natural frequency curve.

In order to understand how the first mode frequency deviates from the idealized circular frequency curve, a line of best fit was applied to the modeled frequency slope for the two scenarios, as seen in Figure 4.17 and Figure 4.18 


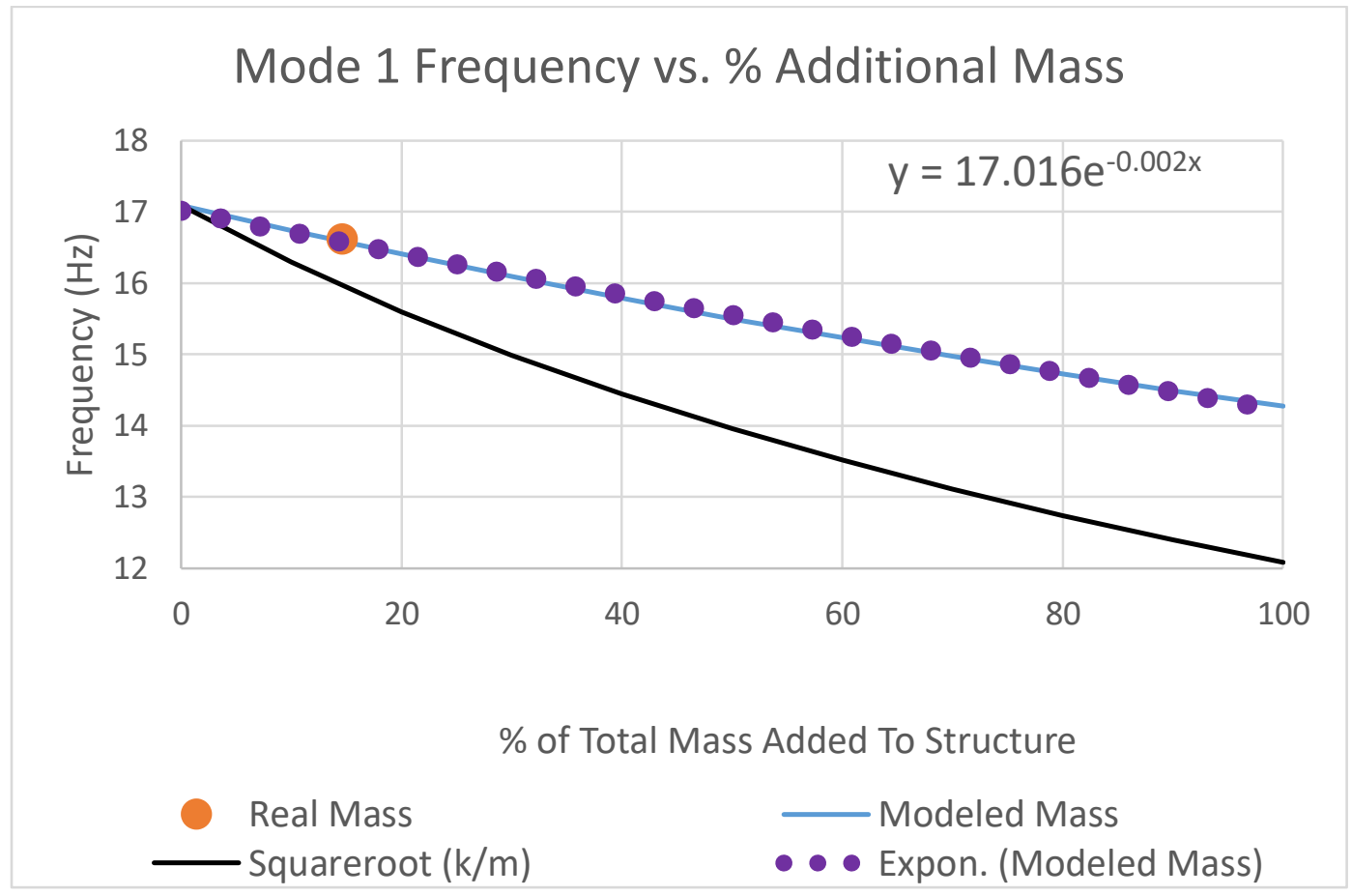

Figure 4.17: Two Stringer Mass Distribution Line of Best Fit

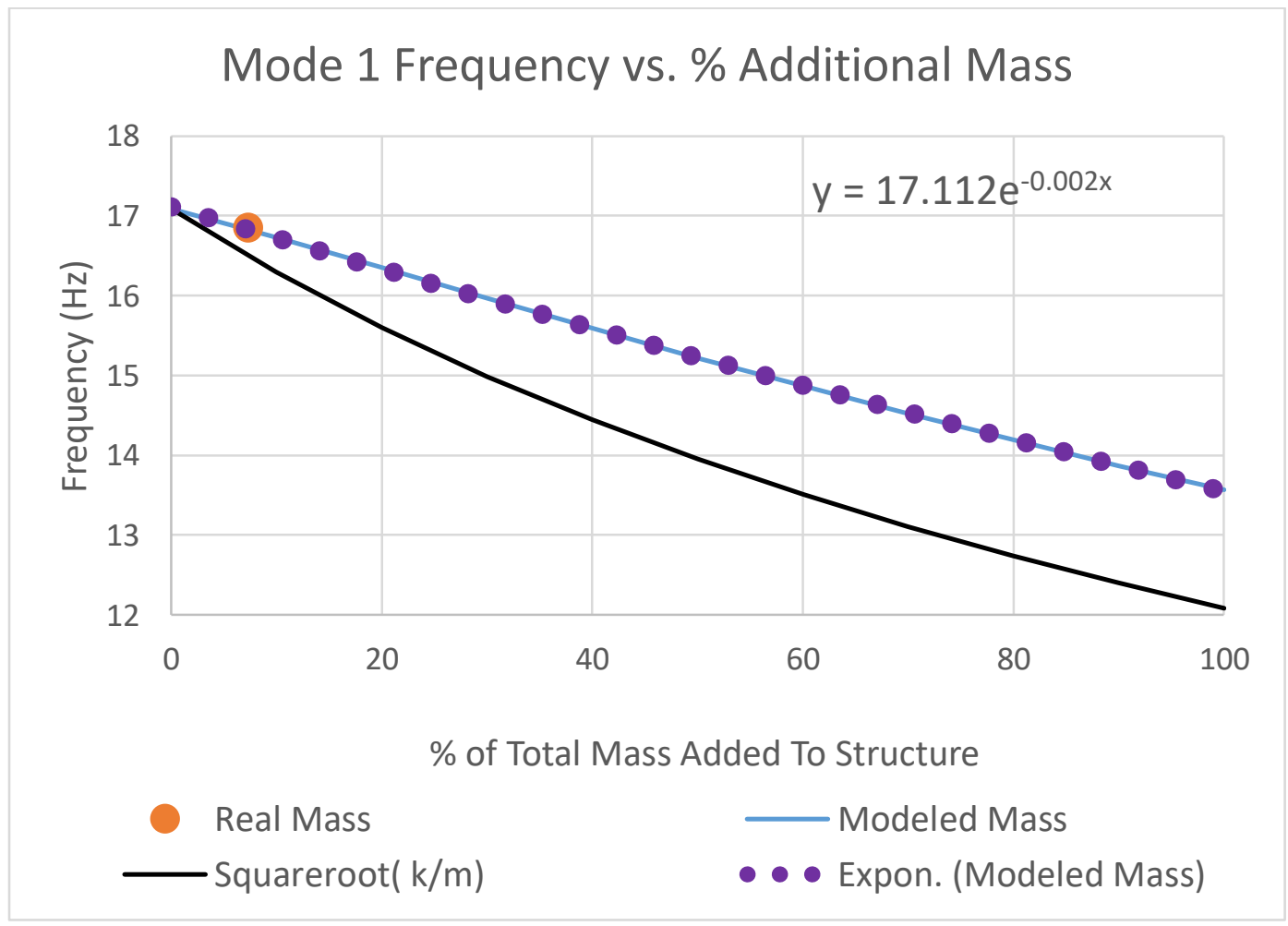

Figure 4.18: One Stringer Mass Distribution Line of Best Fit 
The line of best fit for the modeled frequency versus \% additional mass applied to two stringers for the first mode can be described by Equation (4.1).

$$
y=17.016 \mathrm{e}^{-0.002 x}
$$

The line of best fit for the modeled frequency versus \% additional mass applied to one stringer for the first mode can be described by Equation (4.2).

$$
y=17.112 e^{-0.002 x}
$$

Both of these equations followed the same exponential slope but have slightly different scalars close to the $17.09 \mathrm{~Hz}$ first mode frequency determined when there is no additional mass applied to the railings. Therefore, the equation proposed to represent the change in first mode frequency when additional railing mass is applied to the railings, is presented in Equation (4.3).

$$
f_{n}=\mathrm{Z}^{*} \mathrm{e}^{-0.002 \mathrm{x}}
$$

Where $f_{n}(\mathrm{~Hz})$ is the first mode natural frequency, $Z(\mathrm{~Hz})$ is the staircase frequency when no railing mass is applied, and $x(\%)$ is the percent of stair mass being applied along the stringers.

\subsubsection{Influence of Railing Stiffness on First Mode Frequency}

This section investigates whether the stiffness of the railing has a notable effect on the first mode natural frequency of the stair flights. The stair railing was composed of $3.18 \mathrm{~cm}$ (1.25 in.) diameter pipes and $1.91 \mathrm{~cm}(0.75$ in. $)$ diameter steel bars. The railing was modeled on both sides of the base stair model developed in Chapter 3. This model 
did not include rotational springs applied to the ends of the stringers so that the railings' influence on the frequency could be determined before the model was tuned. This model is representative of the Type 2 staircase. However, the mass due to the railing included in the base model was removed and replaced with a modeled railing. The SAP2000 model with the modeled railing is pictured in Figure 4.19.

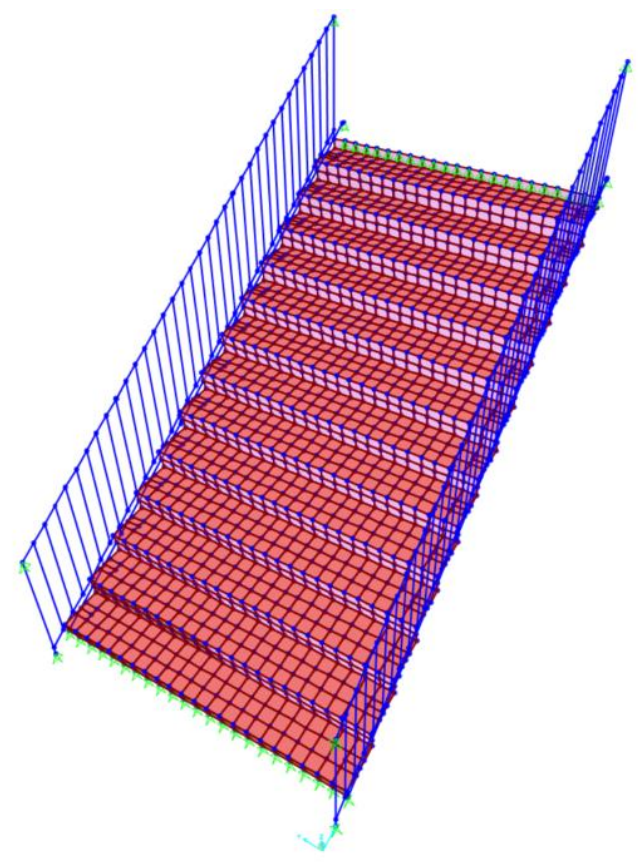

Figure 4.19: Stair Flight Modeled with Railings

When the railing was modeled, it was determined that the relative stiffness difference between the rail and the stair flight was so great that the staircase's global modal response was not captured for a majority of the modes. This meant that the modal response found was that of the railings and not of the entire stair structure. The change in response was noted by both a difference in the mode shape frequencies and a change in mode shape behavior. The mode shape when the railing was modeled was no longer 
representative of the structure because the only elements of the structure affected by the modal analysis for the first two modes were the railings, and not the stringers, treads, or risers. This behavior was captured in the mode shape response of the first two modes, as seen in Figure 4.20 and Figure 4.21.

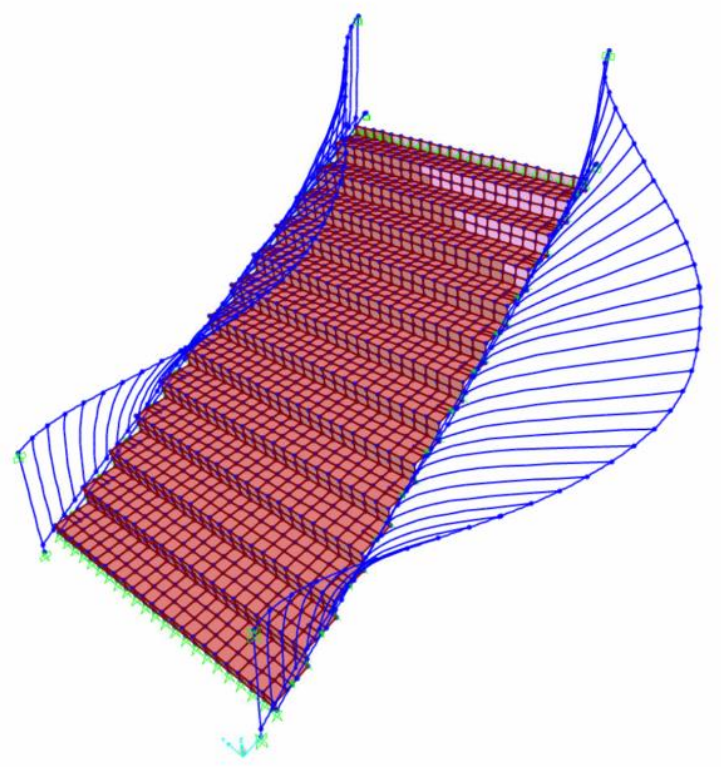

Figure 4.20: Mode 1 of Model with Railings (14.04Hz)

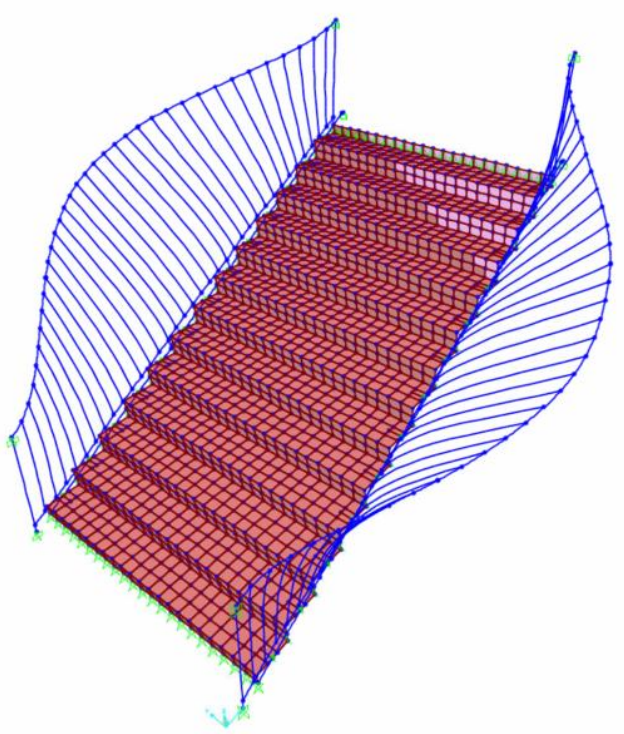

Figure 4.21: Mode 2 of Model with Railings (14.04Hz) 
If the railing is physically modeled on the stair flight, it could give the illusion that the modal frequencies are much lower than they actually are. Although one could believe that this is acceptable because it is a more conservative design estimate since it estimates a lower frequency than actually exists, this conservative estimate is based on a miss-identification of the structure's actual behavior. Therefore, it should be kept in mind that the relative stiffness added due to the railing was so much less than that of the combination of the stringers, treads, and risers, that the stiffness was considered to be insignificant to the modal response of the structure. Therefore, only the mass of the railing was included in the remaining models of the stair flights in the remaining sections.

As a result, it is recommended that when developing models of staircases, close attention should be paid to whether or not the relative stiffness of the railing compared to the rest of the staircase is close enough to necessitate the modeling of the railing. If the difference is great, modeling the railing may lead to inaccurate results. Therefore, it is important for designers to check the modal behavior of stair models to make sure they are properly capturing the correct modal response behavior of the global structure, and not just the modal response of one of the elements of the structure.

\subsubsection{Wall Stringer Influence on Natural Frequency}

Recall the higher first mode frequency of the Type 1 staircase compared to the Type 2 staircase. This change was assumed to come from the change in boundary conditions created by the existence of a wall stringer since that was the only major boundary condition change between the two stair types. Therefore, the boundary conditions of wall stringers should be considered different than face stringers during 
dynamic analysis and modeling. As a result, the next objective was to determine the influence that a wall stringer has on the first and second mode frequencies.

In order to determine the change in dynamic behavior, the mass of one of the railings in the Type 2 staircase model, tuned with $5000 \mathrm{kN}-\mathrm{m} / \mathrm{rad}$ springs, was eliminated. The elimination of the mass of one of the railings in the Type 2 model was then representative of the Type 1 staircase since the Type 1 stair only had a railing on the face stringer. The remaining difference after the railing mass was modified could then be attributed to the difference in boundary conditions due to the wall stringer.

The mass of the Type 1 staircase when only a single railing was applied was $1835 \mathrm{~kg}$. This change in mass resulted in a $5.9 \%$ decrease in mass from the $1951 \mathrm{~kg}$ mass determined in the Type 2 staircase. The change in the mass resulted in a first mode frequency of $16.85 \mathrm{~Hz}$ and a second mode frequency of $30.07 \mathrm{~Hz}$. A comparison of the experimental first mode frequency to the SAP2000 model's first mode frequency can be found in Table 4.19. A comparison of the experimental second mode frequency to the SAP2000 model's second mode frequency can be found in Table 4.20.

Table 4.19: Type 1 Single Stringer Mass with 5000 kN-m/rad Springs First Mode Frequency Difference

\begin{tabular}{|c|c|c|c|}
\hline Stair Flight & $\begin{array}{c}\text { Experimentally } \\
\text { Determined Mode1 } \\
\text { Frequency }(\mathrm{Hz})\end{array}$ & $\begin{array}{c}\text { SAP2000 Mode1 } \\
\text { Frequency (Hz) }\end{array}$ & $\begin{array}{c}\text { Difference in } \\
\text { Frequency (\%) }\end{array}$ \\
\hline Flight 1 & 20.11 & 16.85 & $17.64 \%$ \\
\hline Flight 3 & 21.61 & 16.85 & $24.75 \%$ \\
\hline Average & 20.86 & 16.85 & $21.27 \%$ \\
\hline
\end{tabular}


Table 4.20: Type 1 Single Stringer Mass with 5000 kN-m/rad Springs Second Mode Frequency Difference

\begin{tabular}{|c|c|c|c|}
\hline Stair Flight & $\begin{array}{c}\text { Experimentally } \\
\text { Determined Mode2 } \\
\text { Frequency }(\mathrm{Hz})\end{array}$ & $\begin{array}{c}\text { SAP2000 Mode 2 } \\
\text { Frequency (Hz) }\end{array}$ & $\begin{array}{c}\text { Difference in } \\
\text { Frequency (\%) }\end{array}$ \\
\hline Flight 1 & 30.39 & 30.07 & $1.06 \%$ \\
\hline Flight 3 & 33.33 & 30.07 & $10.28 \%$ \\
\hline Average & 31.86 & 30.07 & $5.78 \%$ \\
\hline
\end{tabular}

The average difference between the experimental and modeled first mode frequency differed by approximately $21 \%$ on average. This difference is attributed to a change in the boundary conditions created by the wall stringer. The wall stringer is considered to be adding the additional flexural stiffness to the stair structure, leading to an increase in the measured natural frequency.

In order to model this additional flexural stiffness, links were applied to all of the nodes on the wall edge of the model. This added resistance to the movement in the direction perpendicular to the plane of the wall. In the actual structure, this resistance to motion is created by the wall's interface with the stringer. The links were utilized in addition to the $5000 \mathrm{kN}-\mathrm{m} / \mathrm{rad}$ spring restraints found at the ends of both stringers to model the unknown stiffness of the structure. The links with translational stiffness allowed for the modeling of the out-of-plane direction perpendicular to the wall, translational stiffness created by the stringer's contact with the wall. A schematic denoting where the links were applied can be found in Figure 4.22. 


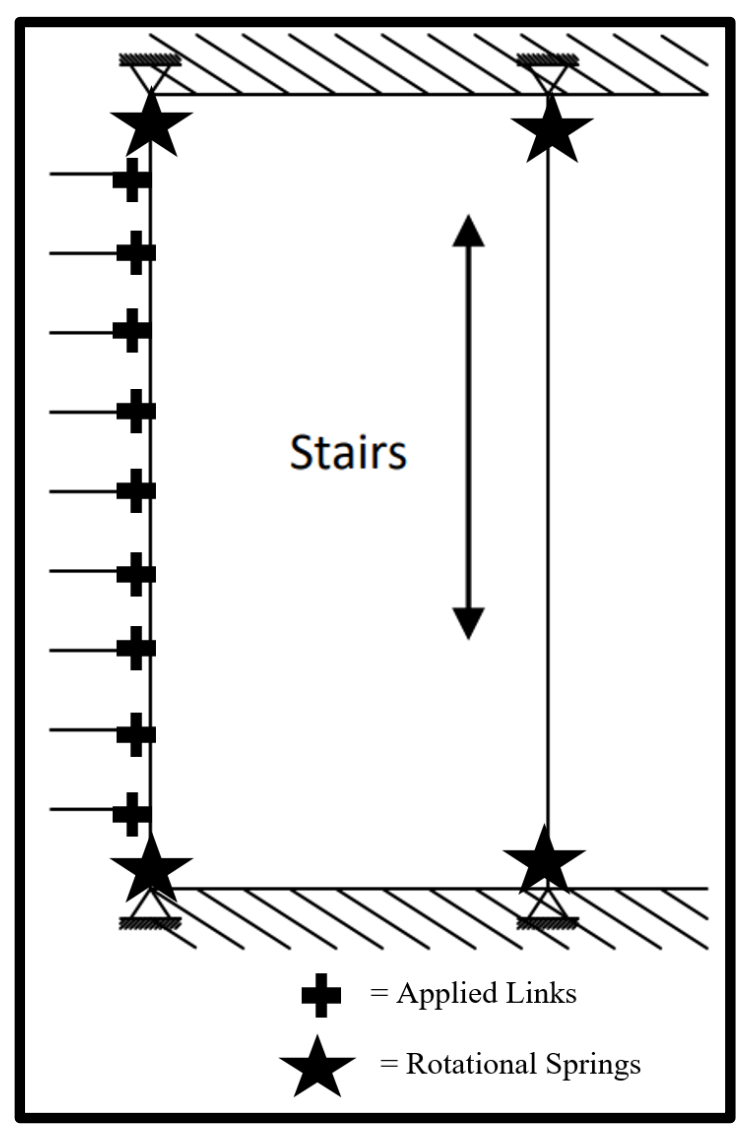

Figure 4.22: Modeled Type 1 Stair Schematic with Links and Springs

The model with the links can be seen in Figure 4.23, and a close up of these links with directions can be found in Figure 4.24. Where the out-of-plane direction is the direction perpendicular to the plane of the wall, denoted as U2, and the in-plane direction is the direction parallel to the wall plane, denoted as U1 and U3. 


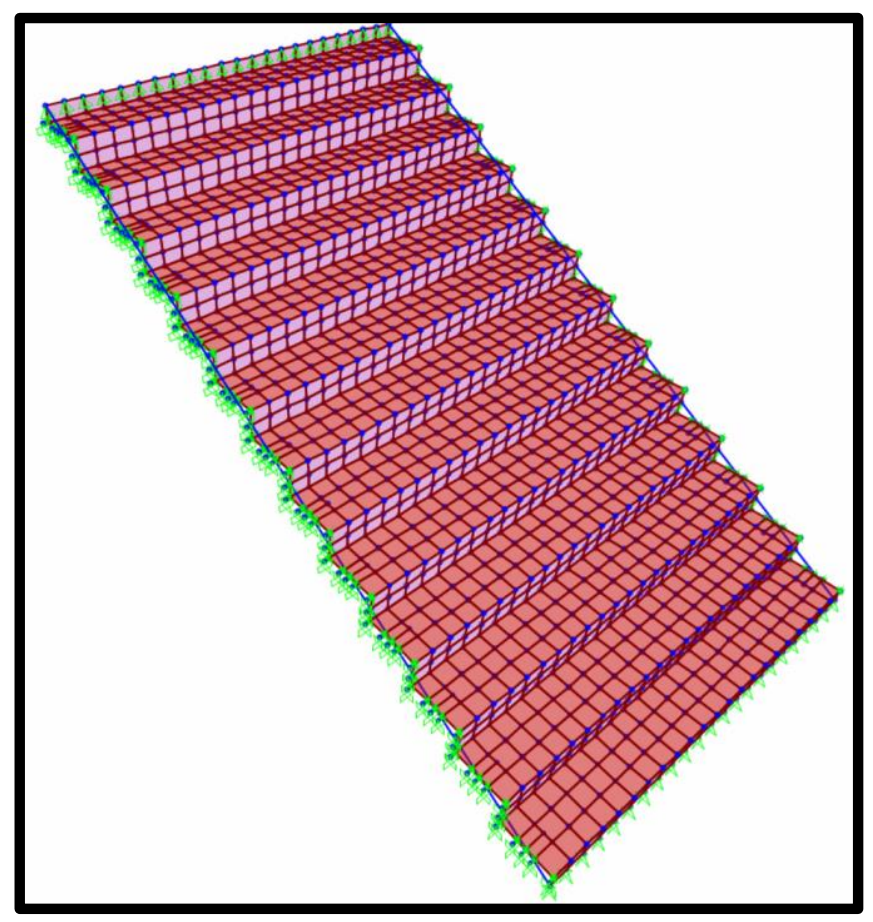

Figure 4.23: Model with Edge Links

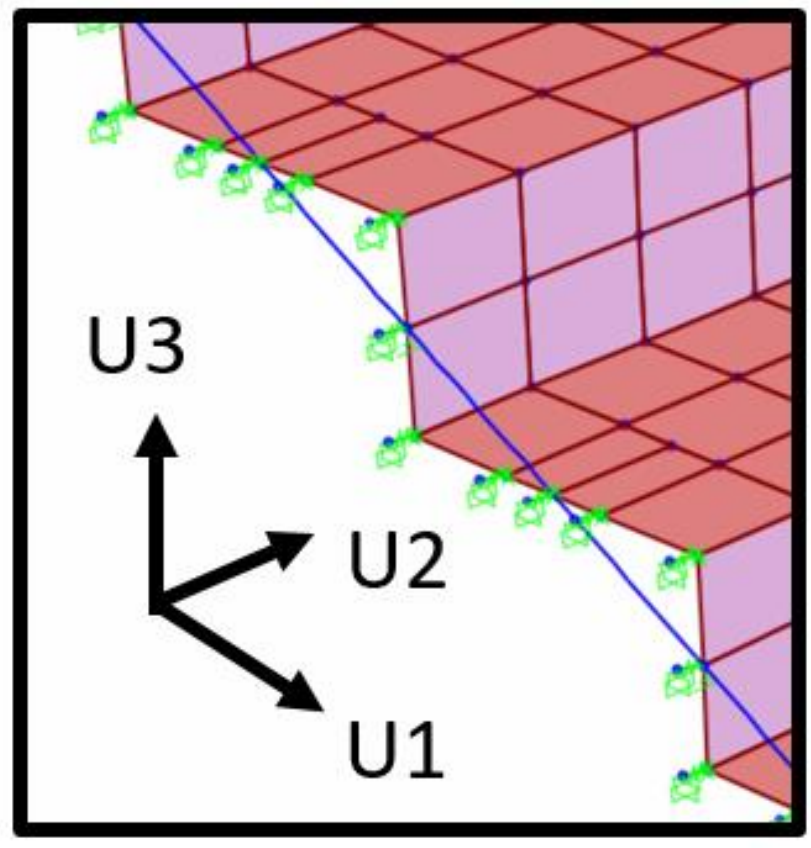

Figure 4.24: Close up of Edge Links 
It was determined that a stiffness of $438 \mathrm{kN} / \mathrm{m}$ (2.5 kips/in) applied to the model's links in the out-of-plane direction was representative of the experimental behavior for the Type 1 staircase. The first mode frequencies of the Type 1 stairs, both without and with the link stiffness, are provided in Table 4.21 and Table 4.22, respectively. The second mode frequencies of the Type 1 stairs, both without and with link stiffness, are given in Table 4.23 and Table 4.24, respectively.

Table 4.21: Type 1 No Translation Link Applied Mode 1 Frequency

\begin{tabular}{|c|c|c|c|}
\hline Stair Flight & $\begin{array}{c}\text { Experimentally } \\
\text { Determined Mode 1 } \\
\text { Frequency (Hz) }\end{array}$ & $\begin{array}{c}\text { Adjusted SAP2000 } \\
\text { Model Mode 1 } \\
\text { Frequency (Hz) }\end{array}$ & $\begin{array}{c}\text { Difference in } \\
\text { Frequency (\%) }\end{array}$ \\
\hline Flight 1 & 20.11 & 16.85 & $17.64 \%$ \\
\hline Flight 3 & 21.61 & 16.85 & $24.75 \%$ \\
\hline Average & 20.86 & 16.85 & $21.27 \%$ \\
\hline
\end{tabular}

Table 4.22: Type 1438 kN/m Translation Link Applied Mode 1 Frequency

\begin{tabular}{|c|c|c|c|}
\hline Stair Flight & $\begin{array}{c}\text { Experimentally } \\
\text { Determined Mode 1 } \\
\text { Frequency (Hz) }\end{array}$ & $\begin{array}{c}\text { Adjusted SAP2000 } \\
\text { Model Mode 1 } \\
\text { Frequency (Hz) }\end{array}$ & $\begin{array}{c}\text { Difference in } \\
\text { Frequency (\%) }\end{array}$ \\
\hline Flight 1 & 20.11 & 18.97 & $5.83 \%$ \\
\hline Flight 3 & 21.61 & 18.97 & $13.01 \%$ \\
\hline Average & 20.86 & 18.97 & $9.49 \%$ \\
\hline
\end{tabular}


Table 4.23: Type 1 No Translation Link Applied Mode 2 Frequency

\begin{tabular}{|c|c|c|c|}
\hline Stair Flight & $\begin{array}{c}\text { Experimentally } \\
\text { Determined Mode 2 } \\
\text { Frequency (Hz) }\end{array}$ & $\begin{array}{c}\text { Adjusted SAP2000 } \\
\text { Model Mode 2 } \\
\text { Frequency (Hz) }\end{array}$ & $\begin{array}{c}\text { Difference in } \\
\text { Frequency (\%) }\end{array}$ \\
\hline Flight 1 & 30.39 & 30.07 & $1.06 \%$ \\
\hline Flight 3 & 33.33 & 30.07 & $10.28 \%$ \\
\hline Average & 31.86 & 30.07 & $5.78 \%$ \\
\hline
\end{tabular}

Table 4.24: Type 1438 kN/m Translation Link Applied Mode 2 Frequency

\begin{tabular}{|c|c|c|c|}
\hline Stair Flight & $\begin{array}{c}\text { Experimentally } \\
\text { Determined Mode 2 } \\
\text { Frequency (Hz) }\end{array}$ & $\begin{array}{c}\text { Adjusted SAP2000 } \\
\text { Model Mode 2 } \\
\text { Frequency (Hz) }\end{array}$ & $\begin{array}{c}\text { Difference in } \\
\text { Frequency (\%) }\end{array}$ \\
\hline Flight 1 & 30.39 & 34.95 & $13.96 \%$ \\
\hline Flight 3 & 33.33 & 34.95 & $4.75 \%$ \\
\hline Average & 31.86 & 34.95 & $9.25 \%$ \\
\hline
\end{tabular}

The application of translational links on the wall stringer side of the stair resulted in a first mode frequency that was within approximately $10 \%$ of the average experimentally determined frequency. This was a $56.6 \%$ decrease in the difference between the modeled and experimental frequencies when the links were added. The application of the translational links on the wall stringer edge nodes resulted in a second mode frequency within $10 \%$ of the average experimentally determined value. Therefore, it was observed that adding the out-of-plan translational stiffness brought the model's first mode frequency closer to the experimentally determined first mode frequency while maintaining a second mode frequency that was relatively close to the experimentally determined second mode frequency. 
The next step was to compare the first two mode shapes of the model with the first two experimentally determined mode shapes. This step was important for making sure that the frequency determined by the model was representative of the experimentally determined mode shape behavior. The Type 1 stair model was compared to the mode shape of Flight 3. The experimentally determined first mode shape of Flight 3 is found in Figure 4.25. The Type 1 first mode shape determined using SAP2000 can be found in Figure 4.26. The experimentally determined second mode shape of Flight 3 is found in Figure 4.27. The Type 1 second mode shape determined using SAP2000 can be found in Figure 4.28.

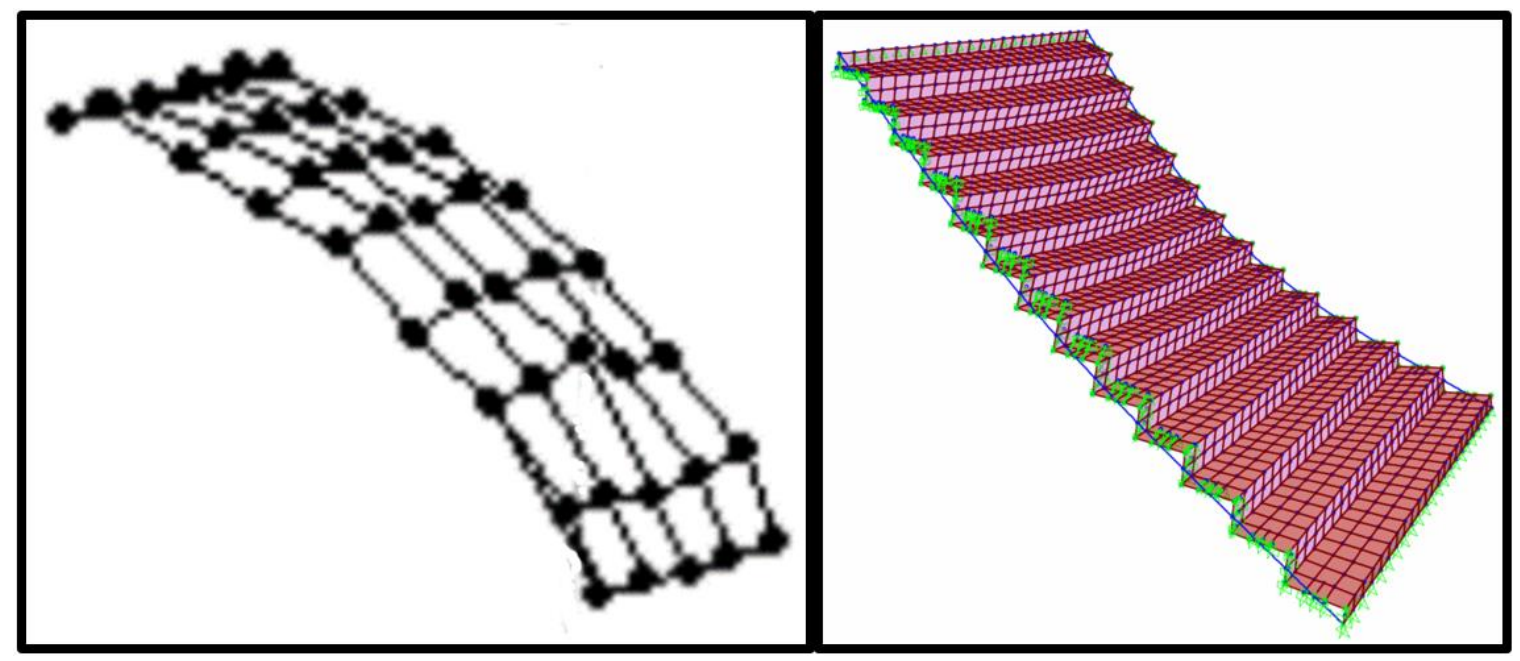

Figure 4.25: Type 1 Experimental Mode 1 (Left)

Figure 4.26: Type 1 SAP2000 Mode 1438 kN/m Links (Right) 


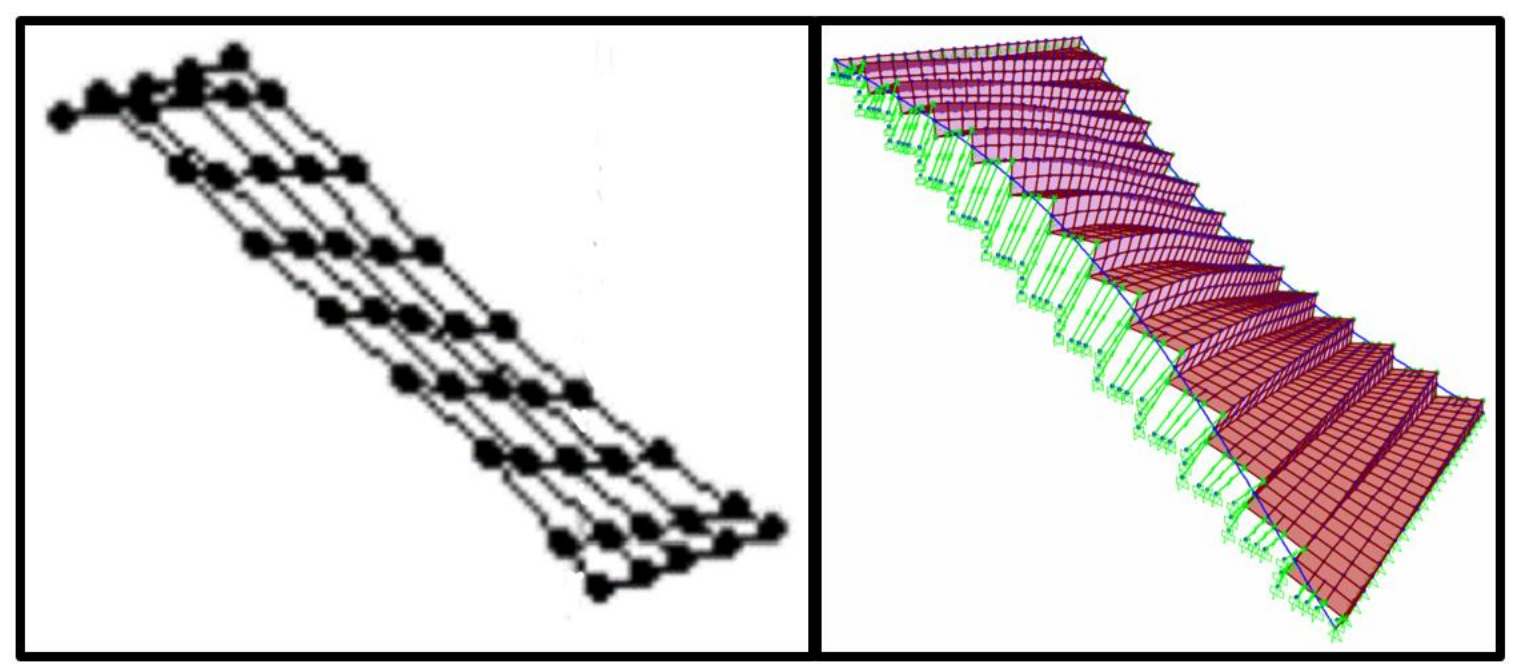

Figure 4.27: Type 1 Experimental Mode 2 (Left)

Figure 4.28: Type 1 SAP2000 Mode 2438 kN/m Links (Right)

From the comparison of mode shapes, it was evident that the SAP2000 model's mode shape behavior was indicative of the experimentally determined behavior. Where the first mode is characterized as a flexure mode with no nodes, and the second mode is characterized as having a torsional behavior. Therefore, it was determined that the boundary condition change, created by a wall stringer's resistance to out-of-plane motion, can be modeled with translational links by adding stiffness in the out-of-plane direction.

It was found that balancing the error between the first and second mode frequencies created the model that best represented the actual structure. Where the modeled first mode frequency was under predicted by approximately $10 \%$, and the second mode was over predicted by approximately $10 \%$. Although it was possible to get the first mode frequency to within $0.19 \%$ on average with the application of $10000 \mathrm{kN} / \mathrm{m}$ links, this drove the second mode frequency to a large over prediction on average by approximately $30 \%$. The comparison of the first and second mode frequencies can be found in Table 4.25 and Table 4.26, respectively. 
Table 4.25: 5000 kN-m/rad and 10000 kN/m Link Mode 1 Comparison

\begin{tabular}{|c|c|c|c|}
\hline Stair Flight & $\begin{array}{c}\text { Experimentally } \\
\text { Determined Mode 1 } \\
\text { Frequency (Hz) }\end{array}$ & $\begin{array}{c}\text { Adjusted SAP2000 } \\
\text { Model Mode 1 } \\
\text { Frequency (Hz) }\end{array}$ & $\begin{array}{c}\text { Difference in } \\
\text { Frequency (\%) }\end{array}$ \\
\hline Flight 1 & 20.11 & 20.82 & $3.47 \%$ \\
\hline Flight 3 & 21.61 & 20.82 & $3.72 \%$ \\
\hline Average & 20.86 & 20.82 & $0.19 \%$ \\
\hline
\end{tabular}

Table 4.26: 5000 kN-m/rad and 10000 kN/m Link Mode 2 Comparison

\begin{tabular}{|c|c|c|c|}
\hline Stair Flight & $\begin{array}{c}\text { Experimentally } \\
\text { Determined Mode 2 } \\
\text { Frequency (Hz) }\end{array}$ & $\begin{array}{c}\text { Adjusted SAP2000 } \\
\text { Model Mode 2 } \\
\text { Frequency (Hz) }\end{array}$ & $\begin{array}{c}\text { Difference in } \\
\text { Frequency (\%) }\end{array}$ \\
\hline Flight 1 & 30.39 & 42.89 & $34.12 \%$ \\
\hline Flight 3 & 33.33 & 42.89 & $25.09 \%$ \\
\hline Average & 31.86 & 42.89 & $29.51 \%$ \\
\hline
\end{tabular}

In addition to the large over prediction of the second mode frequency created by the $10000 \mathrm{kN} / \mathrm{m}$ links, the large increase in stiffness resulted in a change in mode shape, where the wall stringer acted almost as if it were fixed instead of having a flexural bending. The $10000 \mathrm{kN} / \mathrm{m}$ links also changed the second mode shape from being a torsional behavior to a flexure shape with a node located across the middle step of the stair. A visualization of these altered mode shape changes for the first and second mode can be found in Figure 4.29 and Figure 4.30. 


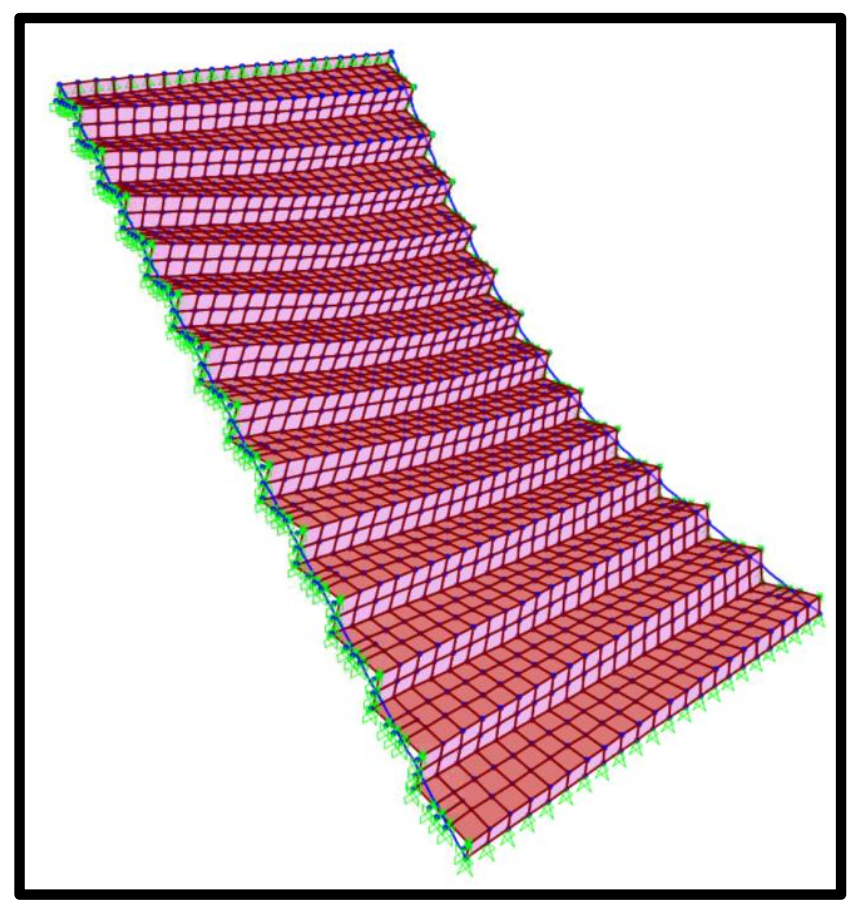

Figure 4.29: Type 1 Mode 110000 kN/rad Links

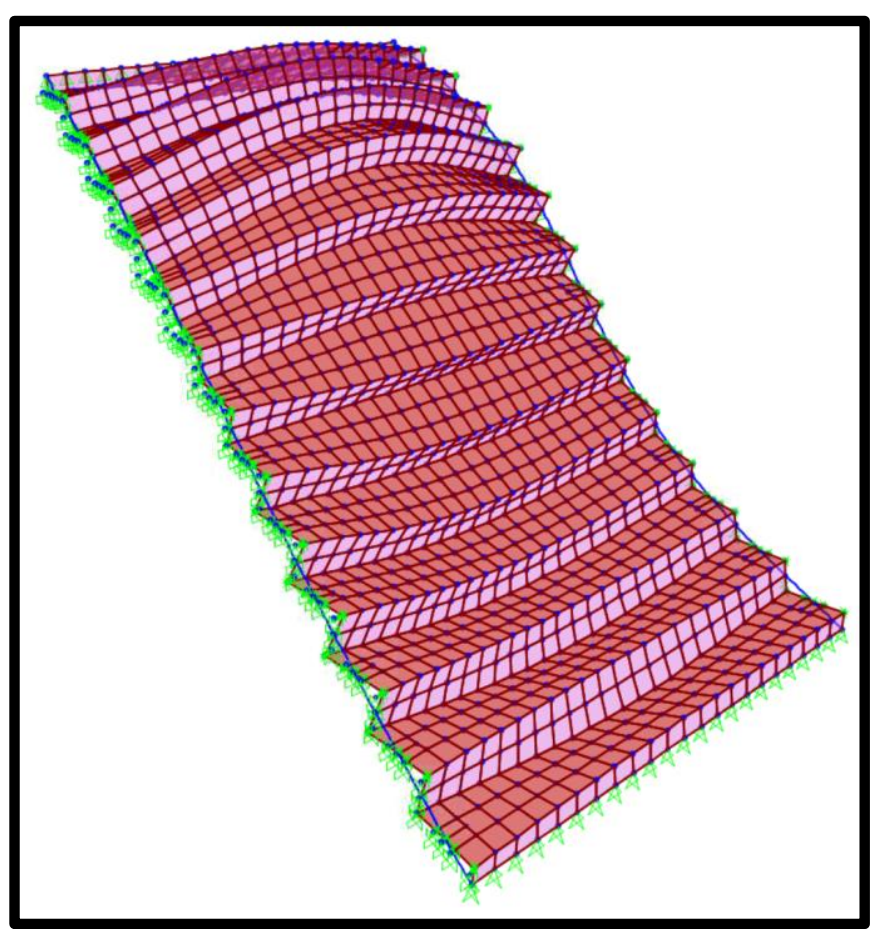

Figure 4.30: Type 1 Mode 210000 kN/rad Links 
After observing the change in mode shape, it becomes evident that the mode shape of the model is no longer representative of the experimentally determined mode shape. Therefore it was determined that finding a balance in error between the first and second mode frequency provided for the best representation of the structure. Since the first mode frequency was an under prediction of the experimentally determined frequency, a balance was made so that the first and second mode frequencies differed by approximately the same amount. This resulted in a conservative estimate for the first mode frequency, being under predicted by $10 \%$, and a less conservative second mode frequency, being over predicted by $10 \%$. Since the first mode frequency is most likely to be excited by stair occupants, the second mode frequency being slightly over predicted is acceptable.

\subsubsection{Alternative Modeling Techniques}

The purpose of this section is to provide suggestions for alternative methods of modeling staircase boundary conditions. Determining alternative methods for modeling is increasingly important as stairs become more architecturally complex. This is because the more complex a staircase becomes, the higher the chance that an overly simplified modeling approach may not be appropriate to properly capture the structure's dynamic behavior. Therefore, having more than one modeling technique available could aid designers in creating models that more appropriately represent the dynamic behavior of the stair structure being modeled. This section specifically looks at modeling unknown stiffness solely with link connections, without the use of rotational springs. 
For this section, the in-plane translation is defined to be the plane of the wall, denoted as U1 and U3, as pictured in Figure 4.31. The out of plane direction is defined as the direction perpendicular to the plane of the wall, as denoted by $\mathrm{U} 2$ as pictured in Figure 4.31.

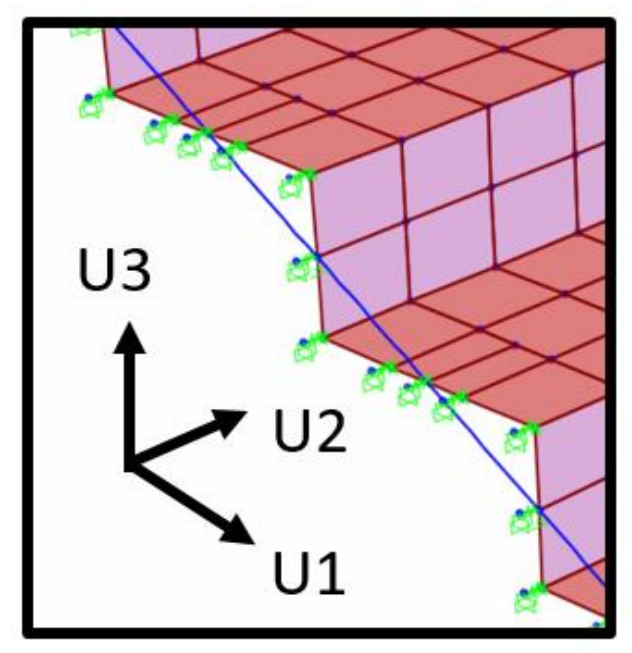

Figure 4.31: Plane Directions

A summary describing the procedure to determine the equivalent link stiffness as a substitute for rotational springs is as follows. The first step was to model the Type 1 staircase with both in-plane and out-of-plane translational stiffness. The out-of-plane stiffness found in the previous section was applied in the U2 direction. The in-plane, U1 and $\mathrm{U} 3$, translational stiffness was then used in substitution of the rotational spring restraints. This model's first and second mode frequencies were then compared to the experimentally determined first and second mode frequencies.

After the Type 1 staircase was modeled, the second step was to remove the outof-plane, U2 direction, stiffness to model the Type 2 staircase. If using links with inplane stiffness, in the $\mathrm{U} 1$ and $\mathrm{U} 3$ direction, was truly an alternative method for modeling 
the unknown stair stiffness, the first and second mode frequency should then be similar to the Type 2 experimentally determined frequencies.

\section{Alternative Modeling for Type 1 Stairs}

The first step was that links were applied to the edges of the Type 1 model, and the rotational springs were removed from the model. A schematic drawing of this can be found in Figure 4.32.

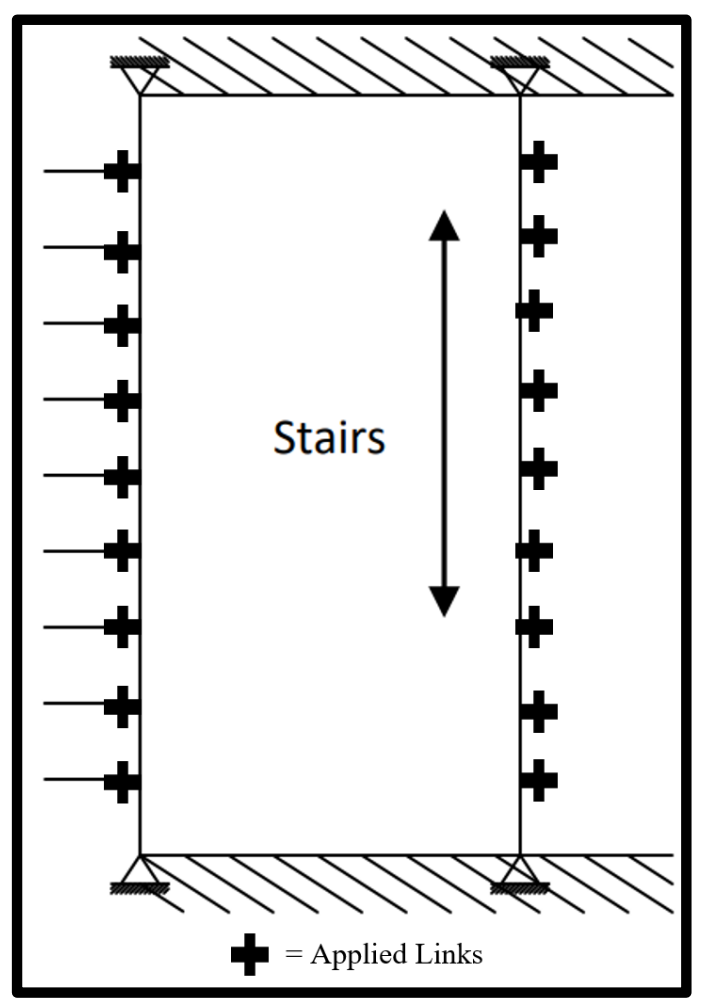

Figure 4.32: Type 1 Stair with Links Schematic

The same out-of-plane horizontal stiffness used to model the Type 1 staircase in the previous section, $438 \mathrm{kN} / \mathrm{m}$ (2.5 kips/in), was applied in the U2 direction, the direction perpendicular to the wall plane. The out-of-plane stiffness was only applied to the links on the wall stringer, and not the face stringer. The second step was to then apply an in-plane translational stiffness in the $\mathrm{U} 1$ and $\mathrm{U} 3$ direction, the directions parallel to the 
wall plane, so that the model was tuned to the experimentally determined first mode frequency of the Type 1 staircase. The translational stiffness in the U1 and U3 direction was applied to both sides of the staircase.

After the out-of-plane, U2 direction, stiffness of $438 \mathrm{kN} / \mathrm{m}(2.5 \mathrm{kip} / \mathrm{in})$ was applied, it was determined that an in-plane stiffness of $438 \mathrm{kN} / \mathrm{m}$ (2.5 kip/in) resulted in a first mode frequency similar to the model that used rotational restraints. The comparison of the first and second mode frequencies to the experimentally determined frequency value is shown in Table 4.27 and Table 4.28, respectively.

Table 4.27: Type 1 Mode 1 Frequency with 438kN/m Links in U1, U2, and U3 Direction

\begin{tabular}{|c|c|c|c|}
\hline Stair Flight & $\begin{array}{c}\text { Experimentally } \\
\text { determined Mode 1 } \\
\text { Frequency (Hz) }\end{array}$ & $\begin{array}{c}\text { SAP2000 Mode 1 } \\
\text { Frequency (Hz) }\end{array}$ & $\begin{array}{c}\text { Difference in } \\
\text { Frequency (\%) }\end{array}$ \\
\hline Flight 1 & 20.11 & 19.32 & $4.01 \%$ \\
\hline Flight 3 & 21.61 & 19.32 & $11.19 \%$ \\
\hline Average & 20.86 & 19.32 & $7.67 \%$ \\
\hline
\end{tabular}

Table 4.28: Type 1 Mode 2 Frequency with 438kN/m Links in U1, U2, and U3 Direction

\begin{tabular}{|c|c|c|c|}
\hline Stair Flight & $\begin{array}{c}\text { Experimentally } \\
\text { determined Mode 2 } \\
\text { Frequency (Hz) }\end{array}$ & $\begin{array}{c}\text { SAP2000 Mode 2 } \\
\text { Frequency (Hz) }\end{array}$ & $\begin{array}{c}\text { Difference in } \\
\text { Frequency (\%) }\end{array}$ \\
\hline Flight 1 & 30.39 & 35.35 & $15.09 \%$ \\
\hline Flight 3 & 33.33 & 35.35 & $5.88 \%$ \\
\hline Average & 31.86 & 35.35 & $10.39 \%$ \\
\hline
\end{tabular}

The application of a $438 \mathrm{kN} / \mathrm{m}$ (2.5 kips/in) lead to a first and second mode frequency of $+/-10 \%$ on average compared to the experimentally determined Type 1 stair 
frequency. Similar to before, a balance between the over and under prediction of the first and second mode frequencies was maintained to preserve the mode shape response of the model. Also as before, in addition to just attempting to match the first and second mode frequency, maintaining the same mode shape behavior was important in making sure that the model was still representing the correct modal behavior of the structure.

For the mode shape comparison, as before, the mode shape of the Type 1 SAP2000 model was compared to the experimentally determined Flight 3 mode shape. The experimental and modeled first mode shape can be found in Figure 4.33 and Figure 4.34, respectively. The experimental and modeled second mode shape can be found in Figure 4.35 and Figure 4.36.

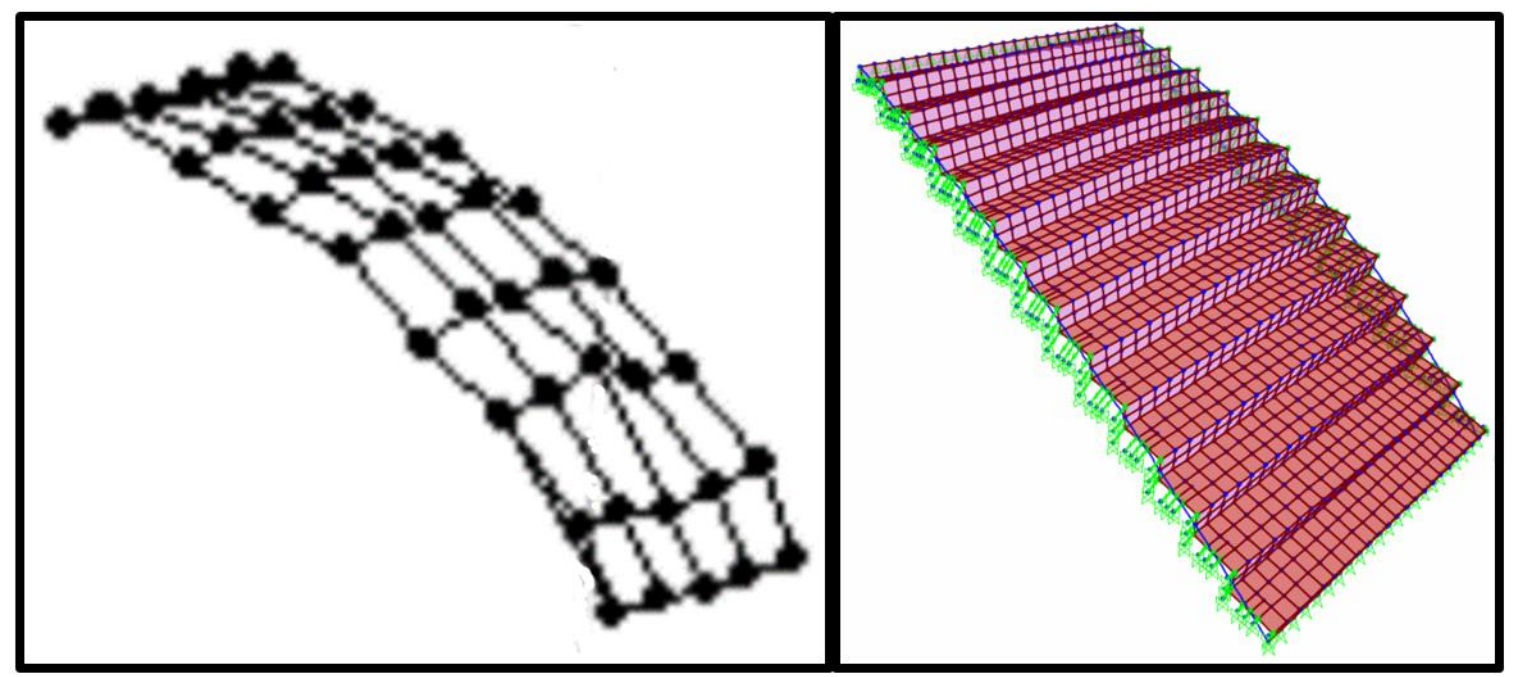

Figure 4.33: Type 1 Experimental Mode 1 (Left)

Figure 4.34: Type 1 SAP2000 Mode 1 Modeled only with Links (Right) 


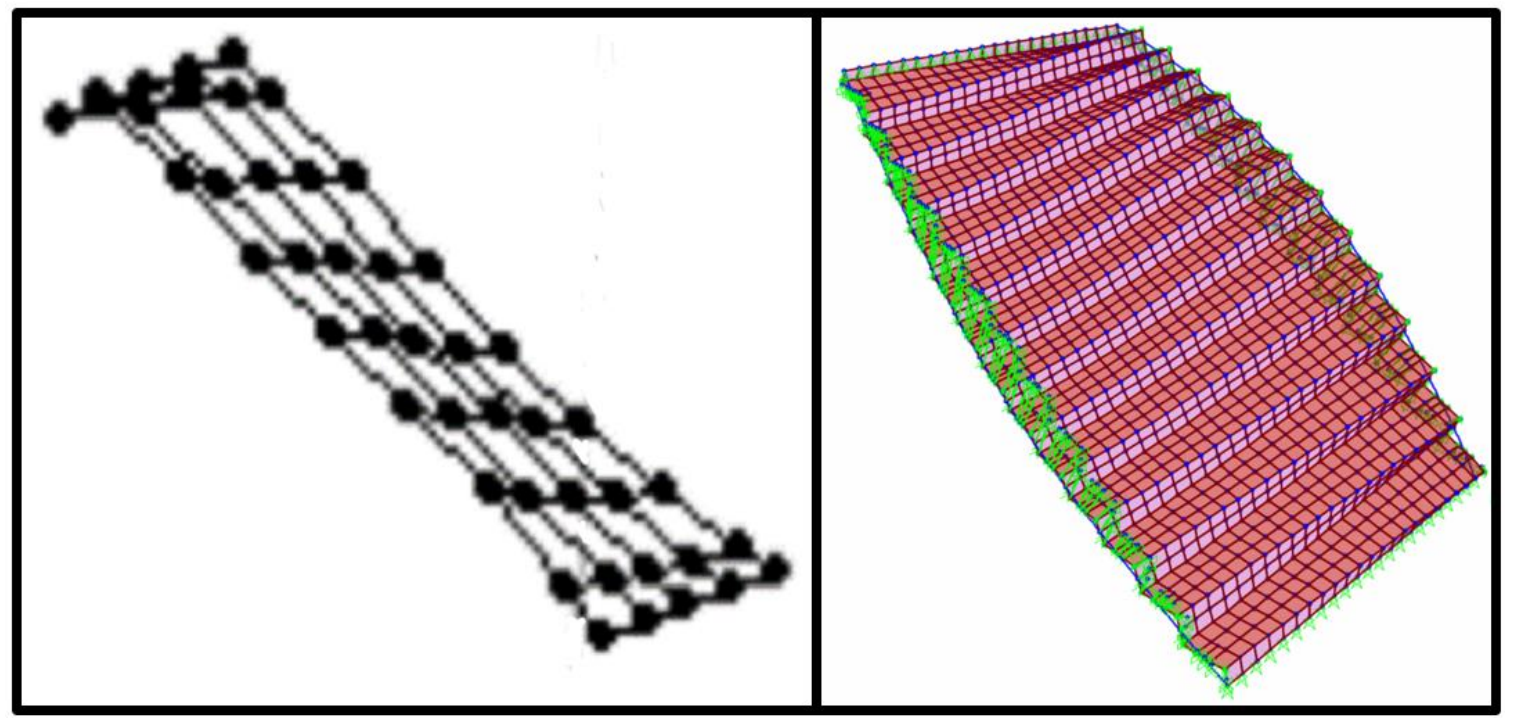

Figure 4.35: Type 1 Experimental Mode 2 (Left)

Figure 4.36: Type 1 SAP2000 Mode 2 Modeled only with Links (Right)

The first and second mode shape behavior between both the model and the experimentally determined mode shapes demonstrated the same respective behavior. In addition, the first and second mode frequencies were within approximately $10 \%$ of the experimentally determined frequencies on average. This difference was determined to be acceptable for design purposes, based on the discussions by Davis and Avci (2015). In their research, Davis and Avci (2015) utilized first mode frequency predictive equations to predict the first mode frequencies of two staircases. They determined that the predicted frequencies for the two staircases using these equations differed from the experimental results by $35.5 \%$ and $17.1 \%$, respectively. Even though they found these types of variations between the predicted and measured first mode frequencies, Davis and Avci (2015) determined that the predictions were "accurate enough for design usage". Since the difference between the predicted and measured frequencies found in this thesis, using 
the FEM technique, were closer in matching than the estimates by Davis and Avci (2015), the differences between the model and experimental results were determined to be small enough to be an acceptable procedure. As a result, it was determined that applying translational links with a $438 \mathrm{kN} / \mathrm{m}$ (2.5 kips/in) stiffness in all orthogonal directions provided accurate enough results to be useful to designers. It was then identified that the use of translational links could be used as an alternative technique to applying rotational restraints at the end of the stringers for the Type 1 staircase, and an alternative technique for modeling the unknown stiffness created by a variation in boundary conditions.

\section{Alternative Modeling for Type 2 Stairs}

The next step was to model the Type 2 staircase. The first step to alternatively modeling the Type 2 staircase with links was to remove the translational stiffness in the axis perpendicular to the wall, the U2 direction. In this model, the links still maintained their $438 \mathrm{kN} / \mathrm{m}$ (2.5 kips/in) in-plane translational stiffness parallel to the wall, the U1 and U3 direction. If the stiffness applied in the direction parallel to the wall is truly an alternative for modeling the unknown stiffness, previously represented by rotational springs, then removing the out-of-plane, U2, direction stiffness would result in a model similar to the Type 2 staircase. Therefore, after removing the out-of-plane stiffness, a comparison of the first and second mode frequencies was made between the model and experimental results of the Type 2 stair, which is presented in Table 4.29 and Table 4.30. 
Table 4.29: Type 2 Mode 1 Frequency with 438kN/m Links in In-Plane Direction

\begin{tabular}{|c|c|c|c|}
\hline Stair Flight & $\begin{array}{c}\text { Experimentally } \\
\text { determined Mode1 } \\
\text { Frequency }(\mathrm{Hz})\end{array}$ & $\begin{array}{c}\text { SAP2000 Mode1 } \\
\text { Frequency (Hz) }\end{array}$ & $\begin{array}{c}\text { Difference in } \\
\text { Frequency (\%) }\end{array}$ \\
\hline Flight 2 & 16.48 & 16.92 & $2.63 \%$ \\
\hline Flight 4 & 16.11 & 16.92 & $4.90 \%$ \\
\hline Average & 16.30 & 16.92 & $3.73 \%$ \\
\hline
\end{tabular}

Table 4.30: Type 2 Mode 2 Frequency with 438kN/m Links in In-Plane Direction

\begin{tabular}{|c|c|c|c|}
\hline Stair Flight & $\begin{array}{c}\text { Experimentally } \\
\text { determined Mode2 } \\
\text { Frequency }(\mathrm{Hz})\end{array}$ & $\begin{array}{c}\text { SAP2000 Mode2 } \\
\text { Frequency (Hz) }\end{array}$ & $\begin{array}{c}\text { Difference in } \\
\text { Frequency (\%) }\end{array}$ \\
\hline Flight 2 & 31.86 & 29.56 & $7.49 \%$ \\
\hline Flight 4 & 30.4 & 29.56 & $2.80 \%$ \\
\hline Average & 31.13 & 29.56 & $5.17 \%$ \\
\hline
\end{tabular}

The application of a $438 \mathrm{kN} / \mathrm{m}$ (2.5 kips/in) stiffness to edge links in the direction parallel to the plane of the wall lead to a first mode frequency that was within approximately $3.7 \%$ of the average experimentally determined first mode frequency. It also lead to a second mode frequency prediction that differed by approximately $5.2 \%$, compared to the experimental frequency of the Type 2 staircase. Therefore, it was determined that using translational links to model the unknown stiffness, created by the boundary conditions, resulted in a model that was representative of the first and second mode frequency of the actual structure.

However, as before, the mode shape behavior of the SAP2000 model and the experimentally determined mode shapes must be compared. Flight 2 was used to 
represent the Type 2 experimental mode shape in the following figures. The experimental and analytical mode shapes for the first mode can be viewed in Figure 4.37 and Figure 4.38. The experimental and modeled mode shapes for the second mode can be viewed in Figure 4.39 and Figure 4.40.

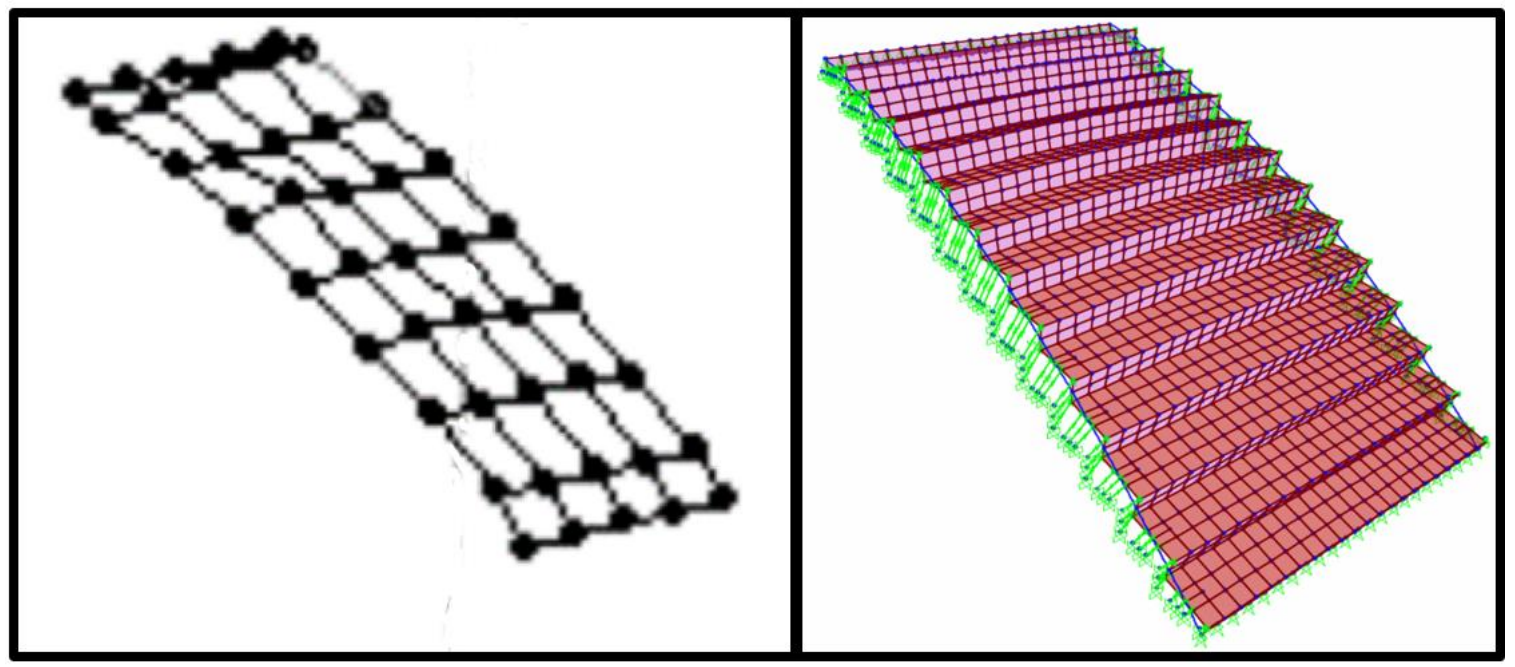

Figure 4.37: Type 2 Experimental Mode 1 (Left)

Figure 4.38: Type 2 SAP2000 Mode 1 Modeled with only Links (Right)

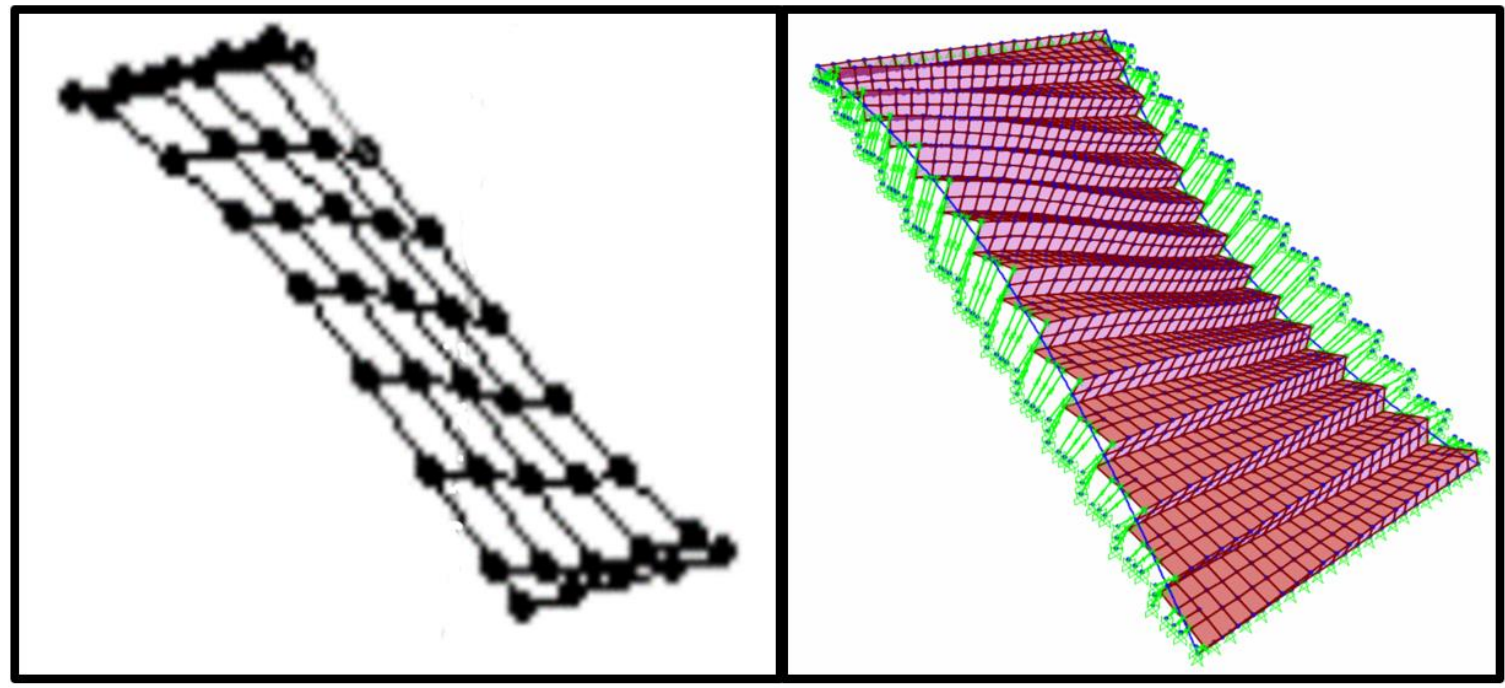

Figure 4.39: Type 2 Experimental Mode 2 (Left)

Figure 4.40: Type 2 SAP2000 Mode 2 Modeled with only Links (Right) 
The FEM and experimental first and second modes both had matching mode shapes and frequencies that were within $10 \%$ of each other, respectively. Therefore, applying the translational links with a $438 \mathrm{kN} / \mathrm{m}$ (2.5 kips/in) stiffness in the in-plane direction was verified to be an alternative technique to applying $5000 \mathrm{kN}-\mathrm{m} / \mathrm{rad}$ rotational spring restraints to the end of the stringers for the Type 2 staircase.

\subsubsection{Effect of Translational Stiffness on First and Second Mode Frequency}

In order to understand the effect that in-plane and out-of-plane translational stiffness has on the first and second mode frequency, two scenarios were tested to understand this behavior. Both scenarios utilized the model with joint links on both sides of the stair model. The first scenario altered the in-plane translational stiffness in the U1 and $\mathrm{U} 3$ direction on both sides of the stairs while leaving the out-of-plane, U2, direction stiffness to be zero. A visualization of the stiffness change in the corresponding orthogonal directions is depicted in Figure 4.41.

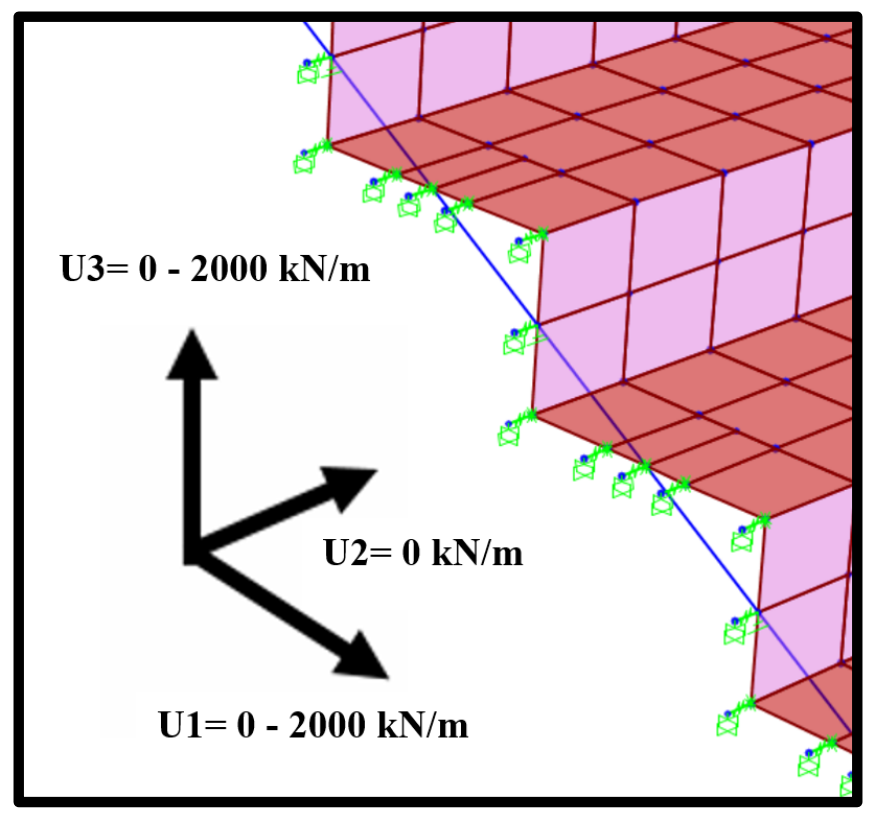

Figure 4.41: Scenario 1 Stiffness Change 
The second scenario alters the out-of-plane translational stiffness, U2, direction on one side of the staircase only, while leaving the in-plane stiffness, U1 and U3, to be zero. A visualization of which stiffness is changing in the corresponding orthogonal direction is depicted in Figure 4.42.

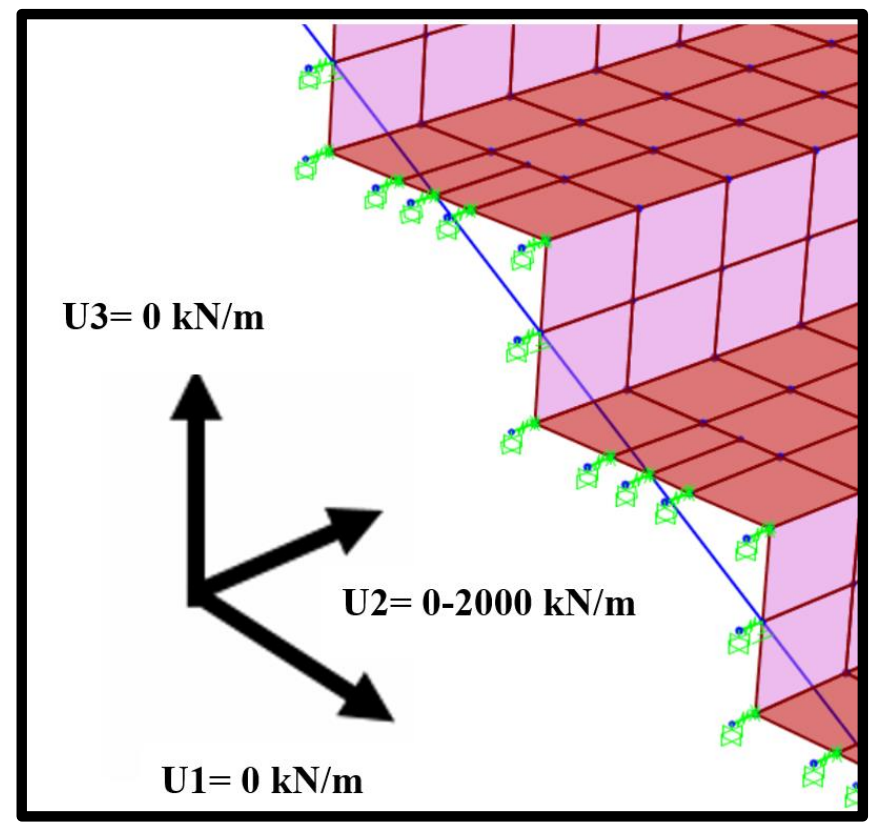

Figure 4.42: Scenario 2 Stiffness Change

The purpose of the two scenarios was to further the understanding of how a change in both the in and out-of-plane stiffness affects the dynamic behavior of the structure. The applied in-plane and out-of-plane stiffness used in the previous study, $438 \mathrm{kN} / \mathrm{m}(2.5 \mathrm{kip} / \mathrm{in})$, is denoted in both frequency versus stiffness graphs to reference where the stiffness applied to the model's links falls in relation to the max allowed stiffness. The max allowed stiffness is the stiffness applied just before the mode shape behavior changes. 
The first scenario involved adjusting the in-plane stiffness while leaving the outof-plane stiffness, the plane perpendicular to the wall, to be zero. The in-plane stiffness adjustments were made to the links on both sides of the staircase. The influence of the change in stiffness to the first and second mode frequency was determined by altering the stiffness from $0 \mathrm{kN} / \mathrm{m}$ to $2000 \mathrm{kN} / \mathrm{m}$. The stiffness was increased in increments of 100 $\mathrm{kN} / \mathrm{m}$. The resulting response of the first and second mode frequency to the change in stiffness can be found in Figure 4.43 and Figure 4.44, respectively.

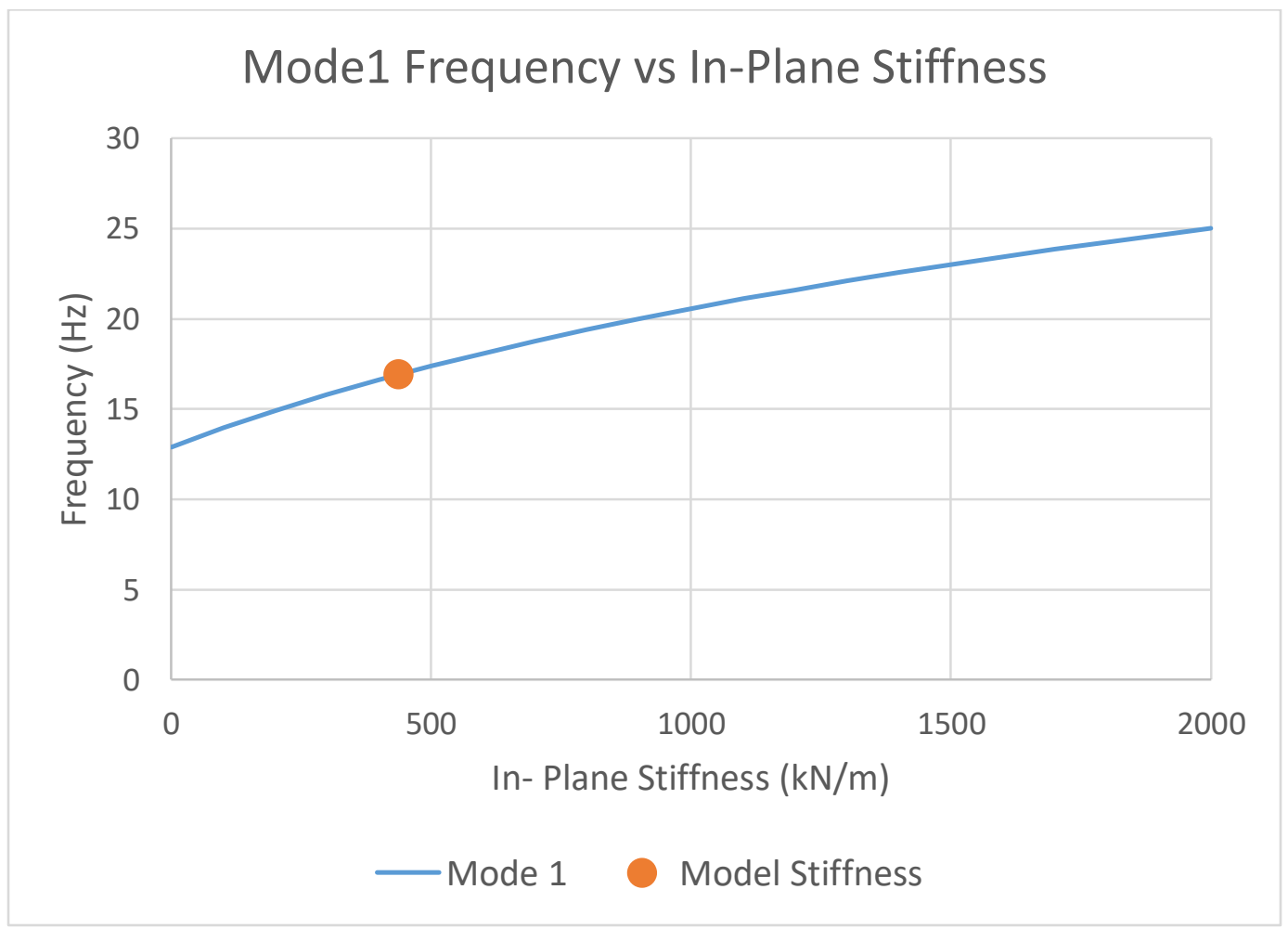

Figure 4.43: Mode 1 Frequency vs. In-Plane Stiffness 


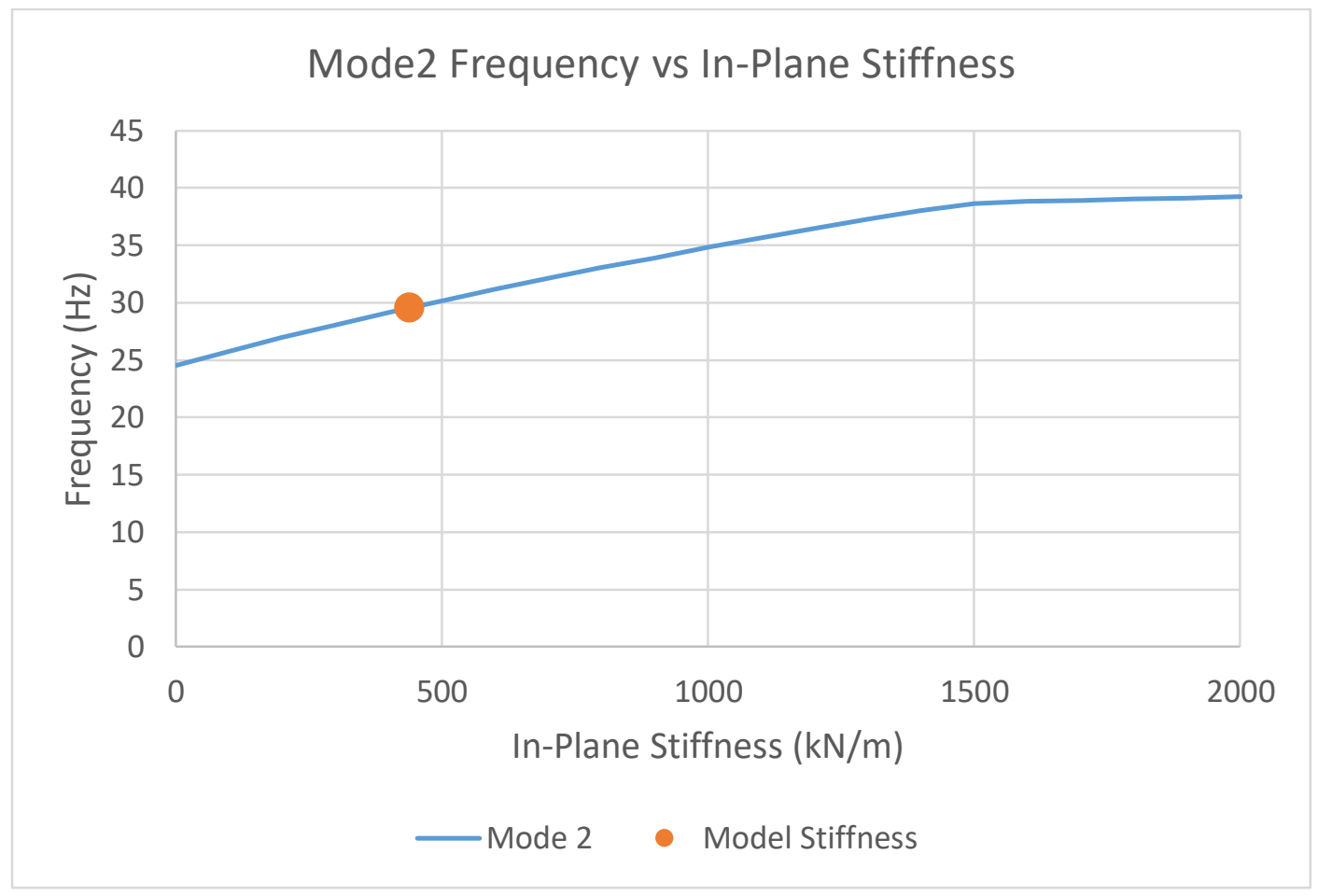

Figure 4.44: Mode 2 Frequency vs. In-Plane Stiffness

After adjusting the in-plane stiffness, it became evident that as the in-plane stiffness increased, the first mode shape remained fairly unchanged, as seen in the comparison of Figure 4.45 and Figure 4.46. 


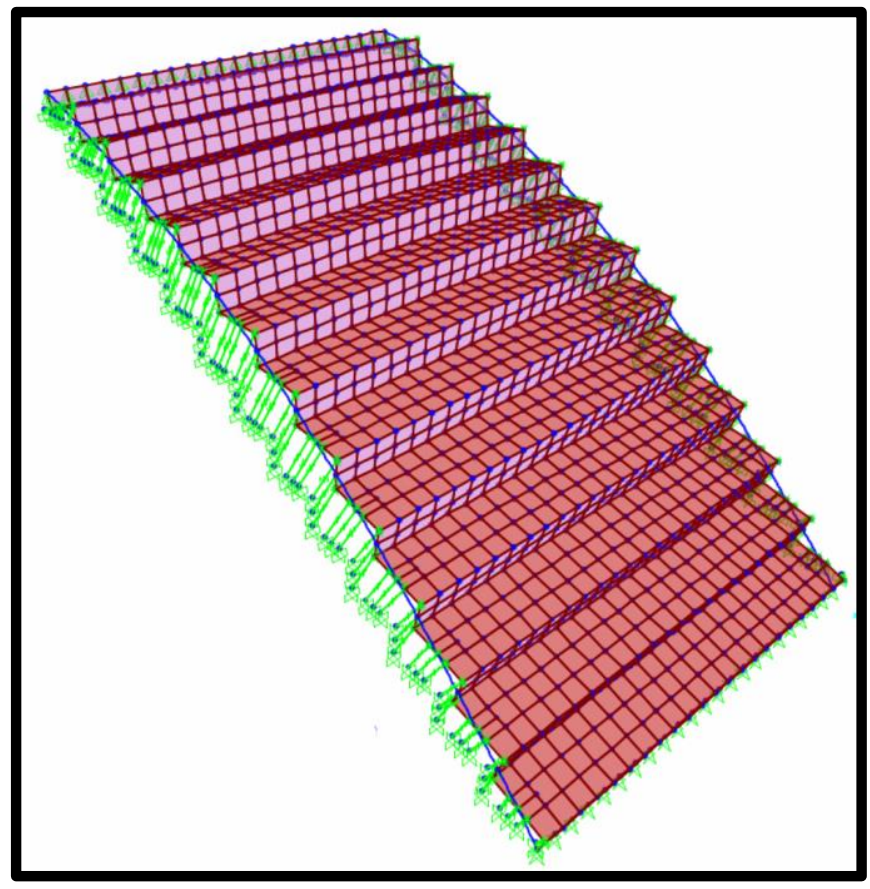

Figure 4.45: Mode 1 Shape, 0 kN/m In-plane Stiffness

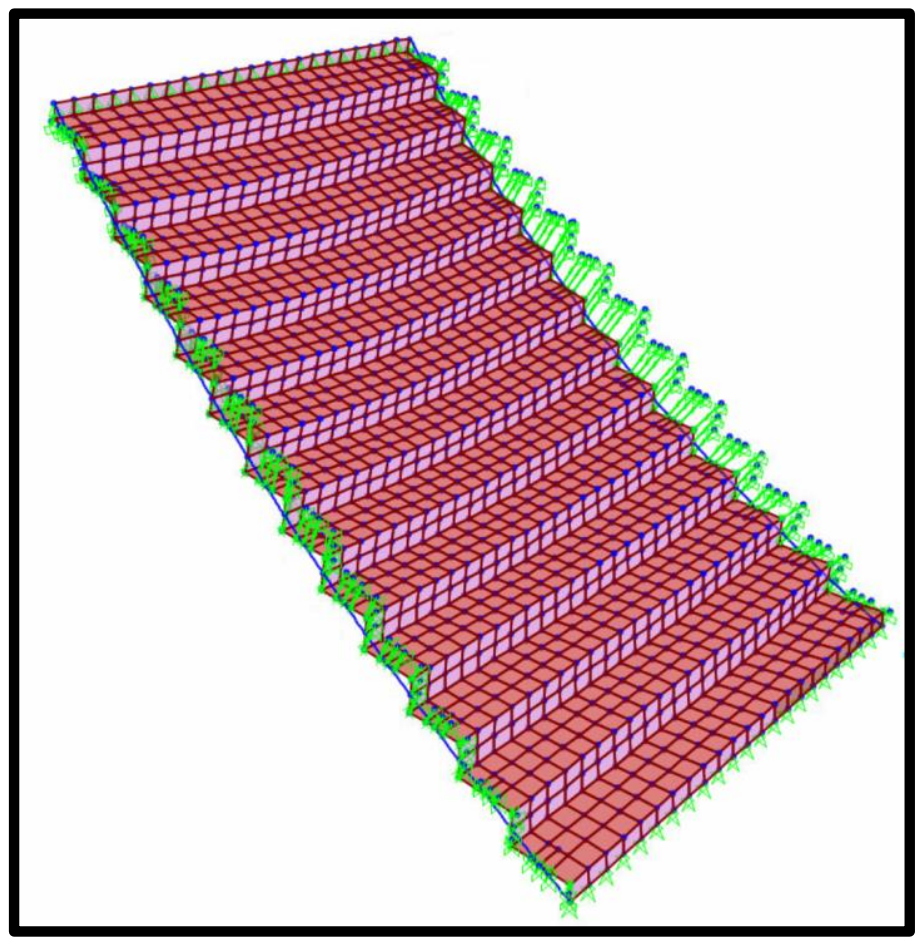

Figure 4.46: Mode 1 Shape, 1500 kN/m applied In-plane Stiffness 
However, as the applied stiffness increased, the rate at which the frequency was changing began to reduce. Therefore, the larger the stiffness gets, the less of an impact the incremental change in stiffness has on the first mode frequency. On the other hand, the second mode frequency maintained a fairly consistent rate of change as the stiffness increased until a break in the slope occurred, flattening out the slope of the graph. This defined change in slope occurred once the stiffness became greater than $1500 \mathrm{kN} / \mathrm{m}$. Once the stiffness was larger than the value where the change in slope occurred, the mode shape behavior changed as well. At $1500 \mathrm{kN} / \mathrm{m}$, the second mode shape changed from a torsional response to a second mode response having a node in across the middle stair of the staircase. The difference in the second mode shape can be seen in the difference between Figure 4.47 and Figure 4.48. Therefore, after a 1500 kN/m stiffness was applied, the model was no longer representative of the actual structure.

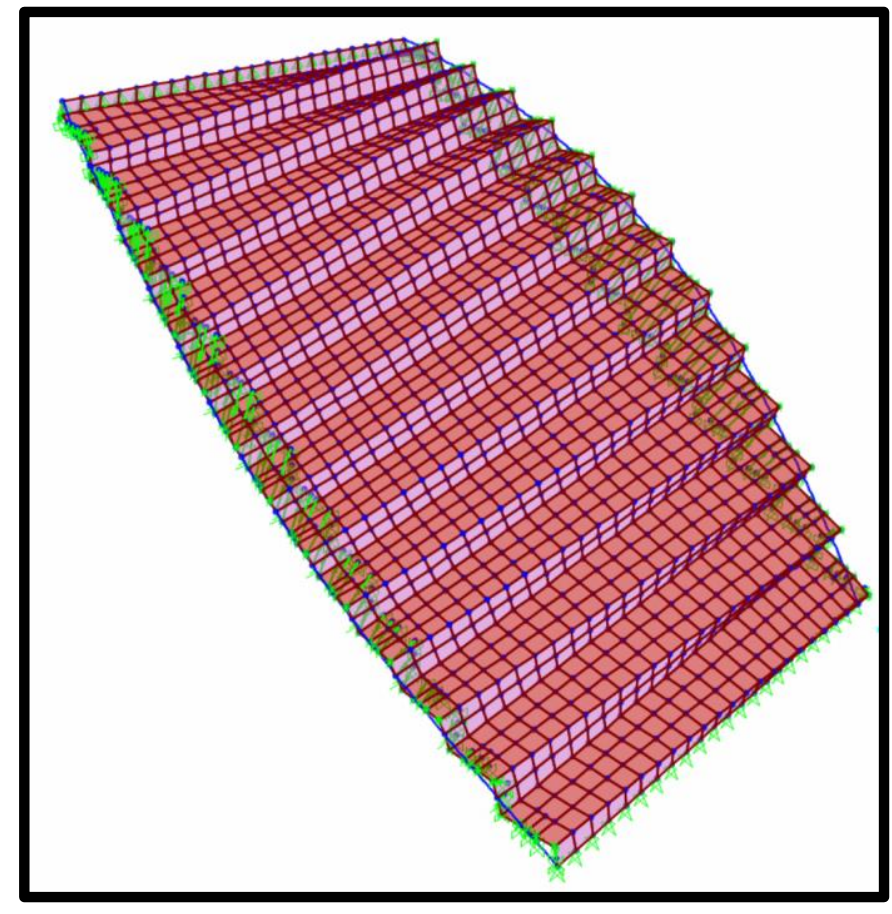

Figure 4.47: Mode 2 Shape, 0 kN/m applied In-Plane Stiffness 


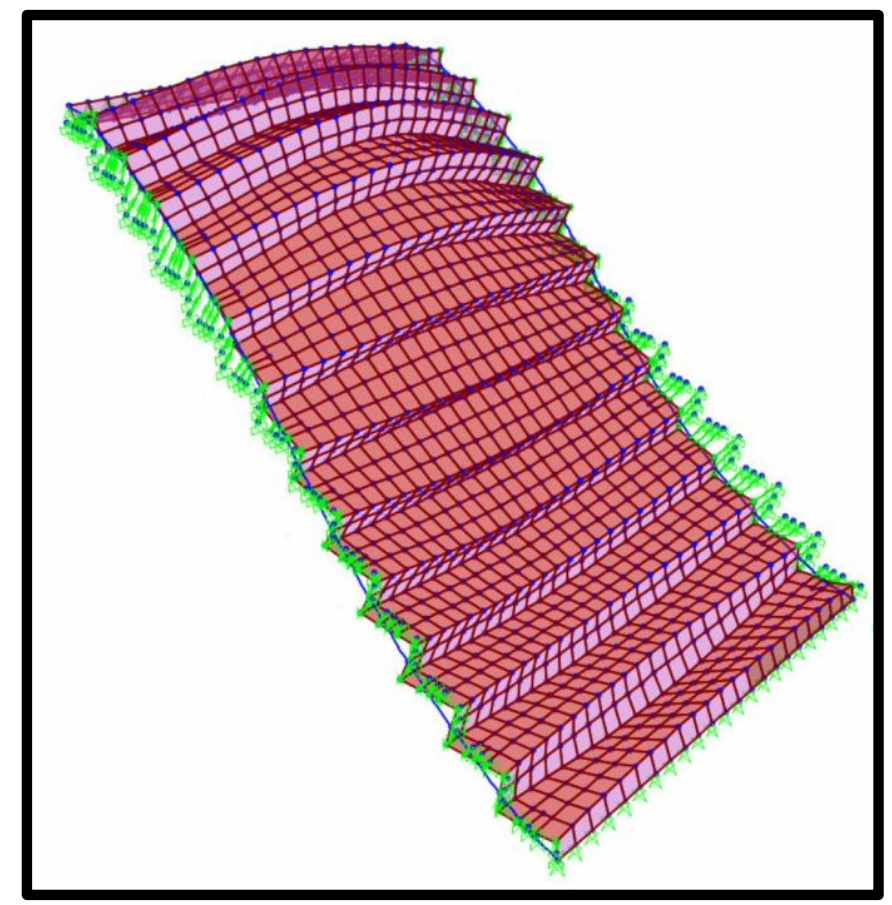

Figure 4.48: Mode 2 Shape, 1500kN/m applied In-Plane Stiffness

The second scenario for determining the influence of translational stiffness on the first and second mode frequencies involved adjusting the out-of-plane stiffness, the plane perpendicular to the wall, while leaving the in-plane stiffness, the plane parallel to the wall, to be zero. The out-of-plane stiffness was adjusted only to the links on one side of the staircase. The translational stiffness was adjusted from $0 \mathrm{kN} / \mathrm{m}$ to $2000 \mathrm{kN} / \mathrm{m}$, in increments of $100 \mathrm{kN} / \mathrm{m}$. The resulting graphs for the first and second mode frequency versus applied stiffness can be seen in Figure 4.49 and Figure 4.50, respectively. 


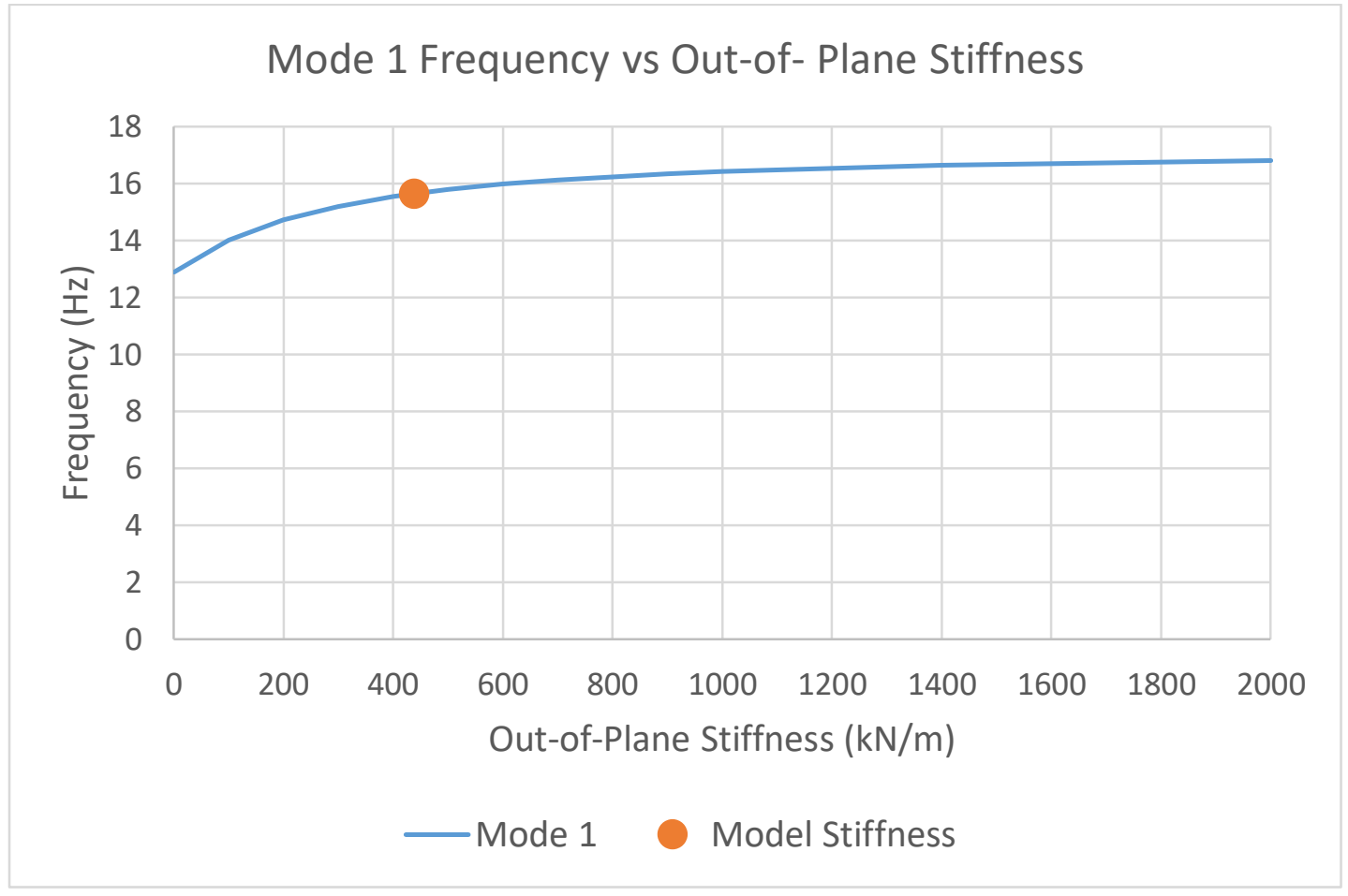

Figure 4.49: Mode 1 Frequency vs. Out-of-Plane Stiffness

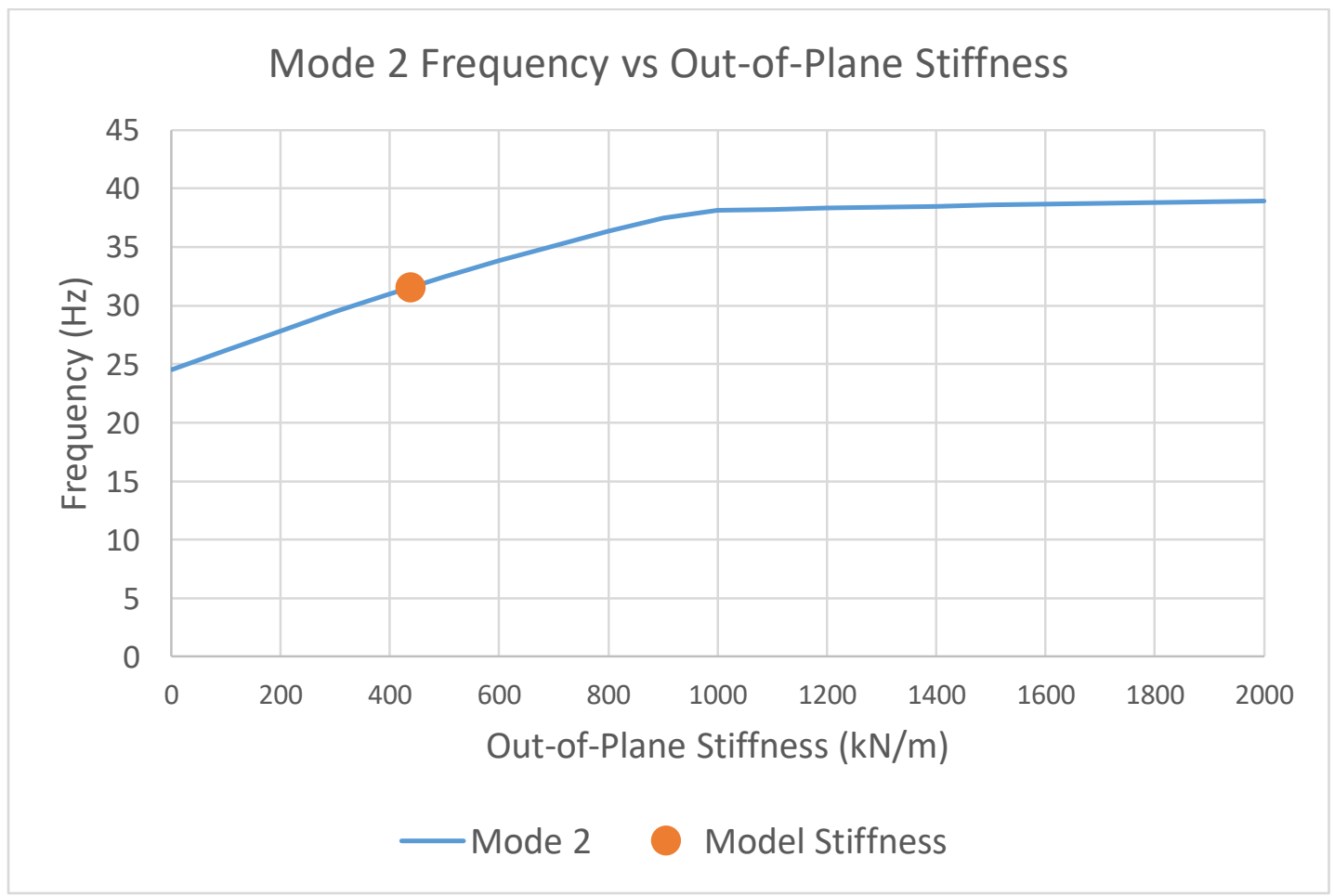

Figure 4.50: Mode 2 Frequency vs. Out-of-Plane Stiffness 
As the out-of-plane stiffness increased, the first mode shape flexure behavior remained unchanged. However, as the stiffness increased the stringer with the out of plane stiffness applied to the links had less deflection, as seen in Figure 4.51 and Figure 4.52. In addition, the rate at which the frequency was changing in relation to the amount of stiffness being applied became much smaller as the stiffness increased, approaching a slope of 0 .

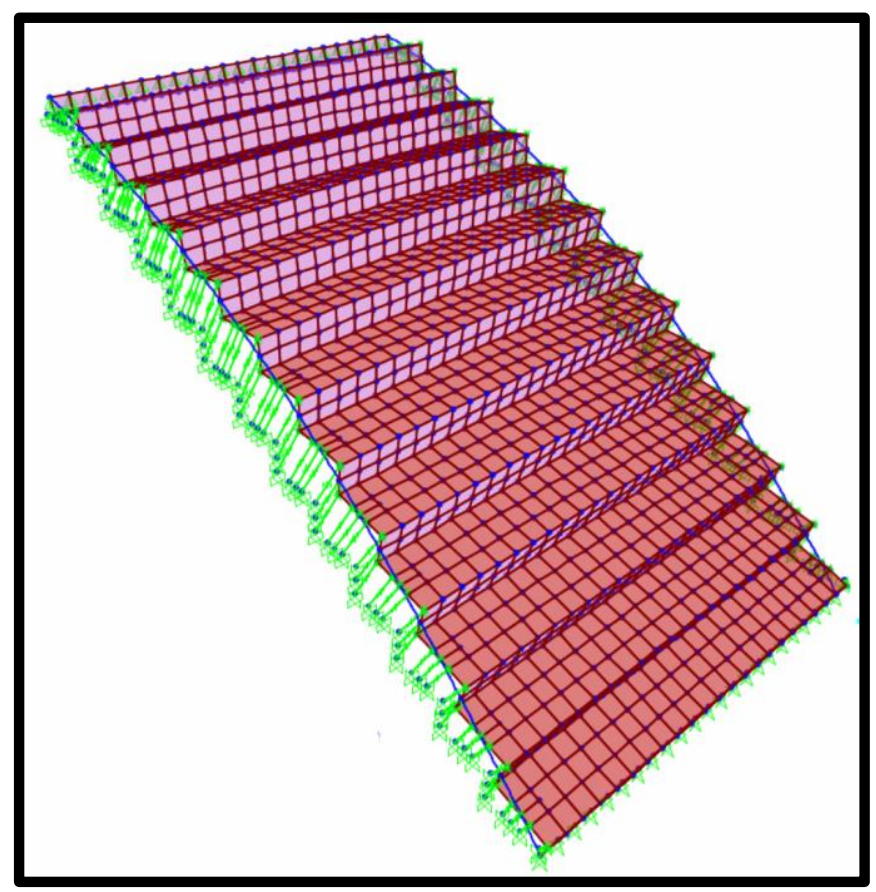

Figure 4.51: Mode 1 Shape, 0 kN/m applied Out-of-plane Stiffness 


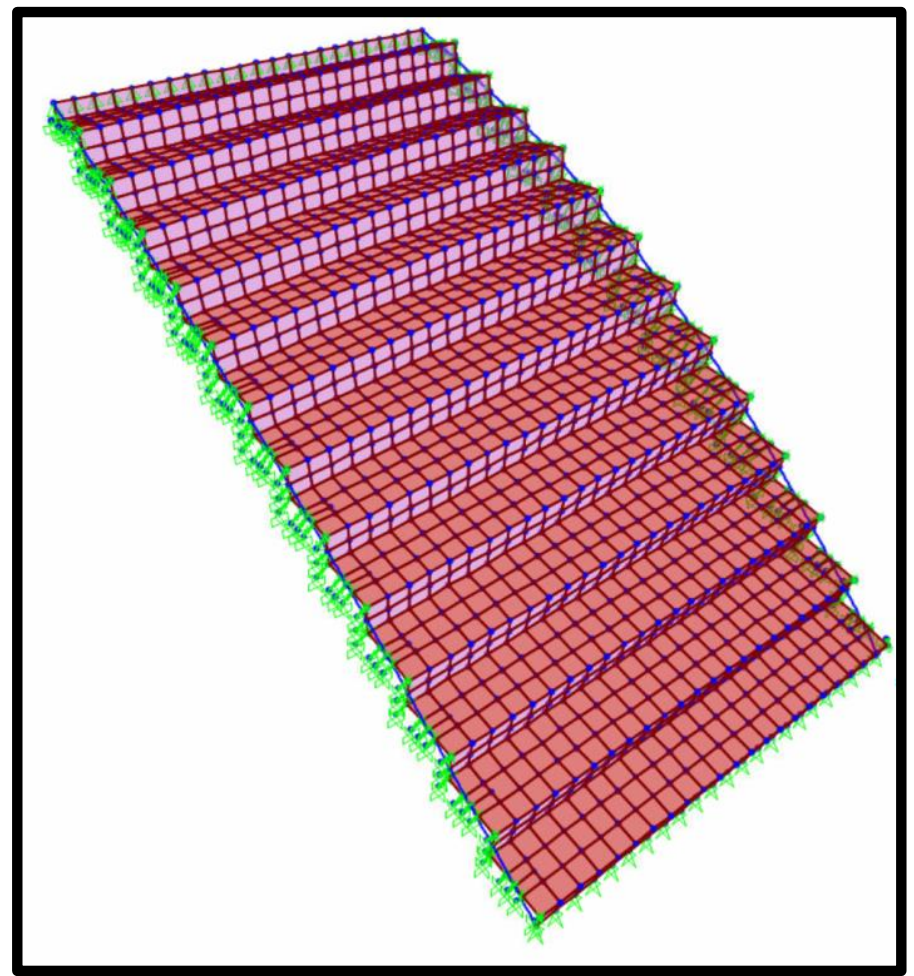

Figure 4.52: Mode 1 Shape, 1000kN/m applied Out-of-plane Stiffness

The second mode frequency versus out-of-plane stiffness maintained a fairly consistent slope until the stiffness became greater than $1000 \mathrm{kN} / \mathrm{m}$. Once the stiffness became greater than this amount, the mode shape behavior for the second mode changed from a torsional response, as seen in Figure 4.53, to a mode response with a node across the middle step of the staircase, as seen in Figure 4.54. This response change can be viewed in the second mode frequency graph in Figure 4.50 by the break in the slope at around $1000 \mathrm{kN} / \mathrm{m}$ in the second mode 


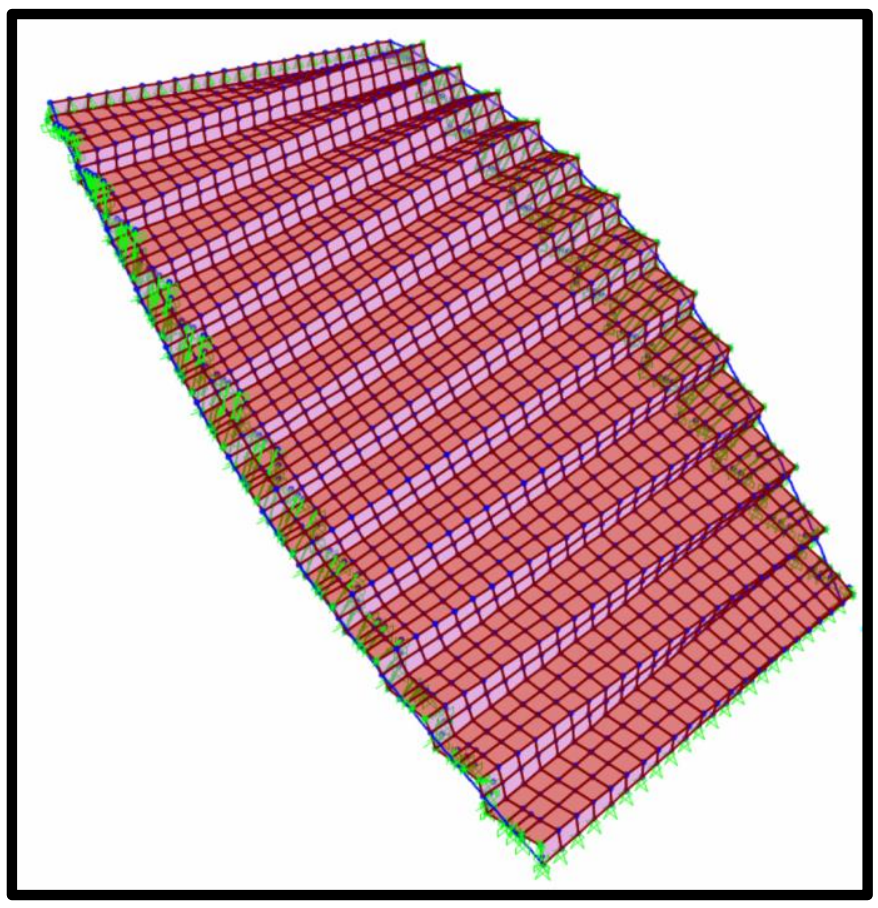

Figure 4.53: Mode 2 Shape, 0 kN/m applied Out-of-Plane Stiffness

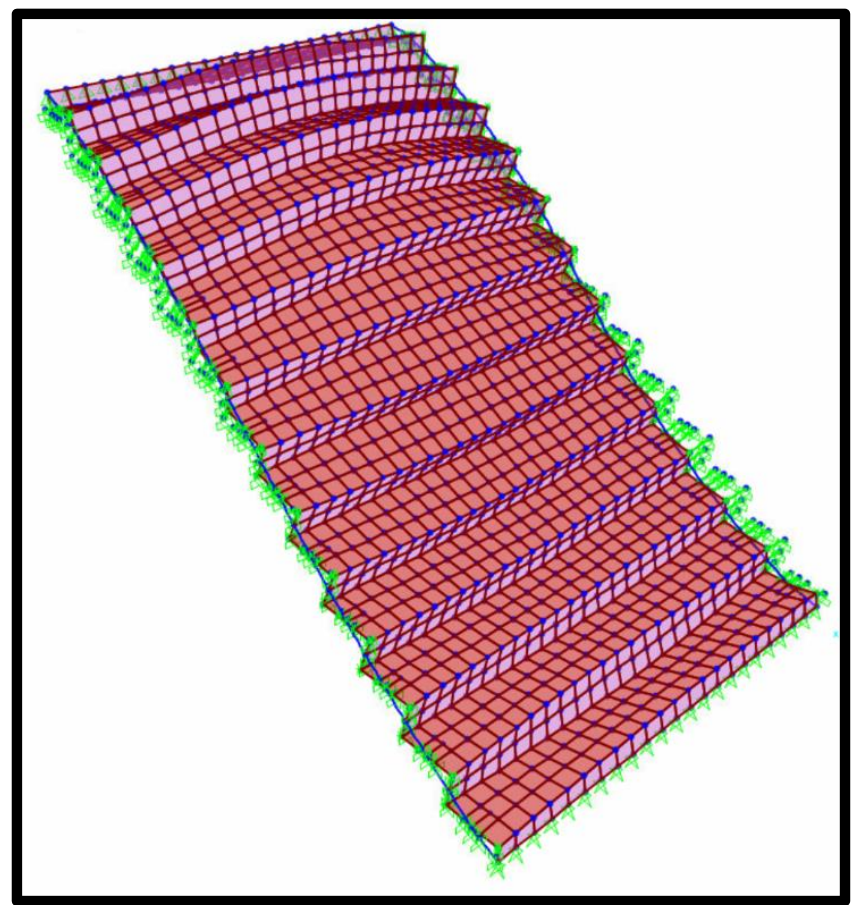

Figure 4.54: Mode 2 Shape, 1000 kN/m applied Out-of-Plane Stiffness 
A comparison of both sets of graphs identified how the in and out-of-plane stiffness differ in their influence on the first and second mode frequencies and shapes. When comparing both sets of graphs, it was observed that an increase in the in-planestiffness created a much larger change in the first mode frequency than when increasing the out-of-plane stiffness. However, the change in the out-of-plane stiffness had a much larger effect than the in-plane stiffness on the second mode frequency, as denoted by the slopes of the graph. In addition, it took an in-plane stiffness of $1500 \mathrm{kN} / \mathrm{m}$ to create a change in the mode shape behavior, compared to the lower $1000 \mathrm{kN} / \mathrm{m}$ out-of-plane stiffness needed to change the mode shape behavior of the model.

In summary, a change in the in-plane stiffness, the direction parallel to the wall, had a greater impact on the first mode frequency, but a change in the out-of-plane stiffness, the direction perpendicular to the wall, had a greater impact on the second mode frequency.

\subsubsection{AISC Design Guide 11 First Mode Frequency Equation Application}

The final topic of interest in this research is the applicability of the AISC Design Guide 11 equation for predicting the fundamental frequency. The equation was adapted from the simply supported beam equation in Murray et al. (2016). The equation in the design guide was also utilized in Davis and Avci (2015). This equation has been validated for long slender staircases which typically have natural frequencies lower than $10 \mathrm{~Hz}$. However, to the knowledge of the author, this equation has not been validated for shorter span staircases with first mode frequencies larger than $10 \mathrm{~Hz}$. Therefore the goal of this section is to assess the application of this equation to shorter span staircases with 
first mode frequencies larger than $10 \mathrm{~Hz}$. The equation to predict the fundamental frequency is noted in Equation (4.4).

$$
f_{n}=\frac{\pi}{2} \sqrt{\frac{g E I}{W L^{3}}}
$$

Where $g\left(\frac{m}{s^{2}}\right)$ is the acceleration due to gravity. E (GPA) is the elastic modulus of the stringer material. I $\left(\mathrm{mm}^{4}\right)$ is the moment of inertia of the stringer. $W(\mathrm{~N})$ is the weight of the stair. $L(\mathrm{~m})$ is the diagonal length of the stringer.

This equation is the natural frequency equation of a simply supported beam and assumes that a staircase acts as a simply supported beam with a uniform mass distribution. The equation also assumes that the stiffness provided in the structure is created by the stringers. The application of the equation to the Type 2 staircase is as follows.

Where, $g=386\left(\frac{i n}{s^{2}}\right)=9.81\left(\frac{m}{s^{2}}\right), E=29000(\mathrm{ksi}) 200$ GPA, I=129 $\left(i n^{4}\right)^{*}$ 2stringers $=111 \mathrm{E} 6$ $\left(\mathrm{mm}^{4}\right), \mathrm{W}=4300(\mathrm{lb})=19127(\mathrm{~N})$, and $\mathrm{L}=169($ in. $)=4.29(\mathrm{~m})$.

$$
\begin{gathered}
f_{n}=\frac{\pi}{2} \sqrt{\frac{\left(386 \frac{i n}{s^{2}}\right) *(29 \mathrm{E} 6 \mathrm{psi}) *\left(258 \mathrm{in}^{4}\right)}{(4300 \mathrm{lb}) *(169 \mathrm{in} .)^{3}}}=\mathbf{1 8 . 5 3} \mathbf{~ H z} \\
f_{n}=\frac{\pi}{2} \sqrt{\frac{\left(\left(9.81 \frac{\mathrm{m}}{\mathrm{s}^{2}}\right) *(200 \mathrm{GPA}) *\left(111 \mathrm{E} 6 \mathrm{~mm}^{4}\right)^{*} 1 \mathrm{E} 9\right.}{(19127 \mathrm{~N}) *(4.29 \mathrm{~m})^{3} * 1000^{4}}}=\mathbf{1 8 . 5 3 ~ \mathbf { ~ H z }}
\end{gathered}
$$


The Type 2 staircase was used to determine the use of this equation because this type of stair only has end restraint boundary conditions, which match the boundary condition assumptions of the equation. The comparison of the natural frequency predicted using this equation for the Type 2 staircase is found in Table 4.31 .

Table 4.31: Comparison of Experimentally Determined Natural Frequency to Predicted Natural Frequency for Type 2 Staircase

\begin{tabular}{|c|c|c|c|}
\hline $\begin{array}{c}\text { Stair Case Flight } \\
\text { Type 2 }\end{array}$ & $\begin{array}{c}\text { Experimentally } \\
\text { Determined Mode 1 } \\
\text { Frequency (Hz) }\end{array}$ & $\begin{array}{c}\text { Equation 4-7 } \\
\text { predicted Mode 1 } \\
\text { Frequency (Hz) }\end{array}$ & Difference (\%) \\
\hline Flight 2 & 16.48 & 18.53 & $11.71 \%$ \\
\hline Flight 4 & 16.11 & 18.53 & $13.97 \%$ \\
\hline Average & 16.30 & 18.53 & $12.81 \%$ \\
\hline
\end{tabular}

It can be observed from comparing the experimentally determined first mode frequency to the first mode frequency predicted by the AISC equation that on average the first mode frequency for the Type 2 staircase was over predicted by about $13 \%$. A higher calculated frequency implies a higher stiffness, which leads to smaller deflections. Since the frequency predicted by Equation (4.4) is an overestimate of the real-life experimental frequency value, the design guide implies that the stairs are stiffer than suggested by the experimental data, which is not conservative. However, this may not be a concern for serviceability because both the predicted and experimental frequencies for the staircases in this study satisfy the $10 \mathrm{~Hz}$ serviceability criteria previously mentioned. 
It is important to better understand why the equation over predicted the first mode frequency in order to better understand the equation's applicability to short-span staircases. Therefore, one potential explanation for this over prediction could be due to the fact that the aspect, length-to-width, ratio of the staircases tested in this study were smaller than the aspect ratio of stairs in other literature, which underestimated the frequency using similar conservative stiffness estimates. In this thesis, the flights tested had a length of $4.3 \mathrm{~m}$ (14.1 ft.) and a width of $2.2 \mathrm{~m}$ (7.25ft), for an aspect ratio of 1.9. However, the use of the equation in other literature such as Davis and Avci (2015) tested staircases with aspect ratios of greater than 4.

In order to better understand how the aspect ratio influences the predicted first mode frequency of the stair structure using Equation (4.4), a parametric study was conducted using SAP2000. The tuned model using the $5000 \mathrm{kN}-\mathrm{m} / \mathrm{rad}$ springs was used, and the aspect ratio was adjusted by increasing the length of the stringers and increasing the number of steps. The ratio was tested at roughly every whole number between 2 thru 6. Images of the models with the length-to-width ratio of approximately three and four can be found in Figure 4.55 and Figure 4.56, respectively. 


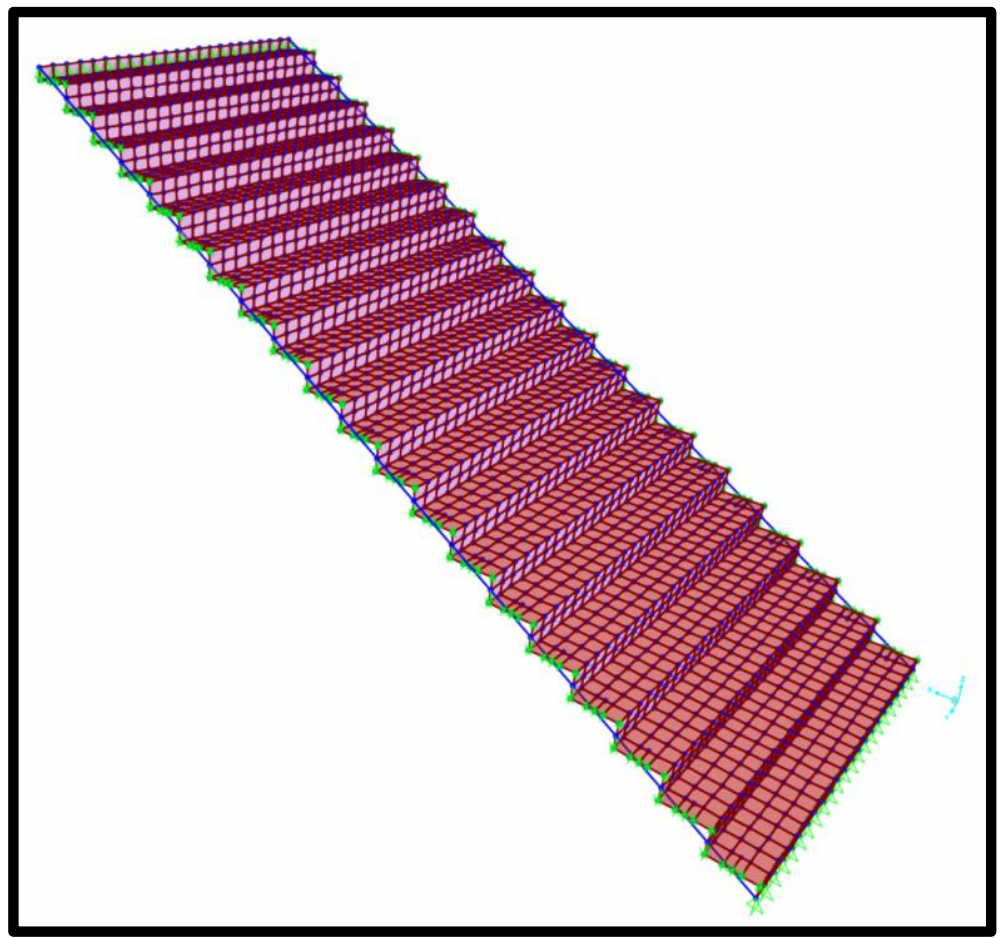

Figure 4.55: Model with Length-to-Width Ratio of Approximately Three

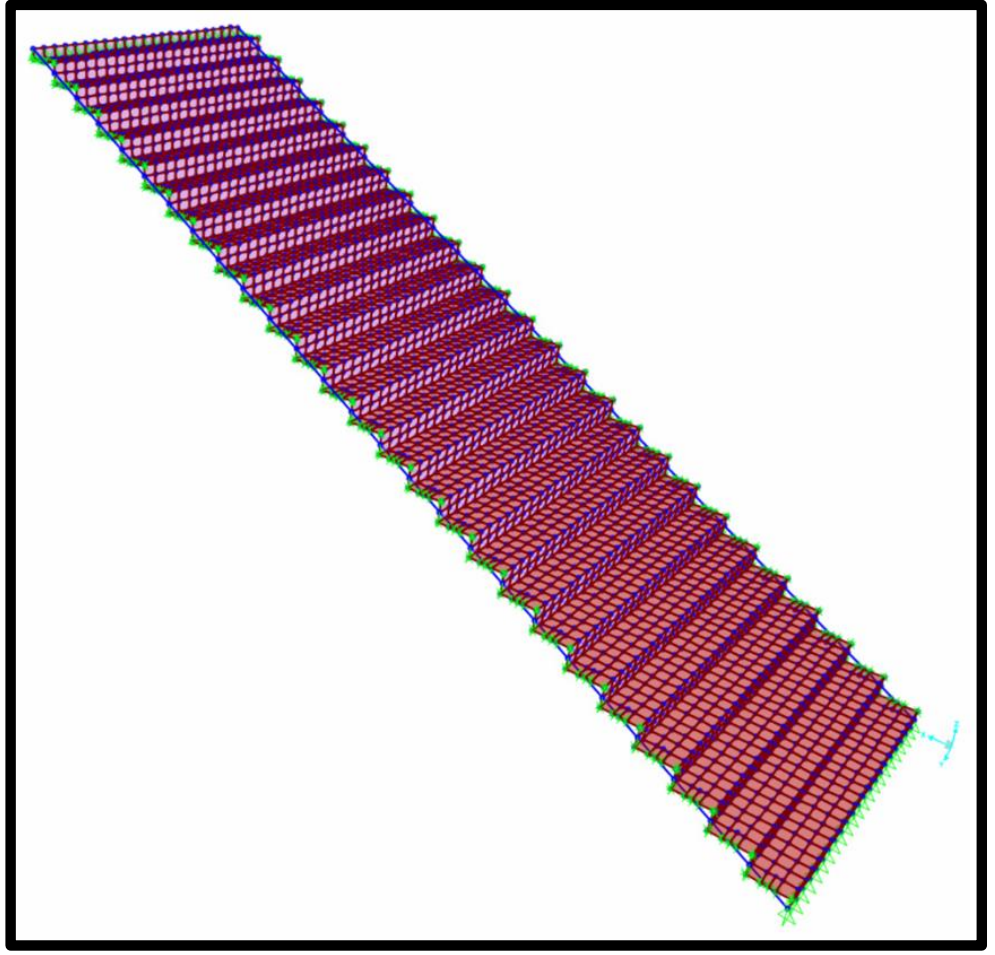

Figure 4.56: Model with Length-to-Width Ratio of Approximately Four 
A table summarizing the ratios and the corresponding modeled natural frequency compared to the AISC natural frequency prediction can be found in Table 4.32. Note: the mode 1 frequency used for the 1.94 ratio was experimentally determined, but the rest of the trial iterations used FEM to model the mode 1 frequencies.

Table 4.32: Modeled Aspect Ratio vs. Equation Predicted Mode 1 Frequency

\begin{tabular}{|c|c|c|c|c|c|c|c|}
\hline $\begin{array}{c}\text { Number } \\
\text { of Steps }\end{array}$ & $\begin{array}{c}\text { Length } \\
\text { of } \\
\text { Stair } \\
\text { (in) }\end{array}$ & $\begin{array}{c}\text { Width } \\
\text { of } \\
\text { Stair }\end{array}$ & $\begin{array}{c}\text { Aspect } \\
\text { Ratio }\end{array}$ & $\begin{array}{c}\text { Weight } \\
\text { (lbs.) }\end{array}$ & $\begin{array}{c}\text { Modeled } \\
\text { Mode 1 } \\
\text { Frequency } \\
(\mathrm{Hz})\end{array}$ & $\begin{array}{c}\text { AISC } \\
\text { DG11 } \\
\text { Prediction } \\
(\mathrm{Hz})\end{array}$ & $\begin{array}{c}\text { Percent } \\
\text { Difference } \\
(\%)\end{array}$ \\
\hline 13 & 169 & 87 & 1.94 & 4300 & 16.30 & 18.53 & $12.80 \%$ \\
\hline 20 & 259 & 87 & 2.98 & 6614 & 7.95 & 7.87 & $-1.05 \%$ \\
\hline 33 & 337 & 87 & 3.87 & 8598 & 5.00 & 4.66 & $-7.14 \%$ \\
\hline 39 & 529 & 87 & 4.92 & 10913 & 3.27 & 2.89 & $-12.35 \%$ \\
\hline
\end{tabular}

The trial iterations presented in Table 4.32 demonstrated that if the staircase tested in this study was longer and constructed using the same boundary conditions, it would have a predicted fundamental frequency of less than $10 \mathrm{~Hz}$. This finding was found using both Equation (4.4) and the FEM. A comparison demonstrating the over and under prediction of the frequency between the FEM and Equation (4.4) is also presented in Table 4.32. The trial iterations tested with aspect ratios greater than 1.9 would have to be redesigned to be stiffer in order to satisfy the previously mentioned serviceability.

The next step was to examine a potential empirical factor to be able to predict a staircase with the Type 1 boundary condition. The Type 1 staircase cannot directly be compared using Equation (4.4) because it has boundary conditions, created by the wall 
stringer, that fall outside the limitations of the equation. An empirical equation was proposed to predict the Type 1 staircase's natural frequency and can be found in Equation (4.5).

$$
f_{n}=1.12 * \frac{\pi}{2} \sqrt{\frac{g E I}{W L^{3}}}
$$

Where $g\left(\frac{m}{s^{2}}\right)$ is the acceleration due to gravity. E (GPA) is the elastic modulus of the stringer material. $I\left(\mathrm{~mm}^{4}\right)$ is the moment of inertia of the stringer. $W(\mathrm{~N})$ is the weight of the stair. $L(\mathrm{~m})$ is the diagonal length of the stringer.

The comparison of the equation to the experimentally determined first mode natural frequency for the Type 1 staircase can be found in Table 4.33 .

Table 4.33: Comparison of the Empirically Adjusted Fundamental Natural Frequency Prediction

\begin{tabular}{|c|c|c|c|}
\hline Stair Case Flight & $\begin{array}{c}\text { Experimentally } \\
\text { Determined Mode 1 } \\
\text { Frequency (Hz) }\end{array}$ & $\begin{array}{c}\text { Equation (4.5) } \\
\text { predicted Mode 1 } \\
\text { Frequency (Hz) }\end{array}$ & Difference (\%) \\
\hline Flight 1 & 20.11 & 20.75 & $3.13 \%$ \\
\hline Flight 3 & 21.61 & 20.75 & $4.06 \%$ \\
\hline Average & 20.86 & 20.75 & $0.53 \%$ \\
\hline
\end{tabular}

The application of the 1.12 factor resulted in a prediction of the first mode frequency that was within $4.1 \%$ of the experimentally determined first mode values, and $0.53 \%$ on average. More research on a larger data pool is needed to further validate the empirical factor. 


\subsection{Model Design Recommendations}

The following are recommendations for designers on how to model stairs based on this research:

1) During the creation of a FEM, creating a model using only pin restraints will provide a conservative estimate for the first mode frequency, and is suggested for design

2) Wall stringers should be modeled differently than face stringers during modeling for retrofitting a staircase in order to account for a difference in boundary conditions. If not modeled properly, the model may be underestimating the additional stiffness created by the difference in the boundary condition.

3) Rotational spring restraints can be applied to the joints at the ends of the stringers to model the end restraints more accurately. The end restraints can then be adjusted with the appropriate stiffness, which is dependent on the staircase being modeled. However, the restraint is limited to behaving between a pin and a fixed connection.

4) A designer should take careful consideration when determining whether to model a stair railing. If the staircase has a relatively high natural frequency, greater than $10 \mathrm{~Hz}$, modeling the railing may have a negligible contribution to the stiffness of the stair and may lead to a misidentification of the mode shape and the first mode frequency. 
5) The boundary condition of a wall stringer can be modeled by applying links that connect a fixed joint to the stair edge and apply a translational stiffness in the direction perpendicular to the wall.

6) Links with translational stiffness can also be used to model unknown boundary conditions that exist in different orthogonal directions. However, caution should be taken to make sure that the applied stiffness does not affect the mode shape of the structural model.

A summary of the recommended modeling procedures, including their pros and cons, are as follows. It is recommended that when creating a model during the design process, the end restraints should be modeled as pins. This model would provide a conservative estimate of the natural frequency of the stair structure because using a pinned restraint results in the lowest fundamental natural frequency estimate. Also, modeling the structure using pinned restraints is the fastest method for modeling the stair structure. If the intended reason for creating a model is to model potential retrofits for an existing stair system, it is recommended that a more detailed tuned model be created.

A tuned model requires that the experimental frequency and mode shape data be collected and used to update the model. For linear staircases, it is recommended that end rotational springs be used to adjust the restraint boundary conditions. Rotational springs, for the study used in this thesis, allowed for a model to be created that predicted the frequency within a $10 \%$ error of the experimental data. This method is also less complex than modeling unknown stiffness using links. 
Also, it is recommended that if the boundary conditions of the stair model are more complex than just a linear staircase attached to a landing on either end, then using links may be the best method for applying unknown stiffness. Applying links to either end could be the best method for applying unknown stiffness because this method allows for the most flexibility in being able to alter the applied boundary conditions. However, this method can also lead to more potential errors during the modeling process due to the number of variables that can change. Therefore, if this method is chosen, great care should be taken to make sure that both the frequencies and mode shapes match between the experimentally determined data and the model.

Finally, it is recommended that during the design process the increased frequency due to the wall stringer should be ignored to produce a more conservative design. However, if a staircase is being modeled to design potential retrofits and the experimental frequency data is known, the wall stringer boundary conditions should be modeled to capture the increased frequency due to difference in the boundary conditions. 


\section{CHAPTER 5- CONCLUSIONS}

\subsection{Conclusions}

As stated in Chapter 1, the overall goal of this thesis is to improve the accuracy of the predicted vibration response of staircases, specifically steel staircases with concrete filled pan treads, and to provide a better understanding of the effect of various design parameters on the vibration response.

In order to accomplish this goal, this research was broken down into different studies. The first study was to understand the dynamic characteristics of the staircase. The second study was to create an experimentally validated SAP2000 model. The third study performed parametric studies that investigated the effect of stiffness, mass, and boundary conditions on the vibration response of the staircases. The fourth study looked into the limitations of the fundamental natural frequency prediction equation presented in AISC Design Guide 11 (Murray et al. 2016). The following conclusions are summarized for each of the objectives listed at the beginning of this thesis.

Objective 1- The experimental data demonstrated that the change in boundary condition created by a wall stringer for the Type 1 stair caused a $24.54 \%$ increase in the first mode frequency and a $2.32 \%$ increase in the second mode frequency on average when compared to the Type 2 stair. Therefore the boundary condition of the wall stringer was determined to be different than that of the face stringer. As a result, the boundary conditions of a wall stringer should be considered different than a face stringer when modeling a staircase for retrofits. 
In addition, it was determined that the percent critical damping for Flight 1 was $3.3 \%$, while the other flights were around $5 \%$. One possible explanation for the difference between the two damping ratios was that additional frictional energy dissipation might be occurring due to a slight difference in the interface between the flight and the floor, compared to the interface of the flight and the landings.

Objective 2- Creating a FEM using pins as the restraint conditions for the stairs was determined to produce a conservative estimate for the natural frequency of the stairs. In this research the base model, without any model tuning, resulted in a conservative first mode natural frequency that differed from the experimental results by approximately $23 \%$. The difference in the results was due to the fact that the actual restraint conditions fall in between a pin and a fixed restraint, where a fixed restraint would have a higher natural frequency than the pinned restraint.

Objective 3- a) The restraint conditions for the stairs were tuned using rotational springs. Applying rotational springs to the stringer ends allowed for the model to have a closer representation of the actual structure, and allowed for a modeled first mode frequency to be within $2 \%$, and a second mode frequency to be within $7 \%$ of the experimentally determined data.

b) Finite element analysis in SAP2000 demonstrated that, in this study, the railing stiffness had a negligible contribution to the overall stiffness of the staircase. Finite element analysis demonstrated that an uneven mass distribution, created by the application of the railing mass on the edge of the stairs, had an influence on the first mode frequency of the structure, but had little effect on the second mode frequency. It 
was also determined that large railing masses create an uneven mass distribution that affects the natural frequency of a stair differently than if the mass were to be evenly distributed.

c) Using a comparison between the FEM and experimental data, it was determined that the wall stringer boundary condition could be modeled using links with applied translational stiffness in the direction perpendicular to the wall plane. The application of the links improved the accuracy of the model by $56.6 \%$, and resulted in a modeled first and second mode frequency to be within $10 \%$ of the experimentally determined frequencies.

Objective 4- Using the FEM, it was determined that joint links could be used as an alternative solution for modeling unknown boundary condition stiffness to determine the first mode natural frequency. The application of the links in the FEM demonstrated that only using links with a translational stiffness to model unknown boundary conditions provided for a more accurate first mode natural frequency prediction in the Type 2 model compared to the Type 1 model.

Objective 5- The use of the AISC Design Guide 11 (Murray et al. 2016) equation for predicting the fundamental natural frequency for a steel stair was determined to overestimate the first mode frequency of a shorter span staircase with a length-to-width ratio of 1.9 and a first mode frequency larger than $10 \mathrm{~Hz}$. It was determined that the Type 2 stair's first mode frequency predicted using the equation was overestimated by $12.8 \%$ compared to the experimentally determined frequency. In addition, for the Type 1 stair in 
this study, it was empirically determined that the increased stiffness due to the presence of a wall stringer could be estimated by applying a factor of 1.12 to this equation.

Summary- Finally, a summary of the results of the different SAP2000 models using different methods can be found in Table 5.1 and Table 5.2. Once again, it is important to note that since the first mode frequencies for all of the flights tested were above $10 \mathrm{~Hz}$, the frequency serviceability criteria were satisfied for these stair flights.

Table 5.1: Type 2 Stair Summary

\begin{tabular}{|c|c|c|c|c|}
\hline \multicolumn{5}{|c|}{ Type 2 Stair } \\
\hline $\begin{array}{c}\text { Experimental } \\
\text { Average (Hz) }\end{array}$ & $\begin{array}{c}\text { SAP2000 Base } \\
\text { Model (Hz/\% } \\
\text { Difference) }\end{array}$ & $\begin{array}{c}\text { SAP 2000 } \\
\text { Model } \\
\text { Rotational } \\
\text { Springs (Hz/\% } \\
\text { Difference) }\end{array}$ & $\begin{array}{c}\text { SAP 2000 } \\
\text { Model Links } \\
\text { (Hz/\% } \\
\text { Difference) }\end{array}$ \\
\hline $\begin{array}{c}\text { Mode } \\
1\end{array}$ & 16.30 & $12.90 /(23.29 \%)$ & $16.62 /(1.94 \%)$ & $16.92 /(3.73 \%)$ \\
\hline $\begin{array}{c}\text { Mode } \\
2\end{array}$ & 31.13 & $24.52 /(23.76 \%)$ & $29.08 /(6.81 \%)$ & $29.56 /(5.17 \%)$ \\
\hline
\end{tabular}

Table 5.2: Type 1 Stair Summary

\begin{tabular}{|c|c|c|c|c|}
\hline \multicolumn{5}{|c|}{ Type 1 Stair } \\
\hline & $\begin{array}{l}\text { Experimental } \\
\text { Average }(\mathrm{Hz})\end{array}$ & $\begin{array}{c}\text { SAP } 2000 \\
\text { Model } \\
\text { Rotational } \\
\text { Springs (Hz/\% } \\
\text { Difference) }\end{array}$ & $\begin{array}{c}\text { SAP2000 } \\
\text { Model } \\
\text { Rotational } \\
\text { Springs and } \\
\text { Links (Hz/\% } \\
\text { Difference) }\end{array}$ & $\begin{array}{c}\text { SAP } 2000 \\
\text { Model Links } \\
(\text { Hz/\% } \\
\text { Difference })\end{array}$ \\
\hline $\begin{array}{c}\text { Mode } \\
1\end{array}$ & 20.86 & $16.85 /(21.27 \%)$ & $18.97 /(9.49 \%)$ & $19.32 /(7.67 \%)$ \\
\hline $\begin{array}{c}\text { Mode } \\
2\end{array}$ & 31.86 & $30.07 /(5.78 \%)$ & $34.95 /(9.25 \%)$ & $35.35 /(10.39 \%)$ \\
\hline
\end{tabular}




\subsection{Recommendations for Future Work}

The results of this thesis prompts several further study ideas, which are discussed in this section.

\section{Effect of Two Wall Stringers on Concrete Filled Pan Tread Staircases}

The results of this thesis showed that wall stringers have the potential to create additional stiffness on a stair structure when there is one wall stringer and one face stringer. The next step would be to conduct a similar study on a staircase that is composed of two wall stringers to analyze if there are additional boundary condition changes created by the addition of another wall stringer.

\section{Evaluation of Dynamic Behavior of Steel Staircases with a Wall Stringer Bolted to an Adjacent Wall}

The purpose of this study would be to investigate if a staircase with a wall stringer behaved differently if the wall stringer had a bolted connection to a wall. This study would allow for the determination if bolting a stringer into the wall creates additional serviceability benefits for the staircase structure.

\section{Increased Data Pool for Short-Span, High Dominant Frequency Staircases}

The purpose of this study would be to increase the data population of short-span high frequency staircases, those with length to width ratios of less than 2 , to be able to reevaluate the limitations of the proposed AISC equation. This study would allow for more refined empirical factors to be applied to the AISC equation that would allow for more accurate predictions of the fundamental natural frequency, using these modified equations. 


\section{Effect of Stair Geometry on Behavior}

The purpose of this study would be to alter different geometric properties of an experimentally verified staircase model to determine the effect of different geometric properties on the staircase's vibration response. This study would improve the understanding of how staircases could be constructed differently to avoid serviceability issues. 


\section{REFERENCES}

“A1521 Accelerometer.” Structural Health Monitoring \& Stress Load Testing Systems by $B D I$

Aw, J. H., Ng, W. H., Lau, T. L., Jaganathan, J., Anwar, M. P., and Elleithy, W. (2018). "Effect of Footfall Induced Vibration on Flat Plate Slabs." International Journal of Engineering \& Technology. 7, 73-77

Bishop, N. W. M., Willford, M., and Pumphrey, R. (1995). "Human induced loading of flexible staircases." Safety Science, 18, 261-276.

Cappellini, A., Manzoni, S., Vanali, M., and Cigada, A. (2016). "Evaluation of the dynamic behavior of steel staircases damped by the presence of people". Engineering Structures, 115, 165-178.

Chopra, A. K. (2012) Dynamics of Structures. Fourth ed., Prentice-Hall.

Computers and Structures, Inc. (2016). CSI Analysis Reference Manual (2016).

Davis, B., and Avci, O. (2015) "Simplified Vibration Serviceability Evaluation of Slender Monumental Stairs." Journal of Structural Engineering, 141(11), 1-9. 
Davis, B., and Murray, T. (2009). "Slender Monumental Stair Vibration Serviceability." Journal of Architectural Engineering, 15, 111-121.

Davis, B., and Salmon, J. (2019) "Structural Vibration Serviceability." Modern Steel Construction, (Dec), 16-21.

Encyclopedia Britannica. (2020). frequency Definition, Symbols, \& Formulas. < https://www.britannica.com/science/frequency-physics> [Accessed 9 Jan. 2020].

Friedman, A.D., (2018). “Design Guide 34: Steel-Framed Stairway Design (First Edition)”. American Institute of Steel Construction, Chicago.

Harihara, P., and Childs, D., "Solving Problems in Dynamics and Vibrations Using MATLAB”, Department of Mechanical Engineering Texas A \& M University

Jeary, A. P. (1997). "Damping in Structures.” Journal of Wind Engineering and Industrial Aerodynamics, 72, 345-355.

Jurgensen, A. (2016) "Vibration Serviceability of Monumental Stairs". Proceedings of the National Conference On Undergraduate Research, 2016: Asheville, NC, 698-708. 
Kerr, S. C., and Bishop, N. W. M. (2001). "Human induced loading of flexible staircases." Engineering Structures, 23, 37-45.

Kim, S. B., Lee, Y. H., Scanlon, A., Kim, H., and Hong, K. (2008) "Experimental Assessment of Vibration Serviceability of Stair Systems.” Journal of Constructional Steel Research, 64(2), 253-259.

Kim, S. Y., Lee, C. H., and Kim, N. E. (2016). "Effective impulse model for prediction of vibration response of high-frequency steel staircases." Journal of Construction Steel Research, 126, 129-138.

Mohd Azaman, N.A., Abd Ghafa, N. H., Azhar, A. F., Fauzi, A. A., Ismail, H. A., Syed Idrus, S. S., Mokhjar, S. S., and Abd Hamid, F. F. (2018). "Investigation of Concrete Floor Vibration Using Heel-Drop Test." Journal of Physics: Conference Series, 995.

Murray, T., Allen, D., Ungar, E. (1997) “Steel design guide series 11: Floor vibrations due to human activity", American Institute of Steel Construction, Chicago.

Murray, T., Allen, D., Ungar, E., and Davis, D. (2016) "Steel design guide series 11: Vibrations of Steel-Framed Structural Systems Due to Human Activity (Second Edition)", American Institute of Steel Construction, Chicago 
Pavic, A., Mizkovic, Z., and Reynolds, P. (2007) "Modal Testing and Finite-Element Model Updating of a Lively Open-Plan Composite Building Floor.” Journal of Structural Engineering, 133(4), 550-558.

Santos, J., Andrade, P., and Escòrcio, P. (2019) "Pre-Design of Laterally Supported Stair Steps.” Engineering Structures, 182, 51-61.

Sondag, T., Erdogmus, E., Puckett, J. (2020). "Evaluation of the Dynamic Behavior of Steel Staircases with Concrete Filled Pan Treads" in preparation for submission to the Journal of Constructional Steel Research.

Yuan, F., Xiaobin, W., Yaoqing, X., Congchun, L., and Wen, Y. (2013). "Seismic performance analysis and design suggestion for frame buildings with cast-in-place stairs." Earthquake Engineering and Engineering Vibration, 12, 209-219. 
Appendix 


\title{
Experimental and Analytical Analysis Code
}

\author{
MATLAB Code for Fast Fourier Transform
}

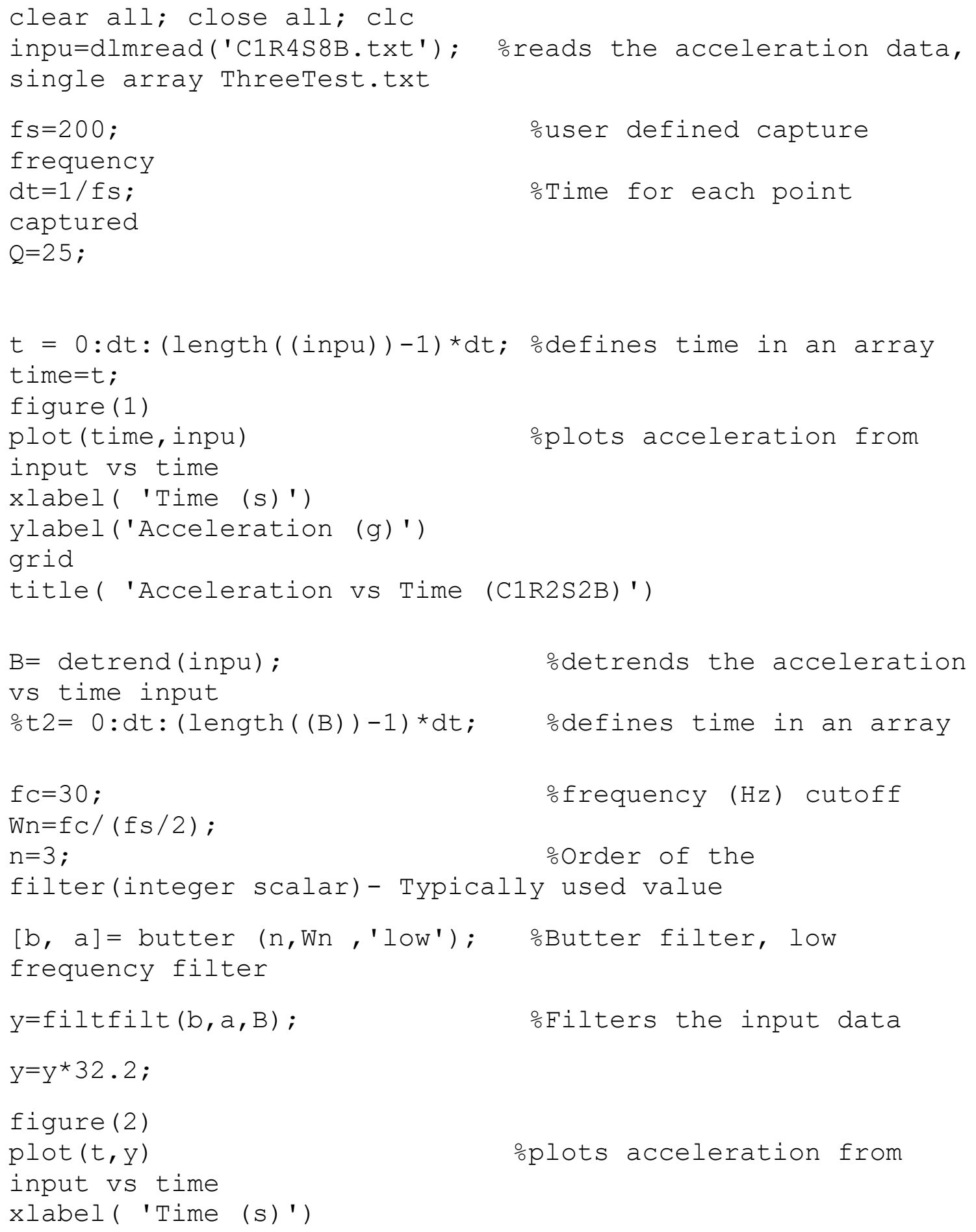




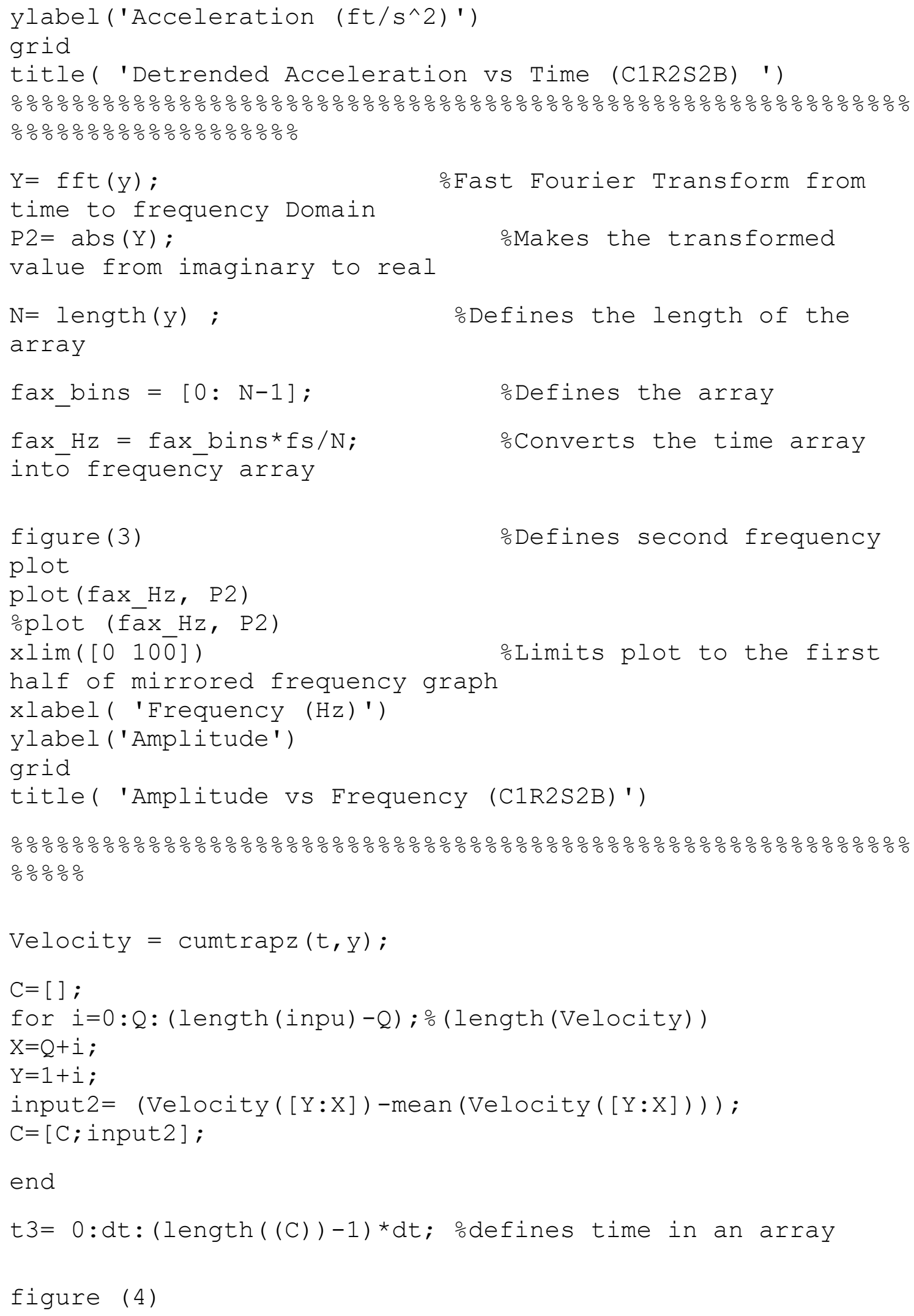




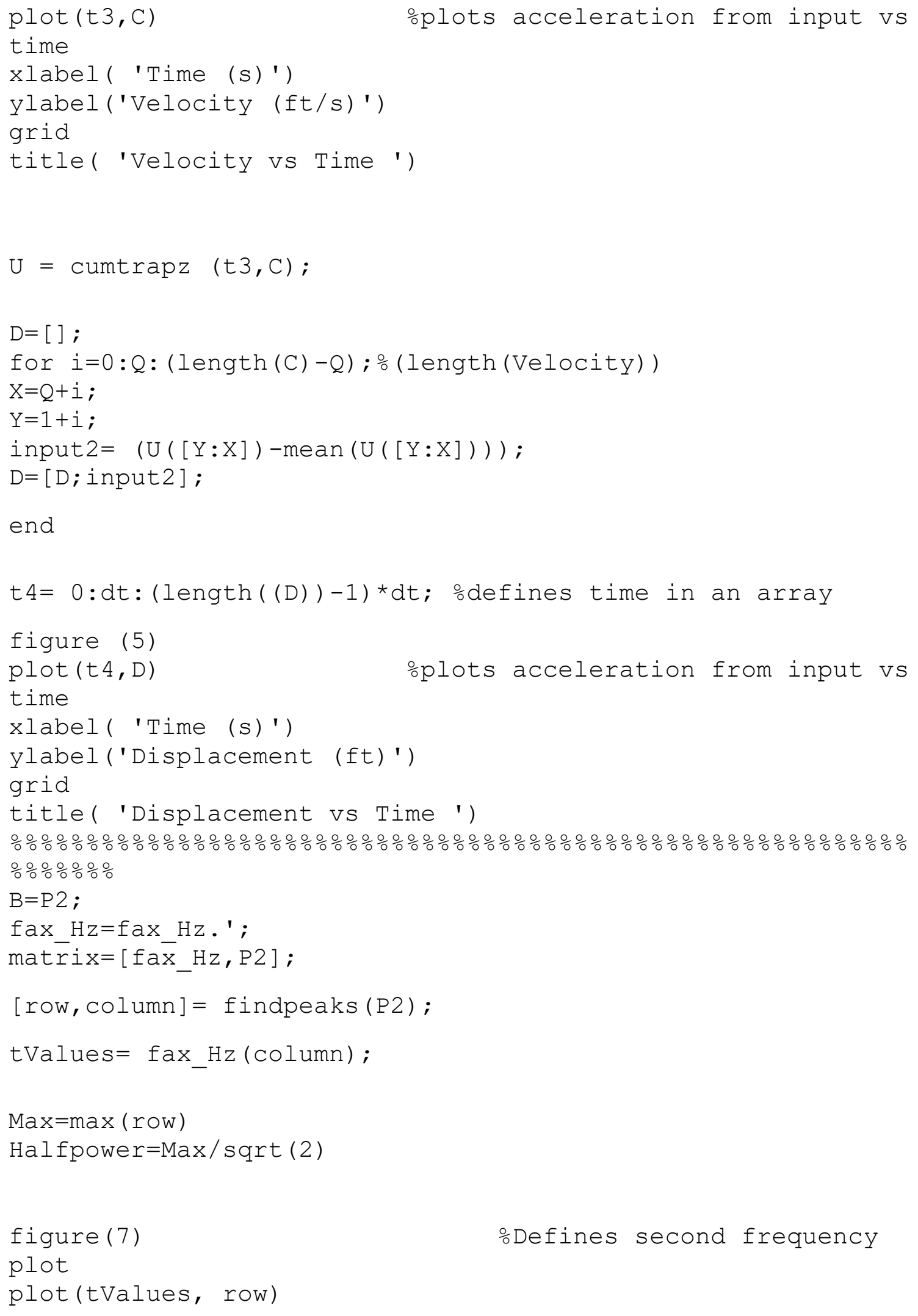




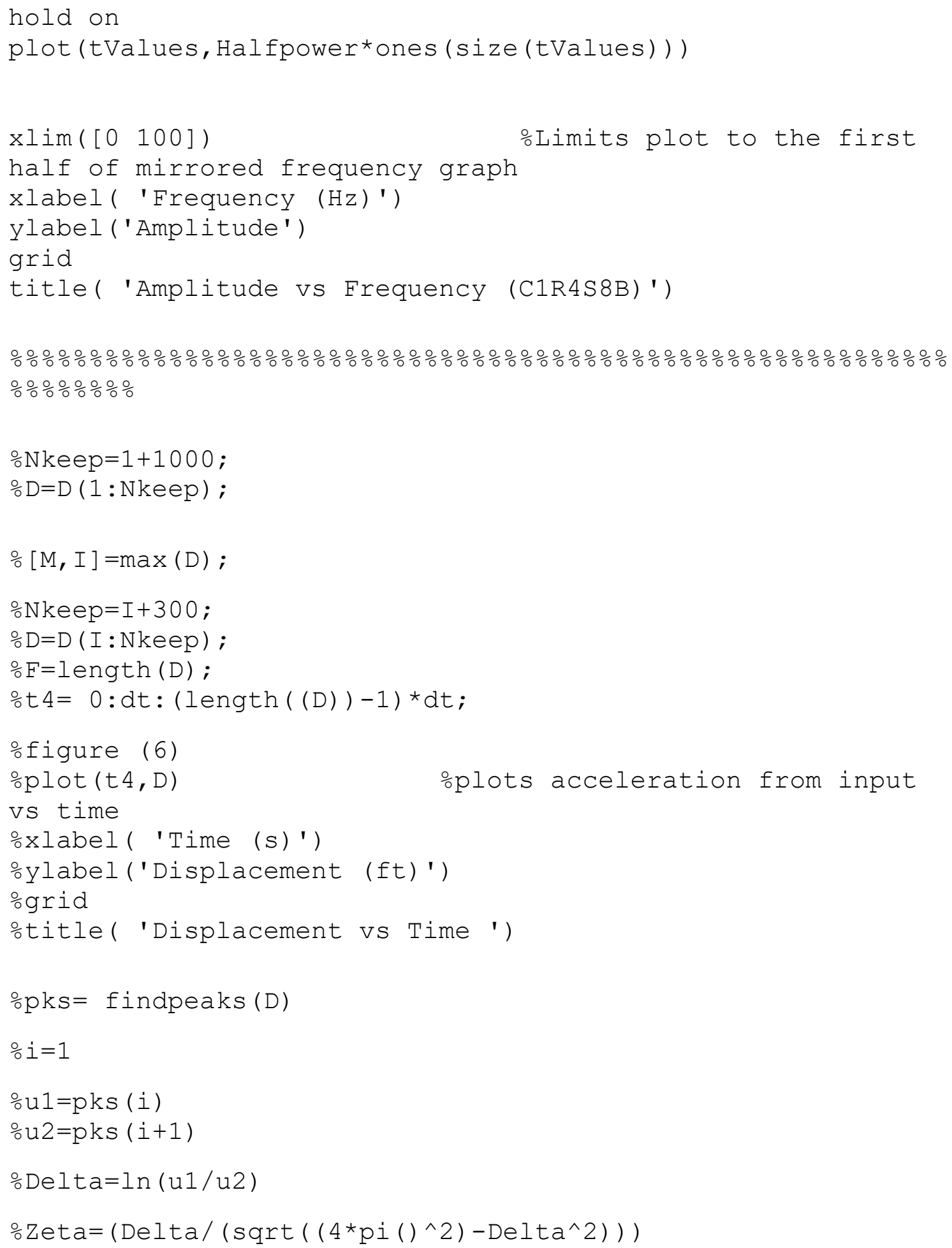




\section{Experimental Accelerometer Data}

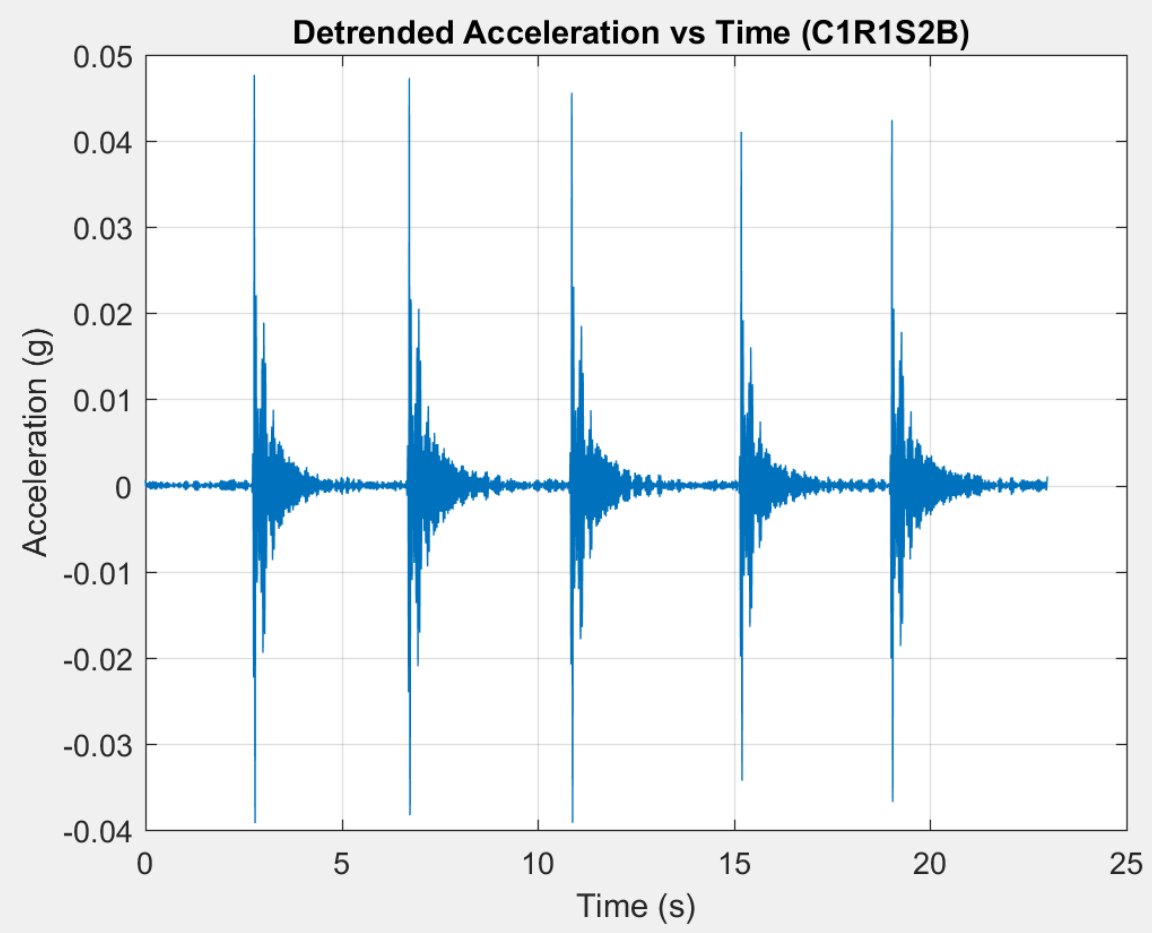

Figure A 1: C1R1S2B Acceleration vs. Time Graph 


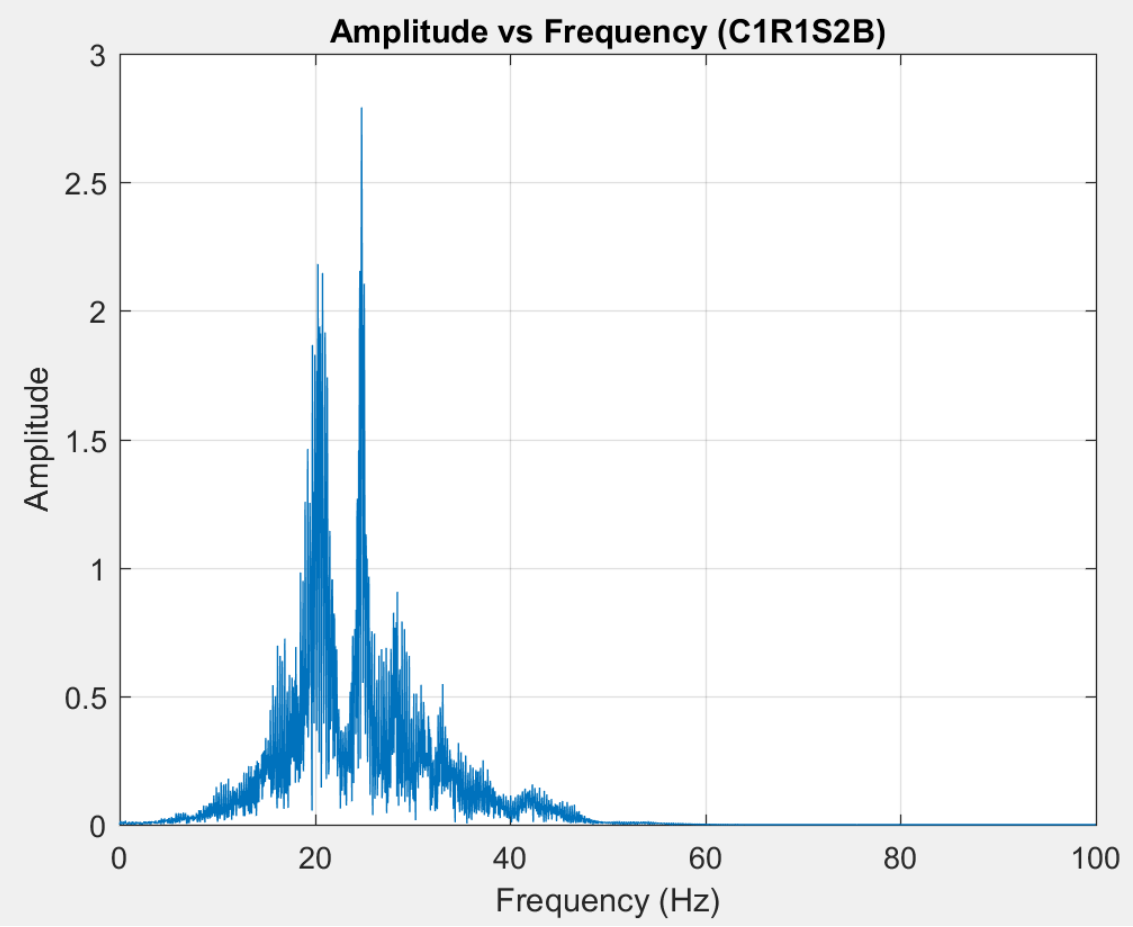

Figure A 2: C1R1S2B Amplitude vs. Frequency 


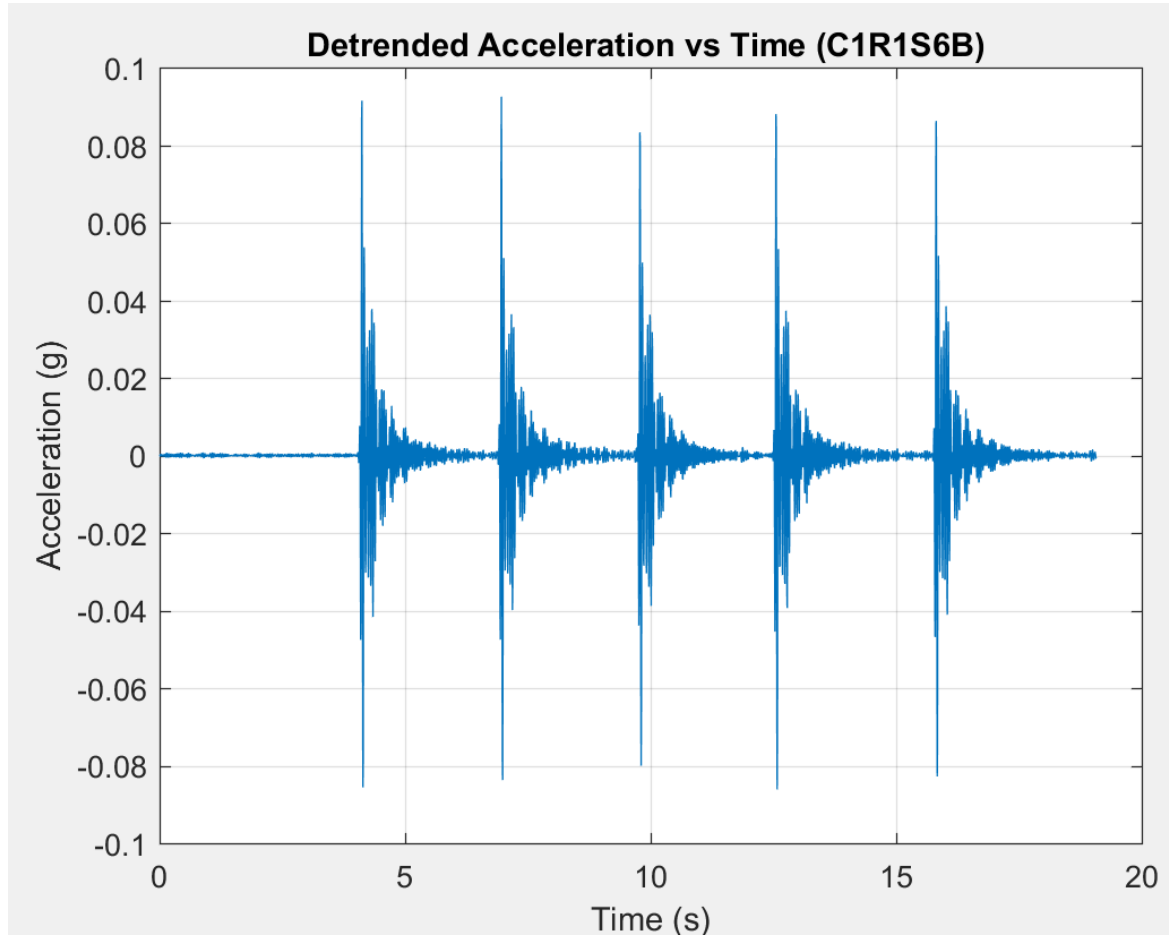

Figure A 3: C1R1S6B Acceleration vs. Time Graph

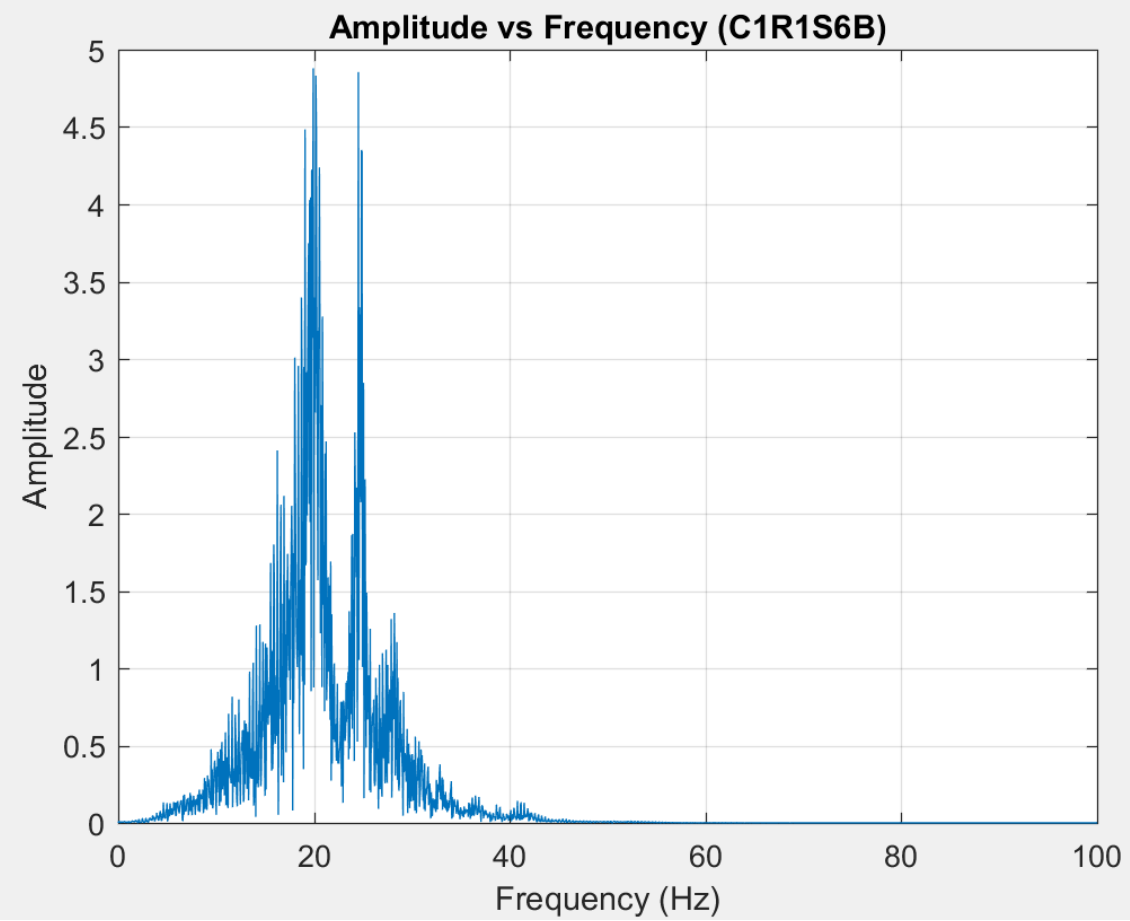

Figure A 4: C1R1S6B Amplitude vs. Frequency 


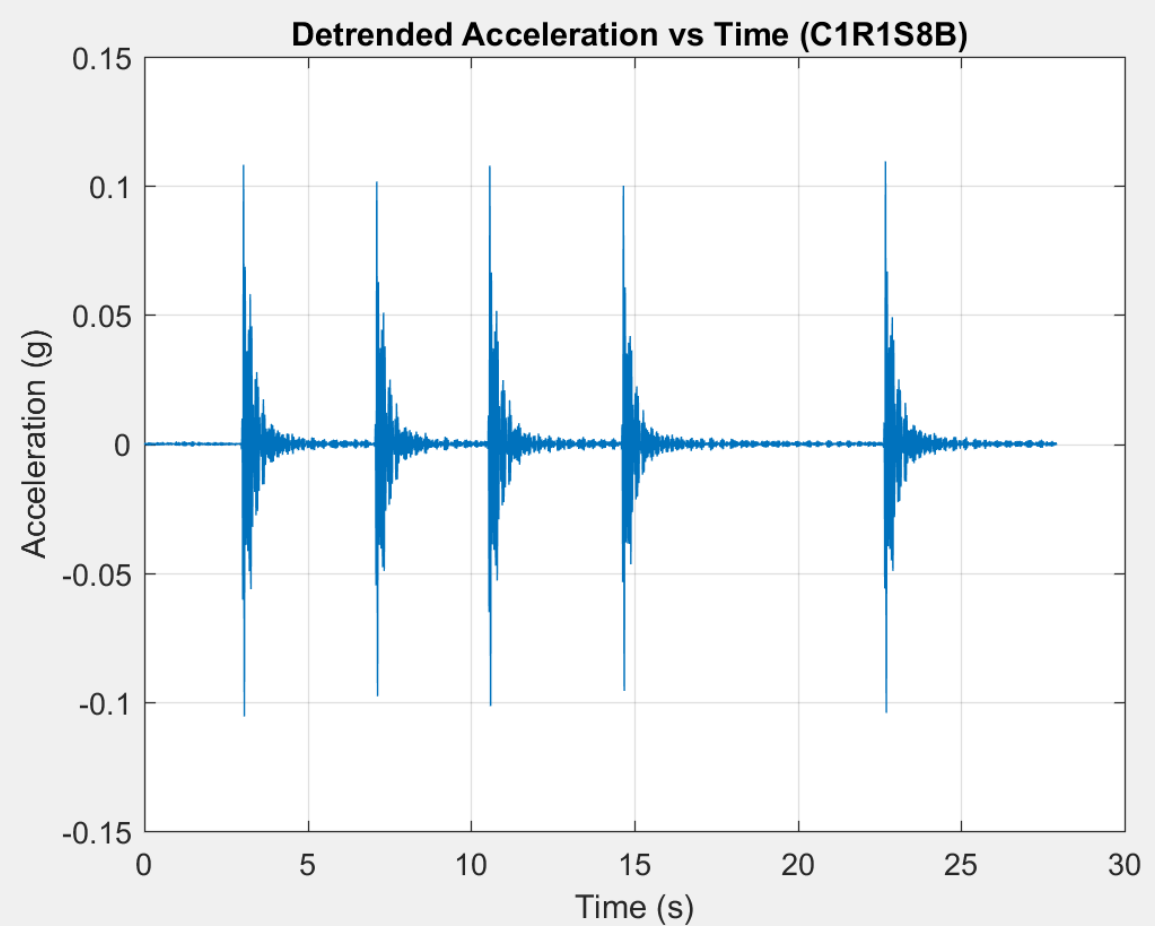

Figure A 5: C1R1S8B Acceleration vs. Time Graph

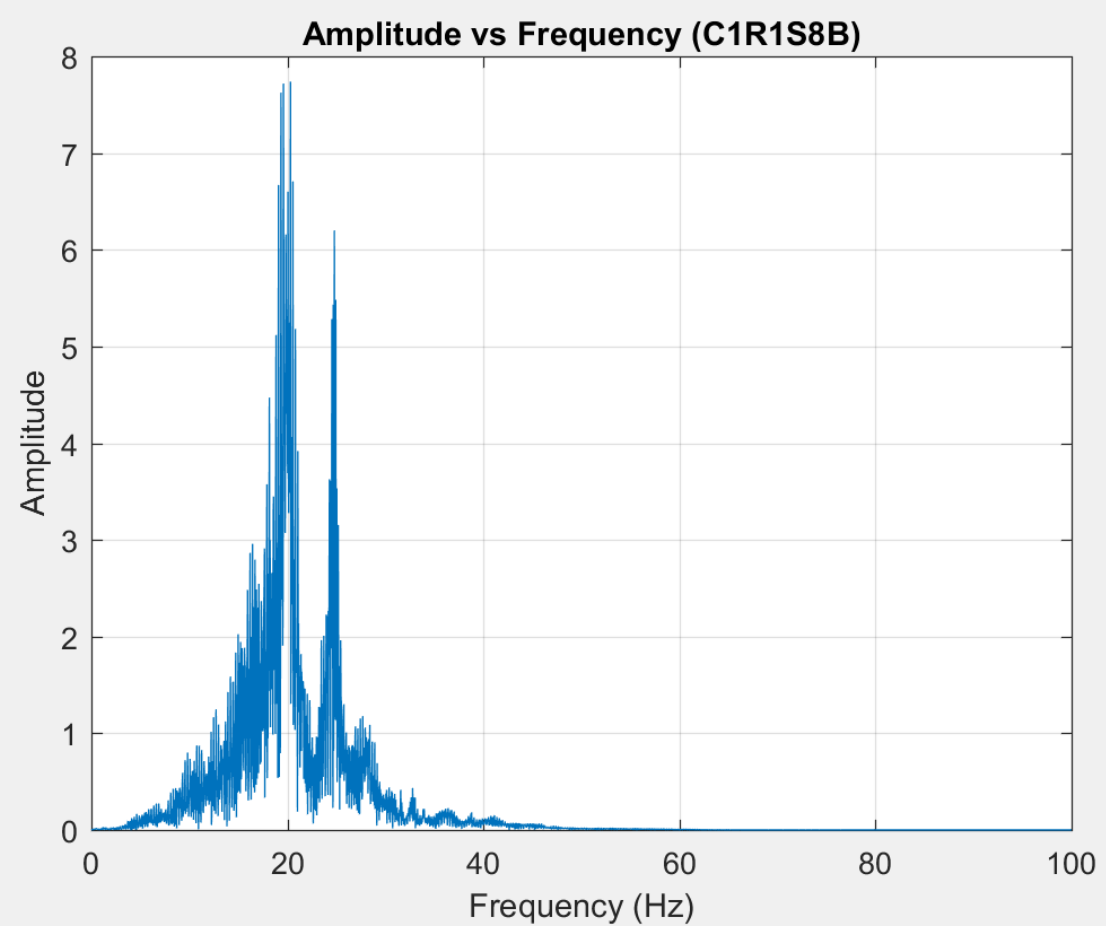

Figure A 6: C1R1S8B Amplitude vs. Frequency 


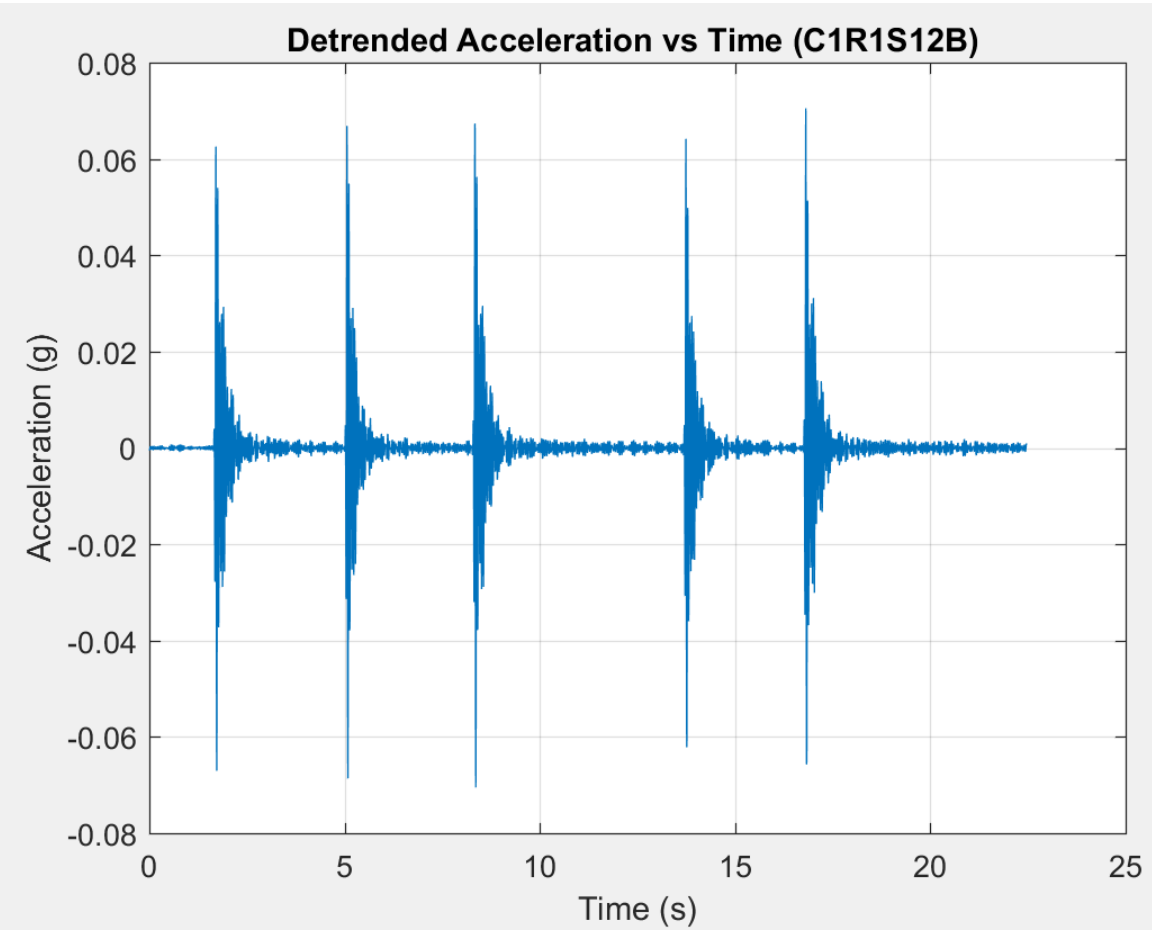

Figure A 7: C1R1S12B Acceleration vs. Time Graph

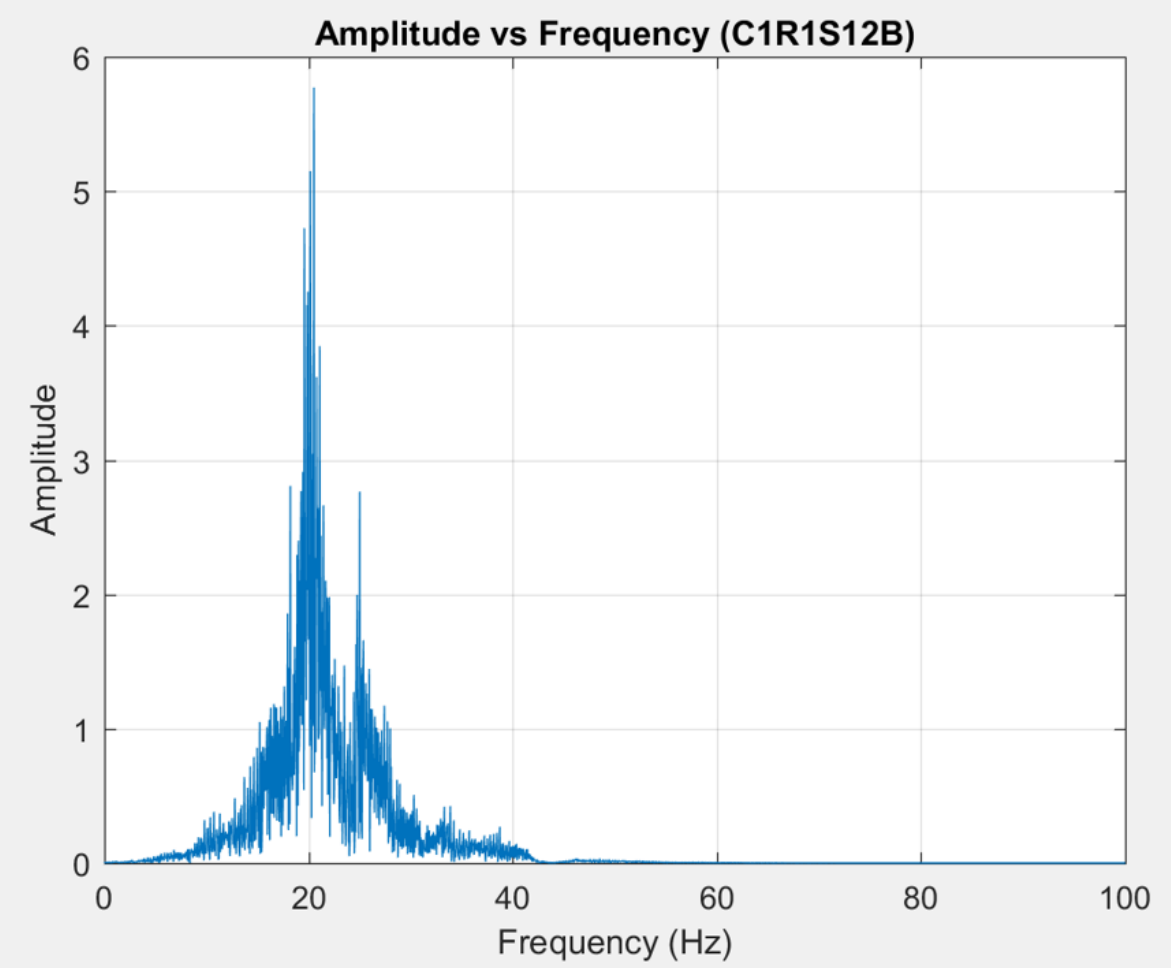

Figure A 8: C1R1S12B Amplitude vs. Frequency 


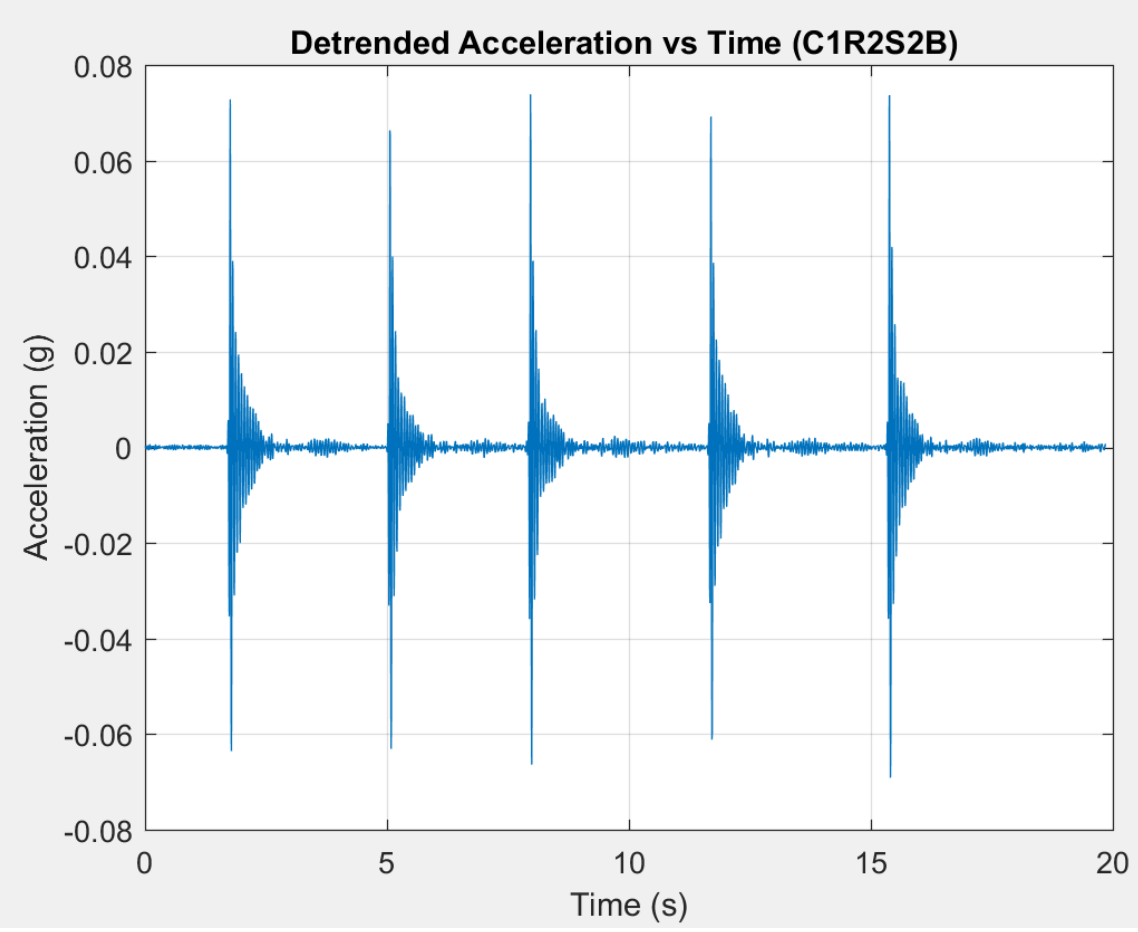

Figure A 9: C1R2S2B Acceleration vs. Time Graph

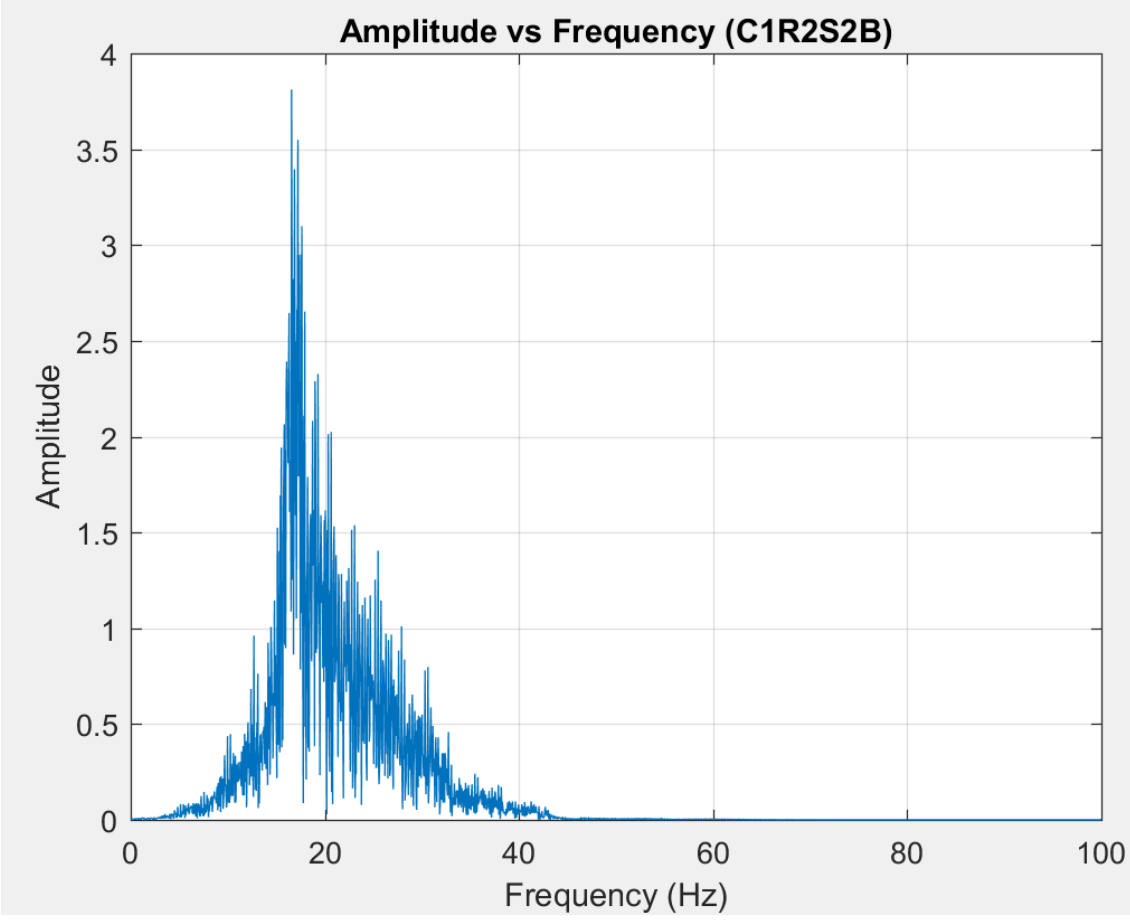

Figure A 10: C1R2S2B Amplitude vs. Frequency 


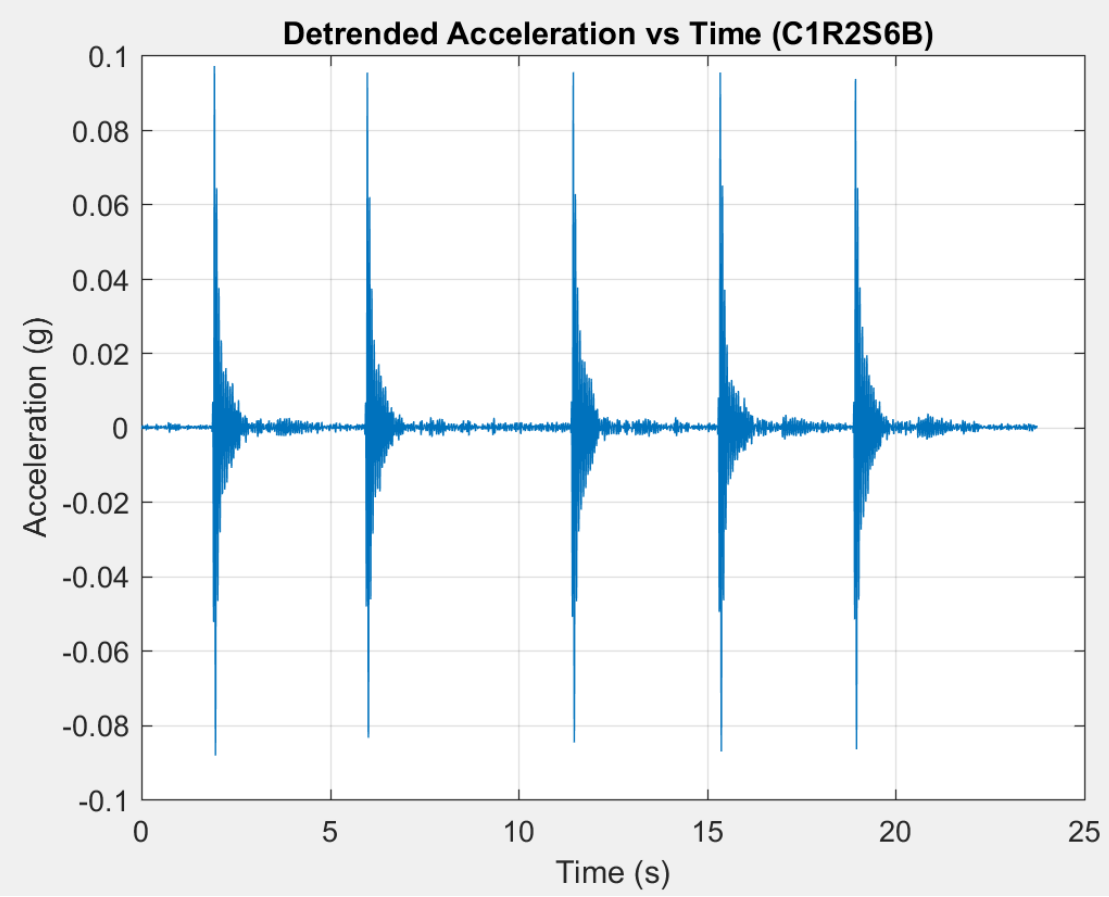

Figure A 11: C1R2S6B Acceleration vs. Time Graph

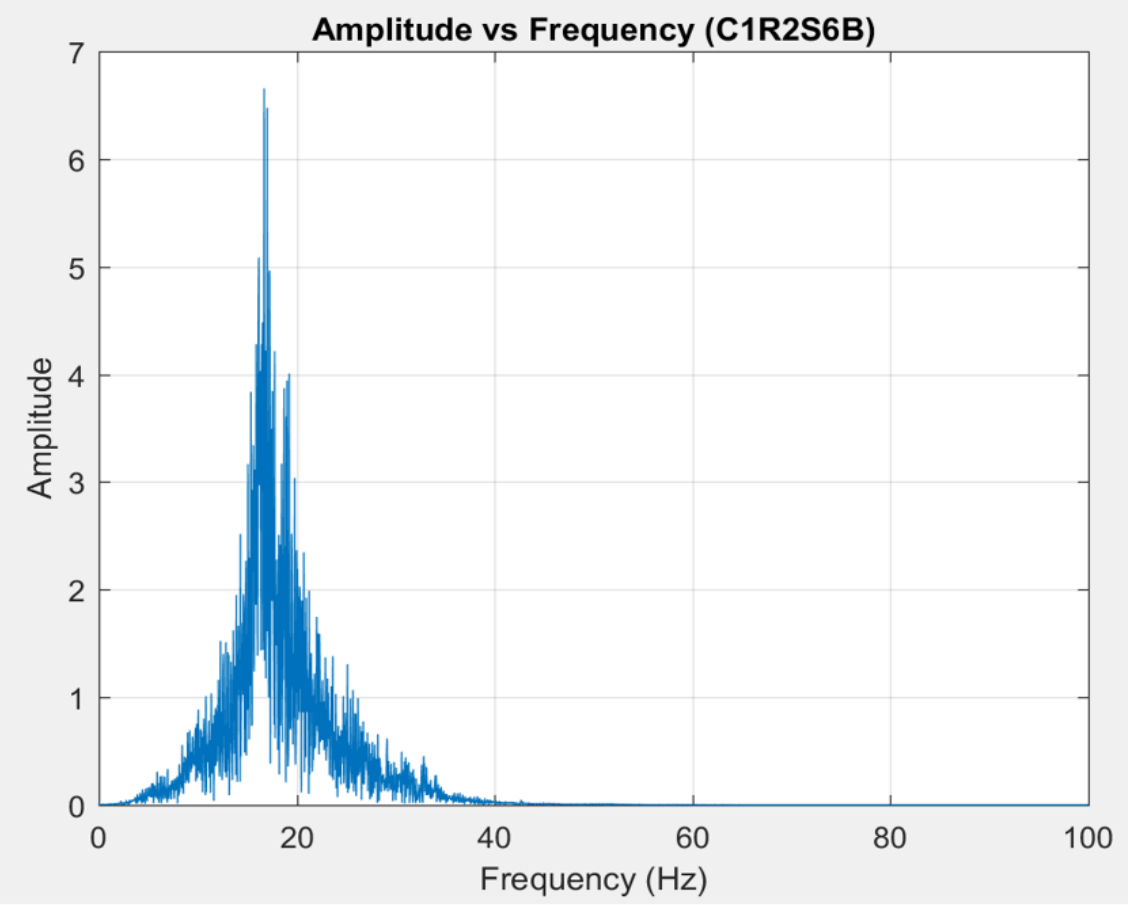

Figure A 12: C1R2S6B Amplitude vs. Frequency 


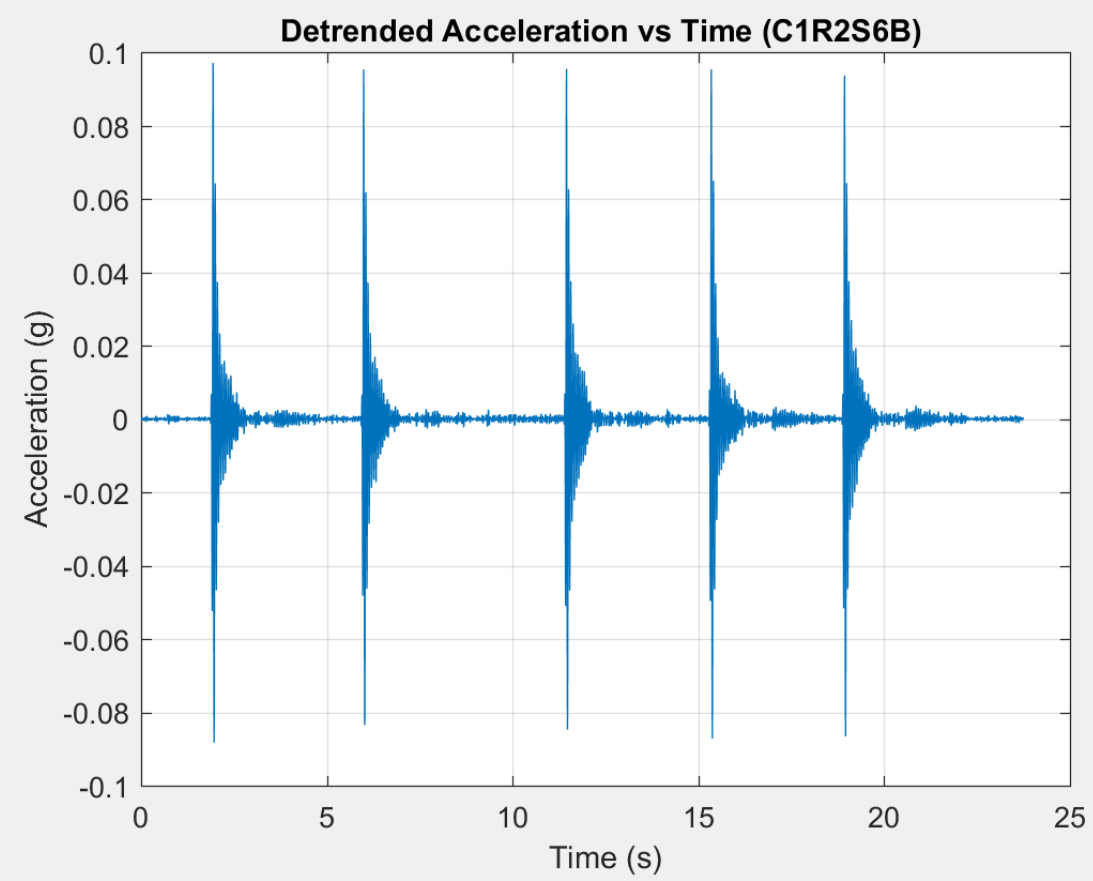

Figure A 13: C1R2S6B Acceleration vs. Time Graph

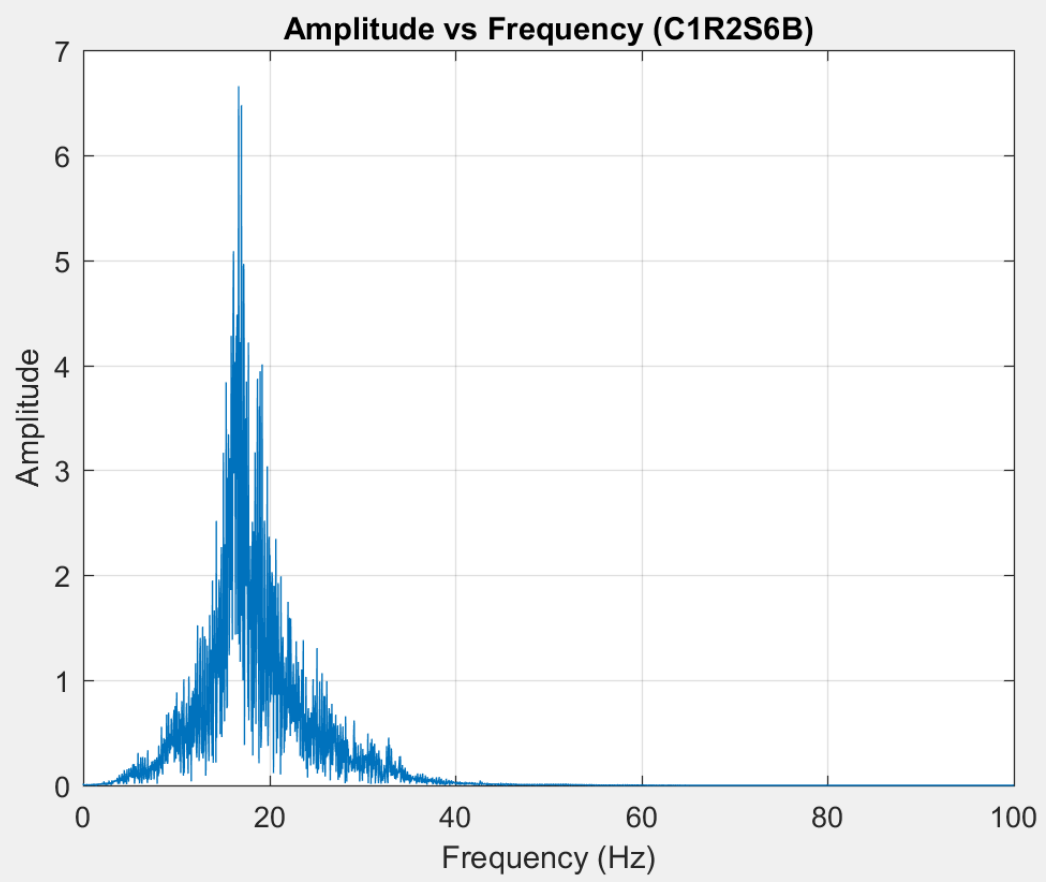

Figure A 14: C1R2S6B Amplitude vs. Frequency 


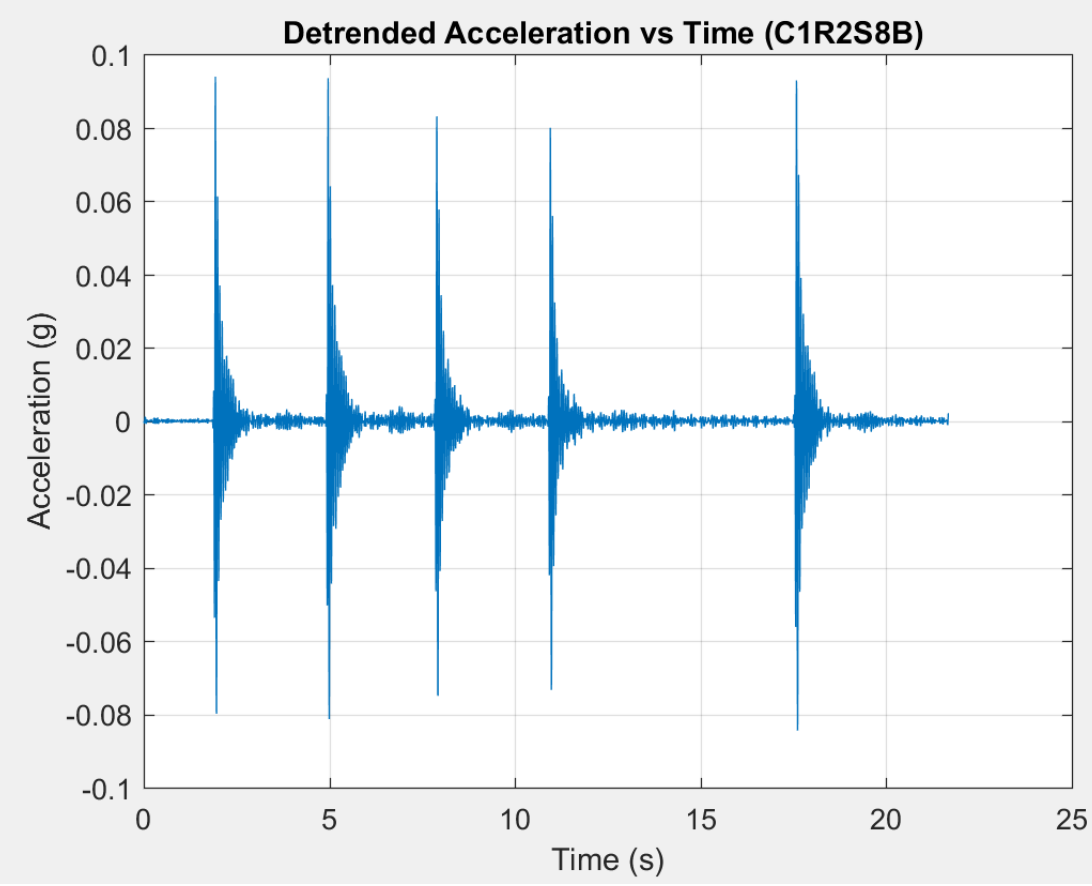

Figure A 15: C1R2S8B Acceleration vs. Time Graph

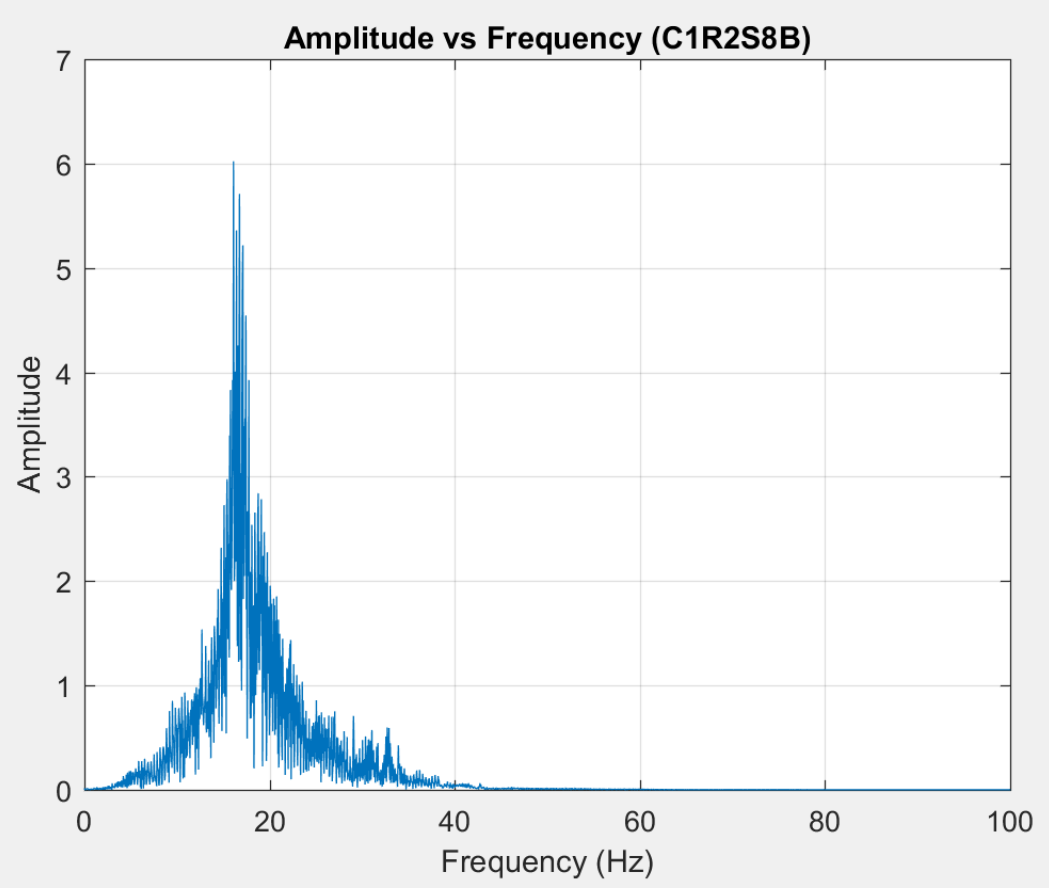

Figure A 16: C1R2S8B Amplitude vs. Frequency 


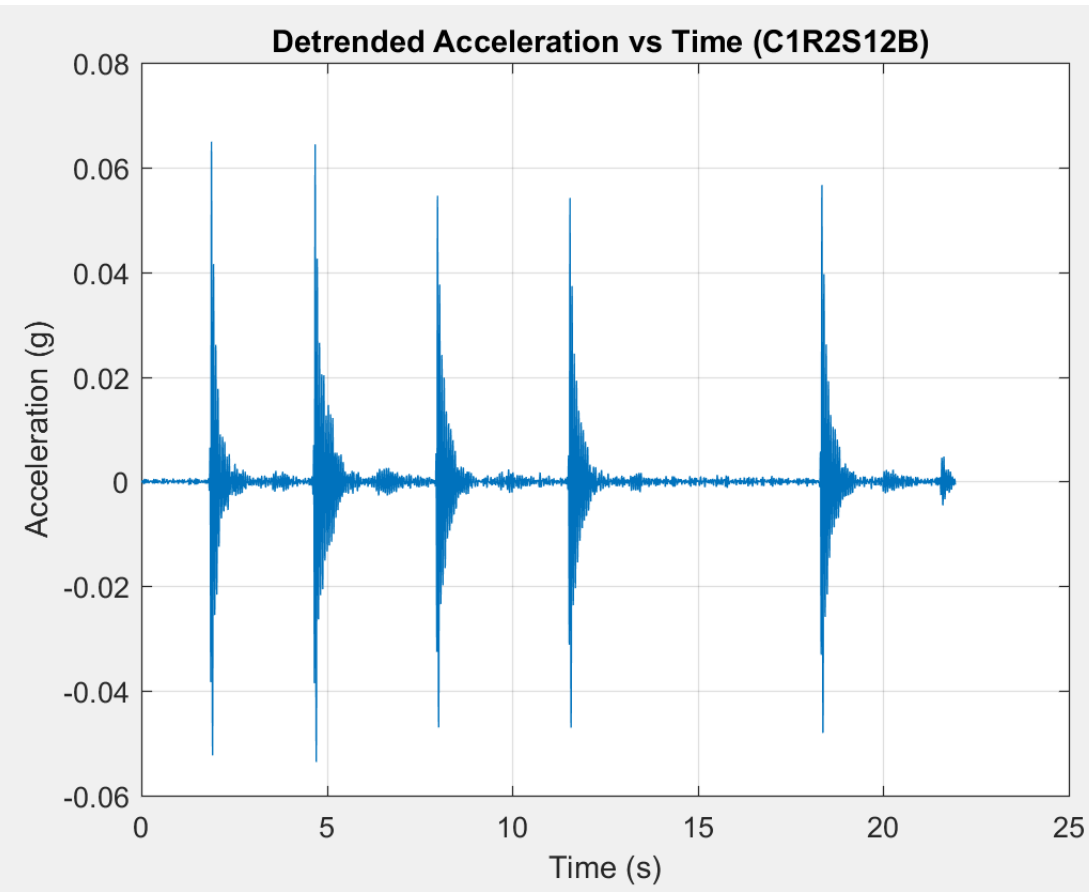

Figure A 17: C1R2S12B Acceleration vs. Time Graph

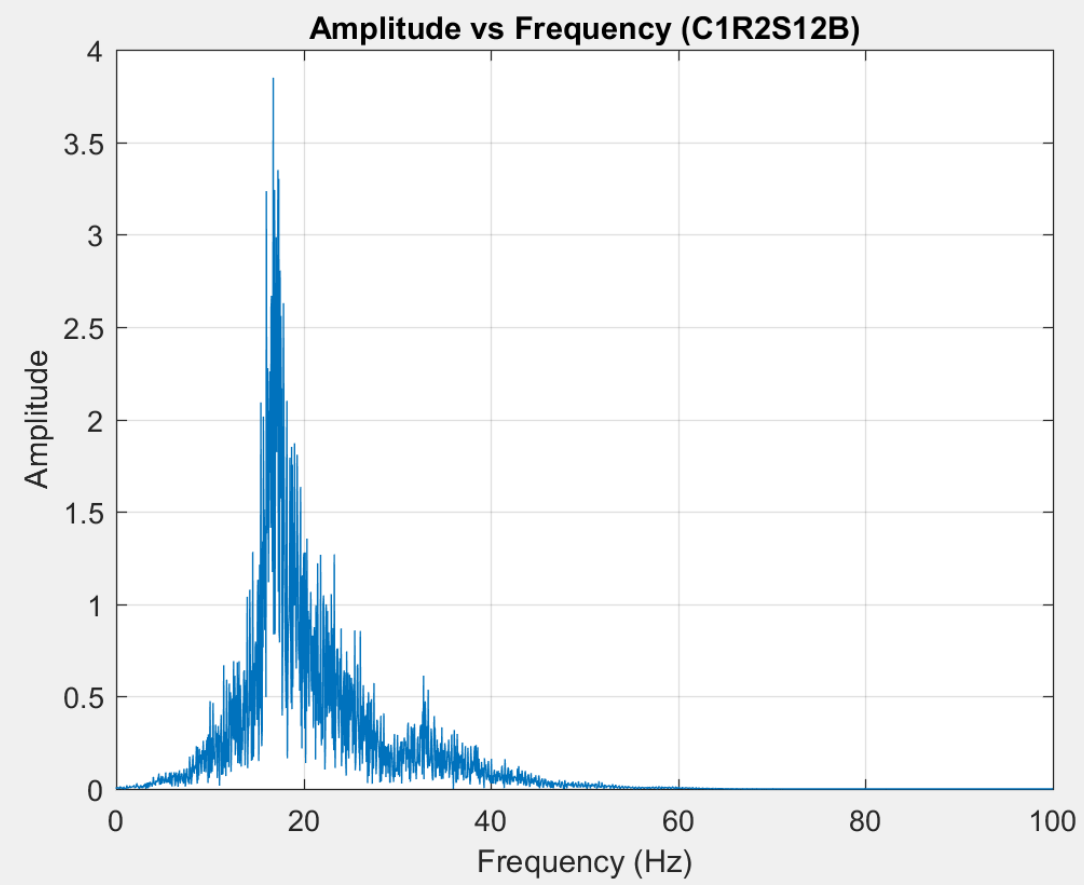

Figure A 18: C1R2S12B Amplitude vs. Frequency 


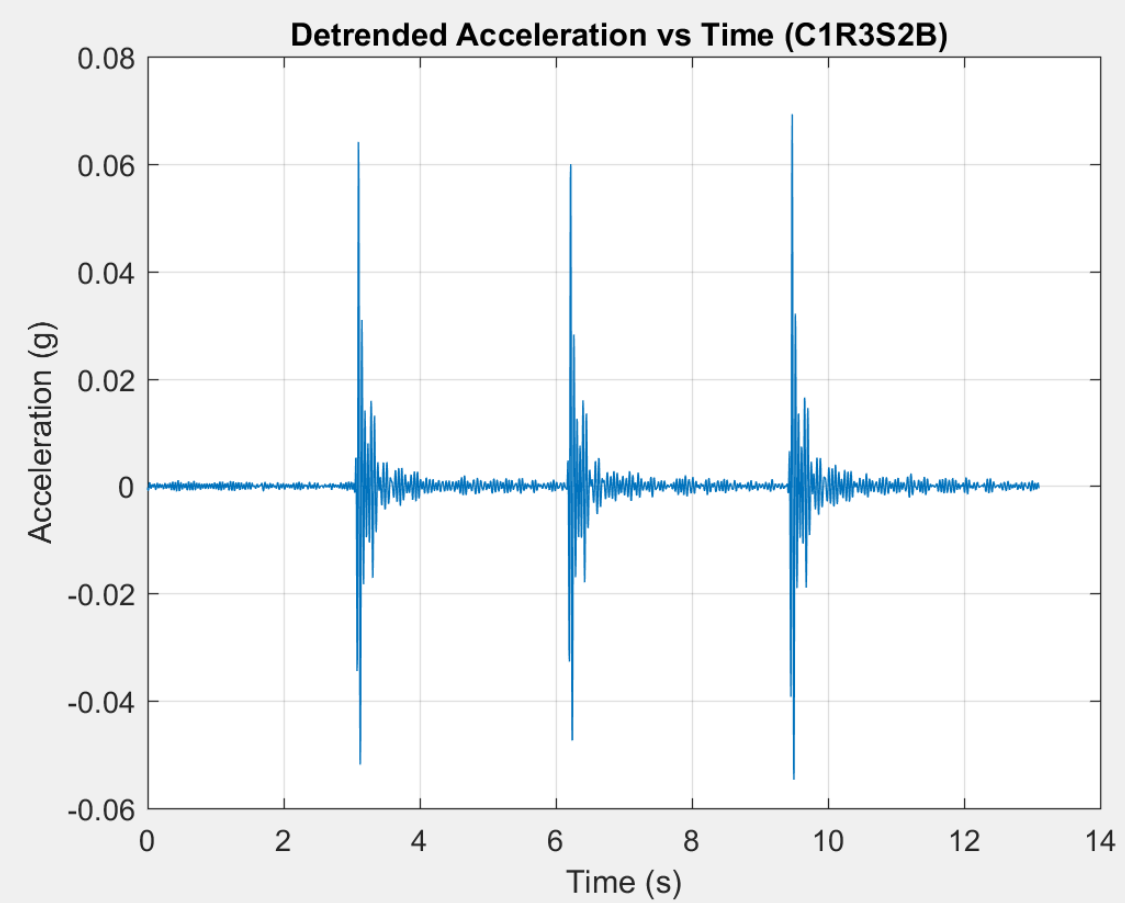

Figure A 19: C1R3S2B Acceleration vs. Time Graph

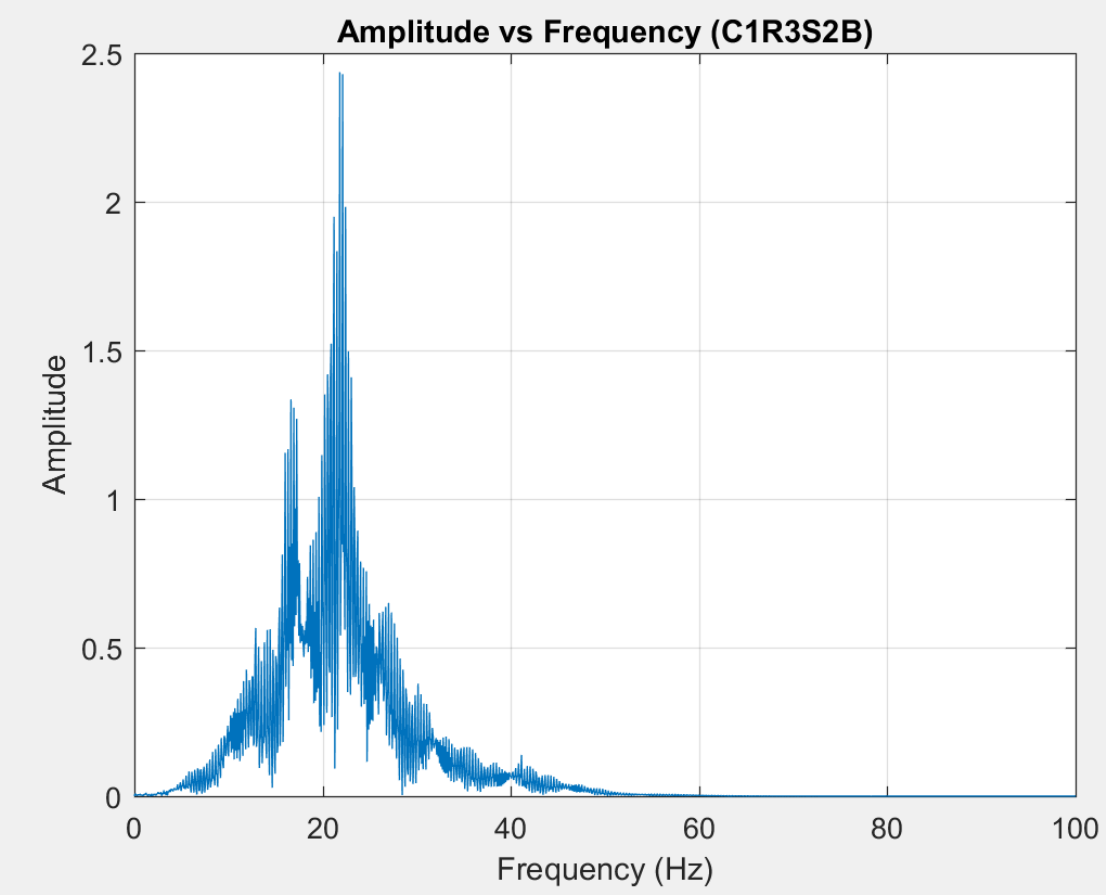

Figure A 20: C1R3S2B Amplitude vs. Frequency 


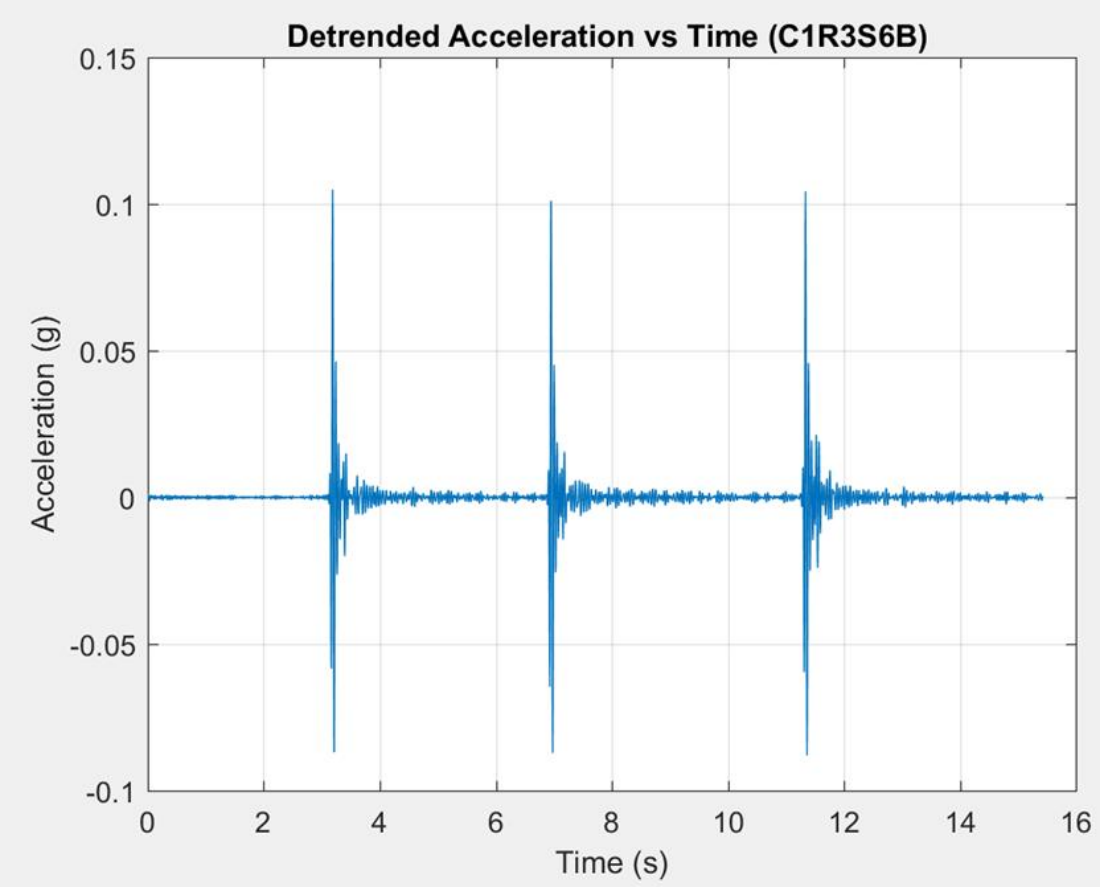

Figure A 21: C1R3S6B Acceleration vs. Time Graph

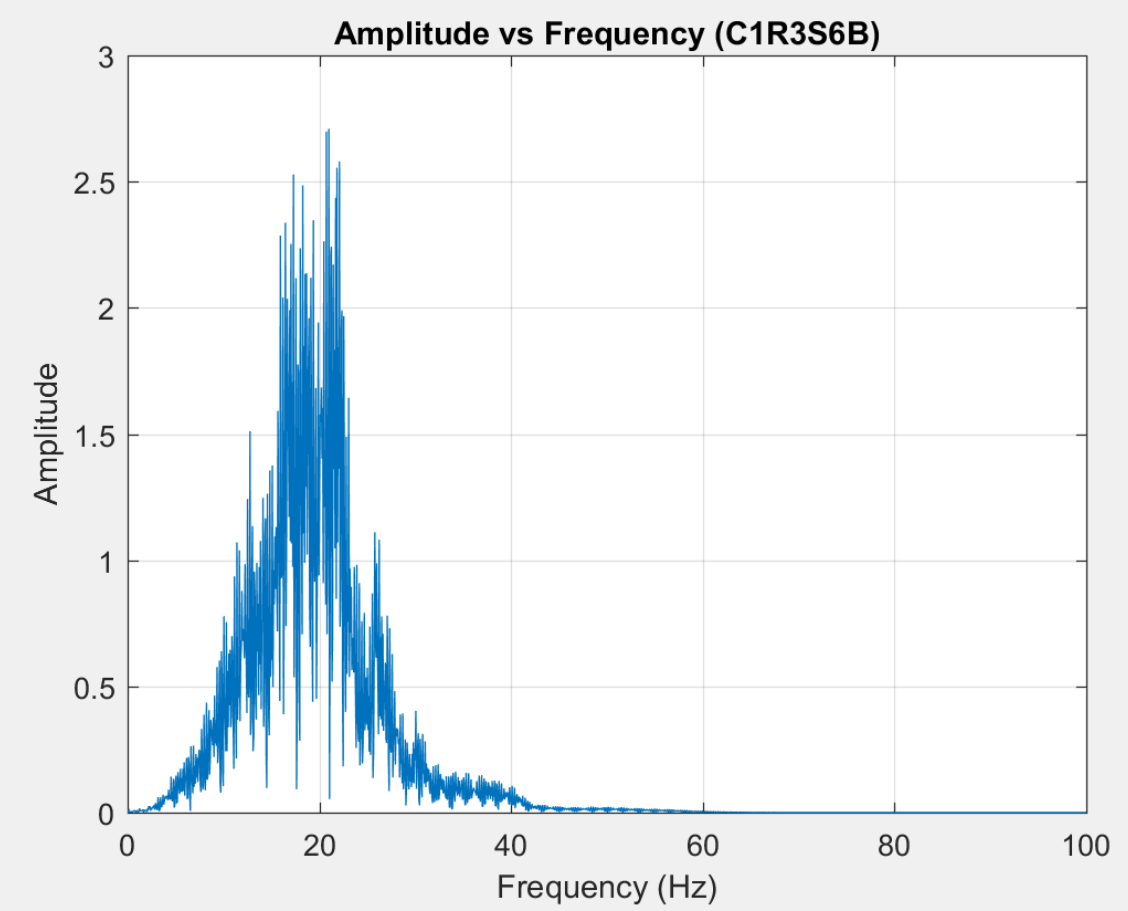

Figure A 22: C1R3S6B Amplitude vs. Frequency 


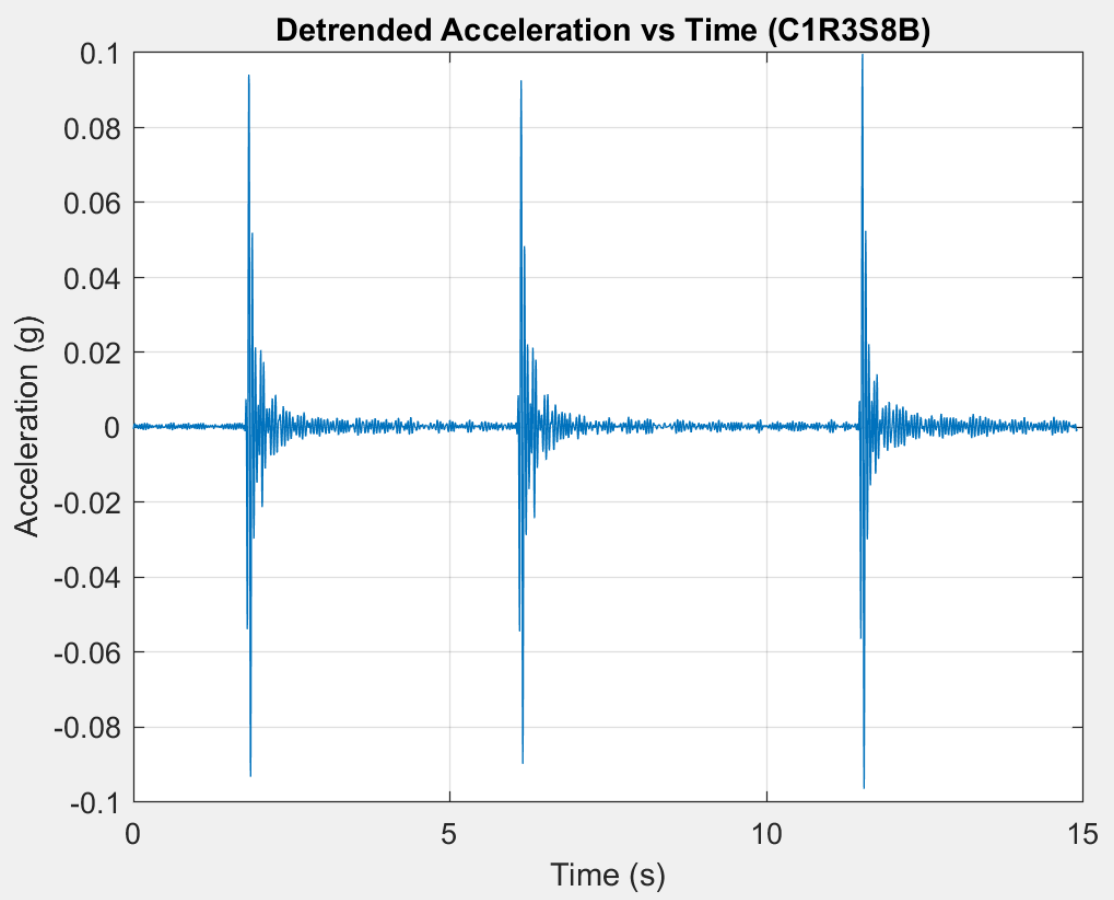

Figure A 23: C1R3S8B Acceleration vs. Time Graph

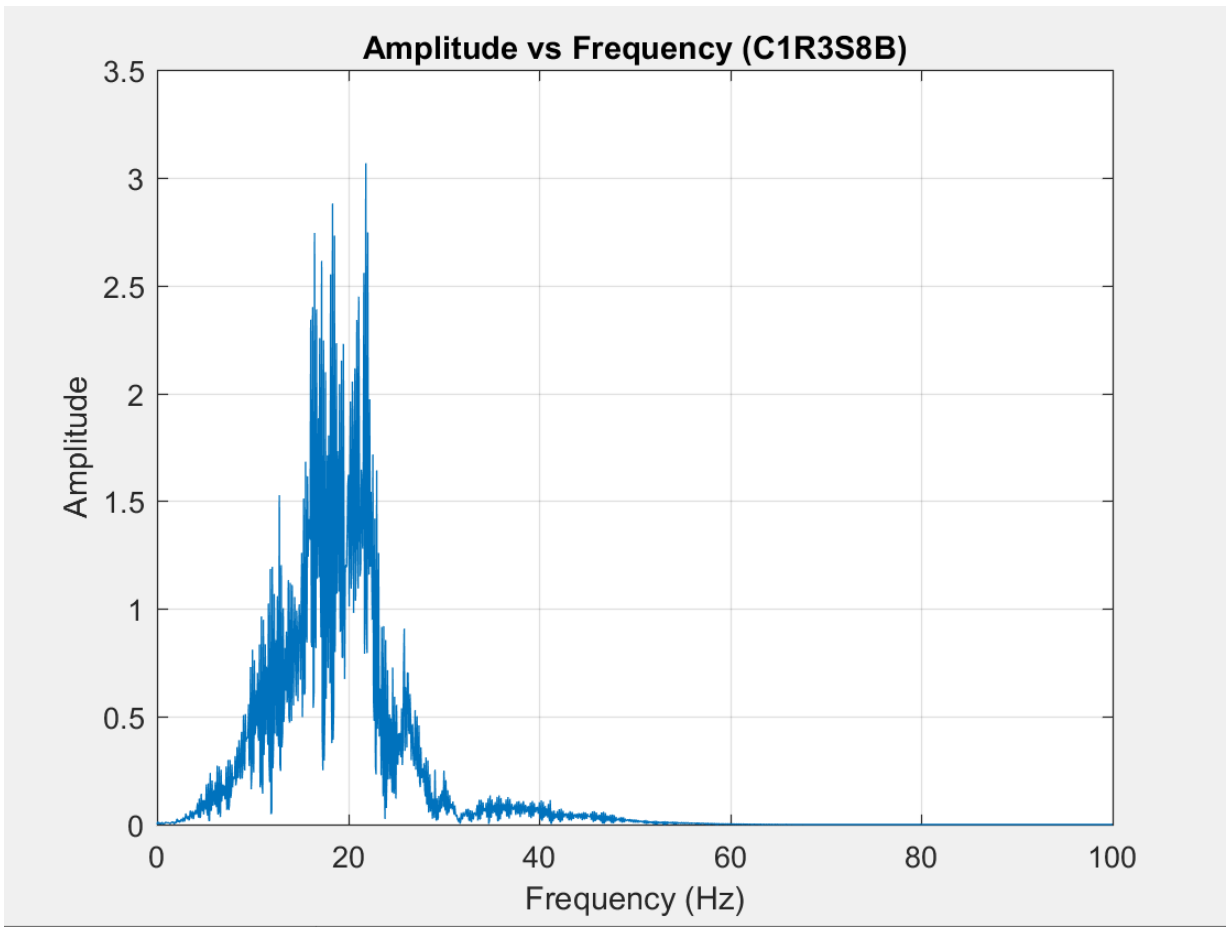

Figure A 24: C1R3S8B Amplitude vs. Frequency 


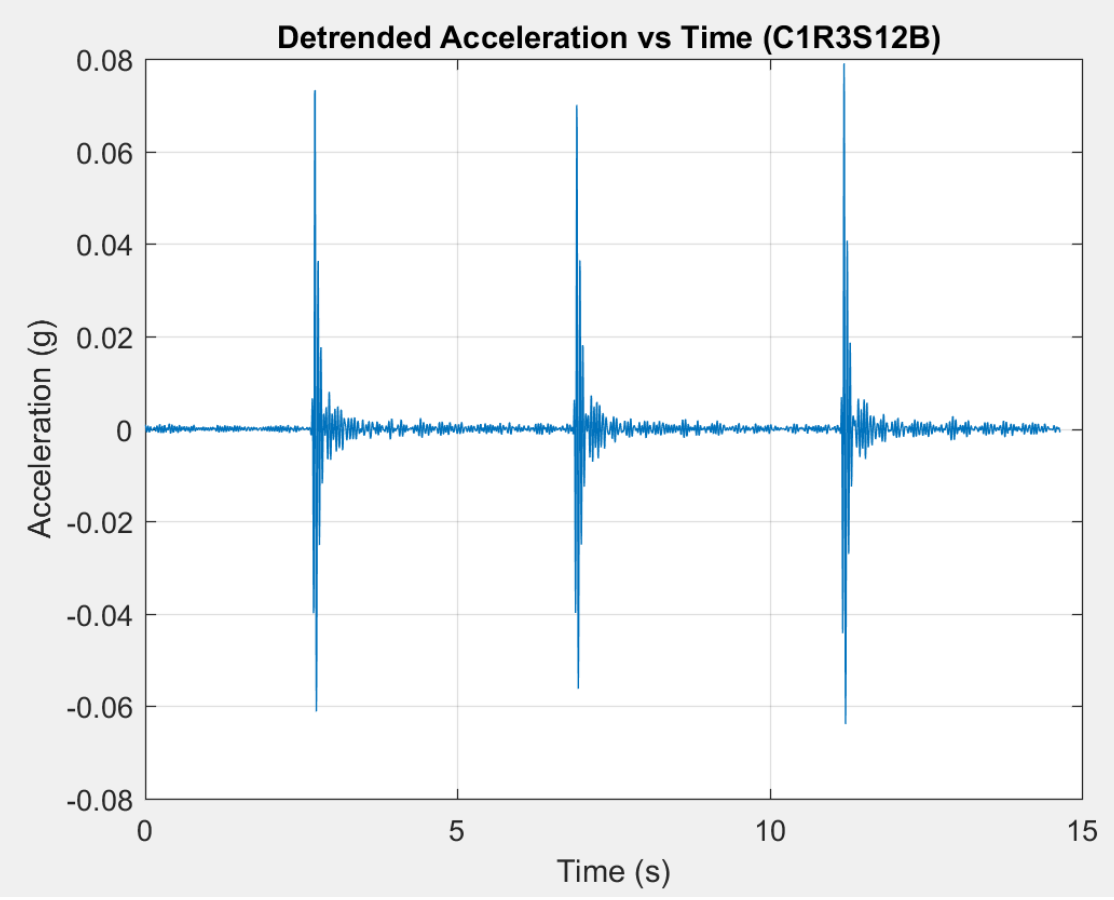

Figure A 25: C1R3S12B Acceleration vs. Time Graph

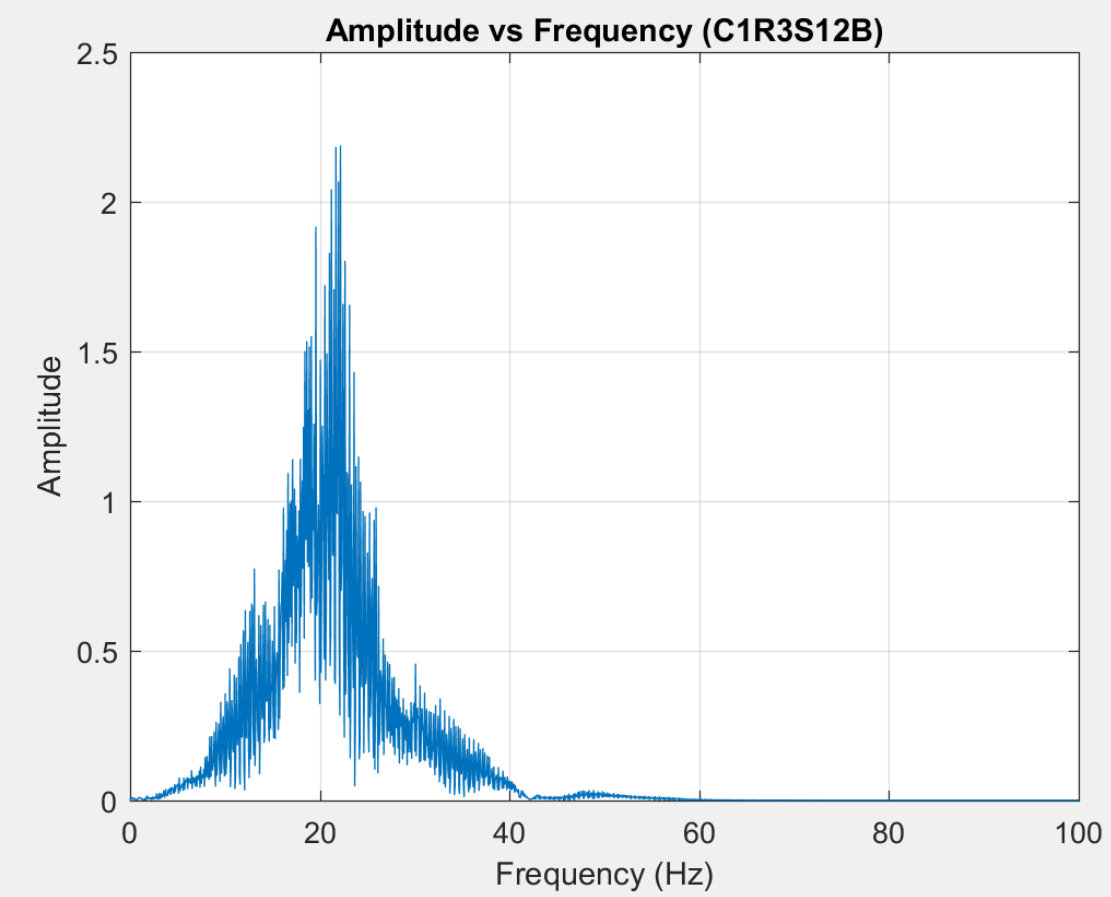

Figure A 26: C1R3S12B Amplitude vs. Frequency 


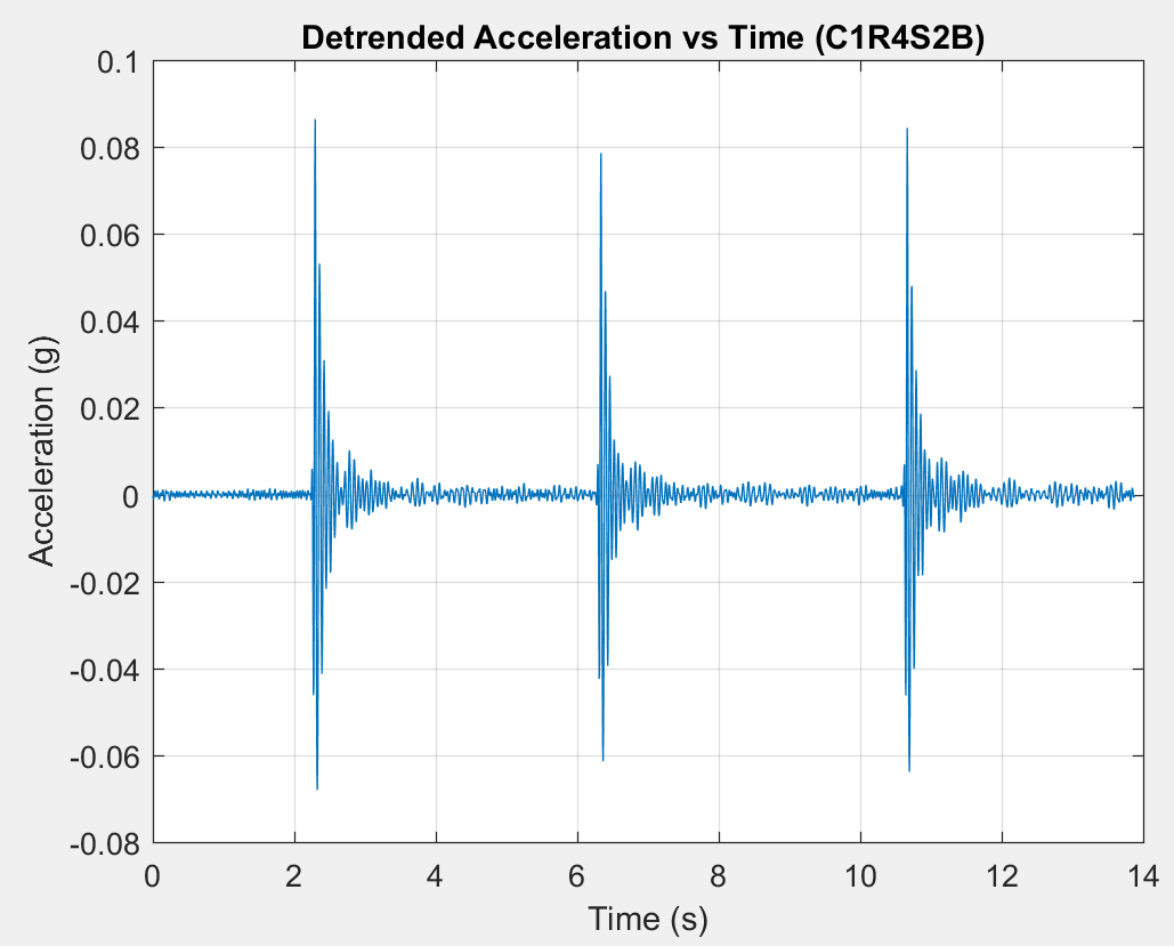

Figure A 27: C1R4S2B Acceleration vs. Time Graph

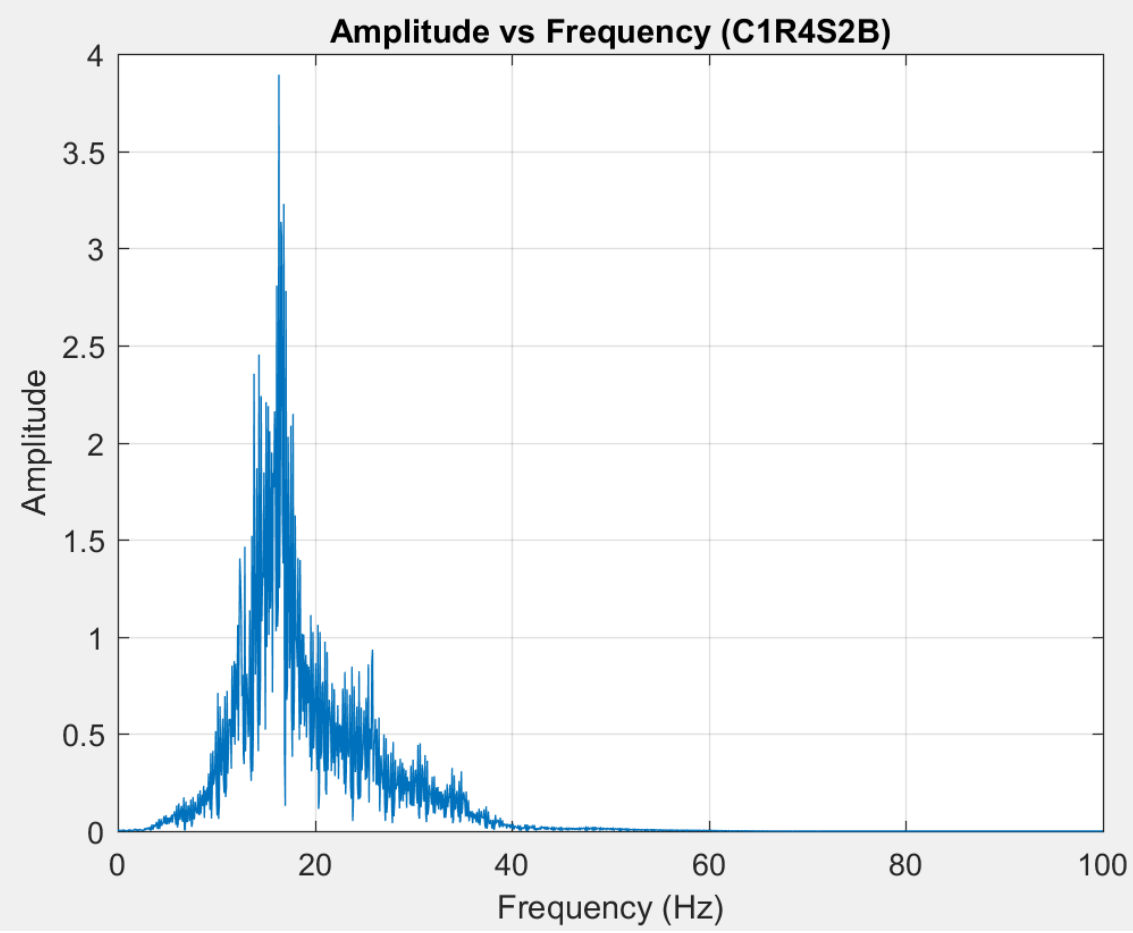

Figure A 28: C1R4S2B Amplitude vs. Frequency 


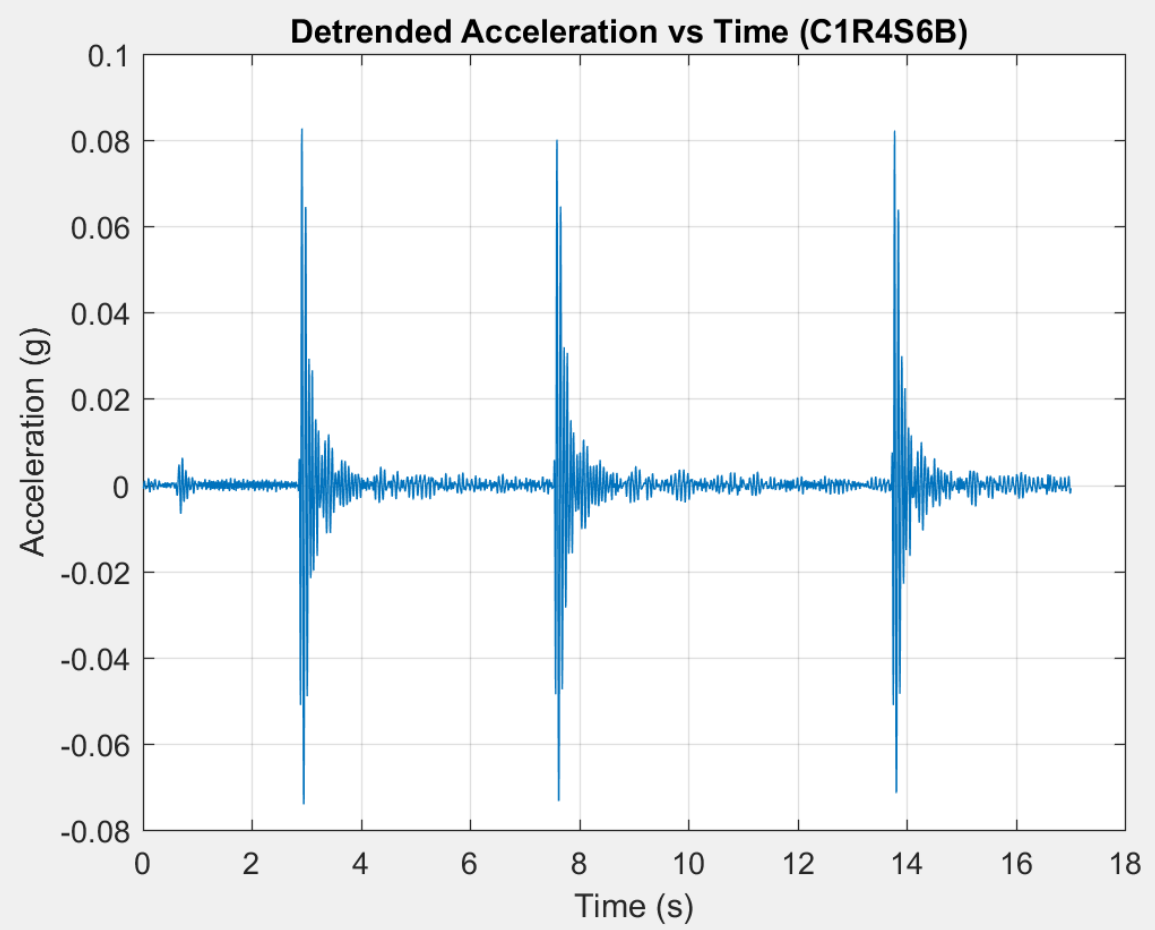

Figure A 29: C1R4S6B Acceleration vs. Time Graph

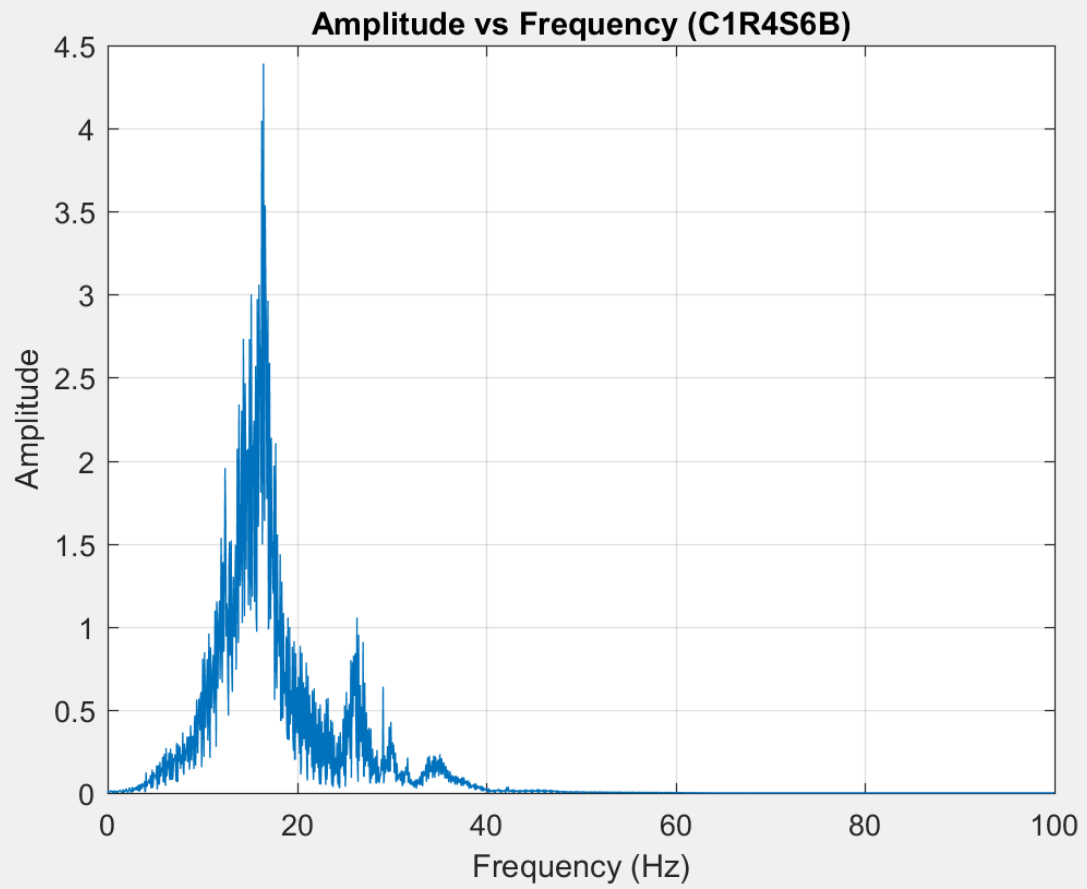

Figure A 30: C1R4S6B Amplitude vs. Frequency 


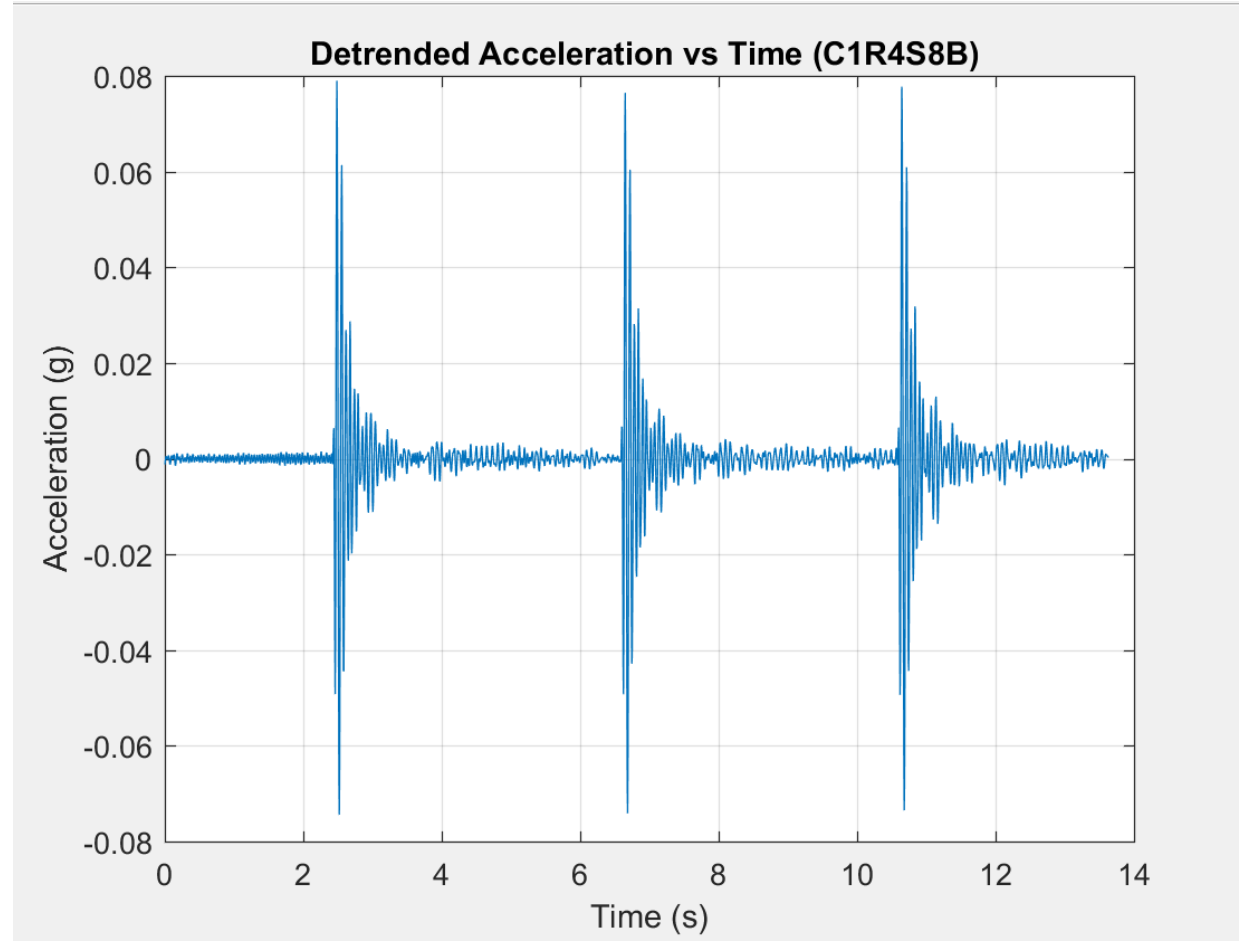

Figure A 31: C1R4S8B Acceleration vs. Time Graph

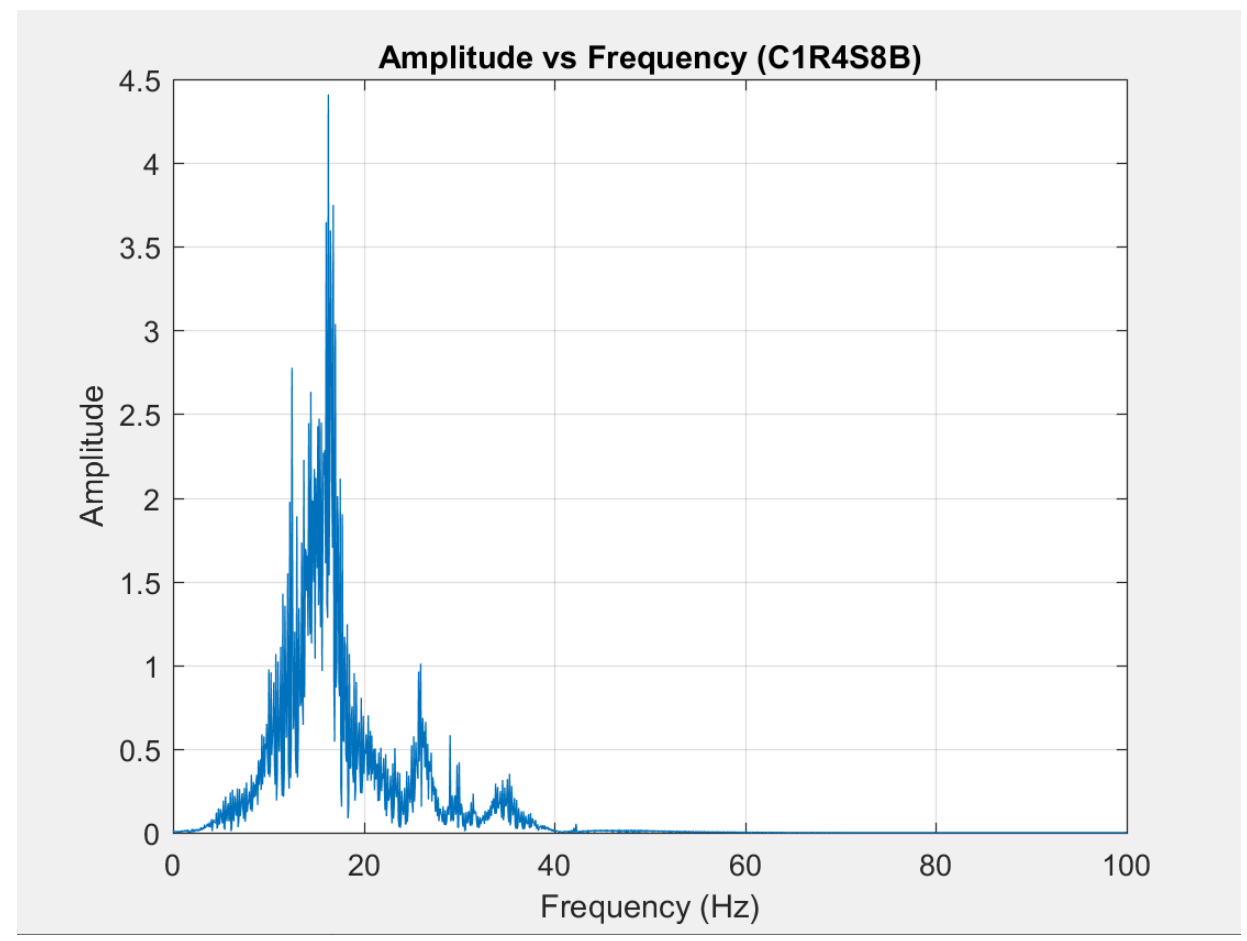

Figure A 32: C1R4S8B Amplitude vs. Frequency 


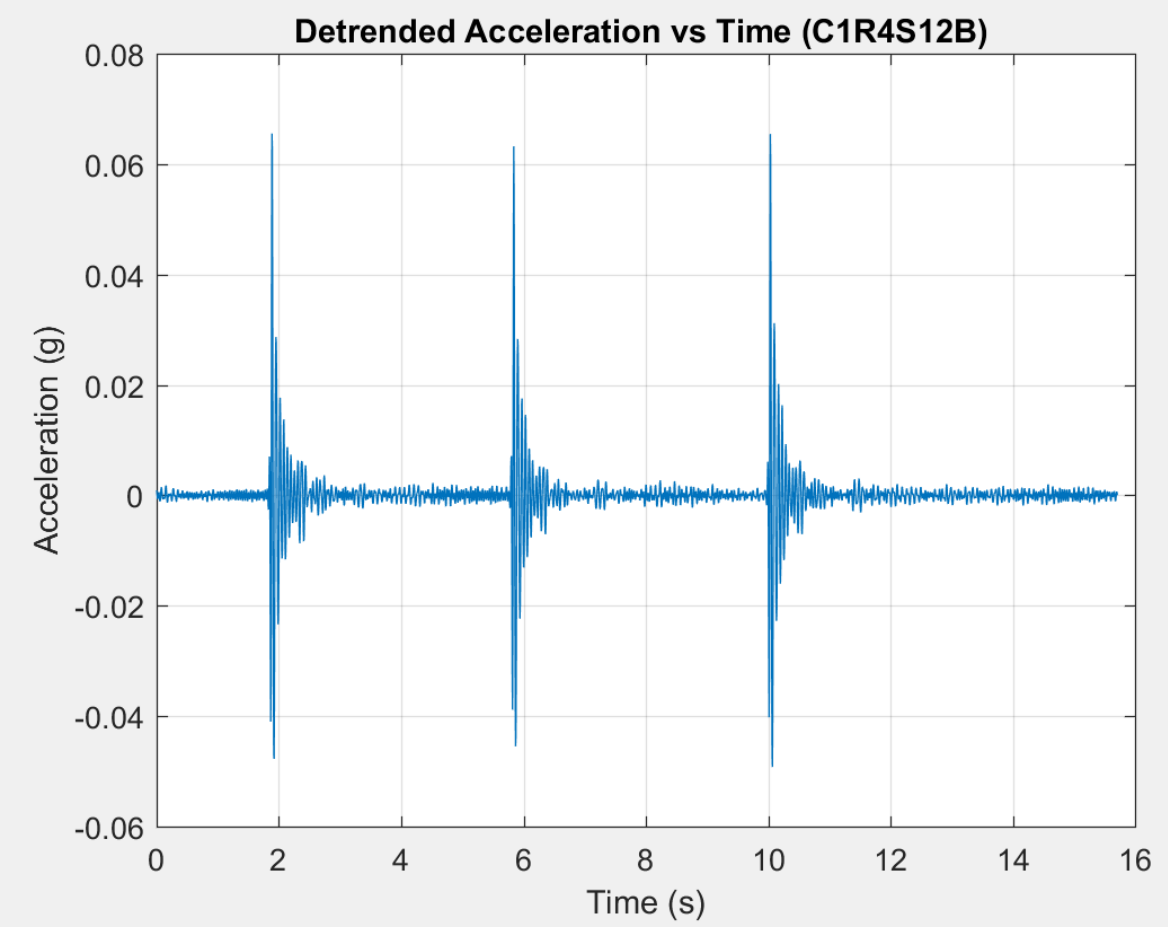

Figure A 33: C1R4S12B Acceleration vs. Time Graph

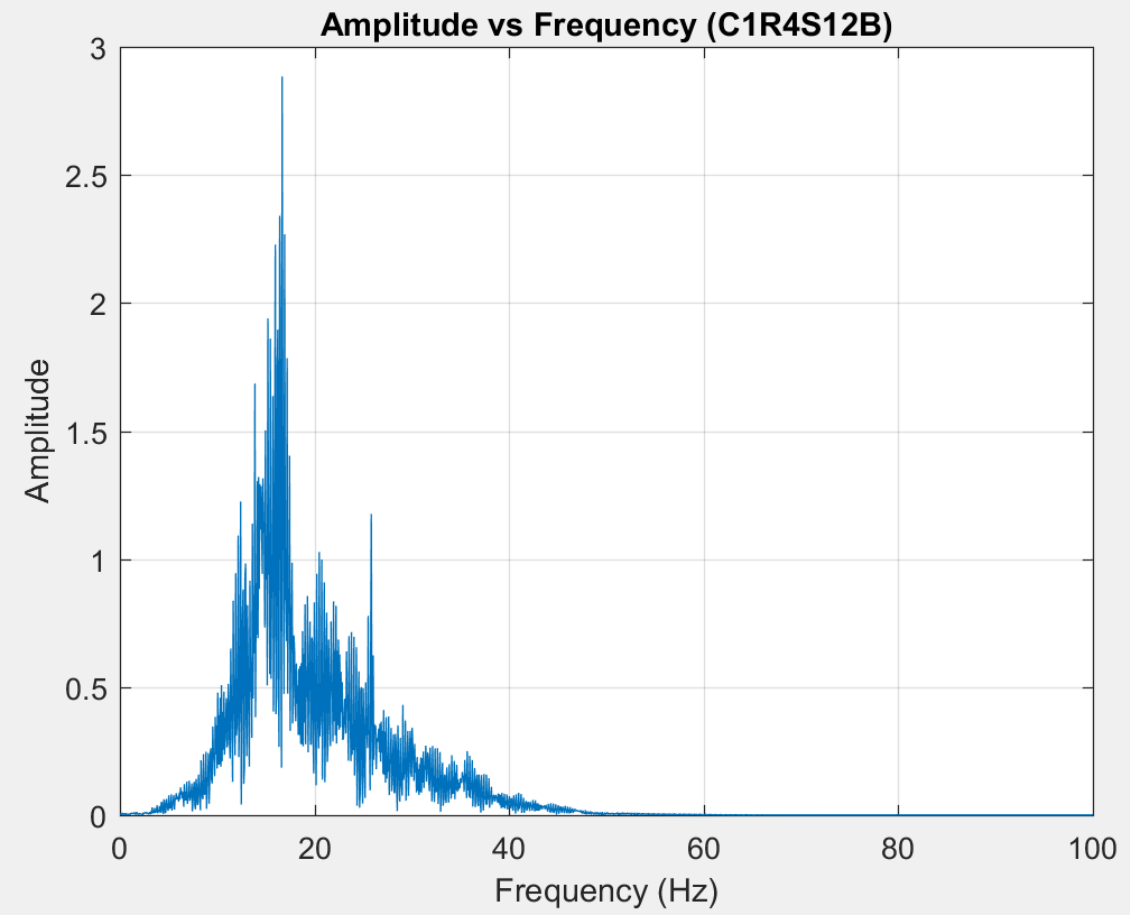

Figure A 34: C1R4S12B Amplitude vs. Frequency 


\begin{tabular}{|c|c|c|c|c|c|c|c|c|c|c|c|c|c|c|c|c|c|c|}
\hline \multirow{9}{*}{ 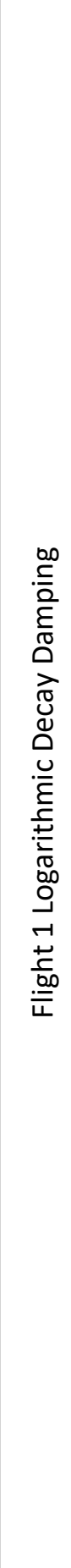 } & 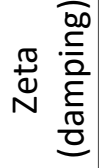 & $\begin{array}{l}\tilde{N} \\
\text { O̊. } \\
0\end{array}$ & 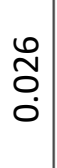 & $\begin{array}{l}\vec{m} \\
0 \\
\dot{0}\end{array}$ & $\begin{array}{l}0 \\
\text { Oִ } \\
0 \\
0\end{array}$ & $\begin{array}{l}0 \\
m \\
0 \\
0\end{array}$ & $\begin{array}{l}\tilde{m} \\
\tilde{0} \\
0\end{array}$ & $\begin{array}{l}m \\
\mathscr{n} \\
0 \\
0\end{array}$ & 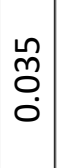 & $\begin{array}{l}\tilde{m} \\
\ddot{n} \\
\dot{0}\end{array}$ & 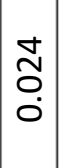 & $\left|\begin{array}{l}\tilde{m} \\
0 \\
0\end{array}\right|$ & $\begin{array}{l}0 \\
\dddot{m} \\
0 \\
0 \\
0\end{array}$ & $\begin{array}{l}m \\
\dddot{m} \\
0 \\
0\end{array}$ & \begin{tabular}{l}
$\infty$ \\
\multirow{0}{*}{} \\
0 \\
0
\end{tabular} & $\begin{array}{l}\infty \\
\text { On } \\
0\end{array}$ & $\begin{array}{l}\stackrel{P}{\circlearrowleft} \\
\text { ○े }\end{array}$ & \\
\hline & $\frac{\pi}{\frac{\pi}{0}}$ & $\begin{array}{l}\text { ने } \\
\text { - }\end{array}$ & $\begin{array}{l}n \\
ٌ \\
\ddots \\
0 \\
0\end{array}$ & 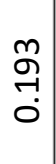 & 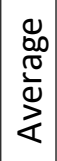 & 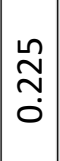 & $\begin{array}{l}0 \\
\stackrel{1}{1} \\
0\end{array}$ & 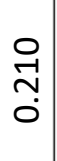 & 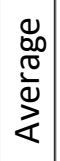 & 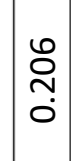 & $\begin{array}{c}n \\
\stackrel{n}{n} \\
\stackrel{0}{0} \\
\end{array}$ & જ. & 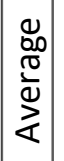 & 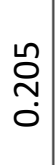 & $\begin{array}{c}\tilde{O} \\
\tilde{m} \\
0 \\
0\end{array}$ & 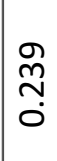 & 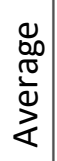 & \\
\hline & 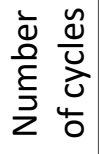 & 우 궁 & $\stackrel{ }{-1}$ & 우 & & $\stackrel{\circ}{-}$ & 욱 & $\underset{\sim}{\sim}$ & & $\stackrel{\sim}{\sim}$ & $\underset{\sim}{\sim}$ & $\stackrel{-}{ન}$ & & $\stackrel{ }{-}$ & $\stackrel{ }{-}$ & $\stackrel{\circ}{-}$ & & \\
\hline & 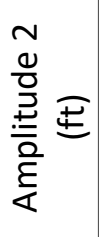 & $\begin{array}{l}0 \\
\varnothing \\
\dot{1} \\
\text { யे } \\
\infty \\
\infty\end{array}$ & \begin{tabular}{c|}
0 \\
0 \\
$\dot{1}$ \\
హ. \\
$\sim$ \\
$\infty$ \\
$\infty$
\end{tabular} & 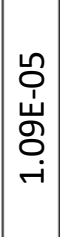 & & 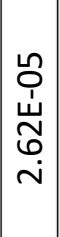 & 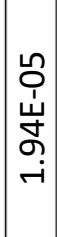 & $\begin{array}{c}\stackrel{\sim}{0} \\
\dot{u} \\
\stackrel{\sim}{n} \\
m \\
-i\end{array}$ & & 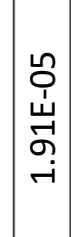 & 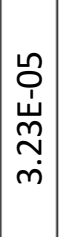 & 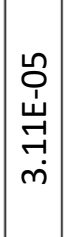 & & 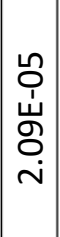 & 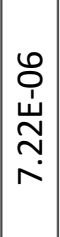 & 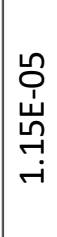 & & 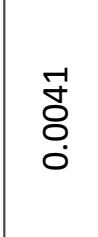 \\
\hline & 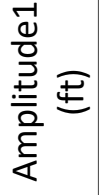 & 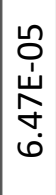 & 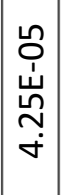 & 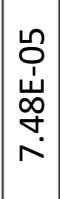 & & 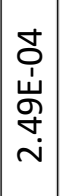 & $\begin{array}{c}\text { O } \\
\dot{1} \\
\dot{u} \\
0 \\
0 \\
-i\end{array}$ & 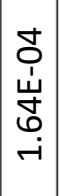 & & 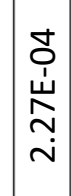 & 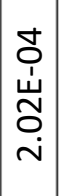 & 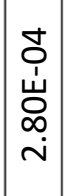 & & $\begin{array}{l}\text { ठ } \\
\dot{u} \\
\text { ஸै } \\
-i\end{array}$ & 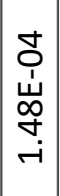 & 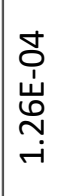 & & 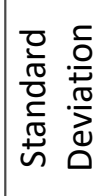 \\
\hline & $\begin{array}{l}\stackrel{0}{d} \\
\stackrel{ \pm}{\sim}\end{array}$ & $\sim$ & $N$ & $N$ & & 6 & 6 & 6 & & $\infty$ & $\infty$ & $\infty$ & & $\stackrel{\sim}{\sim}$ & $\stackrel{\sim}{\sim}$ & $\underset{\sim}{\sim}$ & & \\
\hline & 蒙 & $r$ & -1 & -1 & & $r$ & -1 & $\neg$ & & $r$ & -1 & -1 & & -1 & -1 & -1 & & \\
\hline & 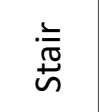 & $r$ & $r$ & $r$ & & $r$ & -1 & - & & $r$ & -1 & -1 & & $r$ & $r$ & $r$ & & $\stackrel{m}{\dddot{n}}$ \\
\hline & 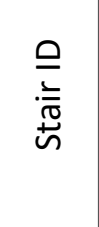 & $\begin{array}{l}\stackrel{\infty}{\sim} \\
\stackrel{\sim}{\sim} \\
\stackrel{\sim}{\sim}\end{array}$ & 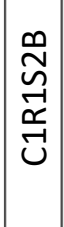 & 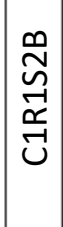 & 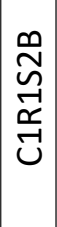 & 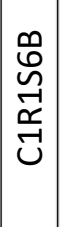 & 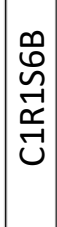 & 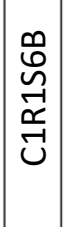 & 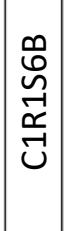 & $\begin{array}{l}\infty \\
\infty \\
\sim \\
\sim \\
\stackrel{\sim}{\sim} \\
\vec{\sim} \\
\end{array}$ & $\begin{array}{l}\infty \\
\infty \\
\sim \\
\stackrel{\sim}{a} \\
\stackrel{\sim}{\sim} \\
u\end{array}$ & 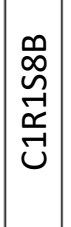 & \begin{tabular}{l|}
$\infty$ \\
$\infty$ \\
$\sim$ \\
$\sim$ \\
$\stackrel{\sim}{\sim}$ \\
$ت$ \\
$ن$
\end{tabular} & 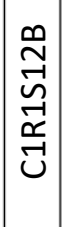 & 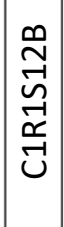 & 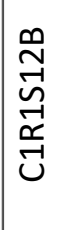 & 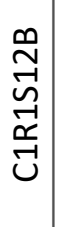 & $\begin{array}{l}\frac{0}{0} \\
\frac{\pi}{0} \\
\frac{1}{2} \\
\frac{\pi}{\pi} \\
\frac{0}{0} \\
\frac{0}{0}\end{array}$ \\
\hline
\end{tabular}




\begin{tabular}{|c|c|c|c|c|c|c|c|c|c|c|c|c|c|c|c|c|c|c|}
\hline \multirow{9}{*}{ 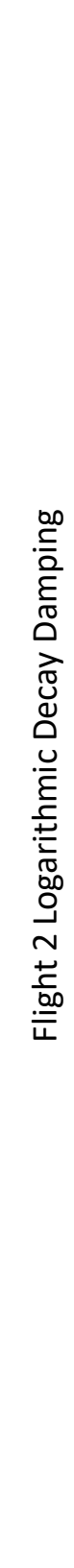 } & 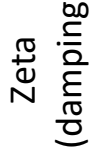 & $\begin{array}{l}\infty \\
\varnothing \\
0\end{array}$ & 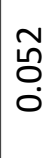 & $\begin{array}{l}\vec{y} \\
0 \\
0\end{array}$ & $\begin{array}{l}\text { ஸे } \\
0 \\
0\end{array}$ & $\begin{array}{l}\text { ֻू } \\
0 \\
0\end{array}$ & $\begin{array}{l}0 \\
0 \\
0\end{array}$ & $\begin{array}{l}\text { ఫे } \\
\text { : }\end{array}$ & $\begin{array}{l}\text { 䓃 } \\
\text { Oे }\end{array}$ & $\begin{array}{l}\text { ڤै } \\
\text { ○’ }\end{array}$ & $\begin{array}{l}\hat{\circ} \\
0 \\
0\end{array}$ & 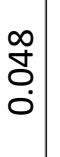 & $\begin{array}{l}\mathscr{0} \\
\stackrel{2}{\circ} \\
\stackrel{0}{ }\end{array}$ & 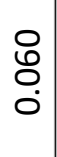 & $\begin{array}{l}\text { f } \\
\dot{0}\end{array}$ & $\begin{array}{l}\vec{G} \\
\dot{O} \\
\dot{0}\end{array}$ & $\begin{array}{l}\text { 융 } \\
\text { ○் } \\
\text {. }\end{array}$ & \\
\hline & $\frac{\pi}{ \pm}$ & $\begin{array}{l}\stackrel{\Im}{f} \\
\stackrel{0}{0}\end{array}$ & 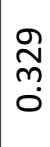 & \begin{tabular}{l}
$\stackrel{\infty}{N}$ \\
\multirow{0}{0}{}
\end{tabular} & 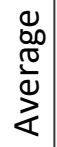 & $\begin{array}{c}\tilde{m} \\
m \\
0\end{array}$ & $\begin{array}{l}\text { న } \\
\stackrel{\infty}{0} \\
0\end{array}$ & $\begin{array}{l}\vec{\delta} \\
\text { ఫे } \\
\dot{0}\end{array}$ & $\begin{array}{l}0 \\
0 \\
\frac{0}{0} \\
\frac{0}{2} \\
\frac{\pi}{2}\end{array}$ & 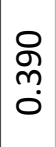 & $\begin{array}{l}\overrightarrow{6} \\
m \\
0\end{array}$ & $\begin{array}{l}\text { शे } \\
\text { مे }\end{array}$ & $\begin{array}{l}0 \\
20 \\
\frac{\pi}{0} \\
\frac{0}{4} \\
\frac{1}{4}\end{array}$ & $\begin{array}{l}\stackrel{\infty}{\infty} \\
m \\
\grave{0}\end{array}$ & 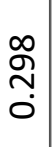 & 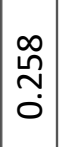 & $\begin{array}{l}0 \\
0 \\
\frac{0}{0} \\
\frac{0}{1} \\
\frac{1}{4}\end{array}$ & \\
\hline & 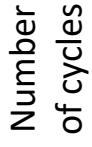 & 의 강 & 윅 & $\stackrel{ }{-}$ & & 욱 & $\stackrel{\circ}{\rightarrow}$ & 욱 & & 욱 & 위 & 엄 & & 욱 & $\stackrel{\circ}{-}$ & 우 & & \\
\hline & 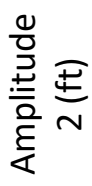 & 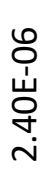 & 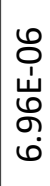 & 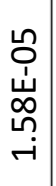 & & 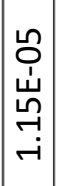 & 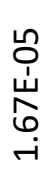 & 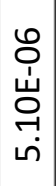 & & 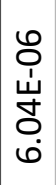 & $\begin{array}{l}\varphi \\
0 \\
\dot{u} \\
m \\
\infty \\
\sigma\end{array}$ & 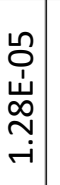 & & 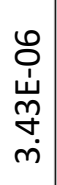 & $\begin{array}{l}\mathscr{0} \\
⿱ \\
\dot{u} \\
o \\
\dot{\sigma} \\
\sigma\end{array}$ & 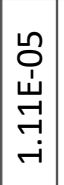 & & $\begin{array}{l}\text { ¿̊ } \\
\text { ¿ }\end{array}$ \\
\hline & 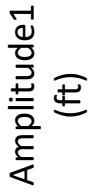 & 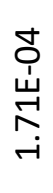 & $\begin{array}{l}\text { ठ } \\
\dot{1} \\
\dot{\infty} \\
\infty \\
\infty \\
-1\end{array}$ & 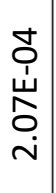 & & 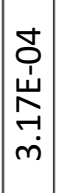 & 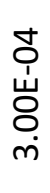 & 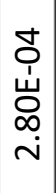 & & 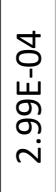 & $\begin{array}{l}\text { Oे } \\
\dot{山} \\
\tilde{\eta} \\
\dot{m} \\
\dot{m}\end{array}$ & 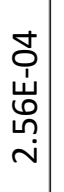 & & 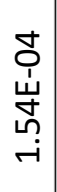 & $\begin{array}{c}\text { J } \\
⿱ \\
山 \\
ٌ \\
\infty \\
- \\
-\end{array}$ & 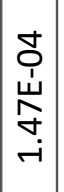 & & 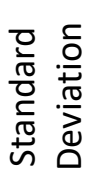 \\
\hline & 离 & $\sim$ & $N$ & $\sim$ & & 6 & 6 & 6 & & $\infty$ & $\infty$ & $\infty$ & & $\stackrel{\sim}{\sim}$ & $\stackrel{\sim}{\neg}$ & $\stackrel{\sim}{\sim}$ & & \\
\hline & 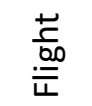 & $N$ & $\sim$ & $\sim$ & & $\sim$ & $\sim$ & $\sim$ & & $\sim$ & $\sim$ & $\sim$ & & $\sim$ & $\sim$ & $\sim$ & & \\
\hline & $\begin{array}{l}. \frac{\pi}{\pi} \\
\stackrel{ \pm n}{n}\end{array}$ & $r$ & - & -1 & & 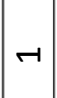 & 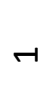 & -1 & & $\neg$ & -1 & $r$ & & -1 & -1 & $\neg$ & & ભ̂̉ \\
\hline & $\begin{array}{l}\text { 은 } \\
\text { 离 } \\
\text { 足 }\end{array}$ & 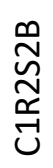 & $\begin{array}{l}\stackrel{\infty}{\sim} \\
\underset{\sim}{\sim} \\
\stackrel{\sim}{U}\end{array}$ & $\begin{array}{l}\stackrel{\infty}{N} \\
\underset{\sim}{\sim} \\
\underset{\sim}{U}\end{array}$ & 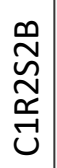 & 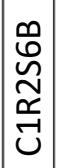 & 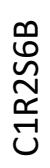 & 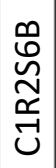 & 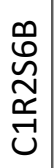 & $\begin{array}{l}\infty \\
\stackrel{\infty}{\sim} \\
\underset{\sim}{\sim} \\
\underset{\sim}{\sim}\end{array}$ & 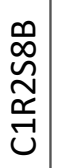 & 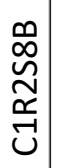 & 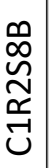 & $\begin{array}{l}\stackrel{n}{\sim} \\
\underset{\sim}{\sim} \\
\underset{\sim}{\sim} \\
\text { ப் }\end{array}$ & 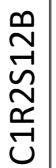 & 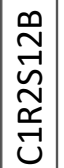 & 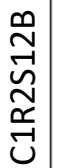 & 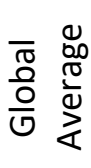 \\
\hline
\end{tabular}




\begin{tabular}{|c|c|c|c|c|c|c|c|c|c|c|c|c|c|c|c|c|c|c|}
\hline \multirow{9}{*}{ 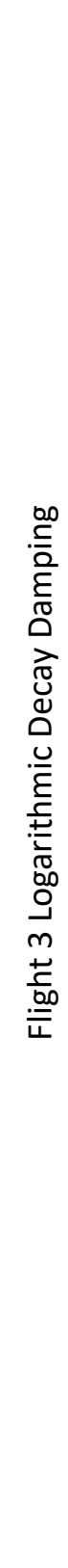 } & 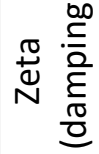 & 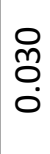 & 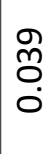 & $\begin{array}{l}\ddot{m} \\
\text { Oे } \\
0\end{array}$ & $\begin{array}{l}m \\
m \\
0 \\
\dot{0}\end{array}$ & $\begin{array}{l}\text { Лે } \\
\circ \\
0\end{array}$ & 苟 & $\begin{array}{l}\hat{n} \\
\text { ถે․ }\end{array}$ & $\begin{array}{l}\hat{n} \\
\text { ọ } \\
\text {. }\end{array}$ & $\begin{array}{l}\mathscr{m} \\
\mathscr{\emptyset} \\
\dot{0}\end{array}$ & 䒘 & $\begin{array}{l}\text { กิ } \\
\text { ○் } \\
\end{array}$ & $\begin{array}{l}\hat{n} \\
\text { ஸे } \\
0\end{array}$ & $\begin{array}{l}0 \\
\text { Ц̊n } \\
0\end{array}$ & $\begin{array}{l}-1 \\
\dot{J} \\
0\end{array}$ & $\mid \begin{array}{l}n \\
ٌ ٌ 0 \\
0 \\
0\end{array}$ & 윰 & \\
\hline & $\frac{\Phi}{\square}$ & $\underset{\text { ㄱ. }}{\stackrel{8}{\circ}}$ & 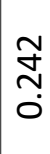 & 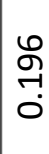 & 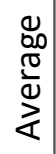 & \begin{tabular}{c}
\multirow{n}{m}{} \\
0
\end{tabular} & $\mid \begin{array}{c}-1 \\
\tilde{m} \\
0 \\
0\end{array}$ & $\begin{array}{l}\stackrel{9}{\leftrightarrow} \\
m \\
0\end{array}$ & 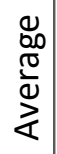 & 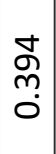 & $\begin{array}{l}0 \\
0 \\
m \\
0\end{array}$ & $\begin{array}{l}0 \\
\tilde{N} \\
\tilde{o} \\
0\end{array}$ & 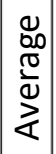 & $\begin{array}{c}\text { N̂} \\
n \\
0 \\
0\end{array}$ & 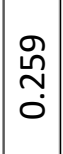 & $\begin{array}{l}\stackrel{n}{m} \\
m \\
0\end{array}$ & 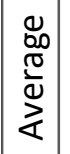 & \\
\hline & 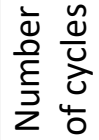 & 어 & 어 & 위 & & $\stackrel{\circ}{-}$ & 어 & 엄 & & 위 & 욱 & 엄 & & 위 & $\exists$ & 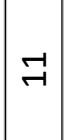 & & \\
\hline & 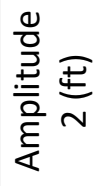 & 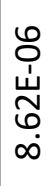 & 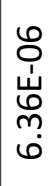 & $\begin{array}{l}0 \\
0 \\
\dot{1} \\
\underline{\omega} \\
m \\
\infty\end{array}$ & & 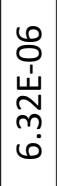 & 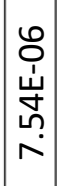 & $\begin{array}{c}\text { 오 } \\
\stackrel{1}{u} \\
\text { ๊ } \\
\text { - }\end{array}$ & & 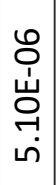 & 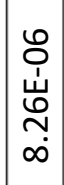 & $\begin{array}{l}\text { o } \\
\dot{1} \\
\stackrel{\omega}{\sigma} \\
\sigma \\
\sigma \\
\sigma\end{array}$ & & $\mid \begin{array}{l}0 \\
0 \\
\dot{u} \\
\underline{ٌ} \\
\emptyset \\
\dot{0}\end{array}$ & 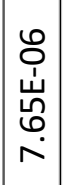 & 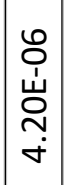 & & $\begin{array}{l}\circ \\
\stackrel{9}{0} \\
0 \\
0\end{array}$ \\
\hline & 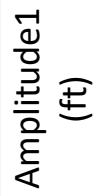 & 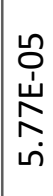 & 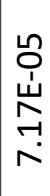 & $\begin{array}{l}\text { ஸे } \\
\text { ய் } \\
\text { ஸे } \\
\text { ம் }\end{array}$ & & 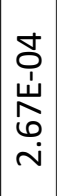 & 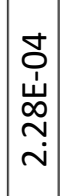 & 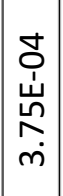 & & 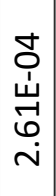 & $\begin{array}{l}\dot{J} \\
\dot{⿱} \\
\dot{u} \\
0 \\
\dot{m}\end{array}$ & 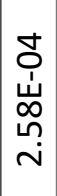 & & 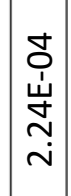 & $\begin{array}{c}\dot{J} \\
\stackrel{+}{u} \\
\stackrel{\sim}{\sim} \\
m \\
-i\end{array}$ & 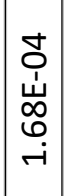 & & 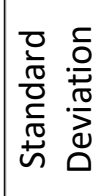 \\
\hline & 这 & $\sim$ & $\sim$ & $\sim$ & & 6 & 6 & 6 & & $\infty$ & $\infty$ & $\infty$ & & $\underset{\neg}{\Im}$ & $\stackrel{\sim}{\neg}$ & $\underset{\sim}{\sim}$ & & \\
\hline & 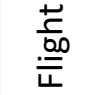 & $m$ & $m$ & $m$ & & $m$ & $m$ & $m$ & & $m$ & $m$ & $m$ & & $m$ & $m$ & $m$ & & \\
\hline & 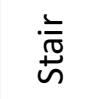 & $r$ & $r$ & $r$ & & -1 & -1 & $r$ & & -1 & $\neg$ & -1 & & $r$ & $\neg$ & $r$ & & 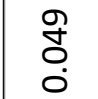 \\
\hline & $\begin{array}{l}\text { 으 } \\
\text { 离 } \\
\text { ثn }\end{array}$ & 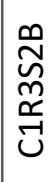 & 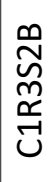 & $\begin{array}{l}\stackrel{\infty}{N} \\
\underset{m}{\sim} \\
\stackrel{\sim}{\sim}\end{array}$ & & 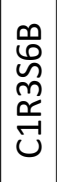 & $\begin{array}{l}\mathscr{0} \\
\mathscr{v} \\
\tilde{m} \\
\widetilde{r} \\
\tilde{U}\end{array}$ & 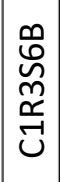 & & $\begin{array}{l}\mathscr{n} \\
\infty \\
m \\
\stackrel{\sim}{\sim} \\
\dot{\cup}\end{array}$ & $\begin{array}{l}\infty \\
\infty \\
\sim \\
m \\
\sim \\
\sim \\
-1\end{array}$ & $\begin{array}{l}\infty \\
\infty \\
\sim \\
\sim \\
\stackrel{\sim}{\sim} \\
\sim\end{array}$ & & 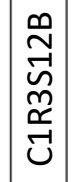 & 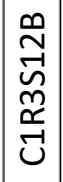 & 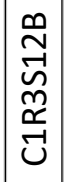 & & 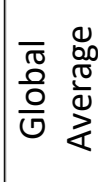 \\
\hline
\end{tabular}




\begin{tabular}{|c|c|c|c|c|c|c|c|c|c|c|c|c|c|c|c|c|c|c|}
\hline \multirow{9}{*}{ 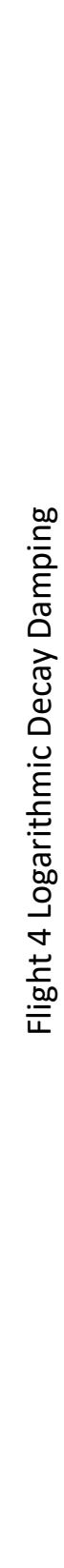 } & 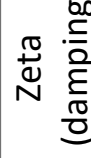 & $\begin{array}{l}n \\
\text { ஸ̊ } \\
\text { ํ. }\end{array}$ & 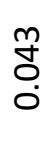 & $\begin{array}{l}-1 \\
\dot{0} \\
0\end{array}$ & \begin{tabular}{l}
0 \\
\multirow{0}{0}{} \\
$\dot{0}$
\end{tabular} & \begin{tabular}{l}
0 \\
\multirow{0}{0}{} \\
0
\end{tabular} & 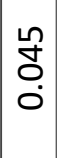 & 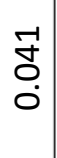 & $\begin{array}{l}\stackrel{J}{ } \\
\stackrel{0}{ }\end{array}$ & $\begin{array}{l}\text { サn } \\
\text { Oீ }\end{array}$ & $\begin{array}{l}0 \\
0 \\
0 \\
0\end{array}$ & $\begin{array}{l}\text { 동 } \\
0 \\
0\end{array}$ & $\begin{array}{l}\tilde{J} \\
\dot{0} \\
\dot{0}\end{array}$ & 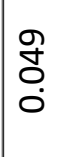 & $\begin{array}{l}\text { ஸે } \\
\text { ○் }\end{array}$ & $\begin{array}{l}\tilde{\vartheta} \\
\varnothing \\
0\end{array}$ & $\begin{array}{l}\text { ஸ் } \\
\stackrel{0}{ }\end{array}$ & \\
\hline & $\frac{\pi}{ \pm}$ & $\begin{array}{l}\stackrel{m}{m} \\
m \\
0\end{array}$ & $\begin{array}{c}\stackrel{-1}{N} \\
\stackrel{0}{0}\end{array}$ & $\begin{array}{l}\stackrel{0}{\mathscr{D}} \\
\text { ல }\end{array}$ & $\begin{array}{l}0 \\
00 \\
\frac{0}{0} \\
\frac{0}{d} \\
\frac{1}{4}\end{array}$ & ஸ్ & 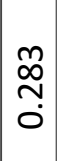 & 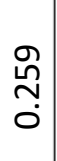 & 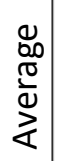 & 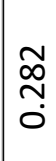 & 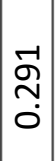 & 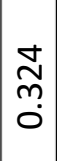 & $\begin{array}{l}0 \\
0 \\
\frac{0}{0} \\
\frac{0}{2} \\
\frac{1}{4}\end{array}$ & $\begin{array}{l}\text { 오 } \\
\text { mִ } \\
\text {. }\end{array}$ & $\begin{array}{l}\stackrel{n}{N} \\
\underset{0}{0}\end{array}$ & $\begin{array}{l}\vec{\rho} \\
\text { m} \\
0\end{array}$ & 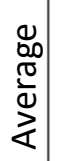 & \\
\hline & 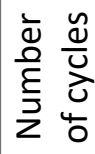 & $\stackrel{\circ}{\rightarrow-1}$ & $\stackrel{\circ}{\circ}$ & ને & & $\stackrel{F}{\neg}$ & $\stackrel{\neg}{\neg}$ & $\stackrel{\neg}{\neg}$ & & $\stackrel{\neg}{\neg}$ & $\stackrel{0}{-1}$ & $\stackrel{\circ}{\circ}$ & & $\stackrel{\neg}{\neg}$ & $\stackrel{-}{-}$ & $\stackrel{\circ}{\rightarrow}$ & & \\
\hline & 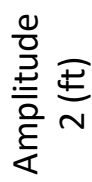 & 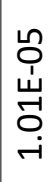 & 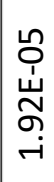 & 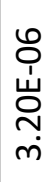 & & 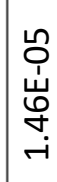 & 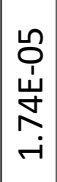 & $\begin{array}{l}\text { 오 } \\
\stackrel{1}{u} \\
\infty \\
\infty \\
-1\end{array}$ & & 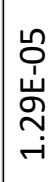 & 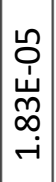 & 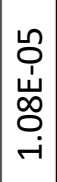 & & 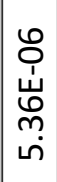 & $\begin{array}{l}\mathscr{D} \\
\dot{u} \\
\ddot{\emptyset} \\
\ddot{\varphi}\end{array}$ & 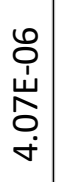 & & $\begin{array}{l}\text { 용 } \\
\text { ㅇ }\end{array}$ \\
\hline & 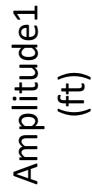 & 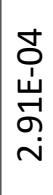 & 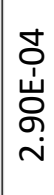 & 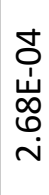 & & $\begin{array}{l}\text { பீ } \\
\text { 山் } \\
\text { ஸุ } \\
\text { m் }\end{array}$ & 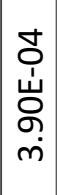 & \begin{tabular}{l} 
ठ \\
$\stackrel{1}{ }$ \\
\multirow{N}{N}{} \\
$m$
\end{tabular} & & 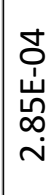 & \begin{tabular}{|c|} 
\\
0 \\
$\dot{u}$ \\
$\mathscr{W}$ \\
$m$ \\
$m$ \\
$m$
\end{tabular} & 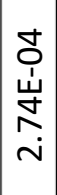 & & 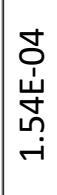 & 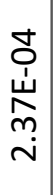 & 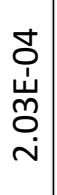 & & 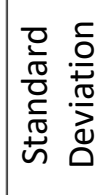 \\
\hline & $\stackrel{0}{\stackrel{ \pm}{n}}$ & $\sim$ & $\sim$ & $N$ & & 6 & 6 & 6 & & $\infty$ & $\infty$ & $\infty$ & & $\underset{\sim}{\sim}$ & $\underset{\sim}{\sim}$ & $\underset{\sim}{\sim}$ & & \\
\hline & 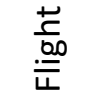 & $\checkmark$ & $\nabla$ & $\nabla$ & & $\nabla$ & $\nabla$ & $\nabla$ & & $\checkmark$ & $\nabla$ & ナ & & $\nabla$ & $\nabla$ & $\nabla$ & & \\
\hline & $\begin{array}{l}\stackrel{\frac{1}{\pi}}{\oplus} \\
\stackrel{n}{n}\end{array}$ & -1 & $r$ & $r$ & & $r$ & $r$ & $r$ & & $r$ & -1 & $r$ & & $r$ & $r$ & $r$ & & $\begin{array}{l}\infty \\
\text { ¿ } \\
0\end{array}$ \\
\hline & $\begin{array}{l}\text { 으 } \\
. \bar{\pi} \\
\text { 离 }\end{array}$ & 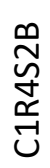 & 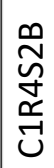 & $\begin{array}{l}\stackrel{\sim}{\sim} \\
\underset{d}{\sim} \\
\stackrel{\sim}{\sim}\end{array}$ & & 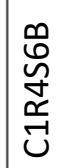 & 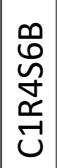 & 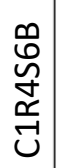 & & 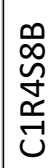 & 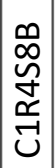 & 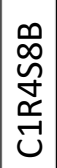 & & $\begin{array}{l}\stackrel{0}{\sim} \\
\underset{\sim}{\sim} \\
\underset{\sim}{\sim} \\
\stackrel{\sim}{v}\end{array}$ & 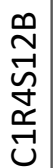 & 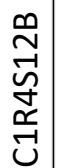 & & 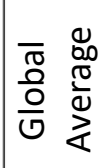 \\
\hline
\end{tabular}


Table A 1: Rail Mass Calculation

\begin{tabular}{|c|c|c|c|}
\hline & & \multicolumn{2}{|c|}{$\begin{array}{l}\text { Mass of Each } \\
\text { Pipe/length }\end{array}$} \\
\hline & & $\mathrm{lb} / \mathrm{ft}$ & $\mathrm{lb} /$ in \\
\hline Pipe1 Diameter & $1.25 \mathrm{in}$ & 2.27 & 0.189 \\
\hline \multirow[t]{2}{*}{ Rod1 Diameter } & $.75 \mathrm{in}$ & 1.5 & 0.125 \\
\hline & $\begin{array}{l}\text { member } \\
\text { lengths }\end{array}$ & & \\
\hline $\begin{array}{l}\text { Supporting Post } \\
\text { Length }\end{array}$ & 38 & inches & \\
\hline Inner Post Length & 35 & inches & \\
\hline Rail Length & 36 & inches & \\
\hline \multicolumn{4}{|l|}{ Weight Per Post } \\
\hline Supporting Posts & 7.19 & Ibs & \\
\hline Inner Posts & 4.38 & Ibs & \\
\hline Rail Length & 6.81 & Ibs & \\
\hline \multicolumn{4}{|l|}{ Weight } \\
\hline Inner Weight & 53.87 & Ibs & \\
\hline Outer Weight & 30.53 & Ibs & \\
\hline Inner Masses & 24.43 & $\mathrm{~kg}$ & \\
\hline Outer Masses & 13.85 & $\mathrm{~kg}$ & \\
\hline Total weight & 276.53 & $\mathrm{Ib}$ & \\
\hline Total Mass & 125.43 & $\mathrm{~kg}$ & \\
\hline Mass per length & 26.98 & $\mathrm{~kg} / \mathrm{m}$ & \\
\hline
\end{tabular}


Modelview 2

Mode $1: 20.11 \mathrm{~Hz}$

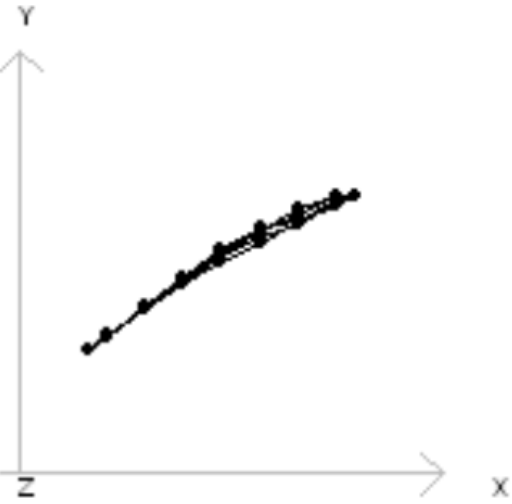

Top

ModelView 4

Mode $1: 20.11 \mathrm{~Hz}$

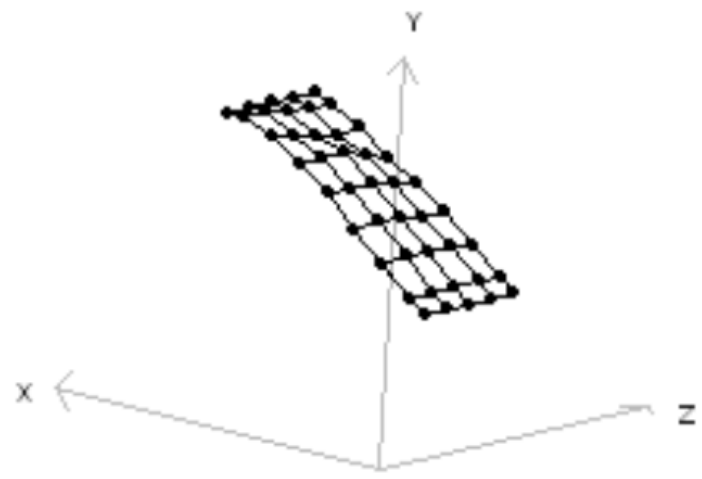

Perspective

Figure A 35: Flight 1 Mode 1 Shape 
ModelView 2

Mode 2 : $30.39 \mathrm{~Hz}$

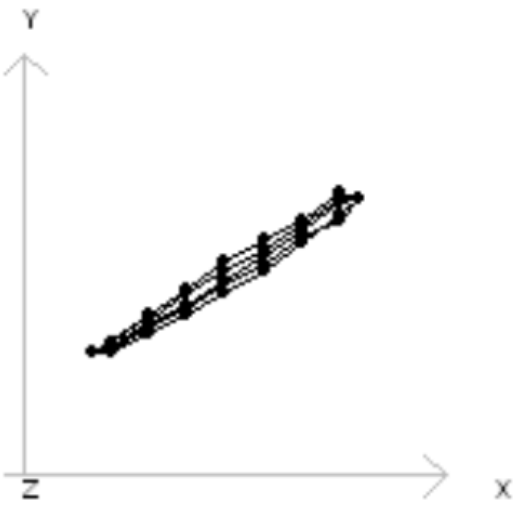

Top

Modelview 4

Mode $2: 30.39 \mathrm{~Hz}$

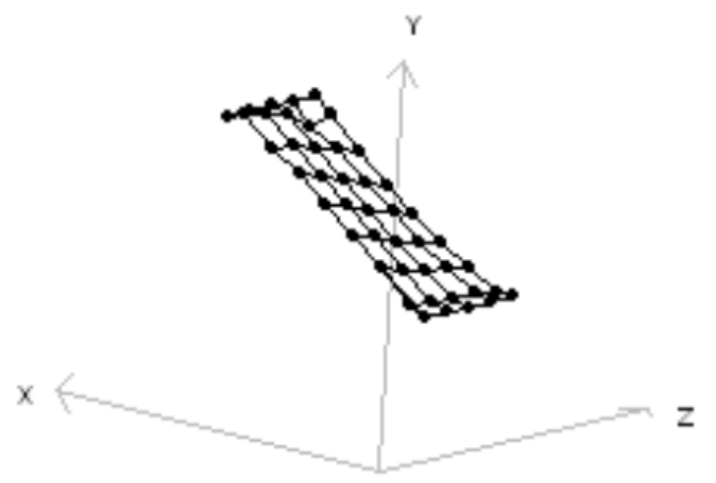

Perspective

Figure A 36: Flight 1 Mode 2 Shape 
Modelview 2

Mode $3: 39.92 \mathrm{~Hz}$

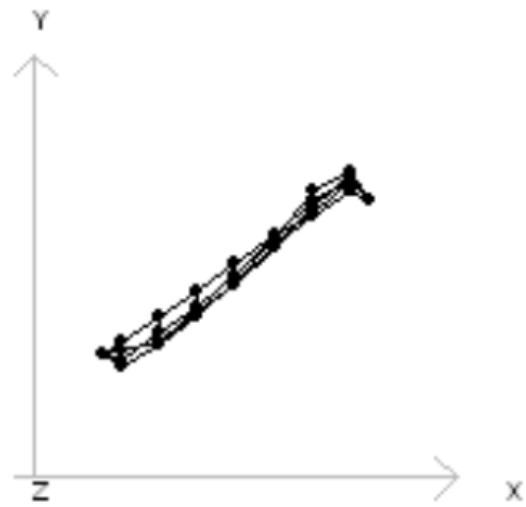

Top

ModelView 4

Mode $3: 39.92 \mathrm{~Hz}$

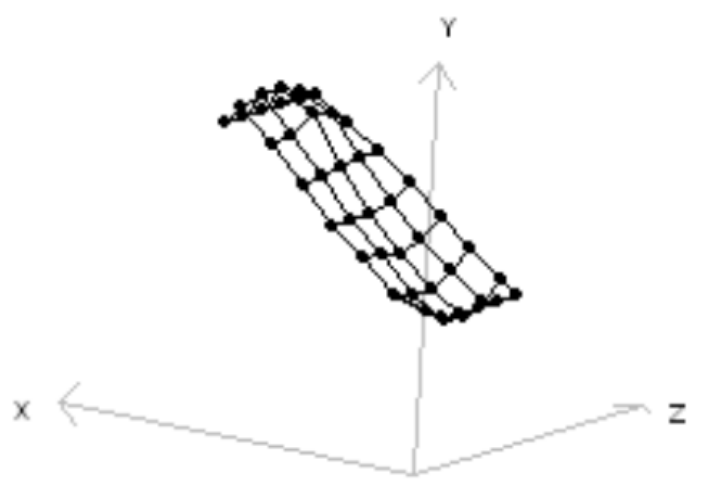

Perspective

Figure A 37: Flight 1 Mode 3 Shape 
ModelView 2

Mode $4: 49.44 \mathrm{~Hz}$

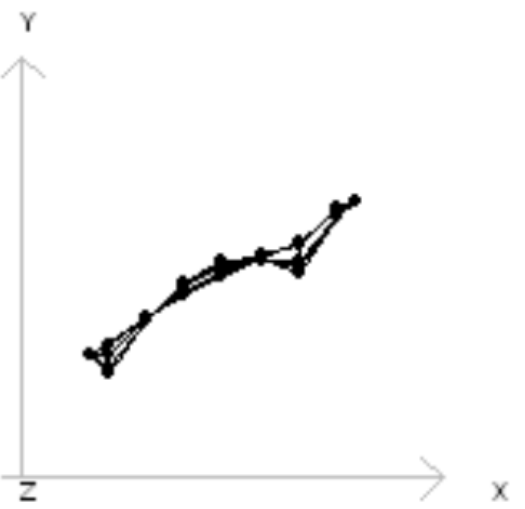

Top

ModelView 4

Mode $4: 49.44 \mathrm{~Hz}$

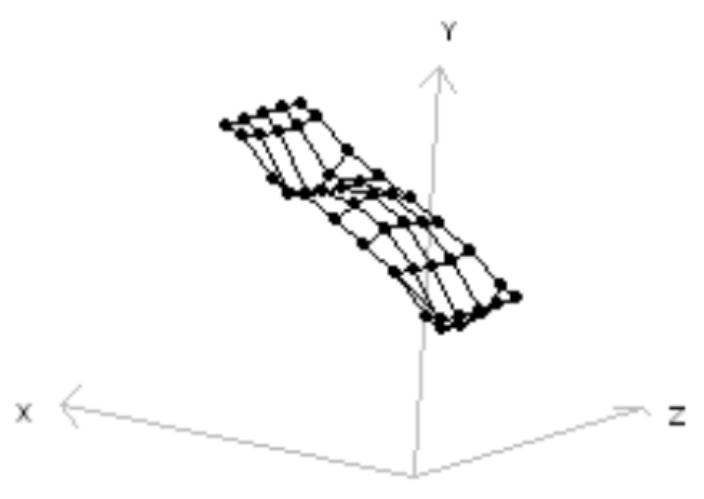

Perspective

Figure A 38: Flight 1 Mode 4 Shape 
Modelview 2

Mode $1: 16.48 \mathrm{~Hz}$

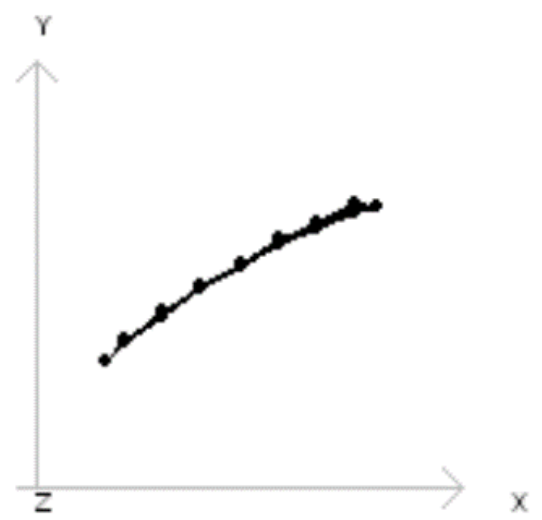

Top

ModelView 4

Mode $1: 16.48 \mathrm{~Hz}$

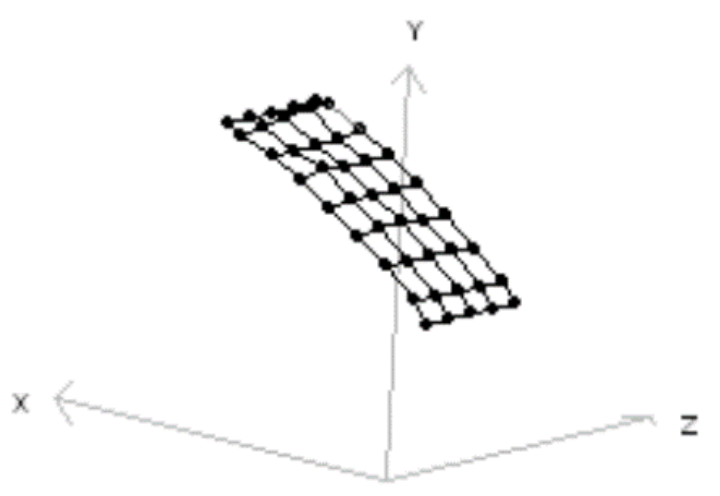

Perspective

Figure A 39: Flight 2 Mode1 Shape 
ModelView 2

Mode $2: 31.86 \mathrm{~Hz}$

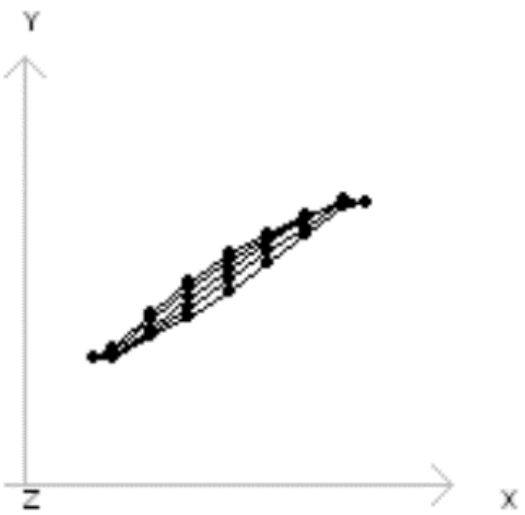

Top

ModelView 4

Mode $2: 31.86 \mathrm{~Hz}$

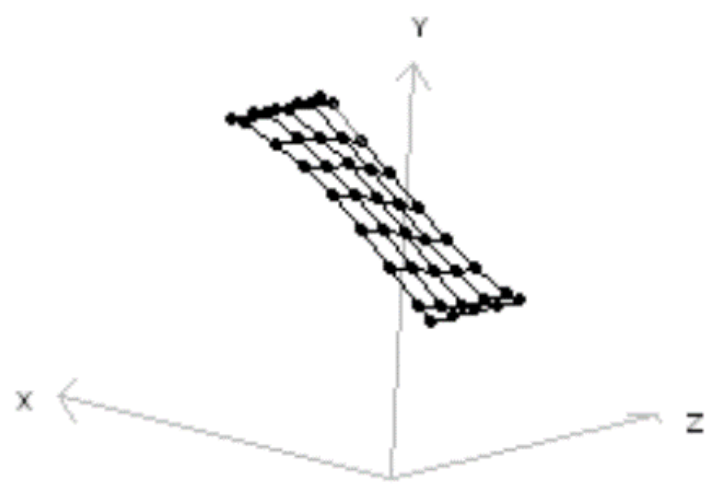

Perspective

Figure A 40: Flight 2 Mode 2 Shape 
ModelView 2

Mode $3: 39.87 \mathrm{~Hz}$

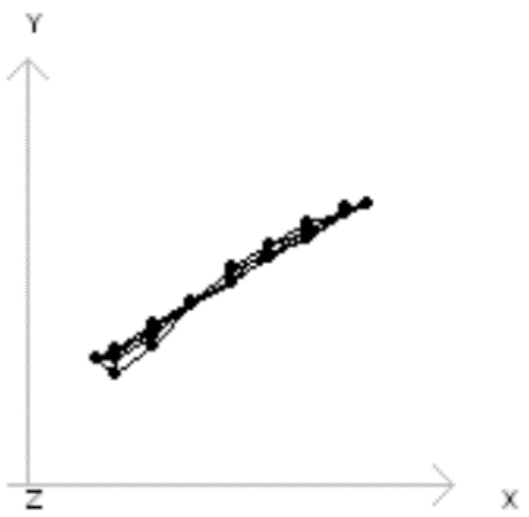

Top

Modelview 4

Mode $3: 39.87 \mathrm{~Hz}$

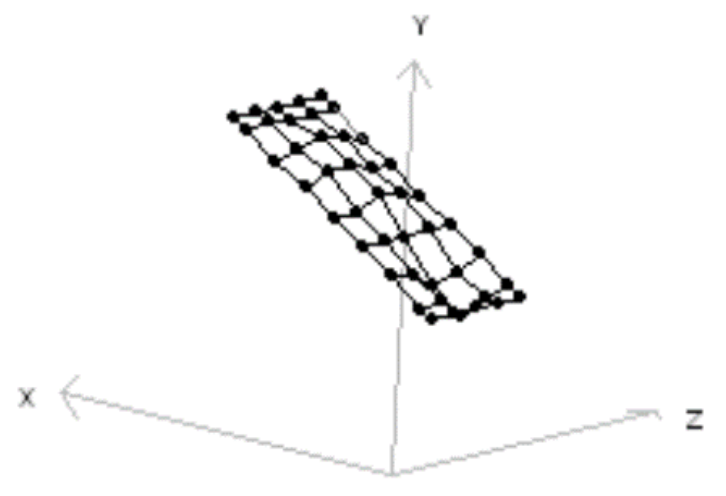

Perspective

Figure A 41: Flight 2 Mode 3 Shape 
Modelview 2

Mode $4: 55.66 \mathrm{~Hz}$

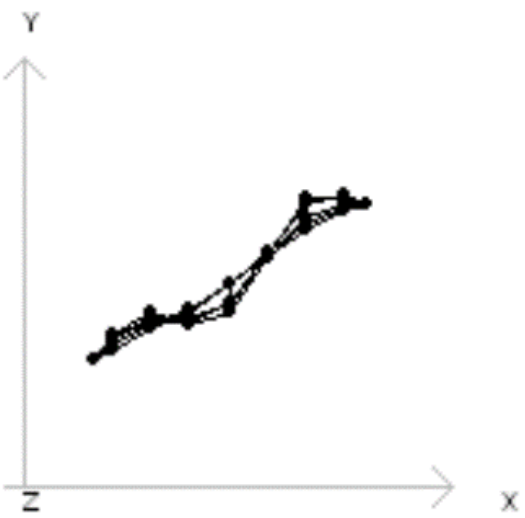

Top

ModelView 4

Mode $4: 55.66 \mathrm{~Hz}$

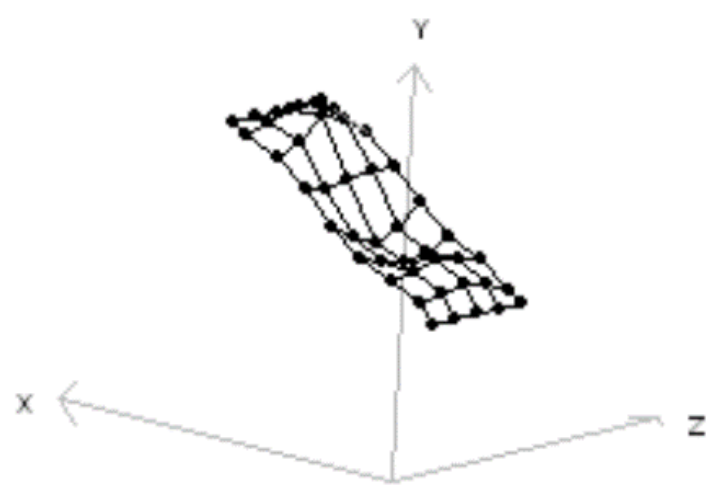

Perspective

Figure A 42: Flight 2 Mode 4 Shape 
Modelview 2

Mode 1 : $21.61 \mathrm{~Hz}$

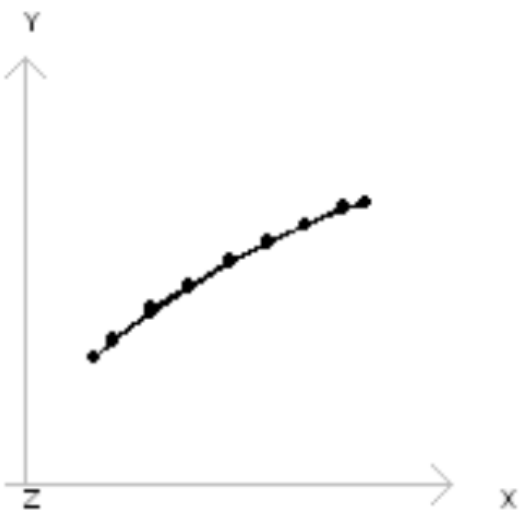

Top

ModelView 4

Mode $1: 21.61 \mathrm{~Hz}$

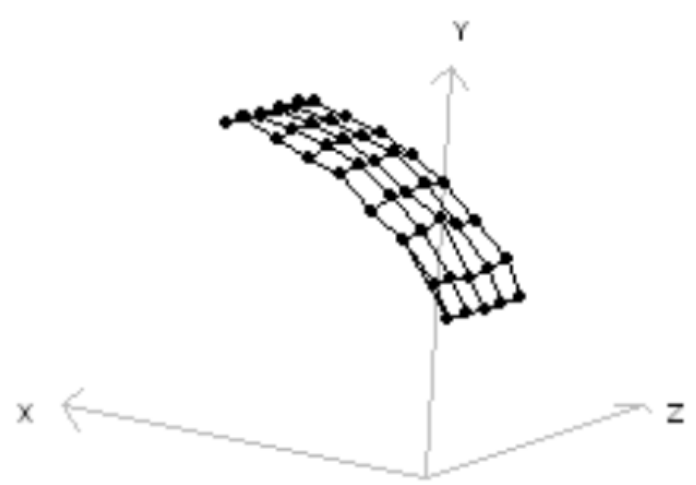

Perspective

Figure A 43: Flight 3 Mode1 Shapes 
Modelview 2

Mode $2: 33.33 \mathrm{~Hz}$

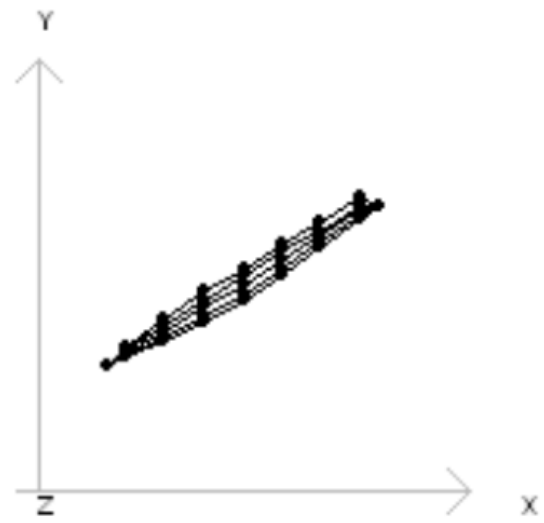

Top

ModelView 4

Mode $2: 33.33 \mathrm{~Hz}$

\section{Perspective}

Figure A 44: Flight 3 Mode 2 Shape 
Modelview 2

Mode $3: 42.11 \mathrm{~Hz}$

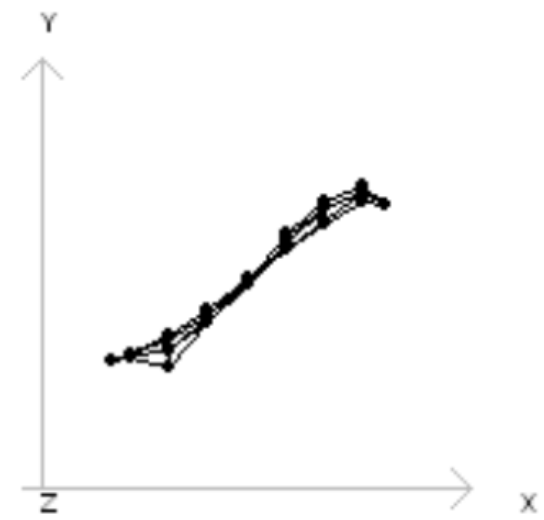

Top

ModelView 4

Mode $3: 42.11 \mathrm{~Hz}$

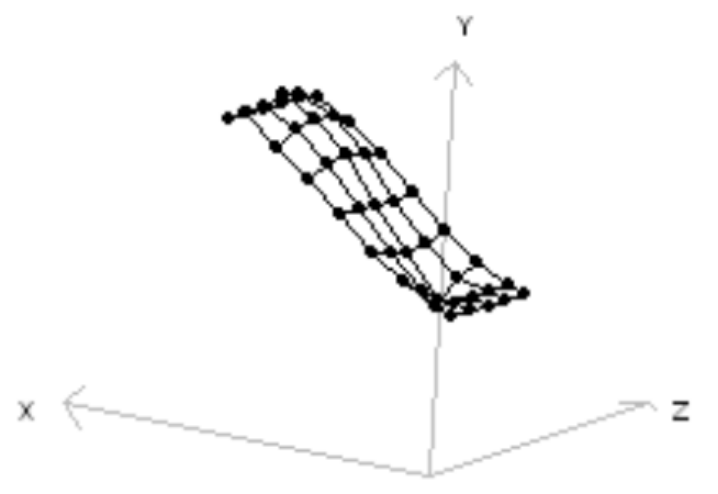

Perspective

Figure A 45: Flight 3 Mode 3 Shape 
Modelview 2

Mode $4: 53.83 \mathrm{~Hz}$

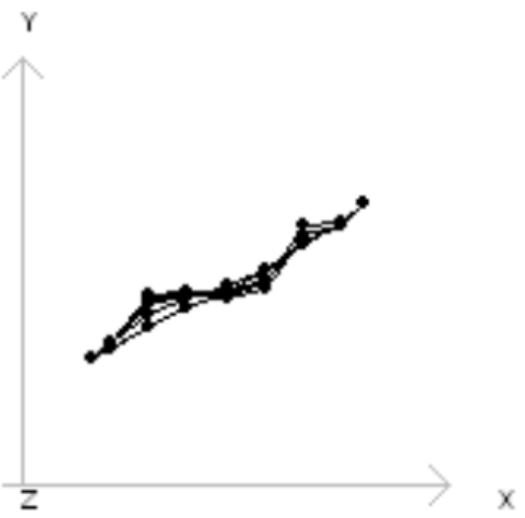

Top

Modelview 4

Mode $4: 53.83 \mathrm{~Hz}$

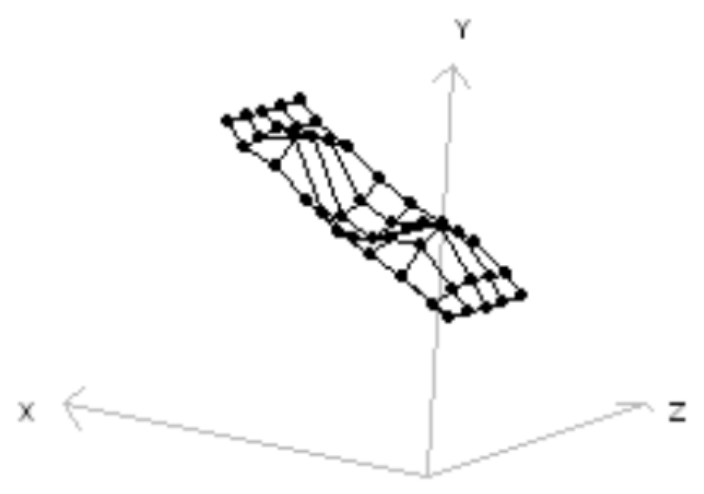

Perspective

Figure A 46: Flight 3 Mode 4 Shape 
Modelview 2

Mode 1 : $16.11 \mathrm{~Hz}$

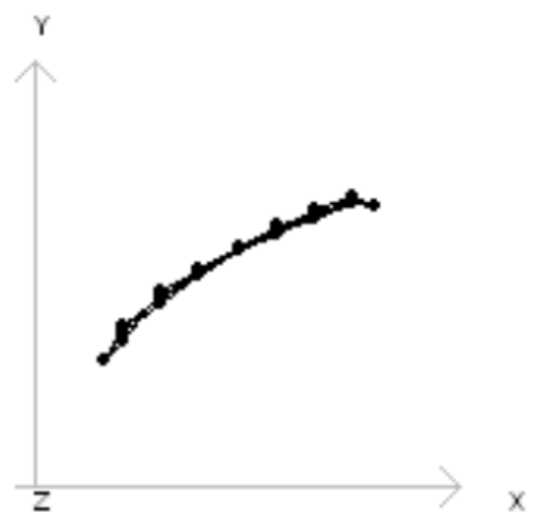

Top

ModelView 4

Mode $1: 16.11 \mathrm{~Hz}$

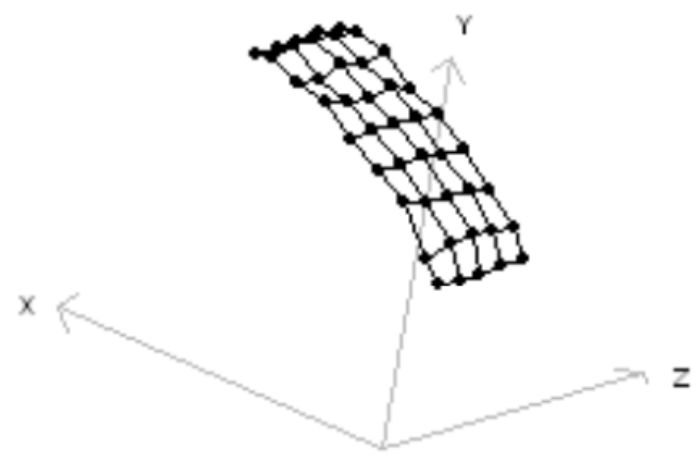

Perspective

Figure A 47: Flight 4 Mode1 Shape 
Modelview 2

Mode $2: 30.40 \mathrm{~Hz}$

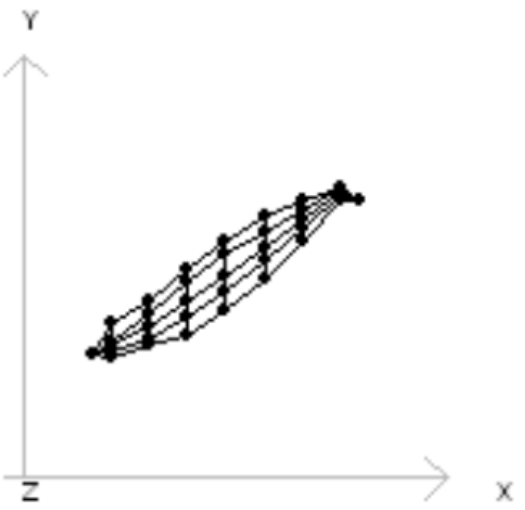

Top

Modelview 4

Mode $2: 30.40 \mathrm{~Hz}$

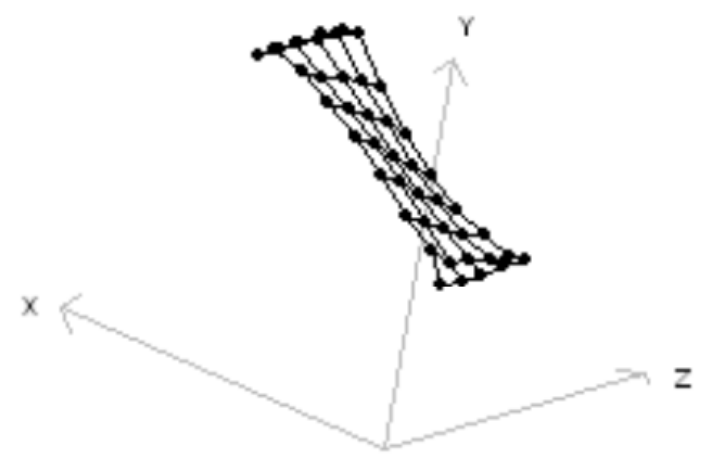

Perspective

Figure A 48: Flight 4 Mode 2 Shape 
ModelView 2

Mode $3: 42.11 \mathrm{~Hz}$

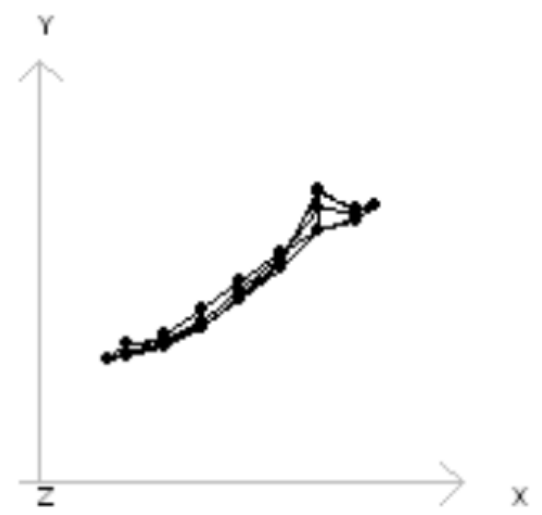

Top

ModelView 4

Mode $3: 42.11 \mathrm{~Hz}$

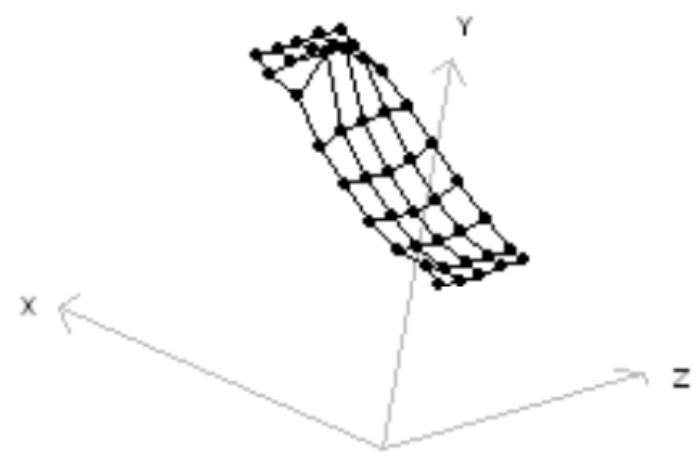

Perspective

Figure A 49: Flight 4 Mode 3 Shape 
Modelview 2

Mode $4: 59.69 \mathrm{~Hz}$

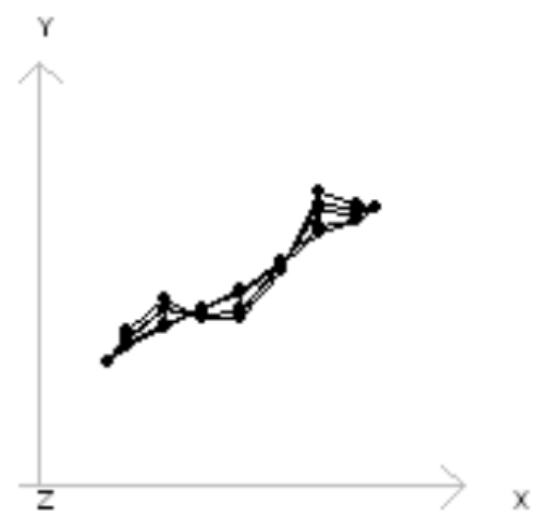

Top

Modelview 4

Mode $4: 59.69 \mathrm{~Hz}$

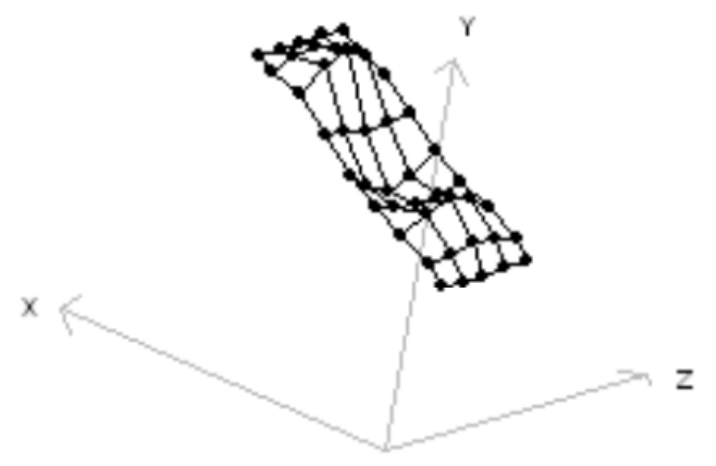

Perspective

Figure A 50: Flight 4 Mode 4 Shape 